Область непознанного, неведомого значительно обширнее суммы

накопленных человечеством знаний.

Академик В.И. Вернадский

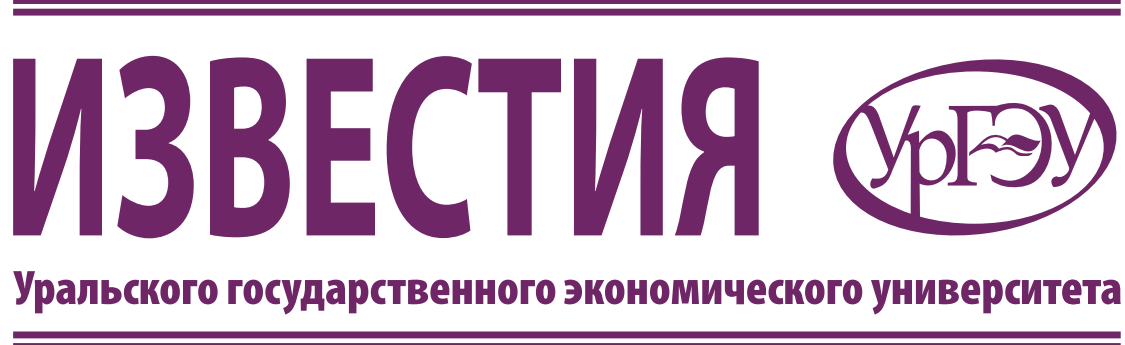

ToM 19 • № 3

2018 


\section{Редакционная коллегия}

Главный редактор

Я. П. Силин, д-р экон. наук, профессор Заместители главного редактора

Е. Г. Анимица, д-р геогр. наук, профессор

В.П. Иваницкий, д-р экон. наук, профессор Члены редколлегии

С. Д. Бодрунов, д-р экон. наук, профессор

Н. Ю. Власова, д-р экон. наук, профессор

Е. Б. Дворядкина, д-р экон. наук, профессор

Д. А. Карх, д-р экон. наук, доцент

А. А. Мальцев, д-р экон. наук, профессор

М.С. Марамыгин, д-р экон. наук, профессор

Р. М. Нижегородцев, д-р экон. наук

Е. В. Попов, чл.-кор. РАН, д-р экон. наук, д-р физ.-мат. наук, профессор

К. К. Рихтер, д-р физ.-мат. наук, профессор

А. Н. Сёмин, академик РАН, д-р экон. наук, профессор

Н. М. Сурнина, д-р экон. наук, профессор

Члены международного совета

Ф. У. Аймел, доцент (США)

Д. Вильямс, $\mathrm{PhD}$ (Economics), $\mathrm{PhD}$ (Science, Technology \& Innovation Management), доцент (Великобритания)

3. Каха, магистр MBA, $\mathrm{PhD}$ (Чехия)

Я. Подгорский, $\mathrm{PhD}, \mathrm{MSc}$, доцент (Словакия)

Э. М. Сандоян, д-р экон. наук, профессор (Армения)

А. Н. Стратан, д-р экон. наук, профессор (Молдова)

B. Стрелковский, $\mathrm{PhD}$, профессор (Великобритания)

Сюй Линьши, д-р экон. наук, профессор (Китай)

В. Н. Шимов, д-р экон. наук, профессор (Белоруссия)

\section{Editorial Board}

\section{Chief Editor}

Ya. P. Silin, Dr. Sc. (Economics), Professor

Deputy Chief Editors

Ye. G. Animitsa, Dr. Sc. (Geography), Professor

V. P. Ivanitsky, Dr. Sc. (Economics), Professor

Editorial Team

S. D. Bodrunov, Dr. Sc. (Economics), Professor

N. Yu. Vlasova, Dr. Sc. (Economics), Professor

Ye. B. Dvoryadkina, Dr. Sc. (Economics), Professor

D. A. Karkh, Dr. Sc. (Economics), Associate Professor

A. A. Maltsev, Dr. Sc. (Economics), Professor

M.S. Maramygin, Dr. Sc. (Economics), Professor

R. M. Nizhegorodtsev, Dr. Sc. (Economics)

Ye.V. Popov, Dr. Sc. (Economics), corresponding member of RAS, Dr. Sc. (Physics \& Mathematics), Professor

K. K. Richter, Dr. Sc. (Physics \& Mathematics), Professor

A. N. Syomin, academician of RAS, Dr. Sc. (Economics), Professor

N. M. Surnina, Dr. Sc. (Economics), Professor

International Council

Ph. W. Imel, Associate Professor (USA)

D. Williams, PhD (Economics), PhD (Science, Technology \& Innovation Management), Associate Professor (Great Britain)

Z. Caha, MBA, PhD (the Czech Republic)

J. Podhorsky, PhD, MSc, Associate Professor (Slovakia)

E. M. Sandoyan, Dr. Sc. (Economics), Professor (Armenia)

A. N. Stratan, Dr. Sc. (Economics), Professor (Moldova)

W. Strielkowski, PhD, Professor (Great Britain)

Syui Linshi, Dr. Sc. (Economics), Professor (China)

V.N. Shimov, Dr. Sc. (Economics), Professor (Belarus)

Учредитель: ФГБОУ ВО «Уральский государственный экономический университет»

Включен в Перечень ведущих рецензируемых научных изданий,

в которых должны быть опубликованы основные научные результаты диссертаций на соискание ученой степени доктора и кандидата наук

Включен в Российский индекс научного цитирования (импакт-фактор журнала на дату подписания в печать 1,016 )

Основан в 1999 г.

Свидетельство о регистрации средства массовой информации ПИ № ФС77-49743 от 15 мая 2012 г.

Подписной индекс Агентства Роспечати: 72059

Цена свободная 


\section{ЦИФРОВИЗАЦИЯ ЭКОНОМИКИ: технология vs человек}

Сорокин Д.Е. Российская экономика: сегодня и завтра (вступительное слово) . . . 5

Popov E.V. Econotronics of the Digital Society $\ldots \ldots \ldots \ldots \ldots \ldots \ldots \ldots \ldots \ldots \ldots$

Силин Я. П., Анимица Е. Г. Контуры формирования цифровой экономики в России 18

Сухарев 0.С. Структурный анализ технологических изменений и стратегия эконо-

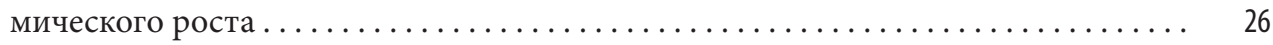

Борщ Л. М. Модернизация экономики: технологии vs человек............. 42

Романова 0.А. Стратегии социально-экономического развития регионов РФ

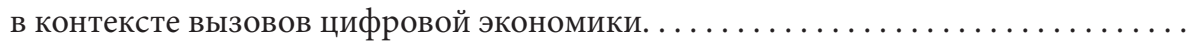

Власова Н. Ю., Куликова Е.С. Маркетинг территории в условиях становления цифро-

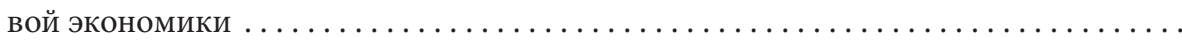

Акбердина В.В. Трансформация промышленного комплекса России в условиях цифровизации экономики. . . . . . . . . . . . . . . . . . . . 82

Korovin G. B. Problems of Industrial Digitalisation in Russia ............... 100

Баев И. А., Соловьева И. А., Дзюба А. П. Управление спросом на поставку энергоресурсов в условиях развития информационно-коммуникационных технологий. ....

Вайсман Е.Д., Никифорова Н.С. Развитие динамических способностей промышленных предприятий в условиях цифровой экономики $\ldots \ldots \ldots \ldots \ldots \ldots \ldots$

Кононов В.Н., Замбржицкая Е.С., Харченко М.В. Жизненный цикл промышленной технологии как объект моделирования и управления................... 


\section{Contents}

\section{DIGITALISATION OF ECONOMY: Technologies vs Humans}

Sorokin D. Ye. Russian Economy: Today and Tomorrow (A Foreword)........... 5

Popov E.V. Econotronics of the Digital Society $\ldots \ldots \ldots \ldots \ldots \ldots \ldots \ldots \ldots \ldots$

Silin Ya. P., Animitsa Ye. G. Contours of the Digital Economy in Russia ............ 18

Sukharev 0.S. Structural Analysis of Technological Changes and the Strategy of Eco-

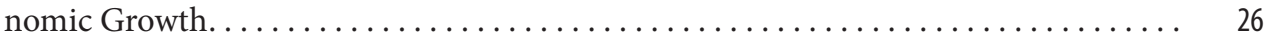

Borshch L. M. Modernisation of the Economy: Technologies vs Humans............ 42

Romanova 0. A. Russian Regions' Socioeconomic Development Strategies in the Context of Challenges Posed by the Digital Economy $\ldots \ldots \ldots \ldots \ldots \ldots \ldots \ldots \ldots \ldots$

Vlasova Na.Yu., Kulikova Ye.S. Place Marketing in Conditions of the Forming Digital

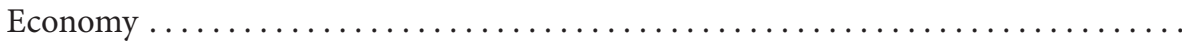

Akberdina V.V. The Transformation of the Russian Industrial Complex Under Digitalisation

Korovin G. B. Problems of Industrial Digitalisation in Russia

Baev I. A., Solovyeva I.A., Dzyuba A.P. Managing the Demand for Energy Resources in Conditions of Development of Information and Communication Technologies......

Vaisman Ye. D., Nikiforova N.S. Development of Industrial Enterprises' Dynamic Capabili-

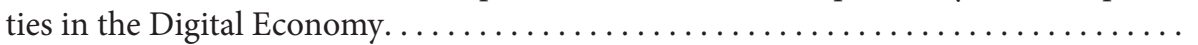

Kononov V.N., Zambrzhitskaya Ye.S., Kharchenko M.V. The Life Cycle of an Industrial Technology as an Object of Modelling and Control . 


\section{СороКИН Дмитрий Евгеньевич}

Член-корреспондент РАН, доктор экономических наук, профессор, научный руководитель

Финансовый университет при Правительстве Российской Федерации 125993, РФ, г. Москва, Ленинградский пр., 49 Контактный телефон: (499) 943-98-55 e-mail: ds@fa.ru

\section{Российская экономика: сегодня и завтра ${ }^{1}$ (вступительное слово)}

$K^{2}$ акой должна быть российская экономика, чтобы у России было будущее? Отвечая на этот вопрос, необходимо иметь в виду, что с учетом ряда геополитико-экономических обстоятельств Россия может сохраниться лишь как один из мировых центров социально-экономического развития, а, следовательно, и силы. Соответственно России необходимо обладать экономикой, способной обеспечить национальную безопасность страны, устойчивое социальное благополучие населения и устойчивость к флюктуациям мирохозяйственных связей. В противном случае Россия, скорее всего, станет лишь ресурсным объектом для других «центров силы».

Очень важно, что высшее политическое руководство эту проблему осознает. В Послании Президента России Федеральному Собранию 15 лет назад, т. е. в то время, которое мы называем началом восстановления России после известной геополитической катастрофы 1990-х годов, отмечалось: «...Весь наш исторический опыт свидетельствует: такая страна, как Россия, может жить и развиваться в существующих границах, только если она является сильной державой. Во все периоды ослабления страны - политического или экономического - перед Россией всегда и неотвратимо вставала угроза распада»².

Та же мысль проходит через последнее Послание Президента Российской Федерации, а также через Указ от 7 мая 2018 г. ${ }^{3}$, которые концептуально заложили основу новой стратегии развития России. Это уже третья стратегия в условиях новой России, но и в предыдущих двух стратегиях (в 2000 г. и в стратегии «Концепция - 2020») именно такая цель ставилась перед российской экономикой. Важным фактором, способствующим достижению этой цели, является то, что, по данным Федерального научно-исследовательского социологического центра Российской академии наук, в сознании абсолютного большинства населения Россия позиционируется как одна из великих мировых держав.

В этой связи первоочередной задачей является перелом стагнационных тенденций, которые вызывают угрозу экономического отставания России от основных геоэкономических и геополитических конкурентов (табл. 1).

Сложившееся темпы экономического роста не только ведут к наращиванию отставания от геополитических конкурентов, но и не способны обеспечить устойчивый рост жизненного уровня населения: с 2014 по 2017 г. происходило снижение реально

${ }^{1}$ По материалам доклада на пленарном заседании IX Евразийского экономического форума молодежи (Екатеринбург, УрГЭУ, 17 апреля 2018 г.).

2 Послание Президента РФ Федеральному Собранию РФ на 2003 г.

${ }^{3}$ Указ Президента РФ от 7 мая 2018 г. № 204 «О национальных целях и стратегических задачах развития Российской Федерации на период до 2024 года». 
располагаемых денежных доходов населения. Расчеты показывают, что стране необходимо минимум втрое увеличить темпы реального экономического роста.

Таблица 1

Динамика ВВП

\begin{tabular}{|l|c|c|}
\hline \multicolumn{1}{|c|}{ Страна } & $\begin{array}{c}\text { ВВП России в 2010 г., } \\
\text { \% к странам }\end{array}$ & $\begin{array}{c}\text { Среднегодовые темпы прироста } \\
\text { в 2010-2017 гг., \% }\end{array}$ \\
\hline Россия & - & 1,7 \\
\hline США & 18,8 & 2,2 \\
\hline Страны Еврозоны & 24,7 & 1,1 \\
\hline Китай & 28,7 & 7,8 \\
\hline
\end{tabular}

* Здесь и далее, если не указано иное, использованы данные Росстата и Минэкономразвития России.

Вместе с тем в нынешней ситуации единственным фактором реального экономического роста является производительность труда. Президентом России сформулирована задача выхода к 2024 г. на пятипроцентный ежегодный прирост производительности труда в базовых несырьевых отраслях экономики. Решение этой задачи осложняется сложившимися в 2010-2016 гг. крайне низкими среднегодовыми темпами роста производительности труда, \%:

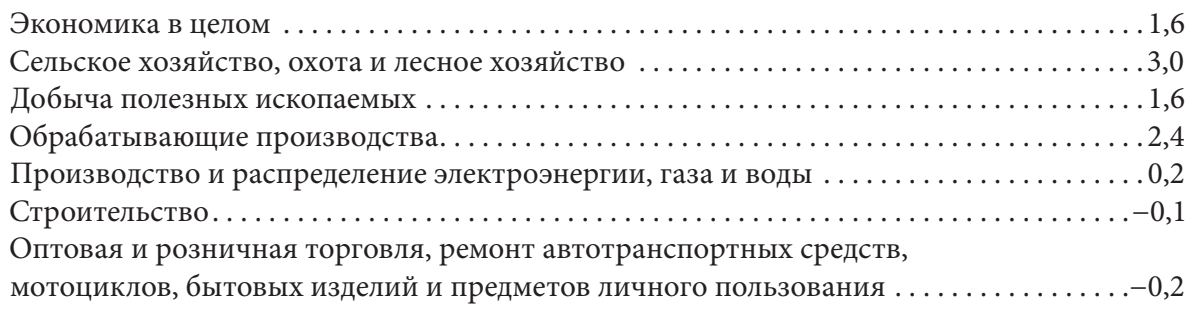

Причина была названа на научной сессии Общего собрания РАН «Научно-технологический прогноз - важнейший элемент стратегии развития России»: если технологически передовые страны находятся в пятом технологическом укладе с элементами шестого, то российская экономика - в основном в четвертом с элементами пятого ${ }^{1}$. Поэтому неслучайно Указ Президента от 7 мая начинается с формулировки о необходимости прорывного научно-технологического развития России. Соответственно определена задача: каждое второе предприятие в течение года должно вносить технологические изменения в производство. Это очень сложная задача, и не потому, что нет инновационных технологий. С точки зрения научно-технологического потенциала проблем нет, но, несмотря на то, что подобные задачи ставятся с 2000 г., доля предприятий, осуществляющих технологические инновации, остается на уровне, не превышающем $10 \%$. Причина в том, что сложившиеся условия хозяйствования не формируют интерес предпринимателей к этому, а именно они являются главными акторами технологического обновления. Следовательно, необходимо создать такие условия хозяйственной деятельности, которые нацеливают критическую массу российских предпринимателей на технологическое и организационное развитие своего дела как главного условия предпринимательского успеха.

Уральский федеральный округ относится к одному из центров, откуда и может пойти технологическое перевооружение современной экономики России. (Вспомним, что исторически первое технологическое перевооружение российской экономики началось

${ }^{1}$ См.: Научная сессия Общего собрания РАН «Научно-технологический прогноз - важнейший элемент стратегии развития России // Вестник РАН. 2009. Т. 79, № 3. 
на Урале при Петре І.) Статистика подтверждает, что в областях, входящих в УрФО, прирост в промышленности и, самое главное, в обрабатывающих отраслях происходит быстрее, чем в промышленности страны в целом (табл. 2).

Таблица 2

Прирост объемов промышленного производства, 2017 г., \%

\begin{tabular}{|c|c|c|}
\hline Территория & Промышленность в целом & Обрабатывающие производства \\
\hline Российская Федерация & 1,0 & 0,2 \\
\hline Уральский федеральный округ & 2,0 & 3,0 \\
\hline Курганская область & 2,1 & 0,4 \\
\hline Свердловская область & 3,1 & 4,0 \\
\hline Тюменская область & 1,8 & 3,2 \\
\hline Челябинская область & 5,3 & 5,7 \\
\hline
\end{tabular}

Исторический опыт показывает, что важным условием успешной реализации любой экономической политики являются не только экономические, но и неэкономические факторы экономического роста. Неслучайно выход Соединенных Штатов из системного, в том числе экономического, кризиса 1929-1933-х годов был осуществлен не только мерами экономики. Беседы «У камина» 32-го президента США Ф. Рузвельта, объясняющие населению политику правительства, мобилизовали фактор доверия населения к действиям государства. Аналогичные результаты показал наш исторический опыт (план ГОЭЛРО, «косыгинские» реформы середины 1960-х годов). Без задействования фактора общественного доверия к проводимой экономической политике, особенно, когда речь идет о кардинальном переломе сложившейся экономической ситуации, трудно достичь экономического успеха.

Ссылка для иитирования: Сорокин Д.Е. Российская экономика: сегодня и завтра (вступительное слово) // Известия Уральского государственного экономического университета. 2018. Т. 19, №3. С. 5-7. DOI: 10.29141/2073-1019-2018-19-3-1

For citation: Sorokin D. Ye. Russian economy: today and tomorrow (A foreword) [Rossiyskaya ekonomika: segodnya i zavtra (vstupitel'noe slovo)]. Izvestiya Uralskogo gosudarstvennogo ekonomicheskogo universiteta - Journal of the Ural State University of Economics, 2018, vol. 19, no. 3, pp. 5-7. DOI: 10.29141/2073-1019-2018-19-3-1 


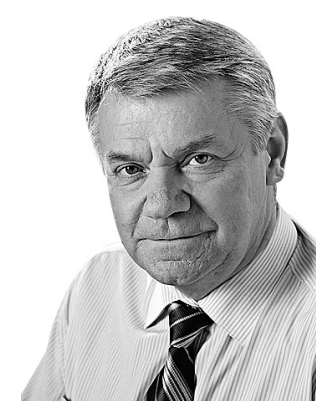

\section{Evgeny V. POPOV}

Corresponding Member of the Russian Academy of Sciences, Dr. Sc. (Econ.), Head of the Center for Economic Theory

Institute of Economics (Ural branch of RAS)

29 Moskovskaya St., Yekaterinburg, Russia, 620014

Head of Political Economy Dept.

Ural State University of Economics

62/45 8 Marta/Narodnoy Voli St., Yekaterinburg, Russia, 620144

Phone: (343) 371-45-36

e-mail:epopov@mail.ru

\section{Econotronics of the Digital Society ${ }^{1}$}

The paper systematises elements of analysis of modern digital society within the author's concept of econotronics. It shows that econotronics is a subdiscipline of social sciences devoted to the dynamics of economic institutions of interaction between actors and society in digital economy. The author analyses research subject of econotronics and on the basis of the modern notion of homo institutionalis argues that the most adequate toolkit to model the processes of digital society development are tools of institutional economics. The research reveals elements of institutional design of econotronics' transactions, identifies directions for institutional modelling of the subject of econotronics, and emphasises that econotronics is a scientific concept for modelling of the digital society development.

JEL classification: A10, B16, B52

Keywords: digital society; econotronics; homo institutionalis; institutional design; modelling.

\section{Introduction}

$\mathrm{M}$ odern economic development largely relies on introduction and implementation of advanced information technologies. Traditional economic methods are substantially complemented, and in some cases replaced, by modern methods of accounting and redistribution of assets. To the greatest extent, this can be seen in the economy of public sector, where low-cost entrepreneurship is a driving force of economic development. In this case, a forming digital society seeks the most adequate, leading-edge methods for modelling of economic activities. However, the world economic literature has not properly addressed the problem of analysing modern digital society from the perspective of rational economy management as yet.

The research aims to develop elements of analysis of modern digital society within the author's concept of econotronics.

The logic of the research appears as follows: first, to examine the research subject of econotronics; second, to determine possibilities for applying institutional economics to describe it; third, to discuss principles of institutional design of econotronics' transactions and methods of their institutional modelling. As a result of the research, econotronics will receive evaluation as a scientific concept used for modelling of the digital society development.

\section{Research subject of econotronics}

Several concepts can be applied to describe driving forces behind the development of modern society: sociodynamics, socioeconomics, constitutional economics and some others.

Sociodynamics is a subfield of sociology devoted to quantitative methods of modelling of interactions between both individuals and public structures ${ }^{2}$. However, institutional

${ }^{1}$ The reported study was funded by RFBR according to the research project no. 17-06-00281 "Modelling of the institutional environment of Russia's socioeconomic development".

${ }^{2}$ Sociodynamics. Available at: http://socio.escience.ifmo.ru/wiki/index. 
interactions do not always have quantitative measurement, more often they are assessed only qualitatively, therefore, application of the sociodynamics concept for institutional modelling of modern production is not entirely appropriate.

Socioeconomics is a research programme founded by Amitai Etzioni, who suggested considering an individual as having at least two basic needs and two sources of judgement: satisfaction and morality [14]. Yet presence of morals is just one limitation to human behaviour. From this standpoint, an institutional view offers a more comprehensive and systemic approach to the analysis of formal and informal norms and rules restricting individuals' behaviour.

Constitutional economics is a research programme that describes mutual influence of legal and economic factors in the state decision-making, as well as interactions of Constitution application problems with the structure and functioning of an economy ${ }^{1}$. Nonetheless, driving forces behind the development of modern economic systems are often generated by innovators who do not allow for problems of constitutional rights' application.

Hence, to describe the development of modern driving forces it is relevant to involve a concept that takes into consideration new social trends. Such concept was formulated by Alvin Gouldner. In his opinion, sociotronics is the name of the concept according to which exclusively informatization of modern society is capable of counteracting existing social pathologies and deviations. Then, experts directly engaged in information, communication and computerization processes are the major actors of social rehabilitation [13]. Obviously, economic sociotronics is the closest to the research subject, driving forces of modern economics. In a shorter variant, econotronics.

Consequently, econotronics is a subfield of social sciences studying the development dynamics of economic institutions of interaction between actors and society in a modern digital economy [7]. It is worth pointing out that this concept is consonant with a number of natural science disciplines: electronics (the science of electrons' interaction with electromagnetic fields and methods of creating electronic devices); chemotronics (a discipline dealing with the fundamental and applied aspects of electrochemical processes occurring at the electrode-electrolyte interface); biotronics (an interdisciplinary programme on creation of artificial biogeocenoses (i.e. systems including a community of living organisms and a set of environmental factors connected with it).

What is then the research subject of econotronics?

In the broadest sense, the subject of econotronics includes modern methods of economic management conditioned by implementation of advanced digital technologies. The subject of econotronics encompasses social innovations, crowdfunding and other economic processes, which gained traction within a modern digital society. A typical subject of econotronics is sharing economy and blockchain technology.

Sharing economy is a technology of rational economic management, which implies that consumers of products and services are actively involved (participate) in development of these products and services. This method of economic management has been known since the ancient times, however it has become widely applied with the spread of digital technologies, first and foremost, with the development of the Internet.

Blockchain is a multifunctional and multilevel information technology designed for reliable accounting of various assets [21].

In a narrower sense, a modelled representation, the research subject of econotronics includes economic institutions of interaction between actors and society. At this, the analysis of development dynamics of these institutions is important.

Let us emphasize that the analysis of economic institutions seems to be particularly relevant for the analysis of digital society, because established rules and norms underlie interaction of individuals in such a society.

${ }^{1}$ Constitutional economics. Available at: https://ru.wikipedia.org/wiki. 


\section{Homo institutionalis vs homo economicus}

Karl Marx and Friedrich Engels wrote that "the way in which men produce their means of subsistence depends first of all on the nature of the actual means of subsistence they find in existence and have to reproduce. This mode of production must not be considered simply as being the production of the physical existence of the individuals. Rather it is a definite form of activity of these individuals, a definite form of expressing their life, a definite mode of life on their part" [4].

"A definite mode of life on their part" was used in the studies of Thornstein Veblen, the founder of classical institutionalism, as a concept of institution, which he regarded as "...habits of thought inherent in all members of the community" [24].

On the other hand, T. Veblen was peculiar to the state. He extolled management as the most important regulatory system, but did not see the necessity in the state, considering it an "abnormal" institution [23]. According to T. Veblen, "abnormality" of the state as an institution consisted in the development of patriotic feelings by strengthening various ceremonies and predatory instincts. At the same time, it is generally accepted that it was T. Veblen who drew attention to the category "institution" as the basis for the economic analysis of economic activity.

Consequently, in this study, institutions will be understood as the established norms of interaction between economic agents (in the presence of control over these interactions) [6. P. 28].

In economic literature, we can find a broader interpretation of institutions - not only as norms of interaction between economic agents, but also as organisational forms of combining economic agents [17]. Such a broad interpretation of the concept "institution" leads to the possibility of a numerical evaluation of the formation of certain organisations [3]. In this study, we will adhere to a more common interpretation of the concept "institution", which allows defining the method for studying economic systems more clearer [5].

We should emphasize that the institutional description of economic systems cannot have a zero level like a neoclassical equilibrium. In the study of Geoffrey Hodgson [10] it was shown that an important methodological problem of describing the evolution of institutions concerns any attempt to explain the emergence of institutions in the situation of a natural preinstitutional state. Any such attempt reaches an impasse because of an inevitable need to recognize initial availability of other institutions such as, for example, language. Hence, a notable feature of recent works on new institutionalism is recognition of the presence of some basic institutions as a starting point for analysis.

Once we admit, further notes Hodgson, that human activity can be studied only in the context of some already existing institutions, we can focus on the effects of institutional constraints and the "reverse explanations" in relation to individuals, as well as understand how the interaction between individuals leads to the emergence of new forms of institutions. We suggest the following: the impact of institutional opportunities and constraints on appropriate habits, ways of thinking and behaviour can contribute to the emergence and development of certain institutions. These statements point to a more open approach to the evolution of institutions, a decrease in the role of static comparison in favour of a more process-focused, algorithm analysis. In terms of the evolution of institutions and individual preferences, such arguments remind of "old" institutionalism, despite the fact that the detailed definition of the mechanisms of the "reverse explanations" has not yet been reflected in the research.

Institutions are structural entities that restrict individuals and influence their behaviour. Accordingly, if institutions influence individuals, they need to be considered separately. In turn, their existence is determined by the actions of other individuals. When will this infinite chain of analysis be interrupted? The goals of individuals can be partially explained with the help of relevant institutions, the cultural environment and so on. The same institutions must 
be subordinated to the interests of other individuals. And so on, down to infinity. We face an infinite reverse row of explanations, similar in meaning to a well-known riddle: "which came first, the chicken or the egg?". Such an analysis has no final result. We can stop at one of the stages and say: "everything depends on individual preferences" or stop at another and assume that everything is determined by institutional factors. But in the infinite reverse row of explanations, none of these hypotheses has superiority over the other.

Institutional function of institutions implies that a kind of order or relative stability can be achieved with all the diversity and differences at the microeconomic level. The existence of institutions presupposes that rules, restrictions, customs and ideas can, with the help of certain psychological and social mechanisms, change the individual goals and preferences in a certain way. This change can increase the possibility of institutions' emergence and contribute to their stability.

As A.M. Sergeev highlights [8] that compared to neoclassical theory the methodological specifics of new institutionalism consist in that new institutionalists pursue the principle of methodological individualism more consistently. According to this principle, all communities are subject to explanation from the perspective of the purposeful behaviour of their members (agents). In addition to the resource and technological constraints that are characteristic of neoclassical models of rational choice, a new class of constraints conditioned by institutional factors is introduced. The behavioural prerequisites for analysis are fundamentally modified by introducing the principles of bounded rationality and economic opportunism [2. P. 654-656].

In this sense, within the framework of modern institutionalism, three-level schemes for the study of economic systems are in demand [11. P. 42]. At the first level of this scheme there is an individual represented in institutional theory as homo institutionalis (contractual man) instead of homo economicus (economic man) in the neoclassical theory. The second level corresponds to various institutional agreements, the third - to the institutional environment.

The institutional description of an economic system is based on the methodological approach of Douglass North, which consists of the following main propositions [1].

1. Only individuals can have their own interests and pursue their goals.

2. Formal and informal sets of institutions always form the framework of individuals' interaction and affect it.

3. Formal and informal institutional changes always result from individuals' interaction in specific situations.

In other words, on the one hand, an individual is restricted by existing institutional structure, and on the other hand, can change this structure in accordance with his/her preferences.

Therefore, the core of institutional description of economic systems is the evolutionary nature of institutional structures' development. In this sense, modern institutional theory is closely linked with evolutionary economic theory and can be viewed as a single whole, as the institutional and evolutionary theory.

A modern digital society changes types of social networks and, as a result, establishes new relationships in the form of institutional infrastructure [16]. Digital society puts forward the problem of agreements between agents, their consent to interact under existing conditions [15].

Consequently, digital society, in which the adopted rules and constraints are the main elements, can best be described within the framework of institutional economic theory.

\section{Institutional design of digital economy}

The most representative areas of digital economy are sharing economy and the use of blockchain technology. The table presents examples of activities within sharing economy.

Apparently, the following set of principles of institutional design characterize the properties (connectivity, resourcing, specificity) of sharing economy. 
First, the efficiency of sharing economy is determined by the presence of highly branched communications, including mobile communications and the Internet. Without digital technologies, sharing economy loses its meaning, as the efficiency of communications with consumers is lost.

Examples of activities within sharing economy

\begin{tabular}{|c|c|c|}
\hline Type & Activity & Examples \\
\hline \multirow[t]{5}{*}{ Services } & Driving opportunities & Blablacar \\
\hline & Timesharing & Room4exchange \\
\hline & Allowing to use tools and space in a repair shop & Selfservegarage.com \\
\hline & Meal sharing & BonAppetour \\
\hline & Taxi sharing & Uber, YandexTaxi \\
\hline \multirow[t]{7}{*}{ Things } & Exchanging & \multirow[t]{7}{*}{ OLX, Allegro, EBay, Amazon } \\
\hline & Borrowing & \\
\hline & Donating & \\
\hline & Bartering & \\
\hline & Leasing & \\
\hline & Renting & \\
\hline & Reselling & \\
\hline \multirow[t]{2}{*}{ Resources } & Reusing of energy and other common resources & Vanderbron in Netherlands \\
\hline & Reusing of food & Food Combay, Food Loop \\
\hline \multirow[t]{2}{*}{ Know-how } & Co-using and developing & Open sources platforms \\
\hline & Teaching /learning & $\begin{array}{l}\text { Open source courses, online lectures, } \\
\text { virtual study groups }\end{array}$ \\
\hline \multirow[t]{4}{*}{ Finance } & Lending & Lending platforms \\
\hline & Currencies & Bitcoin \\
\hline & Insurance & Insurance policy pooling \\
\hline & $\begin{array}{l}\text { Collaborative money optimization and invest- } \\
\text { ments }\end{array}$ & Cash pooling \\
\hline
\end{tabular}

Note. Based on [22].

Second, the implementation of sharing economy procedures is possible if there are the resources necessary to perform the transfer to consumers. Under this approach resourcing is the basis for the movement of goods and services.

Third, the utility of implementing sharing economy procedures results from the specificity of assets transferred to the use of consumers. This is the case when consumers are ready to participate in the shared use of good instead of purchasing products or services.

Proceeding from the properties of blockchain technology (specification of rules, distribution of resources, availability of information) we can formulate the following principles of institutional design of econotronics' transactions.

Efficiency of employing blockchain is determined by the specification of rules of using information resources, which provides users' access codes to blockchain.

Economic relevance of employing blockchain is conditioned by spatial distribution of the accounted assets. The feature of dispersed resources is typical of both real goods, and virtual reality (voting, reputation support, insurance, etc.).

The consumer value of adopting blockchain proceeds from the availability of information for users of this technology. Availability of information provides both a multilateral surveillance over blockchain services, and a possibility to instantly utilize the results of accounting of different assets.

What are then possible methods of institutional modelling of the econotronics' subject? 


\section{Institutional modelling of digital society}

Institutional modelling of digital society within the concept of econotronics can be done by the methods of matrix, parametric, graphical and analytical modelling. Let us consider the last one in more detail.

Analytical modelling is based on establishing causal relationships between various parameters of the object of analysis expressed in formula dependencies.

An example of the analytical institutional modelling is the author's formalization of firm's transaction function.

The analysis of the published research on introducing the transaction function shows that such function can be designed on the basis of classical definitions of the essence of transaction costs followed by verification of the developed ratio.

A classical definition of transaction costs belongs to Thrainn Eggertsson: "in general terms, transactions costs are the costs that arise when individuals exchange ownership rights to economic assets and enforce their exclusive rights" [12]. Yet he also points to that there is no explicit definition to transaction costs just as there is no correct definition to production costs in neoclassical theory. Robert Mathews proposed the following definition: "the fundamental idea of transaction costs consists in that they encompass the costs of drawing up and concluding a contract, as well as the costs of supervising compliance with the contract and ensuring its fulfilment as opposed to production costs, which are the costs of the performance of the contract itself" [18].

These definitions allow us to identify three key dependencies of transaction costs on the parameters of economic systems. According to T. Eggertsson, transaction costs are directly proportional to the number of economic agents contracting each other. And in line with the definition of R. Matthews, transaction costs are inversely proportional to the number of contracts concluded and the established norms that ensure the implementation of these contracts.

If under formal contracts we understand formal institutions, and under rules that ensure the implementation of these contracts - informal institutions, then it is possible to qualitatively model the dependence of transaction costs on the basic institutional parameters of economic systems.

In this case, the exogenous transaction function of the firm will take the form [19]:

$$
C=\frac{B \cdot N^{\lambda}}{F^{\mu}+I^{v}}
$$

where $C$ is transaction costs of a firm (economic agent in a general case); $B$ is coefficient of proportionality, measured in the units of costs; $N$ is the number of economically active agents (actors) that have entered into institutional arrangements with a firm (or a certain agent); $F$ is the number of formal institutions (contracts); $I$ is the number of informal institutions; $\lambda, \mu, v$ are the coefficients of elasticity of the use of actors, formal and informal institutions for the formation of the institutional environment.

In equation (1), formal and informal institutions are represented as additive terms, since they supplement, but do not overlap various directions of economic activity with their norms. In other words, in each concrete situation, contractual relations can be defined in the form of formalized (classical and neoclassical) norms, or in the form of informal (implicit) agreements between economic agents.

Expression (1) describes the exogenous transaction function of the firm, since accounting for endogenous factors would have led to the need to analyse internal transactions and, accordingly, change the form of the ratio.

Another example of analytical institutional modelling is the model for optimizing the transaction costs of information production and consumption. Let us define the conditions under which a firm is at the level of transaction costs of information production and consumption, 
which is optimal for this evolutionary period of time. The model presented in this study is based on the modification of Williamson's model of spending preferences [9. P. 241]. In order to determine the optimal cost of information production and consumption, we need to deal with the following problems:

- to maximize the profit of the firm;

- to maximize the completeness of information;

- to comply with the budget constraint.

The profit function of the firm in our model takes the form:

$$
\pi(Q, I C)=R(Q, I C)-C(Q)-I C,
$$

where $\pi$ is net profit, $Q$ is output, $I C$ is transaction costs of information production and consumption, $R$ is gross revenue, $C$ is production costs.

Consider the following model assumptions:

1. The revenue $R$ in the model depends not only on the output $Q$, but also on the information production costs IC. This means that an increase in the costs of information production and consumption leads to an increase in gross revenue associated with obtaining additional information about the market and earning additional revenue.

2. The above expression (2) is the budget constraint of the model. The firm can direct all received revenue either to increase net profit, or to produce and search for information.

3. The costs of information production and consumption are fixed and do not depend on the output. Despite the fact that some types of transaction costs of information production and consumption may depend on $Q$, it can be assumed that in the short run they are fixed costs.

The task of profit maximization is limited to the following expression:

$$
\max \pi(Q, I C)=R(Q, I C)-C(Q)-I C \text {. }
$$

By differentiating the right-hand side of equation (3) with respect to the parameter $I C$ and equating it to zero, we obtain the following condition:

$$
\frac{\partial \pi}{\partial I C}=\frac{\partial R}{\partial I C}-1=0
$$

Therefore [20]:

$$
\frac{\partial R}{\partial I C}=1
$$

Condition (5) is a condition for the optimum amount of costs of information production and consumption $I C$ and assumes that the growth rate of transaction costs should be equal to the growth rate of gross revenue. Thus, an increase in transaction costs $I C$ by $1 \%$ should result in an increase in revenue by $1 \%$.

Hence, the methods of institutional modelling can be successfully applied to forecast the development of the institutional infrastructure of the objects of digital society.

\section{Conclusion}

The development of the elements of analysis of modern digital society within the author's concept of econotronics has yielded a number of results.

First, econotronics has been defined as a subfield of social sciences studying the development dynamics of economic institutions of interaction between actors and society in a modern digital economy.

Second, we have demonstrated that the research subject of econotronics includes social innovations, crowdfunding, as well as other economic processes which gained traction within modern digital society. Sharing economy and blockchain technology exemplify a typical subject of econotronics. 
Third, in a narrower sense, a modelled representation, the research subject of econotronics encompasses economic institutions of interaction between actors and society. At this, the analysis of development dynamics of these institutions matters greatly.

Fourth, we have considered the principles of institutional design of the subject of econotronics at the example of institutional design of transactions in sharing economy and blockchain technology.

Fifth, we have pointed to that institutional modelling of digital society within the concept of econotronics can be done by the methods of matrix, parametric, graphical and analytical modelling

The methods of econotronics act as a methodological platform for modelling of rational economic management under the use of digital technologies. Stated differently, econotronics is a scientific concept to describe the development of digital society.

\section{References}

1. Ananyin O. I., Odintsova M.I. Metodologiya ekonomicheskoy nauki: sovremennye tendentsii i problemy [The methodology of economic science: Modern trends and problems]. In: ISTOKI. Vyp. 4 [The Beginnings. Issue 4]. Moscow: Institue of Economics of RAS, 2000, pp. 135-136.

2. Avtonomov V., Ananyin O., Makasheva N. Istoriya ekonomicheskikh ucheniy [The history of economic thought]. Moscow: INFRA-M Publ., 2001.

3. Makarov V.L. Ischislenie institutov [Calculus of institutions]. Ekonomika i matematicheskie metody - Economics and Mathematical Methods, 2003, vol. 39, no. 2, pp. 14-37.

4. Marx K., Engels F. Sobraniye sochineny. T. 3 [Collected works. Vol. 3]. Moscow: Politizdat Publ., 1955.

5. Polterovich V.M. Optimal'nyy vybor ekonomicheskikh institutov [The optimal choice of economic institutions]. Ekonomika i matematicheskie metody - Economics and Mathematical Methods, 2003, vol. 39, no. 4, pp. 52-58.

6. Popov E. V. Instituty [Institutions]. Yekaterinburg: Institute of Economics (Ural branch of RAS), 2015.

7. Popov E. V. Ekonotronika [Econotronics]. Ekonomika regiona - Economy of Region, 2018, vol. 14, issue 1, pp. 13-28.

8. Sergeev A.M. Metodologicheskie osobennosti i problemy novogo institutsionalizma [Methodological specifics and problems of new institutionalism]. Yekaterinburg: Institute of Economics (Ural branch of RAS), 2005.

9. Furubotn E., Richter R. Instituty i ekonomicheskaya teoriya [Institutions and economic theory]. Saint Petersburg: Saint Petersburg State University, 2005.

10. Hodgson G. Evolyutsiya institutov: napravleniya budushchikh issledovaniy [The evolution of institutions: An agenda for future research]. Zhurnal ekonomicheskoy teorii-Russian Journal of Economic Theory, 2005, no. 2, pp. 5-22.

11. Shastitko A. Ye. Novaya institutsional'naya ekonomicheskaya teoriya [New institutionalism]. Moscow: TEIS Publ., 2002.

12. Eggertsson T. Ekonomicheskoe povedenie i instituty [Economic behavior and institutions]. Moscow: Delo Publ., 2001.

13. Gouldner A.W. The Dialectic of Ideology and Technology: The Origins, Grammar and Future. N. Y.: The Free Press, 1976.

14. Etzioni A. The Moral Dimension: Toward a New Economics. N. Y.: The Free Press, 1988.

15. Faith B., Prieto-Martin P. Civil Society and Civic Engagement in a Time of Change. Institute of Development Studies Bulletin, 2016, vol. 47, no. 2A, pp. 137-144.

16. Fletcher G., Greenhill A., Griffiths M., McLean R. The Social Supply Chain and the Future High Street. Supply Chain Management, 2016, vol. 21, no. 1, pp. 78-91. 
17. Hodgson G.M. What Are Institutions? Journal of Economic Issues, 2006, vol. XL, no. 1, pp. 1-26.

18. Matthews R. C. O. The Economics of Institutions and Sources of Growth. Economic Journal, 1986, vol. 96, no. 12 (December), pp. 903-910.

19. Popov E. V. Transaction Function. International Advances in Economic Research, 2008, vol. 14 , no. 4 , pp. $474-475$.

20. Popov E. V., Konovalov A. A. Institutional Effects Estimation in the Sphere of Economical Information. Montenegrin Journal of Economics, 2007, no. 5, pp. 59-66.

21. Swan M. Anticipating the Economic Benefits of Blockchain. Technology Innovation Management Review, 2017, vol. 7, no. 10, pp. 6-13.

22. Szetela B., Mentel G. May the Sharing Economy Create a New Wave of Globalization? Economic Annals, 2016, vol. 161, no. 9-10, pp. 31-34.

23. Veblen T. Why is Economics not an Evolutionary Science. Quarterly Journal of Economics, 1898, vol. 12, no. 4, pp. 373-397.

24. Veblen T. The Place of Science in Modern Civilization and Other Essays. N. Y.: Huebsch, 1919.

\section{Эконотроника цифрового общества'}

\section{E. B. Попов}

Исследование направлено на систематизацию элементов анализа современного цифрового общества в рамках авторской концепции эконотроники. Показано, что эконотроника представляет собой раздел социальных наук о динамике развития экономических институтов взаимодействия между акторами и обществом в цифровой экономике. Проанализированы объекты исследования эконотроники. На основе современного представления о человеке институциональном определено, что наиболее адекватным аппаратом моделирования процессов развития цифрового общества являются инструменты институциональной экономической теории. Выявлены элементы институционального дизайна трансакций эконотроники. Выделены направления институционального моделирования объектов эконотроники. Утверждается, что эконотроника является научной концепцией моделирования развития цифрового общества.

Ключевые слова: цифровое общество; эконотроника; человек институциональный; институциональный дизайн; моделирование.

\section{Источники}

1. Ананьин О.И., Одинцова М.И. Методология экономической науки: современные тенденции и проблемы // ИСТОКИ. Вып. 4. М.: ИЭ РАН, 2000. С. 135-136.

2. История экономических учений / под ред. В. Автономова, О. Ананьина, Н. Макашевой. М.: ИНФРА-М, 2001. С. 654-656.

3. Макаров В. Л. Исчисление институтов // Экономика и математические методы. 2003. Т. 39, № 2. C.14-37.

4. Маркс К., Энгельс Ф. Собр. соч. М.: Политиздат, 1955. Т. 3.

5. Полтерович В.М. Оптимальный выбор экономических институтов // Экономика и математические методы. 2003. Т. 39, № 4. С. 52-58.

6. Попов Е. В. Институты. Екатеринбург: Ин-т экономики УрО РАН, 2015.

7. Попов Е. В. Эконотроника // Экономика региона. 2018. Т. 14, вып. 1. С. 13-28.

8. Сергеев А.М. Методологические особенности и проблемы нового институционализма: препринт. Екатеринбург: Ин-т экономики УрО РАН, 2005.

${ }^{1}$ Статья выполнена при финансовой поддержке РФФИ (проект № 17-06-00281 «Моделирование институциональной среды социально-инновационного развития России»). 
9. Фуруботн Э., Рихтер Р. Институты и экономическая теория. СПб.: Изд. дом СПбГУ, 2005.

10. Ходжсон Дж. Эволюция институтов: направления будущих исследований // Журнал экономической теории. 2005. № 2. С. 5-22.

11. Шаститко А.Е. Новая институциональная экономическая теория. М.: ТЕИС, 2002.

12. Эггертссон Т. Экономическое поведение и институты. М.: Дело, 2001.

13. Gouldner A. W. The Dialectic of Ideology and Technology: The Origins, Grammar and Future. N. Y.: The Free Press, 1976.

14. Etzioni A. The Moral Dimension: Toward a New Economics. N. Y.: The Free Press, 1988.

15. Faith B., Prieto-Martin P. Civil Society and Civic Engagement in a Time of Change // Institute of Development Studies Bulletin. 2016. Vol. 47, no. 2A. Pp. 137-144.

16. Fletcher G., Greenhill A., Griffiths M., McLean R. The Social Supply Chain and the Future High Street // Supply Chain Management. 2016. Vol. 21, no. 1. Pp. 78-91.

17. Hodgson G. M. What Are Institutions? // Journal of Economic Issues. 2006. Vol. XL, no. 1. Pp. 1-26.

18. Matthews R. C. O. The Economics of Institutions and Sources of Growth // Economic Journal. 1986. Vol. 96, no. 12. Pp. 903-910.

19. Popov E. V. Transaction Function // International Advances in Economic Research. 2008. Vol. 14, no. 4. Pp. 474-475.

20. Popov E. V., Konovalov A. A. Institutional Effects Estimation in the Sphere of Economical Information // Montenegrin Journal of Economics. 2007. No. 5. Pp. 59-66.

21. Swan M. Anticipating the Economic Benefits of Blockchain // Technology Innovation Management Review. 2017. Vol. 7, no. 10. Pp. 6-13.

22. Szetela B., Mentel G. May the Sharing Economy Create a New Wave of Globalization? // Economic Annals. 2016. Vol. 161, no. 9-10. Pp. 31-34.

23. Veblen T. Why is Economics not an Evolutionary Science // Quarterly Journal of Economics. 1898. Vol. 12, no. 4. Pp. 373-397.

24. Veblen T. The Place of Science in Modern Civilization and Other Essays. N. Y.: Huebsch, 1919.

Сведения об авторе:

E. В. Попов, чл.-кор. РАН, д-р экон. наук, руководитель центра экономической теории, заведующий кафедрой политической экономии

Контактный телефон: (343) 371-45-36

e-mail: epopov@mail.ru

\author{
Институт экономики УрО РАН \\ 620014, РФ, Екатеринбург, ул. Московская, 29 \\ Уральский государственный экономический \\ университет \\ 620144, РФ, г. Екатеринбург, \\ ул. 8 Марта/Народной Воли, 62/45
}

Ссылка для цитирования: Рopov E. V. Econotronics of the Digital Society// Известия Уральского государственного экономического университета. 2018. T. 19, №3. C. 8-17. DOI: 10.29141/2073-1019-2018-19-3-2

For citation: Popov E. V. Econotronics of the Digital Society. Izvestiya Uralskogo gosudarstvennogo ekonomicheskogo universiteta - Journal of the Ural State University of Economics, 2018, vol. 19, no. 3, pp. 8-17. DOI: 10.29141/20731019-2018-19-3-2 


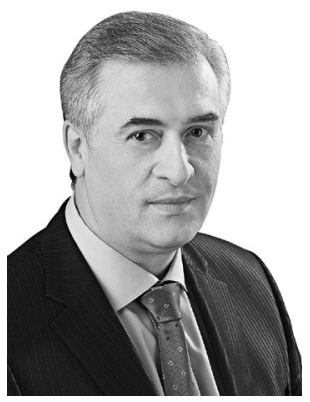

\section{Силин Яков Петрович}

Доктор экономических наук, ректор, профессор кафедры региональной, муниципальной экономики и управления

Уральский государственный экономический университет 620144, РФ, г. Екатеринбург, ул. 8 Марта/Народной Воли, 62/45 Контактный телефон: (343) 221-17-00

e-mail: odo@usue.ru

АНИМИЦА Евгений Георгиевич

Доктор географических наук, профессор, заведующий кафедрой региональной, муниципальной экономики и управления

Уральский государственный экономический университет 620144, РФ, г. Екатеринбург, ул. 8 Марта/Народной Воли, 62/45 Контактный телефон: (343) 221-27-20 e-mail:animieg@usue.ru

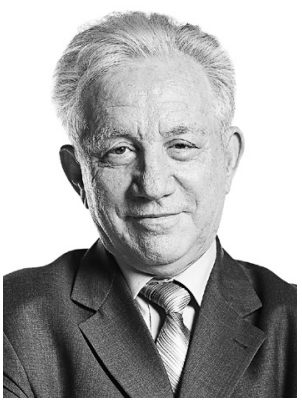

\section{Контуры формирования цифровой экономики в России}

Статья посвящена исследованию содержания дискуссионного понятия «цифровая экономика» и ее основных характеристик. Выявлены и проанализированы научные подходы к трактовке содержания понятия «цифровая экономика». Доказывается, что цифровая экономика знаменует наступление новой информационной эры и что построение цифровой экономики в России - задача, вполне решаемая. Обосновывается необходимость сопряжения процессов становления цифровой экономики, нового индустриального развития страны и улучшения качества жизни населения в течение ближайших лет. Особое внимание уделяется выявлению роли и значимости высшего образования в формировании цифровой экономики. Авторы доказывают, что каждый регион страны, исходя из своей специфики, должен сам определять, какие отрасли, секторы цифровой экономики необходимо развивать в первую очередь на своей территории. Сформулирован вывод: цифровым технологиям, которые в России обретают свои контуры, вполне удастся сделать экономику страны высокотехнологичной, конкурентоспособной и вывести ее на волну роста.

JEL classification: O50, L50

Ключевые слова: цифровая экономика; программа «Цифровая экономика»; новая индустриализация; образовательная среда; регион; вуз.

\section{Введение}

Ц ифровая экономика - одно из новейших интенсивно развивающихся направлений экономической науки. Этот термин активно используют первые лица государства, губернаторы, депутаты разных уровней, мэры, политики, журналисты, а также преподаватели и студенты российских вузов.

В 2016 г. один из главных докладов Всемирного банка содержал отчет о состоянии цифровой экономики в мире. Россия пока не входит в группу лидеров развития цифровой экономики по многим показателям - уровню (размеру) «цифровизации», доле цифровой экономики в ВВП, объему инвестиций компаний в цифровизацию. В 2017 г. доля цифровой экономики в ВВП России была $3,9 \%$, что в два-три раза ниже, чем в странах лидерах, а объем экспорта цифровых технологий в четыре раза меньше импорта. 
В 2010 г. компания Boston Consulting Group оценила объем интернет-экономики в 2,3 трлн дол. для группы из 20 стран (G-20), или около 4,1\% своего ВВП [8]. В докладе Oxford Economics общий размер цифровой экономики в 2013 г. оценивался в 20,4 млрд дол., что составляет около 13,8\% мировых продаж ${ }^{1}$.

Россия стратегически не только не может позволить себе отставание от стран лидеров в развитии цифровых технологий (сейчас оно достигает 5-8 лет), но должна, сделав технологический рывок, догнать и даже обогнать их. Россия способна добиваться лидерства по ряду направлений цифровой экономики. Это констатировал на Петербургском международном экономическом форуме Президент РФ В.В. Путин: «Российские IT-компании, безусловно, глобально конкуренты. Отечественные специалисты не просто предлагают наилучшие уникальные программные решения, а по сути создают новую сферу знаний, новую среду для развития экономики и жизни» [4]. В. В. Путин убежден: «...Цифровая экономика - это не отдельная отрасль, по сути это основа, которая позволяет создавать качественно новые модели бизнеса, торговли, логистики, производства, изменяет формат образования, здравоохранения, госуправления, коммуникаций между людьми, а следовательно, задает новую парадигму развития государства, экономики и всего общества» [4]. Президент подчеркнул, что формирование цифровой экономики становится вопросом национальной безопасности, ибо затрагивает все аспекты жизни общества.

Как считает Н. Касперская, глава рабочей группы по разработке программы «Цифровая экономика Российской Федерации» по направлению «Информационная безопасность», попытка государства догонять и заимствовать чужие технологии чревата тем, что отставание со временем будет увеличиваться. Она уверена, что только национальный проект в области информационных технологий и разработка собственных решений позволят России сохранить цифровой суверенитет [5].

\section{Как специалисты понимают термин «цифровая экономика»}

Развитие цифровой экономики началось на изломе появления новой информационной эры, обозначавшей переход от механической и аналоговой электронной технологии к цифровой электронике $[1 ; 2 ; 3]$.

Как считает К. Шваб, основатель и президент Всемирного экономического форума в Давосе, третью промышленную революцию, которая началась в 1960-е годы, называют компьютерной, или цифровой, революцией [6]. Цифровая революция, по мнению К. Шваба, создает радикально новые подходы, коренным образом изменяющие способ взаимодействия и сотрудничества отдельных людей и учреждений.

Понятие «цифровая экономика» возникло в научном мире в 90-е годы XX века. Ввел в употребление термин «цифровая экономика» в 1995 г. американский ученыйинформатик Н. Негропонте [7]. Наряду с понятием «цифровая экономика» специалисты пользуются и такими понятиями, как «электронная экономика», «интернет-экономика», «новая экономика», «веб-экономика» и др. Четкого и однозначного понимания понятия «цифровая экономика» в научной литературе нет, оно размыто, расплывчато и вызывает много дискуссий и споров ${ }^{2}$.

Можно выделить два основных подхода к трактовке понятия «цифровая экономика». Представители первого, так называемого классического, подхода определяют цифровую экономику как экономическую деятельность, основанную на новых методах

${ }^{1}$ The New Digital Economy. How it Will Transform Business. URL: https://www.pwc.com/mt/en/ publications/assets/the-new-digital-economy.pdf.

${ }^{2}$ When Measuring the Digital Economy, Measure the (Creative) Destruction Too. URL: https:// eaves.ca/2010/11/02/when-measuring-the-digital-economy-measure-the-destruction-too; Цифровая экономика. Опрос // БИТ. Бизнес \& информационные технологии. 2017. № 3 (66). С. 14-17. 
генерирования, обработки, хранения и передачи информации (данных), базирующихся на цифровых компьютерных технологиях. Речь идет, в первую очередь, не столько о разработке и продаже программного обеспечения, сколько об электронных товарах, услугах и сервисах. Это так называемый прямой, или «чистый», онлайн-бизнес. Типичные примеры - Интернет, сотовая связь, дистанционное обучение, продажа медиаконтента (ТВ, книги, кино и др.).

Второй подход существенно расширяет содержание цифровой экономики. Некоторые эксперты считают, что это часть экономических, культурных и социальных отношений, связанных с системой производства, распределения, обмена или потребления цифровых информационно-коммуникационных технологий. Тем самым цифровую экономику формирует вся цепочка товаров и услуг, которые производятся и оказываются с использованием цифровых технологий, в том числе квантовых, новых производственных технологий, сенсорных сетей, мобильных сетей четвертого и пятого поколений ( $4 \mathrm{G}$ и 5G), промышленного (индустриального) Интернета вещей, искусственного интеллекта, нейротехнологии, систем распределения (блокчейн), технологий работы с большими данными.

Отметим, что границы между этими двумя научными подходами понимания цифровой экономики во многом условны. По большому счету, все коммерческие компании, все действия в компьютерной виртуальной реальности можно отнести к цифровой экономике.

Эксперты Всемирного банка предлагают обобщенное определение: «цифровая экономика - это новая парадигма ускоренного экономического развития».

Ученые МГУ убеждены, что «топливом изменений в цифровой экономике являются инновации».

Как считает генеральный директор ГК «Angara», цифровой можно назвать такую компанию, которая стремится перенести бизнес-процессы в онлайн, в частности управление, контроль и анализ всех основных бизнес-процессов компании, - согласование договоров, бухгалтерский учет, логистика, регистрация сделок, закупки, обучение персонала, мониторинг взаимоотношений с партнерами и клиентам, технологическая поддержка и т. п. ${ }^{1}$ Это в совокупности делает компанию «цифровой», обеспечивает ее эффективность, продуктивность и потенциал роста.

Третья группа ученых и экспертов считает, что «цифровой экономики» самой по себе нет. Существует экономика в целом, традиционные сферы которой в той или иной мере «пронизаны автоматизацией». Например, цифровые технологии, трансформируя такую древнейшую отрасль экономики, как медицина, стремительно ее изменяют, требуют дополнительного набора компетенций, связанных с цифровыми технологиями. Однако подобная компьютеризированная медицина остается самостоятельной отраслью народного хозяйства и может быть отдельной структурой виртуальной «цифровой экономики».

Обобщая сказанное, можно утверждать, что, во-первых, цифровая экономика ознаменовала наступление новой информационной эры. Во-вторых, цифровая экономика включает в свой состав все то, что поддается формализации, а по мере появления и развития новых технологий будет пополняться перечень и состав цифровой экономики. Таким образом виртуальная часть экономики совмещается с физической, реальной. В-третьих, задача цифровой экономики - повысить уровень и качество жизни населения на основе увеличения качества товаров и услуг, произведенных с использованием современных цифровых технологий. В-четвертых, построение цифровой экономики - цель сложная, но вполне достижимая. Реализация ее базируется на следующих

${ }^{1}$ Цифровая экономика. Опрос // БИТ. Бизнес \& информационные технологии. 2017. № 3 (66). C. $14-17$. 
основаниях: развитая информационно-коммуникационная инфраструктура; «цифровые» квалифицированные кадры; сотрудничество структур государства, бизнеса и науки (образования); активная хозяйственная деятельность посредством компьютерных сетей; электронная дистрибуция и торговля; нормативно-правовое регулирование; внедрение передовых мировых практик.

Для обеспечения правовых условий совершенствования и исполнения сделок в цифровой экономике Госдумой РФ внесен законопроект, который, в частности, даст возможность власти внести в Гражданский кодекс РФ такие базовые понятия, как «цифровое право» и «цифровые деньги» (криптовалюта). Предполагается, что «цифровые деньги» будут обязательны к приему при осуществлении всех видов платежей, когда для этого будут созданы технические возможности и исключены риски.

Следует подчеркнуть, что либерализация криптовалют в мире идет очень медленно, постепенно и оперируют с ними всего несколько стран, среди которых Япония, США и Канада. К этой группе государств присоединилась и Республика Беларусь, в которой официально разрешена покупка, продажа, обмен и майнинг криптовалюты. Базовым документом, регулирующим криптосферу в Белоруссии, стал декрет «О развитии цифровой экономики», который вступил в силу в марте 2018 г.

В целях ускорения цифровой трансформации России была разработана и утверждена программа, рассчитанная на период до 2024 г. $^{1}$ Программа состоит из пяти базовых направлений: образование, кадры, кибербезопасность, формирование исследовательских компетенций и IT-инфраструктура.

Работа по развитию цифровой экономики в России ведется в тесном сотрудничестве со странами ЕАЭС, и ряд норм и вопросов регулирования будет решаться, как показало заседание ЕАЭС в Алма-Ате в январе 2018 г., на уровне этого международного союза.

Учитывая массовый перенос документов и коммуникаций на цифровые носители, в России для электронного документооборота принят стандарт электронной подписи (ГОСТ Р34.10-2012), поэтому вполне логичным представляется перенос общения населения с государственными и муниципальными структурами на электронную платформу.

Мероприятия по цифровизации экономики потребуют финансирования в размере более 500 млрд р., причем более 150 млрд р. этой суммы должно поступать из бюджета.

По оценкам консалтинговой компании McKinsey, потенциальный экономический эффект от цифровизации экономики России к 2025 г. увеличивает ВВП страны на 4,1-4,8 трлн р. (в ценах 2015 г.), что составляет от 19 до 34\% всего ожидаемого роста ВВП. Начать следует с цифровизации таких социально важных сфер, как образование, здравоохранение, «Умный город» и государственное управление, в развитии которых наиболее значима роль государства.

\section{Новая индустриализация и цифровая экономика}

Для реализации программы «Цифровая экономика» крайне важным представляется сопряжение ее с концептуальными установками формирования новой индустриализации в России, ибо цифровая экономика, выраженная, в первую очередь, в технических и технологических трендах, теснейшим образом связана с новой индустриализацией.

В создании цифровой экономики заложен значительный потенциал для запуска механизма нового индустриального развития страны и улучшения качества жизни населения в течение ближайших семи лет. В частности, в России технологии индустриального Интернета вещей являются одним из динамично развивающихся направлений,

${ }^{1}$ Распоряжение Правительства РФ от 28 июля 2017 г. № 1632-р «Об утверждении программы „Цифровая экономика Российской Федерации“». 
как цифровой экономики, так и новой индустриализации. Компоненты новой индустриализации, получившей название «Индустриализация 4.0», органически вплетены в ткань цифровой экономики. Это робототехника, беспилотные транспортные средства, аддитивные техники, новые материалы.

Особенно важным представляется производство роботов, способных обрабатывать гигантские объемы информации, управлять различными производственными процессами, а также умеющих оценивать физическое и эмоциональное состояние человека, с которым они взаимодействуют.

Известно, что СССР был пионером в области робототехники. Однако в 2015 г. на 10 тыс. работников в России приходился 1 робот, тогда как в мире - в среднем 69, в Южной Корее - 531; Сингапуре - 398; Японии - 305; Германии - 301. Организация производства роботов быстро скажется на восстановлении обрабатывающей промышленности, главным образом станкостроении.

Развитие обрабатывающей промышленности позволит создать собственную элементную базу электроники, микроэлектроники, что необходимо для обретения технического суверенитета и обеспечения национальной безопасности. Отметим, что в настоящее время более $80 \%$ компонентов электроники закупается за рубежом.

В эпоху бурного развития технологии, цифровизации практически всех сфер жизни общества электроника играет ключевую роль. Собственные разработки и серийное производство продукции электроники - основа для инновационного развития экономики, повышения ее качества и конкурентоспособности. Электроника позволит заменить шоферов, летчиков, машинистов, в результате чего так называемый «человеческий фактор» не будет причиной различных транспортных катастроф.

России следует иметь собственную линейку 3D-принтеров для самостоятельного производства дефицитных изделий, которые сейчас приходится завозить из-за границы.

Развитие электроники объективно потребует стимулирования добычи редкоземельных металлов (Р3М), без которых невозможно производство полупроводниковых элементов и иных высокотехнологичных устройств, включая технику вооружений. РЗМ оказываются столь же важным стратегическим сырьем, как нефть, тем более, что свыше 90\% РЗМ производит Китай.

Все эти основные стратегические направления крайне важны, как для развития цифровой экономики, так и при новой индустриализации.

Целесообразным представляется включить в программу «Цифровая экономика» проект «Умный город». Исследования и разработки в проекте «Умный город» - это очень сложные и долговременные задачи. Именно в нем накоплено и сконцентрировано наибольшее количество «социально чувствительных» проблем, именно по их оперативному решению оценивается эффективность цифровой экономики. В октябре 2017 г. был создан Национальный консорциум развития и внедрения цифровых технологий в сфере городского управления «Умный город». К 2025 г. в России должно быть создано 50 «умных городов», среди которых все города-миллионники.

\section{Высшее образование и формирование цифровой экономики}

Цифровизация экономики непосредственным образом связана с формированием образовательной среды. С существующими методами образования, как школьного, так и высшего, России затруднительно будет оперативно и полномасштабно ответить на вызовы новой технологической революции. Приоритет должен быть отдан подготовке кадров, образованию, исследованиям и разработкам в области IT-технологий, которые повлекут за собой естественное развитие информационной инфраструктуры, сформируют устойчивое кадровое обеспечение цифровой экономики.

В сентябре 2017 г. на Международной образовательной конференции \#EdCrunch2017 заместителем министра образования и науки был представлен приоритетный проект 
«Современная цифровая образовательная среда в РФ» (СЦОС). Среди ключевых партнеров Минобрнауки по реализации данного проекта названы были крупные корпорации и ведущие вузы страны. Минобрнауки провел конкурс российских вузов по разработке элементов единой образовательной платформы, выбрав 17 победителей. В стране были созданы 10 региональных опорных центров компетенций в области онлайнобучения.

Единая цифровая среда обеспечивает всем гражданам страны равный доступ к качественному и самому современному на данный момент образованию. Цифровой мир позволяет каждому человеку выстраивать собственную образовательную траекторию, брать на себя ответственность за свое обучение.

На портале СЦОС зарегистрированы 300 учебных курсов, и студент сам выбирает нужные ему курсы. Насчитывается более 500 тыс. пользователей. Все курсы проверяются федеральными учебно-методическими объединениями на соответствие требованиям федеральных государственных образовательных стандартов. Прохождение онлайн-курсов засчитывается студенту как часть учебного плана вуза, в котором тот обучается.

Главной задачей университетов должно стать создание плодотворной образовательной и научно-исследовательской среды с яркими и харизматичными преподавателями, интересными специалистами и увлеченными студентами. Задача коллектива Уральского государственного экономического университета (УрГЭУ) - сформировать вуз с законченным циклом институтов (факультетов), который покрывал бы все поле социально-экономического развития Уральского региона. Преподавание в университете должно тесно переплетаться с исследовательской и аналитической работой студентов, с практическим консультированием региональных и муниципальных органов власти и управления, крупных корпораций. Это задача, так сказать, для себя. Но если она будет решена, то УрГЭУ займет достойное место в системе высшего образования России, в числе лидеров российского экономического образования.

Одна из серьезных проблем вуза не только в том, чтобы научить преподавателей разрабатывать онлайн-курсы, но и в том, чтобы научиться использовать цифровую среду. Она требует от преподавателей нового видения картины мира, знания новых процессов в системе государственного и муниципального управления, экономики, финансов, бизнеса, социальной сферы, что в итоге предопределяет необходимость разработки новых способов работы со студентами.

Преподаватель в эпоху «цифровизации» становится для студента наставником, «проводником» по сложному лабиринту цифрового мира. Наряду с зарождением новой информационной культуры приходит и новая образовательная культура. Одной из сложных проблем вузовского сообщества является перестройка сознания преподавателей. В эпоху «цифровизации» актуальной становится формула: «меняйся или увольняйся», так как в университет приходят учиться студенты, рожденные и воспитанные уже в цифровую эпоху.

Преподаватель на портале университета должен выложить читаемые лекционные курсы, модули своих дисциплин, учебные планы, соответствующие по содержанию и форме требованиям федеральных государственных образовательных стандартов, а также согласованные с требованиями и пожеланиями работодателей.

Каждый регион России должен определить, исходя из своей специфики, какие разделы, отрасли, секторы цифровой экономики ему необходимо формировать в первую очередь, какие региональные бренды, какую собственную уникальность поддерживать и развивать. В этом важное значение имеет и организация инновационной системы высшего образования.

Для промышленных районов, к которым относится, в частности, Уральский регион, основной эффект от применения цифровых технологий будет проявляться в промыш- 
ленном производстве при реализации концепции «Индустрия 4.0». В Уральском государственном экономическом университете открыты филиалы выпускающих кафедр на ведущих предприятиях региона, среди которых Уралвагонзавод, Завод им. М.И. Калинина. Учитывая, что университет дислоцируется в городе-миллионнике, а также то, что в Свердловской области насчитывается 44 города, важную роль для вуза играет такой сегмент цифровой экономики, как проект «Умный город». В начале 2018 г. УрГЭУ подписал с одной из крупных компаний-застройщиков АО «РСГ-Академическое» и управляющей компанией $3 \mathrm{AO}$ «УК „Академический“» соглашение о реализации концепции «Умный город» на территории г. Екатеринбург, а также о сотрудничестве в области внедрения в ЖКХ IT-технологий, новыХ знаний в сфере менеджмента и маркетинга. Одна из целей соглашения - повышение квалификации работников жилищно-коммунального хозяйства по направлениям информационно-телекоммуникационных технологий.

Есть основания полагать, что цифровым технологиям, которые в России обрели первые контуры, удастся сделать экономику страны и ее регионов сильнее.

\section{Заключение}

Для современной России выдвижение на передний край программы «Цифровая экономика» в ряду с другими социально-экономическими реформами и преобразованиями становится приоритетной и стратегически важной задачей. Необходимо стимулировать создание инновационных технологий, развивать IT-сектор, обеспечить информационный и технологический суверенитет, а следовательно, и безопасность страны.

Цифровая экономика, сопрягаясь с концептуальными установками формирования новой индустриализации в России, призвана стать основой развития системы государственного и муниципального управления, предпринимательства, социальной сферы, общества.

Цифровизация экономики предполагает формирование образовательной среды, подготовку квалифицированных специалистов, доступ к онлайн-программам высшего образования.

\section{Источники}

1. Абилов А.В. Закономерности развития регионального инфокоммуникационного комплекса. М.: Горячая линия - Телеком, 2008.

2. Кастельс М. Информационная эпоха: экономика, общество и культура: пер. с англ. М: ГУ ВШЭ, 2000.

3. Костюк В.Н., Смолян Г.Л., Черешкин Д.С. Об экономическом фундаменте информационного общества // Информационное общество. 2000. № 5. С. 6-13.

4. Путин В. В. Цифра и факты // Российская газета. 2017. № 120 (7286). 5 июня.

5. Шадрина Т. Обогнать, не догоняя // Российская газета - Столичный выпуск. 2018. № 7510 (47). 5 марта.

6. Шваб К. Четвертая промышленная революция: пер. с англ. М.: Изд-во «Э», 2017.

7. Negroponte N. Bits \& Atoms. URL: https://www.phoenix.edu/lectures/nicholas-negroponte/bits-and-atoms.html.

8. The Internet Economy in the G-20 / D. Dean, S. DiGrande, D. Field et al. / The Boston Consulting Group web site. URL: https://www.bcg.com/publications/2012/technology-digital-technology-planning-internet-economy-g20-4-2-trillion-opportunity.aspx. 


\title{
Contours of the Digital Economy in Russia
}

\author{
by Yakov P. Silin and Yevgeny G. Animitsa
}

The paper discusses the content of the concept "digital economy" and its main characteristics. It reveals and analyses scientific approaches to treatment of the concept "digital economy". The authors prove that digital economy marks the dawn of a new information era and the goal of building digital economy in Russia sounds highly realistic. The paper justifies the necessity to align the formation processes of the digital economy with new industrial development of the country and improvement of the quality of life in the coming years. The authors devote particular attention to the role and importance of higher education in formation of the digital economy. They prove that every Russian region should determine which industries, sectors of the digital economy to develop in the first place in its territory proceeding from the regional specifics. The researchers arrive at the conclusion that digital technologies, which are taking their shape in Russia, are completely able of making the national economy high-tech intensive, competitive and bring it to the wave of growth.

Keywords: digital economy; programme "Digital Economy"; new industrialisation; educational environment; region; higher education institution.

\section{References:}

1. Abilov A. V. Zakonomernosti razvitiya regional'nogo infokommunikatsionnogo kompleksa [Development regularities of the regional info-communication complex]. Moscow: Goryachaya liniya - Telekom Publ., 2008.

2. Castells M. Informatsionnaya epokha: ekonomika, obshchestvo i kul'tura [Information age: Economics, society and culture]. Moscow: SU HSE, 2000.

3. Kostyuk V.N., Smolyan G.L., Chereshkin D.S. Ob ekonomicheskom fundamente informatsionnogo obshchestva [On the economic foundation of the information society]. Informatsionnoe obshchestvo - Information Society, 2000, no. 5, pp. 6-13.

4. Putin V. V. Tsifra i fakty [The digit and facts]. Rossiyskaya gazeta, 2017, no. 120 (7286), 5 June.

5. Shadrina T. Obognat', ne dogonyaya [Overtake, not catching up]. Rossiyskaya gazeta - Stolichnyy vypusk, 2018, no. 7510 (47), March 5.

6. Schwab K. Chetvertaya promyshlennaya revolyutsiya [The Fourth industrial revolution]. Moscow: "E” Publ., 2017.

7. Negroponte N. Bits \& Atoms. Available at: https://www.phoenix.edu/lectures/nicholas-negroponte/bits-and-atoms.html.

8. Dean D., DiGrande S., Field D. et al. The Internet Economy in the G-20. The Boston Consulting Group website. Available at: https://www.bcg.com/publications/2012/technology-digital-technologyplanning-internet-economy-g20-4-2-trillion-opportunity.aspx.

Contact Info:

Yakov P. Silin, Dr. Sc. (Econ.), Rector, Prof.

Ural State University of Economics

of Regional, Municipal Economics

and Governance Dept.

Phone: (343) 221-17-00

e-mail: odo@usue.ru

Yevgeny G. Animitsa, Dr. Sc. (Geography),

Prof., Head of Regional, Municipal 62/45 8 Marta/Narodnoy Voli St., Yekaterinburg, Russia, 620144

Economics and Governance Dept.

Phone: (343) 221-27-20

e-mail: animieg@usue.ru

Ural State University of Economics

62/45 8 Marta/Narodnoy Voli St., Yekaterinburg,

Russia, 620144

Ссылка для цичтирования: Силин Я.П., Анимица Е.Г. Контуры формирования цифровой экономики в России // Известия Уральского государственного экономического университета. 2018. Т. 19, № 3. C. 18-25. DOI: 10.29141/2073-1019-2018-19-3-3

For citation: Silin Ya. P., Animitsa Ye. G. Kontury formirovaniya tsifrovoy ekonomiki v Rossii [Contours of the digital economy in Russia]. Izvestiya Uralskogo gosudarstvennogo ekonomicheskogo universiteta - Journal of the Ural State University of Economics, 2018, vol. 19, no. 3, pp. 18-25. DOI: 10.29141/2073-1019-2018-19-3-3 


\title{
СУХАРЕВ Олег Сергеевич
}

Доктор экономических наук, профессор, заведующий лабораторией институциональной экономики

Институт проблем рынка РАН

117418 , РФ, г. Москва, Нахимовский пр., 47

Контактный телефон: (499) 724-27-61

e-mail: 0_sukharev@list.ru

\section{Структурный анализ технологических изменений и стратегия экономического роста'}

\begin{abstract}
Исследование направлено на определение структурных параметров экономики при формировании макроэкономической политики роста. Обозначаются два базовых режима экономического развития, характеризующихся различным соотношением процессов отвлечения и создания ресурса. Показано, что отношение скоростей этих процессов - «созидательного разрушения» и «комбинаторного наращения» - обусловливает характеристики модели экономического роста. Анализируется инвестиционная стратегия как основное направление модели экономического роста на новых факторах, которая определяется уровнем технологичности и возможностью соотношения скоростей отвлечения и создания нового ресурса. Сделан вывод: модель развития российской экономики должна учитывать структуру «старые - новые технологии», которая определит режим экономического роста. Предложено решение проблемы - на микроуровне фирма выбирает технологическую структуру в рамках шкалы «реальные - виртуальные технологии», причем эта процедура детерминирована соотношением эффективности конкурирующих фирм, влияющим на выбор масштаба применения виртуальных и реальных технологий.
\end{abstract}

\section{JEL classification: $\mathrm{O} 32$}

Ключевые слова: технологические изменения; структурный анализ; инвестиционная стратегия; экономический рост; реальные и виртуальные технологии; технологический выбор фирмы.

\section{Введение}

труктурный анализ экономики, и технологий в том числе, является важным элементом при разработке инвестиционной стратегии развития $[1 ; 4]$. Именно в аспекте формирования структуры решается вопрос о количестве видов деятельности, рынков, величине общего благосостояния и его распределения (неравенства доходов). Это затрагивает многие виды экономической политики, решения правительства, определяет требования к применяемым инструментам, например к налоговой системе $[1 ; 2]$.

Структурную задачу представим как сочетание двух режимов технологического развития: 1) «созидательного разрушения» [13], когда ресурсы прежних хозяйственных комбинаций отвлекаются на развитие вновь возникающих комбинаций; 2) «комбинаторного наращения» $[7 ; 9 ; 10 ; 12]$, когда развитие происходит не за счет отвлечения ресурсов, а в результате создания нового ресурса под новые комбинации (возможности), либо технологического комбинирования (объединение двух или большего числа технологий, дающих новые возможн6ости).

${ }^{1}$ Статья подготовлена в рамках темы государственного задания Института проблем рынка РАН «Макроэкономическая и промышленная политика роста: институциональные, структурные и технологические изменения» (№ 0163-2018-0002), а также государственного задания Института экономики РАН для Центра Институтов социально-экономического развития. 


\section{Структурные параметры технологических изменений экономики}

Допустим, что инвестиции в развитие новых комбинаций определяются в виде двух компонент: $\alpha$ - доля ресурса за счет отвлечения от прежних комбинаций; $\mu$ - доля вновь созданного ресурса (в том числе в результате комбинаторного эффекта). Процесс отвлечения и создания ресурса под новые комбинации обычно происходит с разными скоростями, что отражается на возможностях роста экономики и оказывает мало изученное влияние на темп инвестиций (который, вне всяких сомнений, влияет на общий темп экономического роста). Соотношение скоростей задает соответствующий режим развития экономики: $V_{\alpha}>V_{\mu}$ - режим «созидательного разрушения» в развитии экономической системы, так как отвлечение ресурса от старых комбинаций происходит быстрее; $V_{\alpha}<V_{\mu}$ - режим «комбинаторного наращения». Создание нового ресурса происходит быстрее, чем отвлечение ресурса от действующих комбинаций. При этом в первом случае должно быть $\alpha>\mu$, т. е. доля отвлечения ресурса от старых комбинаций под новые должна быть больше, а во втором случае $\alpha<\mu$, когда создание нового ресурса (комбинации) явно доминирует по доле и скорости отвлечения.

Возможны ситуации, когда оба параметра изменяются в одном направлении - увеличиваются или уменьшаются. В какие-то периоды один из параметров может оставаться неизменяемым, в то время как другой изменяется. На величину отвлечения ресурса от старых комбинаций в пользу новых, как и на возможность создания нового ресурса под новую технологию (комбинацию), влияют следующие условия: состояние старых производств (технологий); износ фондов; новые технологии; правила перелива ресурса или замещения; сопряжение и дополнение технологий; уровень монополизма рынков; формы организации бизнеса; контракты; рынок труда'; режим технологического развития экономической системы и др. [9. С. 339-341].

Таким образом, фактически имеются два режима развития экономической системы - «созидательного разрушения» и «комбинаторного наращения», каждый из которых имеет (как минимум) два варианта (табл. 1).

Таблица 1

Режимы развития экономической системы

\begin{tabular}{|l|c|c|l|}
\hline Режим развития & $\begin{array}{c}\text { Базисный } \\
\text { тип }\end{array}$ & $\begin{array}{c}\text { Подтипы для каждого } \\
\text { базисного типа развития }\end{array}$ & \multicolumn{1}{|c|}{ Характеристика } \\
\hline $\begin{array}{l}\text { Созидательное } \\
\text { разрушение }\end{array}$ & $\alpha>\mu$ & $V_{\alpha}>V_{\mu}$ & Устойчивый, согласованный \\
\cline { 2 - 3 } & $V_{\alpha}<V_{\mu}$ & $\begin{array}{l}\text { Неустойчивый, несогласованный } \\
\text { (условное «комбинаторное наращение») }\end{array}$ \\
\hline $\begin{array}{l}\text { Комбинаторное } \\
\text { наращение }\end{array}$ & $\alpha<\mu$ & $V_{\mu}>V_{\alpha}$ & Устойчивый, согласованный \\
\cline { 2 - 4 } & $V_{\mu}<V_{\alpha}$ & Неустойчивый, несогласованный \\
\hline
\end{tabular}

Согласованный режим экономического роста означает повышательную динамику экономической системы по продукту за счет отвлечения ресурса от старых комбинаций при превосходстве и скорости отвлечения над скоростью создания нового ресурса, либо превосходство создания нового ресурса и скорости создания над скоростью отвлечения ресурсов Несогласованный режим роста означает, что параметры отвлечения и создания ресурса и скорости соотносятся противоположным образом. Если величина отвлечения ресурса превосходит величину создания, но скорость отвлечения меньше скорости создания, то комбинаторный эффект набирает силу, несмотря на то, что созидательное разрушение сохраняет определяющее влияние. Однако такой

${ }^{1}$ Перечисляем только основные по значимости факторные условия. 
режим можно назвать условно «комбинаторным наращением». Если объем отвлечения ресурса меньше объема создания, но скорость создания меньше скорости отвлечения, то при определяющей роли комбинаторного эффекта режим является неустойчивым и его можно считать условным «созидательным разрушением» (по скорости).

Законы изменения параметров $\alpha, \mu$, как и $V_{\alpha}=d \alpha / d t, V_{\mu}=d \mu / d t$, в общем случае могут оказаться любыми для каждой экономической системы. Но эти параметры следует рассматривать как влияющие факторы на общий уровень технологичности экономической системы и посредством такого влияния - на темп экономического роста данной системы. В перспективе данный подход позволит так модифицировать эти институциональные параметры, чтобы можно было управлять ростом, обеспечивая его необходимый и приемлемый темп.

На рисунке показано произвольное соотношение скоростей отвлечения и создания ресурса, в общем смысле отвечающее табл. 1.

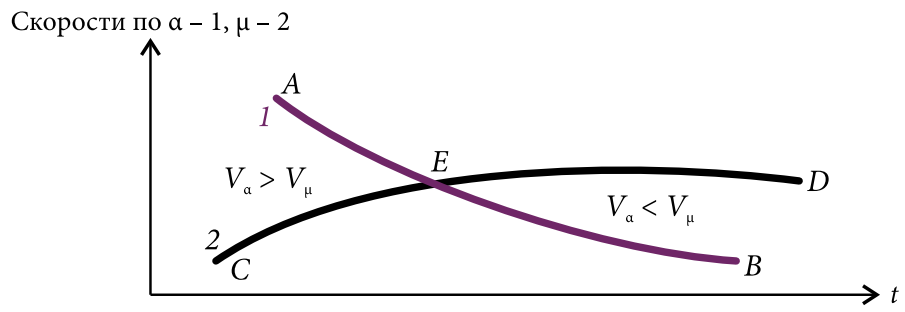

Режимы «созидательного разрушения» и «комбинаторного наращения»

Зона $A E C$ при $\alpha>\mu$ является зоной «созидательного разрушения», зона $D E B$ условным «комбинаторным наращением». При $\alpha<\mu$, наоборот, зона AEC - условное «созидательное разрушение», DEB - «комбинаторное наращение». Дальнейшее исследование причин изменения параметров $\alpha, \mu$ и скоростей отвлечения и создания ресурсов закладывает основу для формирования конкретных способов институционального воздействия на экономический рост, а следовательно, решения задачи управления ростом. Конечно, при этом необходимо учитывать, как изменяются инвестиции, потребительские расходы, связав эти изменения с указанными параметрами, сведя тем самым картину управления ростом к изменению уровня технологичности экономической системы.

Положим, что валовой продукт создается за счет новых и старых технологий (комбинаций), иными словами - новаторов $Y_{n}$ и консерваторов $Y_{k}$, тогда $Y=Y_{n}+Y_{k}$. Параметры, задающие экономическую структуру: $X=Y_{k}-Y_{n}, K=Y_{n} / Y_{k}$. В начальной точке можно считать, что объем производства, полученный на основе старых комбинаций, превосходит объем производства, полученный в результате новых комбинаций. Если отношение числа новаторов $N$ к консерваторам $K R$ обозначим как $L$, а технологическую структуру обозначим в виде отношения производительности на новых и старых комбинациях - новаторов и консерваторов $Z=P_{n} / P_{k}$, то нетрудно заметить, что произведение структуры занятых $L$ на технологическую структуру $Z$ даст продуктовую структуру $K=L Z$. Параметр технологической структуры фактически является функцией связи производительности новаторов и консерваторов, поскольку производства могут оказаться взаимосвязанными. Даже если это не так, то эффекты технологического замещения все равно сказываются на уровнях производительности по новым и старым технологиям (комбинациям).

Изменение числа новаторов, обеспечивающих положительный темп экономического роста системы (по сути, изменение новых комбинаций, которое обеспечивает темп роста выше нуля), можно получить исходя из следующих соображений. 
Примем: $X=n-k$, доли новаторов $(n=N / S)$ и консерваторов $(k=K R / S)$, величина рабочей силы $S=N+K R+U(U-$ число безработных). Запишем выражение

$$
\frac{d u}{d t}=-\mu\left(\frac{d Y}{d t}-h_{0}\right)
$$

где $u=U / S$ (тогда $n+k+u=1$ ).

Оно представляет собой аналог закона А. Оукена, обеспечивающего связь между изменением валового продукта и изменением безработицы $\left(\mu, h_{0}\right.$ - параметры этого закона, определяются для данной экономической системы эмпирически с помощью метода наименьших квадратов) $[6 ; 9 ; 13]$.

Отрицательные для российской экономики 2008-2014 гг. параметры отвлечения и создания ресурсов под новые технологии говорят о процессе дезинвестирования создания новых технологий. Такой эффект возможен, если ресурсы, которые изначально выделяются на какую-то программу, недостаточны для развития этого направления. Новые технологии возникают, но одновременно сокращаются уже используемые технологии.

Технологический уровень ${ }^{1}$, оцениваемый по изменению (величине) добавленной стоимости на единицу используемого ресурса, и по экономике России в целом, и по обрабатывающим секторам понизился. Доля расходов на старые технологии в ВВП России составила от 13,5 до 15,5\%, на новые - от 1,06 до 1,14\% ВВП [9]. При этом увеличение данных расходов в первом случае улучшало технологический уровень, во втором - понижало. Конечно, присутствует и обратная связь: чем ниже технологический уровень экономики и обрабатывающих производств, тем более высокий объем расходов (инвестиций) понадобится на новые технологии. Возможно, величина этих расходов будет автоматически изменять наклон данной кривой связи технологического уровня и инвестиций/расходов на новые технологии. Чтобы всеобъемлюще учесть влияние структурных изменений на функционирование экономики, необходимо:

- оценить сложившуюся экономическую структуру, выделив, например, влияние секторов услуг (финансов), обработки, сырьевого комплекса на общую экономическую динамику;

- определить оптимальные варианты движения системы в плане изменения данной структуры, т. е. выделить наиболее перспективные виды деятельности, которые воспроизводятся уже в системе и которые необходимо создать;

- оценить уровень индустриализации/деиндустриализации обрабатывающих секторов, их технологичности, технического оснащения, состояния фондов и кадров (уровень деквалификации);

- использовать критерии индустриализации с учетом технологической структуры в каждом секторе в аспекте анализа «старые - новые технологии»;

- выделить сырьевой и несырьевой режимы развития, провести эмпирический анализ наблюдаемых изменений режимов, учесть в дальнейшем их инерцию;

- определить величину инвестиций в старые и новые технологии, исходя из имеющегося потенциала инвестирования данных объектов, осуществить поиск инвестиционного ресурса, если текущие возможности недостаточны и сильно отличаются от потребных величин, т. е. развернуть исследование по линии «потребности - возможности - результаты»;

- подбрать и обосновать инструменты экономической/промышленной политики, изучив вопрос их факторного влияния на параметры текущей структуры и показатели

${ }^{1}$ Понятия «технологичность экономики» и «технологический уровень» используются как эквивалентные термины, однако второй термин применяется с точки зрения измерения, а не общей характеристики, как первый. 
функционирования рассматриваемой системы, выделив наиболее релевантные по воздействию инструменты;

- определить этапы и спланировать ввод мер экономической политики, предусмотрев способы мониторинга изменений при введении выбранных инструментов воздействия.

Предложенный общий алгоритм формирования политики роста превосходит тот методологический подход, согласно которому нужно всего лишь определить причины торможения роста и затем подобрать средства (инструменты макроэкономической политики) для полного либо частичного устранения этих причин. Такая логика в самом лучшем случае возвратит рост на прежних факторах (если только причина не в самих факторах, которые изменились $\left.{ }^{1}\right)[5 ; 11]$.

Таким образом, проблема в подлинно методологическом смысле (организации политики роста) сводится к определению силы воздействия тех или иных причин и изменчивости самих причин и к получению способа их установления. Самый простой способ изучения проблем экономического роста - исследование компонент, слагающих валовой продукт. Наибольшая по доле компонента будет первой при рассмотрении, так как даже небольшие ее изменения способны сильно повлиять на динамику продукта. Меньшие компоненты по доле в ВВП будут меньше влиять на его динамику, но общий итог влияния зависит от темпа изменения этих компонент. Если сама компонента небольшая, но быстро увеличивается, то она на данном интервале будет вносить весомый вклад в рост продукта/дохода системы. Быстрый рост приводит к насыщению компоненты, затем ее влияние на итоговый параметр (доход, продукт) ослабевает, и темп экономического роста изменяется. Если инвестиции занимают в ВВП меньшую долю, нежели совокупное потребление, то для того, чтобы их влияние было значительным, требуется довольно высокий темп их наращения. Для потребления, чтобы влияние и вклад его в рост был соразмерен инвестициям, достаточен менее высокий темп прироста. Безусловно, требуется учитывать эффект кривой В. Базарова, обозначающий, что с вовлечением факторов в обеспечение темпа роста по мере их исчерпания (или при длительном времени действия), а также при трудностях замены или ввода новых факторов темп роста может затухать.

\section{Технологический выбор фирмы: теоретическое решение в рамках шкалы «реальные - виртуальные технологии»}

Технологии, которые применяет или намерена применить фирма, исполняют роль инструмента, позволяющего достигать некоторой величины прибыли для данной фазы эволюции фирмы. На фирме функционируют как технологии производства, т. е. преобразования материального ресурса в продукт, так и технологии принятия решений, организации, обработки (генерации $\left.{ }^{2}\right)$ и использования информации. Назовем первые технологии «реальными», касающимися материального ресурса, вторые - «виртуальными» ${ }^{3}$.

Опишем ситуацию в рамках модели конкуренции двух фирм, стремящихся к прибыли как к соблюдению условия (правила) своей конкурентоспособности. Величину прибыли для каждой фирмы представим в виде разницы между совокупным доходом фирмы $(R=p Q)$, равным произведению цены продаваемого блага на объем блага, величиной материальных затрат (производственные технологии) и трансакционных

\footnotetext{
${ }^{1}$ Тогда задача сведется к тому, чтобы узнать причины изменения факторов.

${ }^{2}$ О рынке, продуктах, самих технологиях и конкурентах.

${ }^{3}$ Широкая классификация технологий, включая и эту дихотомию, приведена в работе [9]. Привязывать технологии к издержкам - трансформационные и трансакционные - считаю некорректным выделением, так как все технологии представляют собой способ изменения, а значит, трансформации, неважно, какого объекта и предмета.
} 
издержек (виртуальные технологии). Потенциал рынка оценим как величину $Q^{*}$, объем производства первой фирмы как $Q$, второй - как $q\left(Q^{*}=Q+q\right)$. Считаем потенциал рынка неизменным, а вот объемы производства каждой фирмы изменяемыми величинами. Цена на благо на рынке одинакова для двух фирм - $p$. Будем предполагать, что материальные затраты символизируют масштаб применения реальных технологий, трансакционные - виртуальных технологий. Обозначим соответственно $M(Q)$ и $\operatorname{Tr}(N$, Q) - материальные и трансакционные затраты первой фирмы, где $N$ - число занятых в ней людей, $m(q), \operatorname{tr}(n, q)$ - материальные и трансакционные затраты второй фирмы, где $n$ - число занятых людей на второй фирме. Все величины, кроме $Q^{*}$ - масштаба рынка, являются функцией времени. Изменение структуры рынка, долей фирм происходит за счет изменения технологий, так что общий потенциал рынка $Q^{*}$ остается неизменным для данного блага. Тогда запишем прибыль первой и второй фирмы $r_{1}$ и $r_{2}$ :

$$
r_{1}=p Q-M(N, Q)-\operatorname{Tr}(N, Q) ; r_{2}=p q-m(n, q)-\operatorname{tr}(n, q) .
$$

Материальные затраты зависят от объема производства и от числа занятых на фирме агентов. Можно записать, что $M(Q(N))$, сведя материальные затраты к объему производства, который зависит от числа занятых на фирме людей.

Важно отметить, что трансакционные издержки зависят от числа работающих на фирме людей и от объема производства, так как больший объем требует большего складского хозяйства, перевозки, больших усилий по сбору информации о рынке, логистике, судам и т. д.

Введем связь между материальными и трансакционными издержками: $M=a \operatorname{Tr}-$ для первой фирмы и $m=b t r$ - для второй фирмы (это модельное предположение, принятое для простоты анализа). Будем считать параметры $a, b$ структурными, воплощающими соотношение между реальными и виртуальными технологиями для каждой фирмы. Параметр структуры рынка обозначим как $s=q / Q$, параметры эффективности фирм как $z_{1}=(\operatorname{Tr}+M) / Q, z_{2}=(t r+m) / q$ соответственно.

Полагая, например, что для первой фирмы $a=$ const, т. е. структура технологий, не изменяется по оценке затрат, несложно получить $r_{1}=R-a \operatorname{Tr}-\operatorname{Tr}=R-(1+a) T r$. Далее будем исследовать функцию прибыли на экстремум. Возьмем производную по времени и получим

$$
\frac{d r_{1}}{d t}=\frac{d R}{d t}-\frac{d T r}{d t}(1+a)=0 ; \frac{d R}{d T r}=1+a
$$

Иными словами, в точках экстремума прибыли (максимума и минимума) изменение дохода по трансакционным издержкам равно $(1+a)$.

Если технологическая структура изменяется, то выражение принимает более громоздкий вид:

$$
\frac{d r_{1}}{d t}=\frac{d R}{d t}-\frac{d \operatorname{Tr}}{d t}(1+a)-\operatorname{Tr} \frac{d a}{d t}>0 ; d R>d \operatorname{Tr}(1+a)+\operatorname{Tr} d a
$$

Это условие роста прибыли первой фирмы, для соблюдения которого совокупному доходу, зависящему от ситуации на рынке, необходимо изменяться так, чтобы это изменение превосходило сумму взвешенного (на структуру затрат) изменения трансакционных издержек и взвешенного (на величину трансакционных издержек) изменения структуры затрат (технологий).

Исследование функции прибыли на экстремум требует приравнивания выражения к нулю. Тогда

$$
\frac{d r_{1}}{d t}=\frac{d R}{d t}-\frac{d \operatorname{Tr}}{d t}(1+a)-\operatorname{Tr} \frac{d a}{d t}=0 ; d R=d \operatorname{Tr}(1+a)+\operatorname{Tr} d a
$$


Если пренебречь связью материальных и трансакционных издержек $(M \neq a \mathrm{Tr}$, объем производства не связан с трансакционными издержками $\left.{ }^{1}\right)$, но считать, что рыночная цена как-то связана с трансакционными издержками (что переговоры между фирмами ведутся: $p=f(T r)$ ), то, если взять производную прибыли по трансакционным издержкам, получим $d R / d T r-1=0$, откуда $d p / d T r=1 / Q$. Окончательно получаем

$$
\int d \operatorname{Tr}=\int Q(p) d p ; \operatorname{Tr}=\int Q(p) d p+C,
$$

где $C$ - константа интегрирования.

Если связь между материальными и трансакционными издержками имеется, то объем производства $Q$ при дифференцировании по $\operatorname{Tr}$ не будет равен нулю $(d Q / d \operatorname{Tr} \neq 0)$ и выражение для трансакционных издержек, при котором прибыль принимает оптимальное значение (максиму или минимум), представим как

$$
\operatorname{Tr}=\frac{1}{1+a}\left[\int Q(p) d p+\int p(Q) d Q\right]+C_{1},
$$

где $C_{1}$ - константа интегрирования.

Таким образом определяется оптимальный масштаб виртуальных технологий (при данной величине "реальных» технологий, задающих величину материальных затрат M) по величине трансакционных издержек (главный параметр оценки их масштаба), чтобы прибыль фирмы принимала экстремальное значение (минимальное или максимальное). Для обозначения максимума прибыли, нужно ввести ряд неравенств на производную прибыли по времени или трансакционным издержкам, описывающих точку максимума прибыли. Иными словами, уровень виртуальных технологий, применяемых фирмой, должен давать трансакционные издержки, обозначенные в выражении $\left(^{*}\right)$, причем на их величину влияет объем производства и уровень цен на рынке. Большему производству не всегда, но часто необходима более детальная качественная, обработанная (аналитическая) информация. Поэтому затраты на ее поиск и обработку обычно выше. Тем самым рынок может задавать возможность применения современных или устаревших технологий, если следовать такому правилу. Когда фирме важнее применение новой технологии, поскольку она составляет ее перспективу, но это не может обеспечить трансакционные издержки на уровне наибольшей прибыли (здесь важен знак изменения функции прибыли), фирма принимает решение, которое, если рассматривать его вне стратегической перспективы, будет казаться ограниченно рациональным, хотя это и есть самое рациональное решение, так как новая технология даст возможность в будущем получать более высокую прибыль. Подобные ожидания имеют свойство и не сбываться, т. е. новая технология, конкурируя на следующих этапах жизни с иными технологиями, может не дать предполагаемого результата и принятое рациональное решение, ориентированное на будущее, окажется ошибочным².

Объем производства фирмы зависит от персонала $N, n$, в связи с чем можно записать прибыль для одной и второй фирмы:

$$
r_{1}=p Q(N)-M(N, Q)-\operatorname{Tr}(N, Q) ; r_{2}=p q(n)-m(n, q)-\operatorname{tr}(n, q) .
$$

Тогда

$$
\frac{d r_{1}}{d N}=p \frac{d Q}{d N}-\frac{d M}{d N}-\frac{d T r}{d N}=0 ; \frac{d r_{2}}{d n}=p \frac{d q}{d n}-\frac{d m}{d n}-\frac{d t r}{d n}=0
$$

${ }^{1}$ В реальной ситуации, отличающейся от модели, это далеко не так. Рост трансакционных издержек может существенно повлиять на сокращение объема производства.

${ }^{2}$ От этого оно не станет менее рациональным. С еще большей величиной ошибки могут приниматься нерациональные (иррациональные) или недостаточно рациональные решения. 
Отсюда получаем

$$
\operatorname{Tr}=\int p(Q) d Q-M+C_{2} ; \operatorname{tr}=\int p(q) d q-m+C_{3},
$$

где $C_{2}, C_{3}$ - константы интегрирования.

Аналогичный результат получается, если искать $d r_{1} / d Q=0$ и $d r_{2} / d q=0$, т. е. взять производную прибыли фирмы по производству приравнять к нулю в поиске оптимума (максимума или минимума). Это величина трансакционных издержек для точки оптимума прибыли фирм. Предположив, что технологическая структура фирм не зависит от числа занятых работников $a \neq \varphi(N), b \neq \varepsilon(n)$, можно записать:

$$
\begin{gathered}
\frac{d r_{1}}{d N}=p \frac{d Q}{d N}-\frac{d T r}{d N}(a+1)-\frac{d a}{d N} \operatorname{Tr}=0 ; \frac{d r_{2}}{d n}=p \frac{d q}{d n}-\frac{d t r}{d n}(b+1)-\frac{d b}{d n} t r=0 ; \\
\frac{d a}{d N}=0 ; \frac{d b}{d n}=0 .
\end{gathered}
$$

Отсюда получаем

$$
\operatorname{Tr}=\frac{1}{1+a} \int p(Q) d Q+A ; \operatorname{tr}=\frac{1}{1+b} \int p(q) d q+B,
$$

где $A, B$ - константы интегрирования.

Аналогичные соотношения получатся, если анализировать изменение прибыли по объему производства $d r_{1} / d Q=0, d r_{2} / d q=0$ или по трансакционным издержкам, при условии, что объемы производства $Q \neq f(T r), q \neq x(t r)$ не зависят от трансакционных издержек (хотя в действительности, как показано выше, это не так).

Вводя условие, при котором прибыль фирм должна расти $\left(d r_{1} / d Q>0, d r_{2} / d q>0\right.$ либо $d r_{1} / d N>0, d r_{2} / d n>0$ или $\left.d r_{1} / d T r>0, d r_{2} / d t r>0\right)$, получим, что трансакционные издержки должны быть меньше выражения справа в неравенстве для каждой фирмы:

$$
\operatorname{Tr}<\frac{1}{1+a} \int p(Q) d Q+A ; t r<\frac{1}{1+b} \int p(q) d q+B .
$$

И для общего случая

$$
\operatorname{Tr}<\int p(Q) d Q-M+C_{2} ; \operatorname{tr}<\int p(q) d q-m+C_{3} .
$$

Это является ограничением затрат на применение виртуальных технологий, чтобы прибыль фирм росла. Запишем выражение для прибыли фирм, учтя эффективность $z_{1}=(\operatorname{Tr}+M) / Q, z_{2}=(t r+m) / q:$

$$
r_{1}=p Q-z_{1} Q ; r_{2}=p q-z_{2} q
$$

Найдя производные $d r_{1} / d Q$ и $d r_{2} / d q$, приравняв их к нулю, рассчитаем величину эффективности фирм в точке оптимальной прибыли (максимум и минимум прибыли):

$$
z_{1}=p+\frac{\exp \left(c_{1}\right)}{Q} ; z_{2}=p+\frac{\exp \left(c_{2}\right)}{q},
$$

где $c_{1}$ и $c_{2}$ - константы интегрирования.

Чтобы прибыль росла в зависимости от изменяемого объема производства, требуется $d r_{1} / d Q>0, d r_{2} / d q>0$, из чего несложно определить, в каком диапазоне должна быть записанная в общем виде эффективность $z$ :

$$
p<z>p+\exp (c) / Q
$$

где $c$ - константа интегрирования. 
Если рыночная цена не зависит от объема производства $Q$, то эффективность фирмы $z=(\operatorname{Tr}+M) / Q$ будет равна в точке оптимальной прибыли $d r_{1} / d Q=0$ следующей величине (исходя из условий задачи):

$$
z=p-\exp (c) / Q \text {. }
$$

Рассмотрим две фирмы, каждая из которых характеризуется своей технологической структурой и эффективностью функционирования. Воспользуемся введенными обозначениями:

$\mathrm{Q}^{*}=\mathrm{Q}+q$;

$a=M / T r, b=m / t r-$ технологическая структура каждой фирмы;

$s=q / Q-$ структура рынка;

$z_{1}=(\operatorname{Tr}+M) / Q, z_{2}=(t r+m) / q-$ эффективность фирм: чем ниже общий объем затрат для одного и того же выпуска, тем эффективнее работает фирма. Откуда следует, что $z_{1}=(1+a) \operatorname{Tr} / Q, z_{2}=(1+b) \operatorname{tr} / q$, причем $t_{1}=\operatorname{Tr} / Q, t_{2}=\operatorname{tr} / q-$ величина трансакционности каждой фирмы или трансакционного сектора $t=t_{1}+t_{2}$. Для объемов производства будет справедливо $Q=Q^{*} /(1+s), q=s Q^{*} /(1+s)$.

Используя указанные соотношения, несложно получить выражения для эффективности фирм:

$$
z_{1}=(1+a)(1+s) \frac{T r}{Q^{\star}} ; z_{2}=(1+b) \operatorname{tr} \frac{1+s}{s Q^{*}} .
$$

Условие, когда эффективность первой фирмы выше, чем второй, отвечает неравенству $z_{1}<z_{2}$. Получим, каким должно быть соотношение трансакционных издержек, символизирующих применение виртуальных технологий на двух фирмах:

$$
\frac{\operatorname{Tr}}{\operatorname{tr}}<\frac{1}{s} \frac{1+b}{1+a} .
$$

Очевидно, что чем выше доля второй фирмы на рынке при неизменном ее потенциале, тем меньшими должны быть трансакционные издержки первой фирмы для сохранения превосходства по своей эффективности над второй фирмой, либо должны резко повыситься трансакционные издержки второй фирмы.

Технологические структуры фирм определяют также возможности относительного применения виртуальных технологий. Повышение значения реальных технологий на первой фирме (a) потребует снижения ее трансакционных издержек либо роста трансакционных издержек второй фирмы, чтобы соотношение по эффективности сохранялось в пользу первой фирмы. Это означает или применение более эффективных виртуальных технологий на первой фирме, или расширение виртуальных технологий более низкого уровня (затратного) на второй фирме. Увеличение параметра может означать для первой фирмы снижение эффективности реальных технологий, но компенсация может возникнуть, если у второй фирмы снизится эффективность виртуальных технологий (повысятся трансакционные издержки $t r$ ), или снизится эффективность реальных технологий второй фирмы (повысится $b$ ). Однако параметры $a$ и $b$ могут повыситься в связи с применением новой технологии, которой нужен более дорогой материальный ресурс, ибо новая технология дает экономию (эффект масштаба) только на стадии ее тиражирования или близкой к ней, когда производство окупает осуществленные вложения.

Запишем прибыль двух фирм:

$$
r_{1}=p Q-M-\operatorname{Tr} ; r_{2}=p q-m-\operatorname{tr} ; \operatorname{Tr}=z_{1} Q /(1+a) ; \operatorname{tr}=z_{2} q /(1+b) .
$$

Получаем

$$
r_{1}=Q\left(p-z_{1}\right) ; r_{2}=Q\left(p-z_{2}\right) ; \frac{r_{2}}{r_{1}}=s \frac{p-z_{2}}{p-z_{1}}
$$


Далее возьмем $d r_{1} / d t=0, d r_{2} / d t=0$, определяя оптимальную прибыль для каждой фирмы.

Отсюда

$$
Q\left(p-z_{1}\right)=\exp \left(c_{1}\right) ; s Q\left(p-z_{2}\right)=\exp \left(c_{2}\right) .
$$

Получаем структуру рынка, при которой в зависимости от складывающейся цены и эффективности двух данных фирм прибыль может быть наибольшей, при условии: если функция прибыли $d r_{1} / d t>0$ и $d r_{2} / d t>0$, то точки $t=t_{\max }$. После этой точки производная функции прибыли меньше нуля для каждой фирмы. Итак,

$$
s=\frac{p-z_{1}}{p-z_{2}} \exp \left(c_{2}-c_{1}\right) .
$$

При той же рыночной цене (стабильный рынок) повышение эффективности первой фирмы изменит структуру рынка не в пользу второй фирмы ( $s$ понизится), при повышении эффективности второй фирмы - в ее пользу ( $s$ повысится). Увеличение (уменьшение) цены на рынке при той же эффективности фирм существенно не скажется на структуре данного рынка (по условиям задачи отсутствуют агенты, которые могут выйти на этот же рынок, третья фирма не рассматривается).

Сохранение превосходства по эффективности для первой фирмы $\left(z_{1}<z_{2}\right)$ потребует, чтобы структура рынка была $s>\exp \left(c_{2}-c_{1}\right)$ при $z_{2}<p$, и, что равнозначно (второй случай $), s<\exp \left(c_{2}-c_{1}\right)$ при $z_{2}>p$.

Выражение для цены при оптимальной прибыли обеих фирм будет следующим ${ }^{1}$ :

$$
p^{\star}=\frac{s^{\star} z_{2}{ }^{\star}-z_{1}{ }^{\star} \exp \left(c_{2}-c_{1}\right)}{s^{\star}-\exp \left(c_{2}-c_{1}\right)} .
$$

Через подобные параметры можно определить связь эффективности первой и второй фирмы.

Будем считать, что материальные затраты и трансакционные издержки первой фирмы не зависят от объема производства $q$ второй фирмы. Тогда запишем функцию прибыли первой фирмы и возьмем производную ее функции прибыли по объему производства второй фирмы, выразив объем производства первой фирмы как разницу общего потенциала рынка $Q^{*}$, который изменяется, и производства второй фирмы $q$ :

$$
r_{1}=p\left(Q^{*}-q\right)\left[Q^{*}-q\right]-M-T r .
$$

Тогда получим

$$
\frac{d r_{1}}{d q}=\frac{d p}{d q}\left[Q^{\star}-q\right]+p\left[\frac{d Q^{*}}{d q}-1\right]=0 .
$$

Преобразовывая и интегрируя, приходим к

$$
p\left(Q^{*}-q\right)=\exp (B) .
$$

Получаем объем производства первой и второй фирмы, когда производная прибыли первой фирмы по объему производства второй равна нулю:

$$
Q=\frac{1}{p} \exp (B) ; q=Q^{*}-\frac{\exp (B)}{p} .
$$

${ }^{1}$ Звездочкой отмечено значение соответствующих параметров для точки оптимальной прибыли фирм. 
Для цены $p_{0}$ можно получить $Q_{0}$ и $q_{0}$. Как видим, система взаимосвязей довольно сложна. Даже при рассмотрении двух конкурирующих фирм изменение технологической структуры фирм и рынка влияет на результат их функционирования. Здесь не рассматривался эффект власти, обучения одной и второй фирмы, копирования технологии другой фирмы и т. д. Эти институциональные особенности совокупно влияют на технологические возможности фирм, потенциал их обновления и конкуренцию, макроэкономическую структуру технологий и динамику.

\section{Эмпирическая оценка структуры технологий (макроуровень)}

Проведем анализ изменений в структуре технологий, выделяя «старые» и «новые» ${ }^{1}$ компоненты производства соответственно $[10 ; 12]$. Это позволит подчеркнуть структурный аспект инвестиционной стратегии развития российской экономики для формирования новой модели экономического роста. Выводы и содержание данного параграфа автор базирует на предыдущей работе, выполненной под руководством академика РАН А. И. Татаркина [10].

Согласно данным официальной статистики, в 2009-2014 гг. общая величина инвестиций в секторы промышленности России возрастала, инвестиции в технологические инновации росли в абсолютном выражении, повышалась также их доля в структуре инвестиций. За 2009-2014 гг. объем инвестиций в «новые» технологии увеличился в 2,9 раза, в «старые» - в 1,8 раза без учета инфляции, что объясняется политикой поощрения инновационной деятельности предприятий ${ }^{2}$.

Число занятых в «новых производствах» за данный период несколько сократился (табл. 2-3), в «старых производствах» - более существенно. Следовательно, в обрабатывающих секторах (промышленности) наблюдается явный отток кадров, что создает существенное ограничение в смысле организации роста экономики этих секторов.

Таблица 2

Численность занятых в «новых производствах», чел. [10; 12]

\begin{tabular}{|l|c|c|c|c|c|c|c|c|}
\hline \multicolumn{1}{|l}{ Показатель } & 2005 & 2010 & 2011 & 2012 & 2013 & 2014 & 2015 & 2016 \\
\hline $\begin{array}{l}\text { Экономика } \\
\text { России }\end{array}$ & 813207 & 736540 & 735273 & 726318 & 727029 & 732274 & 738857 & 722291 \\
\hline
\end{tabular}

Составлено по: Регионы России. Социально-экономические показатели. 2015: стат. сб. / Росстат. М., 2015. С. 189-195; Регионы России. Социально-экономические показатели. 2017: стат. сб. / Росстат. М., 2017.

Таблица 3

Численность занятых в «старых производствах», чел. [10; 12]

\begin{tabular}{|l|c|c|c|c|c|c|c|c|}
\hline Показатель & 2005 & 2010 & 2011 & 2012 & 2013 & 2014 & 2015 & 2016 \\
\hline $\begin{array}{l}\text { Экономика } \\
\text { России }\end{array}$ & 13861993 & 12518660 & 12547727 & 12470482 & 12348371 & 12116526 & 12641143 & 12634709 \\
\hline
\end{tabular}

Составлено по: Труд и занятость в России. 2017: стат. сб. / Росстат. М., 2017. С. 107-109.

Утверждается, что низкая производительность является ценой низкой безработицы и если ликвидировать эту якобы «избыточную занятость», несоразмерную фондам,

${ }^{1}$ Тем самым под «новыми» технологиями понимаются технологические инновации, под «старыми» - имеющиеся традиционные (созданные, но уже используемые) технологии. Когда употребляется термин «новое производство», то имеется в виду производство по новым технологиям, т. е. при осуществлении технологических инноваций.

${ }^{2}$ Официальный сайт Федеральной службы государственной статистики. URL: http://www. gks.ru/wps/wcm/connect/rosstat_main/rosstat/ru/statistics/science_and_innovations/science/\#. 
то параметры развития обрабатывающих секторов улучшатся. Подобное объяснение не выдерживает критики, если принять во внимание эволюцию обрабатывающих секторов и состояние технологического базиса, которое может еще более ухудшиться при сокращении занятости, вызывая на последующих этапах развития сокращение трудового потенциала. Эволюционный аспект необратимых изменений требуется учитывать в структурном анализе экономических систем $[6 ; 14 ; 15 ; 16]$.

Кроме того, необходимо учитывать, не перемещаются ли занятые в производстве на старых технологиях агенты в те производства, которые переходят на новые технологии, что может обусловить представленное изменение в числе занятых в соответствующих производствах. Важно также исследование потерь квалифицированной рабочей силы в условиях технологического замещения и при отсутствии таковых. Для российской экономики технологическое замещение не обнаруживает себя как устойчивое явление, поскольку происходит снижение общего технологического уровня экономики, что подтверждается количественными оценками. Если бы наблюдалось технологическое замещение, такого эффекта (снижения общего уровня) не существовало бы. Он наблюдается в силу того, что происходит большая потеря старых технологий и какое-то наращение новых технологий в результате концентрации небольших ресурсов на приоритетных направлениях развития в рамках реализуемых государственных программ (табл. 4).

Таблица 4

Динамика технологий по секторам промышленности, ед. [10; 12]

\begin{tabular}{|c|c|c|c|c|c|c|c|c|c|c|c|c|c|}
\hline \multicolumn{9}{|c|}{ «Новые» технологии } & \multicolumn{7}{c|}{ «Старые» технологии } \\
\hline 2010 & 2011 & 2012 & 2013 & 2014 & 2015 & 2016 & 2010 & 2011 & 2012 & 2013 & 2014 & 2015 & 2016 \\
\hline 221 & 320 & 340 & 420 & 439 & 446 & 585 & 144565 & 128970 & 132777 & 137565 & 143824 & 160403 & 184658 \\
\hline
\end{tabular}

Рассчитано на основе данных официального сайта Федеральной службы статистики. URL: http://www.gks.ru/wps/wcm/connect/rosstat_main/rosstat/ru/statistics/economydevelopment/\#.

Как видно из табл. 4 , число новых технологий возросло в два раза за пять лет ${ }^{1}$, но при этом число старых технологий сначала сократилось на 10-12 тыс. ед. за три года, затем за два года резко увеличилось (см. табл. 4). Стоит отметить, что рост числа новых и старых технологий приходится на кризисный 2015 и 2016 гг. Это говорит не только о специфике учета нововведений, но и о том, что кризис не был связан с фундаментальной основой развития обрабатывающих секторов. Причины были внешние, величина внутренних затрат на внутренние исследования и разработки оставалась на уровне $1,1 \%$ ВВП, в 2011-2014 гг. она была несколько ниже. Следовательно, важен не просто рост технологий, а расширение использования некоторых типов технологий в конкретных секторах, причем отечественных. Число работников снизилось и на старых, и на новых производствах (см. табл. 2-3). Если производительность не повышалась, то это был отрицательный результат внедрения новых и расширения старых технологий.

В период положительного темпа роста создание нового ресурса при той же величине отвлечения ресурса от старых технологий будет повышать темп роста, а его снижение будет происходить медленнее. В период отрицательного темпа роста (спада) при попытке создавать новые виды ресурса спад будет (ожидается) сильнее. Следовательно, необходимо сосредоточиться на существующих технологических возможностях и использовать ресурсы по уже освоенным направлениям, что подтверждается статистикой последних лет по России $[9 ; 10 ; 12]$.

${ }^{1}$ Разумеется, важно учитывать новые технологии в оборонном комплексе и гражданских производствах. Можно предположить (в силу объективного отсутствия точной информации по оборонно-промышленному комплексу), что число новых технологий в гражданских производствах сильно уступает их числу в оборонном комплексе страны. 
Теория $q$-Тобина, описывающая влияние денежно-кредитной политики на объем выпуска через курсы ценных бумаг (акций), связана с развиваемым здесь представлением о скорости отвлечения ресурса от старых технологий и скорости создания нового ресурса, которые ассоциируются с параметрами $\alpha, \mu$. Возникает своеобразное q-правило (институт), с помощью которого можно описать смену режимов развития (переключение) с одной модели на другую. Как известно, величина $q$, по Тобину, представляет собой отношение рыночной стоимости фирм к восстановительной стоимости их капитала. Когда рыночная стоимость превосходит стоимость капитала, то новая комбинация средств производства будет относительно дешевой (если сравнить со стоимостью фирм), акций будет выпущено немного, инвестиции возрастут, будут создаваться новые мощности, комбинации (технологии). Это отвечает доминированию новой технологии. Если $q$ низок, т. е. рыночная стоимость фирм невысока относительно их капитала, новые комбинации будут довольно дорогими, поэтому фирмы будут торговать старым капиталом. Это отвечает доминированию старых комбинаций и режиму отвлечения ресурса, задаваемого параметром $\alpha$. Инвестиции в новые комбинации сократятся или будут низкими. Рыночная стоимость фирмы оценивается по суммарной стоимости акций (акционерному капиталу). Если котировки снижаются, то и параметр q снижается, порождая режим торговли старым капиталом, что сводится в предложенной модели к отвлечению ресурсов от старых комбинаций в пользу новых комбинаций.

С ростом цен акций будут увеличиваться, по q-правилу, возможности системы в создании новых комбинаций (инвестиций в новые средства производства). Монетарная экспансия может способствовать такому развитию. Если в экономической системе акционерный капитал незначителен, т. е. большое число компаний не выпускают акций, то применение $q$-правила становится затруднительным. В связи с этим может оказаться удобным проводить анализ напрямую через оценку параметров скорости отвлечения и создания нового ресурса. Динамика инвестиций в старые технологии обеспечивает основное воздействие на темп экономического роста, например в России. Инвестиции в новые технологии незначительны по величине и не оказывают сильного влияния на уровень технологичности $[8 ; 9 ; 10]$.

Снижение трудоемкости возможно только при повышении технологичности - это будет следствием данного процесса, а рост выработки возможен при сокращении персонала при том же объеме производства. Наращение объема выпуска при тех же технологиях и фондах, когда отсутствует должный спрос, окажется на складе. Существует и обратная связь, когда рост заработной платы должен стимулировать рост производительности труда, как и рост инвестиций из прибыли владельцев капитала должен повышать производительность в результате технологического обновления. Часто темп роста производительности отстает (причем на длинном временно́м интервале) от темпа технических изменений (парадокс Р. Солоу [16 ${ }^{1}$ ), но детерминируется именно этими изменениями, когда возможности повышения производительности за счет фактора «труд» исчерпаны.

\section{Заключение}

«Технологический рост» экономики зависит не столько от роста необходимых инвестиций в технологии, сколько от эффективного их распределения между старыми и новыми технологическими возможностями, а также от состояния сферы науки, обеспечивающей производство фундаментальных результатов, из которых затем тиражируются различные технологии.

${ }^{1}$ В России работы в данном направлении обобщил член-корреспондент РАН В. Е. Дементьев [3. C. 26-27]. 
Технологические цепочки в России необходимо восстанавливать, причем технологическая структура и распределение инвестиций между старыми и новыми технологиями составляют релевантный фактор экономического роста. Управление переливом ресурсов между секторами и технологиями определит не только темп роста экономики, но и будущее качество ее структуры и развитие. Речь необходимо вести не о новом укладе, а о взаимосвязанном и определяющем друг друга наборе технологий, позволяющих увеличить технологичность функционирования экономики и тем самым обеспечить соответствующий уровень ее индустриализации. Цифровые технологии исполняют функцию инфраструктурной связки с другими видами технологий, улучшая их качество и возможности применения, но и сами по себе они обладают большим трансакционным эффектом, аккумулирование которого, может дать существенную экономию самого ценного ресурса - времени. Подобный результат не является предопределенным и зависит от многих причин распространения и применения таких технологий.

\section{Источники}

1. Аганбегян А.Г. Сокращение инвестиций - гибель для экономики, подъем инвестиций - ее спасение // Экономические стратегии. 2016. № 4. С. 74-83.

2. Глазьев С. Ю. О путях обеспечения роста российской экономики // Научные труды Вольного экономического общества России. 2017. Т. 203. С. 229-242.

3. Дементьев В.Е. Возможности приспособления к парадоксу производительности при обновлении технологической базы экономики // Львовские чтения - 2017: сб. ст. V Bсерос. науч. конф. / под науч. ред. Г. Б. Клейнера. М.: Изд. дом ГУУ, 2017. С. 26-29.

4. Ивантер В.В. Структурно-инвестиционная составляющая долгосрочной экономической стратегии России // Общество и экономика. 2017. № 8. С. 5-32.

5. Кругман П. Депрессии - это нечто иное // Экономика для любознательных. О чем размышляют Нобелевские лауреаты. М.: Изд-во Ин-та Гайдара, 2017. С. 24-35.

6. Маевский В.И. Введение в эволюционную макроэкономику. М.: Япония сегодня, 1997.

7. Перес К. Технологические революции и финансовый капитал. М.: Дело, 2011.

8. Сухарев О.С. Эволюционная экономическая теория институтов и технологий. Проблемы моделирования. М.: Ленанд, 2017.

9. Сухарев О.С. Экономический рост, институты и технологии. М.: Финансы и статистика, 2014.

10. Татаркин А.И., Сухарев О.С., Стрижакова Е.Н. Определение вектора промышленной политики на основе неошумпетерианской теории // Вестник Пермского университета. Экономика. 2017. Т. 12, № 1. С. 5-22.

11. Хэлпман Э. Загадка экономического роста. М.: Изд-во Ин-та Гайдара, 2012.

12. Цветков В.А., Сухарев О.С. Экономический рост России: новая модель управления. М.: Ленанд, 2017.

13. Шумпетер Й. Теория экономического развития. Капитализм, социализм и демократия. М.: ЭКСМО, 2007.

14. Nelson R. Economic Development from the Perspective of Evolutionary Economic Theory // Oxford Development Studies. 2008. Vol. 36, issue 1. Pp. 9-21.

15. Silverberg G., Verspagen B. Evolutionary Theorising on Economic Growth // Discussion Paper MERIT, Maastricht. 1995, August. Pp. 1-20.

16. Solow R. M. The Last 50 Years in Growth Theory and the Next 10 // Oxford Review of Economic Policy. 2007. Vol. 23, no. 1. Pp. 3-14. 


\title{
Structural Analysis of Technological Changes and the Strategy of Economic Growth
}

\author{
by Oleg S. Sukharev
}

The paper explores the issue of determining the structural parameters of the economy during the formation of macroeconomic growth policy. It points to two basic economic development regimes, which differ in terms of the relationship between the processes of diverting and creating a resource. The paper proves that ratio between the speeds of these processes, namely "creative destruction" and "combinative expansion", preconditions the characteristics of the economic growth model. The author examines an investment strategy, which constitutes the principal part of the model of economic growth based on new factors, at this, the level of technologies and the possibility to correlate the rates of diverting and creating a new resource significantly determine it. The researcher concludes that the Russian economic development model should allow for the structure "old-new technologies", which will define the regime of economic growth. The author suggests a solution: at the microlevel, a firm chooses a technological structure within the scale "real-virtual technologies", at this the ratio between the efficiencies of competing firms, affecting the choice of the scale of virtual and real technologies' application, crucially influences this procedure.

Keywords: technological changes; structural analysis; investment strategy; economic growth; real and virtual technologies; technological choice of a firm.

\section{References:}

1. Aganbegyan A.G. Sokrashchenie investitsiy - gibel' dlya ekonomiki, podyem investitsiy - ee spasenie [Reduced investment is the death for the economy, increased investment is its salvation]. Ekonomicheskie strategii - Economic Strategy, 2016, no. 4, pp. 74-83.

2. Glazyev S. Yu. O putyakh obespecheniya rosta rossiyskoy ekonomiki [On the ways of maintaining growth of the Russian economy]. Nauchnye trudy Volnogo ekonomicheskogo obshchestva Rossii - Scientific Works of the Free Economic Society of Russia, 2017, vol. 203, pp. 229-242.

3. Dementyev V. Ye. Vozmozhnosti prisposobleniya k paradoksu proizvoditel'nosti pri obnovlenii tekhnologicheskoy bazy ekonomiki [Possibilities of adaptation to the paradox of productivity when updating the technological base of the economy]. Materialy V Vserossiyskoy nauchnoy konferentsii "Lvovskie chteniya - 2017" [Proc. 5 ${ }^{\text {th }}$ All-Russian Sci. Conf. "Lvov Readings 2017]. Moscow: State University of Management, 2017, pp. 26-29.

4. Ivanter V. V. Strukturno-investitsionnaya sostavlyayushchaya dolgosrochnoy ekonomicheskoy strategii Rossii [Structural investment component of Russia's long-term economic strategy]. Obshchestvo i ekonomika - Society and Economics, 2017, no. 8, pp. 5-32.

5. Krugman P. Depressii - eto nechto inoe [Depression is something else]. In: Ekonomika dlya lyuboznatel'nykh. O chem razmyshlyayut Nobelevskie laureaty [Economics for the inquisitive. What the Nobel laureates are thinking about]. Moscow: Gaydar Institute, 2017, pp. 24-35.

6. Maevskiy V.I. Vvedenie v evolyutsionnuyu makroekonomiku [Introduction to evolutionary macroeconomics]. Moscow: Yaponiya segodnya Publ., 1997.

7. Perez C. Tekhnologicheskie revolyutsii i finansovyy kapital [Technological revolutions and financial capital]. Moscow: Delo Publ., 2011.

8. Sukharev O. S. Evolyutsionnaya ekonomicheskaya teoriya institutov i tekhnologiy. Problemy modelirovaniya [Evolutionary economic theory of institutions and technologies. Problems of modelling]. Moscow: Lenand Publ., 2017.

9. Sukharev O.S. Ekonomicheskiy rost, instituty i tekhnologii [Economic growth, institutions and technologies]. Moscow: Finansy i statistika Publ., 2014.

10. Tatarkin A. I., Sukharev O. S., Strizhakova Ye. N. Opredelenie vektora promyshlennoy politiki na osnove neoshumpeterianskoy teorii [Defining the vector of industrial policy based on the neo-Schumpeterian theory]. Vestnik Permskogo universiteta. Ekonomika - Perm University Herald. Economy, 2017, vol. 12, no. 1, pp. 5-22.

11. Helpman E. Zagadka ekonomicheskogo rosta [The mystery of economic growth]. Moscow: Gaydar Institute, 2012.

12. Tsvetkov V.A., Sukharev O.S. Ekonomicheskiy rost Rossii: novaya model' upravleniya [Russia’s economic growth: A new management model]. Moscow: Lenand Publ., 2017. 
13. Schumpeter J. Teoriya ekonomicheskogo razvitiya. Kapitalizm, sotsializm i demokratiya [The theory of economic development. Capitalism, socialism and democracy]. Moscow: EKSMO Publ., 2007.

14. Nelson R. Economic Development from the Perspective of Evolutionary Economic Theory. $O x$ ford Development Studies, 2008, vol. 36, issue 1, pp. 9-21.

15. Silverberg G., Verspagen B. Evolutionary Theorising on Economic Growth. Discussion Paper MERIT, Maastricht, 1995, August, pp. 1-20.

16. Solow R. M. The Last 50 Years in Growth Theory and The Next 10. Oxford Review of Economic Policy, 2007, vol. 23, no. 1, pp. 3-14.

Contact Info:

Oleg S. Sukharev, Dr. Sc. (Econ.), Prof.,

Head of Institutional Economics Laboratory

Phone: (499) 724-27-61

e-mail: o_sukharev@list.ru
Market Economy Institute of RAS

47 Nakhimovsky Ave., Moscow, Russia, 117418

Ссылка для ицитирования: Сухарев О.С. Структурный анализ технологических изменений и стратегия экономического роста // Известия Уральского государственного экономического университета. 2018 . Т. 19, № 3. C. 26-41. DOI: 10.29141/2073-1019-2018-19-3-4

For citation: Sukharev O.S. Strukturnyy analiz tekhnologicheskikh izmeneniy i strategiya ekonomicheskogo rosta [Structural analysis of technological changes and the strategy of economic growth]. Izvestiya Uralskogo gosudarstvennogo ekonomicheskogo universiteta - Journal of the Ural State University of Economics, 2018, vol. 19, no. 3, pp. $26-41$. DOI: 10.29141/2073-1019-2018-19-3-4 


\title{
БОРщ Людмила Михайловна
}

Доктор экономических наук, профессор кафедры

финансов предприятий и страхования

Крымский федеральный университет имени В.И. Вернадского

295015, РФ, г. Симферополь, ул. Севастопольская, 21/4

Контактный телефон: (3652) 27-05-65

e-mail: I-borsh49@mail.ru

\section{Модернизация экономики: технологии vs человек}

\begin{abstract}
Статья посвящена исследованию актуальной научно-практической проблемы экономической теории - выдвигается гипотеза, основанная на зарождении теории смыслов рациональности и иррациональности, не нарушая теорию «золотого отношения». Проведен аналитический обзор теоретических подходов российских и зарубежных экономистов по данной проблеме, который позволил автору выявить теоретико-методологические и прикладные основы для определения направлений в рамках государственной стратегии планирования социально-экономического развития. Оценивается научная дискуссия относительно условий смены модели экономического развития, модернизации экономики с переходом на платформы первого и второго поколения, именуемые в дальнейшем экосистемами. Определены принципиальные отличия теоретической аргументации сторонников продвигаемых цифровых технологий и их оппонентов. Проанализированы позиции аргументации воздействия на изменение движущих факторов с целью корректировки методов государственной политики и выбора вектора технологических процессов. Рассмотрен вопрос о корреляции макроэкономической теории в эволюционном смысле, выходящей за пределы известных принципов экономической мысли цифровой трансформации. Обзор теоретических подходов исследуемой проблематики позволит более точно выделить их контрольные функции в осуществлении цифровой трансформации.
\end{abstract}

JEL classification: B40, F63, O33

Ключевые слова: технологический процесс; рациональность; иррациональность; «золотое отношение»; цифровая экономика; коэффициент корреляции.

\section{Введение}

$\mathrm{M}$ ировая экономика усиленными темпами внедряет прогрессивные технологии, применяя непрерывную трансформацию в режиме реального времени на базе обновления. Это определяется инновационными процессами, которые формируют их сбалансированность, создавая предпосылки перехода системы на новый уровень в перспективном периоде.

Новые тенденции экономической теории раскрывают стратегические направления цифровой трансформации экономики, модернизацию технологических процессов с переходом на платформы первого и второго поколения, именуемые также экосистемами. Современные архитектурные мощности не совместимы с внедрением прорывных технологий, таких как нейросети, блокчейн-технологии, искусственный интеллект.

С целью выявления приоритетных направлений производственной сферы развитие и апробация положений основываются на теории, которая в прикладном смысле имеет современное начало «созидательного разрушения».

Зарождение теории смыслов и смена модели экономического развития создают методологическую базу новых архитектурных форм организации общественного 
производства, социально-экономических отношений. Выстраивание и взаимодействие категорий, процессов и явлений трансформирует экономику, создавая экосистемы.

Процессы модернизации экономики в практическом решении должны раскрывать: общее взаимопонимание между институциональными, законодательными и производственными отношениями, сущность организационных преобразований, формулировку базовых положений по инструментальному обеспечению независимого перехода технологических процессов на новый виток социально-экономических связей. В основу процессов должны быть заложены новые характеристики стандартизации, методологии функционирования системы, технических условий, норм, правил, инструкций и положений, что предусматривает внесение институциональных изменений. Совершенствование технологических процессов российской экономики возможно за счет режима робоэдвайзеров, управления и наращивания результатов применения технологий и повышения технологичности экономической системы.

Цель исследования - показать, что задачи и установки вектора технологических процессов цифровой экономики выходят далеко за пределы известных принципов экономического развития, вливаясь в русло общемировых тенденций.

Для достижения поставленной цели необходимо решить следующие задачи:

- исследовать сущность организационных преобразований, раскрывая теорию смыслов рациональности и иррациональности;

- выявить теоретико-методологические и прикладные основы для определения направлений в рамках государственной стратегии планирования социально-экономического развития;

- проанализировать научные дискуссии относительно условий смены модели экономического развития и определения вектора экономического развития;

- проанализировать информационно-аналитические инструменты, применяемые органами власти.

\section{Сущностные характеристики эволюционного развития: трансформация экономики}

Модель трансформационной экономики меняет парадигму и сущностные характеристики экономической теории [4]. Именно новая технологическая парадигма экономической мысли превращает человеческий капитал в доминанту экономического развития, способного обеспечить независимый переход технологических процессов. Совместно с институтами, которые формируют социально-экономические отношения в трансформационной экономике с переходом на платформы, имеющие необратимые процессы, создадутся условия «созидательного разрушения», которые определят начало наступательного прогресса [15].

Технологическая парадигма позволяет применять новые концептуальные решения и формировать теоретико-методологические подходы, что является началом новой модели экономического развития, или переходной в категорию цифровой экономической теории. Предметная сфера трансформации экономики с переходом на платформы - это начало определения функционирования законодательной и судебной власти, определение сроков, когда исполнительная власть сможет перейти в программируемый контекст посредством «умных контрактов». На наш взгляд, в первую очередь необходимо выработать и утвердить методологию изменения институциональных основ, в соответствии с которой институты власти должны формировать институциональную инфраструктуру [5].

Рассмотрим составляющие цифровой трансформации (см. таблицу).

Методология данного исследования направлена на обоснование выбора режима управления производственными технологиями, институциональными человеческими ресурсами в условиях перехода на платформы [4; 5]. В рамках анализа следует учитывать релевантные факторы трансформации экономики в прикладном смысле 
Цифровая трансформация и ее составляющие

\begin{tabular}{|l|l|l|}
\hline \multicolumn{2}{|c|}{ Люди } & \multicolumn{1}{|c|}{ Цифровая трансформация } \\
\hline Сотворчество. & Облачные инструменты & \multicolumn{1}{|c|}{ Продукты } \\
Краудфандинг. & и приложения. & ным кодом. \\
Краудсорсинг. & Мобильный интернет. & Оплата по мере потребления. \\
Приватность. & Датчики. & Технологии на основе \\
Форумы и блоги. & Большие и открытые данные. & геолокации. \\
Социальные сети и платформы & Искусственный интеллект. & Носимые устройства. \\
& Роботы & Дополненная реальность. \\
& & 3D-принтеры \\
\hline
\end{tabular}

Построено по: $[4 ; 5]$.

положений современной неошумпетерианской теории. В зависимости от основных трансформационных процессов экономики формируется новая структура экономики «созидательного разрушения» и «комбинаторного наращения», образуя новую экономическую реальность экономического развития с его темпами роста [15]. В своем исследовании Я.П. Силин и Е.Г. Анимица утверждают, что национальная технологическая инициатива может быть предвестником новой индустриализации, но, на наш взгляд, альтернатива этому феномену заложена в технологической модернизации [8]. Последовательное исследование сочетания различных подходов в управлении дает возможность увидеть новые управленческие возможности с применением/внедрением технологических решений.

Исследования в этом направлении осуществляют институты РАН, ведущие университеты России, зарубежные научные школы. Представителем одной из таких школ является Й. Шумпетер с его теорией «созидательного разрушения», прочно вошедшей в интеллектуальный каркас экономической теории, подчиненной принципу «комбинаторного наращивания». Его теория подразумевает комбинирование любых мыслимых форм, видов вещей и сил к получению чего-то нового [15].

О.С. Сухарев с точки зрения теории исследует экономический рост быстроизменяющейся экономики: «Цифровая экономика уже вошла много лет назад, просто о ней не принято было говорить» $[9 ; 10]$.

А.И. Татаркин, рассматривая промышленную политику как основу системной модернизации экономики России, определяет инновационное предпринимательство в качестве самостоятельного экономического явления, занимающего собственные позиции в конкретных областях экономики [11].

А.Н. Асаул исследует феномен модернизации экономики на основе технологических инноваций. Инновационно-инновативные процессы в России рассматриваются как источники роста. Особое значение уделяется коммерциализации объектов интеллектуальной собственности [12].

Д. Костень считает, что объединение и использование блокчейн-технологий с такими направлениями, как Big Data, Интернет вещей, 3D-печатание и алгоритмы искусственного интеллекта, полностью изменят социально-экономическую текстуру общества в ближайшие 5-10 лет. Без перехода на новые бизнес-модели и методы управления современные производственные мощности морально устареют и рискуют превратиться в невостребованные элементы инфраструктуры [6].

К.Б. Костин считает, что с точки зрения сегментирования единственно верным решением проблемы будет применение масштабирования блокчейна. Автор исследует трансформацию и модернизацию экономики как процесс, который отражает экономическое пространство с его влиянием на экономическое поле, где технологическое развитие складывается под воздействием факторов спроса в экономической системе [7]. 
Д.Д. Буркальцева утверждает, что использование индустриального Интернета вещей подразумевает создание комплексного решения, объединяющего информационные процессы с производственными, и это направление развития цифровой экономики является достаточно новой задачей. Автор считает, что эволюционные процессы смены модели экономического развития в цифровых технологиях через механизм инновационного прорыва коренным образом изменят экономические, финансовые, производственные процессы и процессы управления [5].

По мнению А. Абрамова, цифровая экономика в России уже присутствует, хотя этот показатель существенно влияет на высокопроизводительные рабочие места. Цифровая экономика несет риски, одновременно давая преимущества [1].

Б. Хейфец считает, что цифровая экономика силой ворвалась в нашу жизнь. С четвертой промышленной революцией она займет главенствующее положение в ближайшие 5-10 лет [13]. Робототехника, беспилотники, машины без водителей, 3D-принтеры - все это цифровая экономика. В России стоимость программного обеспечения IT-технологий в 2015 г. составила 7 млрд дол.; в Индии в 2005 г. - 5 млрд дол., в 2015 г. 115 млрд дол. Один очень большой минус - трудно определить и оценить риски.

Выдвигаемая гипотеза исследования основывается на зарождении теории смыслов рациональности и иррациональности, не нарушая теорию «золотого отношения». Данная гипотеза должна учитываться при разработке концепции институциональных основ контрольной функции государства в трансформировании экономики, модернизации технологических процессов с применением технологии VS-человек. Определение сущности организационных преобразований, разработки новых подходов в социально-экономических отношениях необходимо для формирования характеристик функционирования системы, основанной на развитии технологической парадигмы комбинированных технологий, что позволит системе создавать новое качество. Комбинированные технологии в экономике обеспечат модернизацию и трансформацию социально-экономических отношений на основе технолого-инновационного подхода.

На основании вышеизложенного можно сделать выводы:

- применение инновационных, прогрессивных и трансформационных подходов изменит структуру экономики, обеспечив экономический рост;

- смена модели экономического развития сочетается с процессом технологических инноваций.

Поскольку новые технологии являются прорывными во всех слоях организации общества, формирование их должно подкрепляться законодательно через механизм институциональных и социально-экономических отношений. На наш взгляд, это приведет к смене модели экономического развития, к формированию новой технологической парадигмы, экономической мысли в поисках истины «начала».

\section{Эволюционная парадигма смены модели экономики}

Обоснование сингулярного начала постепенной эволюции мира раскрывает иррациональность как доступную только теоретическому познанию истину. В книге «Десятая» (1548-1620) Симон Стивен провозгласил полное равновесие рациональных и иррациональных чисел [2].

Исследуя процессы эволюционного развития, мы, в первую очередь, рассматриваем рациональность и иррациональность, природный интеллект как систему научных принципов, идей, обобщающих практический опыт с их закономерностями.

Рассмотрим цифровую трансформацию и ее способность влиять на развитие общества, уровень человеческого мышления, количественные и качественные параметры. Эволюция природы технологий имеет постоянно прогрессивный наступательный характер, и только человеку подвластно определять границы и функции этого наступления в пропорциях «золотого отношения». Человеку свойственно комплексно 
и объемно рассматривать весь спектр объекта (предмет, процесс и явление) оптимального и устойчивого равновесия, поскольку отношение его внутренних и внешних полей равно иррациональному критерию - «золотому отношению».

Исходя из данной гипотезы мы наблюдаем соединение совокупности событий, заключенных в объект, в котором есть предмет, процесс и явление. Чтобы исследовать и понять объект, необходимо заглянуть в глубину его преобразований. Наша задача по возможности найти истину, которая кроется в смене модели экономического развития трансформации экономики с переходом на платформы. Если обосновывать все три составляющие объекта и их исходные положения (предмет, процесс и явление), мы увидим качественные глубины сетевой системы. Развитие любого качества сопровождается количеством, мерой. Заглядывая в глубину, мы вычисляем свою меру, на которой формируется основа.

Применив экономическую инверсию (нарушение привычного хода вещей обратного порядка), извлечем корень из трехмерного объекта, повернув время его развития вспять. Этот метод мы называем 3D. Только 3D может указать нам на начало, на исходное событие (на исходный объект). Извлечение корня - это операция (процесс), обратная возведению в степень, т. е. обратная умножению (процесса развития):

$$
\sqrt[n]{a}=a^{\frac{1}{n}}=a^{n^{-1}}=x_{n}
$$

В поисках начала меры подставим в формулу реальные правомерные величины:

$$
\begin{gathered}
\sqrt[\infty]{\infty_{A}}=\sqrt[\infty]{0_{A}}=\infty_{A^{\frac{1}{\infty}}}=\infty_{A^{0}}=0_{A^{0}}=1=\sqrt[\infty]{\mathrm{C}_{\mathrm{M}}}=\sqrt[\infty]{X_{M}} \times \sqrt[\infty]{Y_{M}} \times \sqrt[\infty]{Z_{M}}=1 \cdot 1 \cdot 1= \\
=1^{3} \pm\left(0,0, \ldots, 0\left(+a^{+1}+\left(-a^{-1}\right)=1\right)\right)^{3}=\left(1 \pm 10^{-\infty}\right)^{3}=1^{3},
\end{gathered}
$$

где $a$ - комплексное число (полярное), величина в диапазоне от нуля до бесконечности; $\mathrm{C}_{\mathrm{M}}$ - смена модели экономического развития, модернизация экономики (емкость экономики); $X_{M}, Y_{M}, Z_{M}$ - любые линейные ортогональные размеры секторов экономики и ее объектов; $\infty_{A}$ под корнем - реальный сектор экономики - полиномы его объектов с внутренними полями до запятой и внешними полями после запятой; $1^{3}-$ исходная экономическая среда, охватывающая все и содержащая никогда не исчезающие потенциальные ресурсы; $\infty$ как знак степени корня, означает бесконечное извлечение корня, или возведение подкоренного выражения в нулевую степень, когда $\infty^{\frac{1}{\infty}}=\infty^{0}=1$; $0_{A}$ - актуальный ноль иррациональности, минимальное начало, которое только можно себе представить (если внутреннее поле равно 1 , то внешнее поле равно 0 ); $+a^{+1}-$ комплексная часть экономики или комплексный объект, в котором потенциальное или реальное внутреннее (мнимое) поле (со знаком плюс) и внешнее (действительное) поле (со знаком минус) находятся в «золотом отношении», что будет характеризовать начало модернизационной экономики как целостную единичность.

Уравнение уводит нас в область иррациональных и комплексных объемных чисел, отражающих внутреннее (мнимое) поле объекта (новой модели экономики) и внешнее рациональное (действительное в данное время экономики) поле объекта. Общее поле экономики (объект) в 3D $=3^{1}$.

Действительно, извлечем квадратный корень, например, в трех направлениях по типу (2) бесконечно большое число раз из любого большего, чем единица, значения плотности поля трансформационной экономики (объекта) и его событий. В итоге получим результат, который будет, уменьшаясь, стремиться к единице (причем одной мнимой - стороной комплексного значения), но никогда не станет равным единице, сколько бы мы ни продолжали эту операцию [3]. 
В пределе своей иррациональности результат равен потенциальной неисчезающей мощности модели экономического развития (единицы).

И наоборот, извлечем корень бесконечно большое число раз из любого меньшего, чем единица, значения плотности объекта (события). В итоге получим результат, который будет, увеличиваясь, стремиться к единице (причем другой - действительной стороной комплексного значения), но никогда не станет равным единице, сколько бы мы ни продолжали эту операцию. В пределе своей иррациональности результат тоже равен потенциальной неисчезающей энергии единицы. Неполяризованную полноту Единицы будем называть «модель экономического развития, основанная на воспроизводственной функции», где невидимая часть этих функций заключена в 3D. Потенциальность Единицы означает ее возможность вновь поляризоваться, делиться и размножаться до современного состояния микро-, макро-, мегауровней, сохраняющего изначальную энергию единицы.

Единица - это идеальный математический стволовой стержень древа эволюции, у которого можно наблюдать объект (экономику), предмет, процесс, явления одновременно. В понимание определения приоритетности вносятся существенные изменения в пользу цифровых трансформаций, где инновации и новые технологии занимают первое-второе места. На третьем месте находятся профессиональные кадры, далее место отводится стратегии управления. Новые технологии выходят на передний план в соотношении, представленном на рис. 1, который построен на основании интернет-опроса крупных компаний 2017 г..

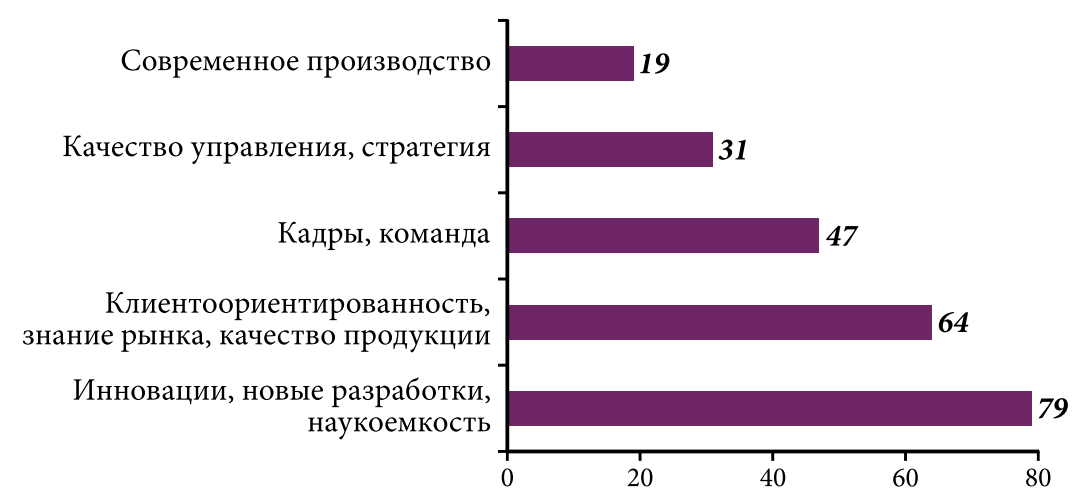

Рис. 1. Основа эффективного развития компании

Можно сделать вывод, что смена модели экономического развития требует рефлексии экономической мысли по формированию трансформационной экономики.

Придерживаясь вышеизложенного, можно определить, что технологическая парадигма новой экономической мысли, инновации нового мышления, нововведений при взаимодействии категорий экономической теории способна развивать цифровые технологии. Таким образом, цель статьи - проанализировать позиции и аргументы воздействия движущих факторов смены модели экономического развития, трансформации экономики - достигнута.

\section{Процессы трансформации экономики, основанные на ресурсах}

Человечество живет в эпоху глобализации и интеграции мирового хозяйства, меняя содержание основных видов деятельности. В управлении и экономике происходит трансформация процессов и явлений.

Человек трансформируется вместе с системой, приобретает новые качества, что влечет за собой трансформацию социальных отношений в группах, в быту и на работе. 
Данные изменения несут некую всемирную адаптацию, а также новые угрозы. Цифровая экономика направлена, в первую очередь, на цифровую трансформацию институтов власти, судебной и налоговой системы, законодательной базы, сферы услуг. Внедрение цифровых технологий в реальную жизнь происходит не только в рамках технологического прогресса экономики. Данные технологии применяются почти во всех сферах жизнедеятельности человека - культурной, духовной, образовательной, медицинской, сервисной, IT и телекоммуникационной.

Поэтому пока у всех, кто готов к переменам, есть время на подготовку. В более отдаленной перспективе цифровая (электронная) экономика может стать тем инструментом, который осуществит многовековую мечту о свободе людей, обреченных сегодня на тяжелый физический труд. Откроются широчайшие возможности для творчества, науки (как фундаментальной, так и прикладной) и искусства. Неожиданно для многих будет востребована «советская» модель интеллектуального общества. Однако чтобы такое оптимистичное будущее стало возможным, уже сегодня надо осознать, описать, утвердить и начать реализацию нового проекта цифровой (электронной) экономики.

Целенаправленное и осмысленное движение в данном направлении позволит избежать зависимости операционной и технологической деятельности отечественной экономики от иностранных цифровых платформ, технологий и стандартов, а также активного и неуправляемого хождения виртуальных валют (криптовалют). Необходимы четкое видение проблем и последовательная политика действий, чтобы вовремя использовать появляющиеся возможности, сохраняя свой цифровой, а значит, и реальный суверенитет. Естественный ход вещей уже приводит к постановке проблем и поиску решений в государственном управлении. Исследуя труды многих отечественных ученых, экономистов и отслеживая научные форумы, можно сделать вывод: реальная цифровая трансформация базируется на реальном секторе экономики, ресурсах, развитости инфраструктуры, и, на наш взгляд, именно инновации и инвестиции сменят модель экономического развития. Модернизация экономики с переходом на платформы-экосистемы заложена в цифровой трансформации с применением VS-человека в российской экономике. По мнению специалистов, этот процесс станет источником прироста ВВП.

Рассмотрим источники прироста ВВП к 2025 г. (рис. 2).

\begin{tabular}{|c|c|c|c|}
\hline $\begin{array}{l}\text { Оптимизация } \\
\text { производственных } \\
\text { и логистических } \\
\text { операций }\end{array}$ & $\begin{array}{l}\text { • Мониторинг производственных } \\
\text { линий в режиме реального времени } \\
\text { • Оптимизация логистических } \\
\text { маршрутов и определение порядка } \\
\text { приоритетных направлений ........ }\end{array}$ & $1,4-4,0$ & \\
\hline $\begin{array}{l}\text { Повышение } \\
\text { эффективности } \\
\text { рынка труда }\end{array}$ & $\begin{array}{l}\text { • Эффективный и быстрый } \\
\text { поиск работы и заполнение вакансий } \\
\text { • Возможности удаленной работы } \\
\text { • Новые профессии и рабочие места }\end{array}$ & $2,1-2,9$ & $4,1-8,9$ \\
\hline $\begin{array}{l}\text { Повышение } \\
\text { производительности } \\
\text { оборудования }\end{array}$ & $\begin{array}{l}\text { - Сокращение простоев оборудования } \\
\text { и расходов на ремонты } \\
\text { - Повышение загрузки оборудования }\end{array}$ & $0,4-1,4$ & $\begin{array}{l}\text { трлн р. } \\
(19-34 \% \\
\text { общего }\end{array}$ \\
\hline $\begin{array}{l}\text { Повышение } \\
\text { эффективности НИОКР } \\
\text { и разработки продуктов }\end{array}$ & $\begin{array}{l}\text { • Быстрое прототипирование } \\
\text { к контроль качества } \\
\text { • Анализ больших массивов данных при } \\
\text { разработке и совершенствовании продуктов }\end{array}$ & $0,2-0,5$ & ВВП) \\
\hline $\begin{array}{l}\text { Снижение расхода } \\
\text { ресурсов } \\
\text { и производственных } \\
\text { потерь }\end{array}$ & $\begin{array}{l}\text { • Снижение расхода электроэнергии } \\
\text { и топлива } \\
\text { - Сокращение производственных } \\
\text { потерь сырья }\end{array}$ & $<0,1$ & \\
\hline
\end{tabular}

Рис. 2. Источники прироста ВВП к 2025 г. за счет цифровизации, трлн р. (в ценах 2015 г.) [14] 
Последовательная политика действий позволит своевременно использовать появляющиеся возможности, сохраняя цифровой и реальный суверенитет. Происходят сдвиги и в мировоззрении, и в этике общества. Однако конечный результат этих изменений не предопределен. Он зависит от подготовленности общества и государства, так как цифровизация рождает возможности, которые могут нести с собой как новые блага, так и неожиданные угрозы.

Анализ уровня использования информационно-аналитических инструментов органами государственной власти показывает, что в большинстве структурных подразделений он составляет $41,9 \%$, в отдельных структурных подразделениях - 41,6\%, и в $16,5 \%$ учреждений они не используются совсем. Из них в федеральных органах исполнительной власти уровень активного применения достигает $53,1 \%$, в отдельных подразделениях - 38,8\%, в 8,2\% учреждений не применяются совсем. Что касается региональных органов власти, то использование информационно-аналитических инструментов наблюдается в $41,0 \%$ учреждений, в отдельных структурных подразделениях - 41,8\% и в $17,2 \%$ организаций не используются.

Проанализируем виды информационно-аналитических инструментов в процентном соотношении в целом по стране:

- стандартные средства офисных приложений (MS Excel или аналоги) - 79,9\%;

- инструменты, базирующиеся на промышленных аналитических платформах иностранных производителей, - 18,5\%;

- инструменты, базирующиеся на промышленных аналитических платформах отечественных производителей, - 14,9\%;

- оригинальные инструменты собственной (заказной) разработки - 20,7\%;

- формирование отчетов - 85,7\%;

- аналитический мониторинг - 79,6\%;

- планирование - 67,3\%;

- прогнозирование - 62,9\%;

- моделирование ситуаций - 11,5\%.

Вышеизложенное подводит нас к тому, что информационно-аналитические инструменты, применяемые в органах власти, требуют перехода на новый технологический уровень, который закладывается в смене развития экономической системы, уже определен на законодательном уровне и заключается в трансформации экономики с переходом на экосистемы. На наш взгляд, для успешной реализации цифровых трансформаций, в основе которых лежит технология, дающая огромное конкурентное преимущество, достижение необходимых результатов возможно при правильно сформулированных требованиях к системе, техническим решениям, опыту и инновационным прорывным идеям в командах. Попробуем сформулировать семь слагаемых успеха цифровой трансформации:

1) обеспечение управления проектом, вовлечение профессионалов и заинтересованных лиц;

2) разработка этапов реализации проекта;

3) демонстрация, обсуждение в команде достижений, закладывающих ее успех;

4) разработка гибкого плана с резервом маневренности и движения в нескольких направлениях;

5) формирование и запуск производственной системы;

6) мотивирование команды изучать и применять новые технологии;

7) определение качеств и последовательности в управлении, организационные изменения, подготовка системы для пользователя, вовлечение заинтересованных лиц в работу и выделение новаторов истины.

Система цифровых трансформаций только тогда станет успешной, когда будет освоена персоналом. Названные семь слагаемых успеха могут быть инструментами, 
позволяющими обучать персонал в процессе создания и внедрения цифровых трансформаций.

Россия по распространению Интернета с наибольшим количеством интернет-пользователей и по уровню проникновения Интернета находится на 7-м месте в мире (рис. 3).

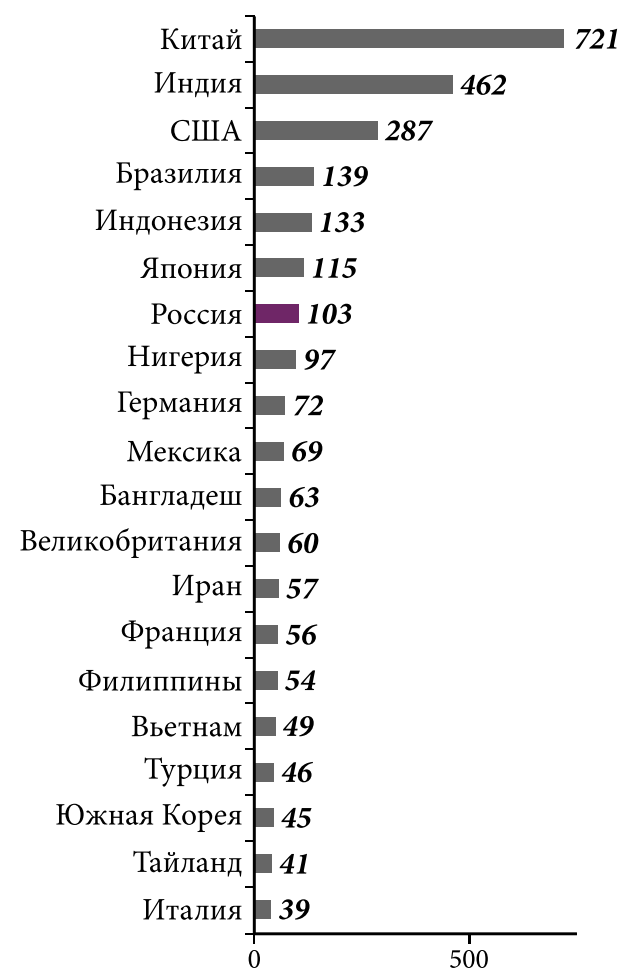

Рейтинг стран с наибольшим количеством интернет-пользователей, млн чел.

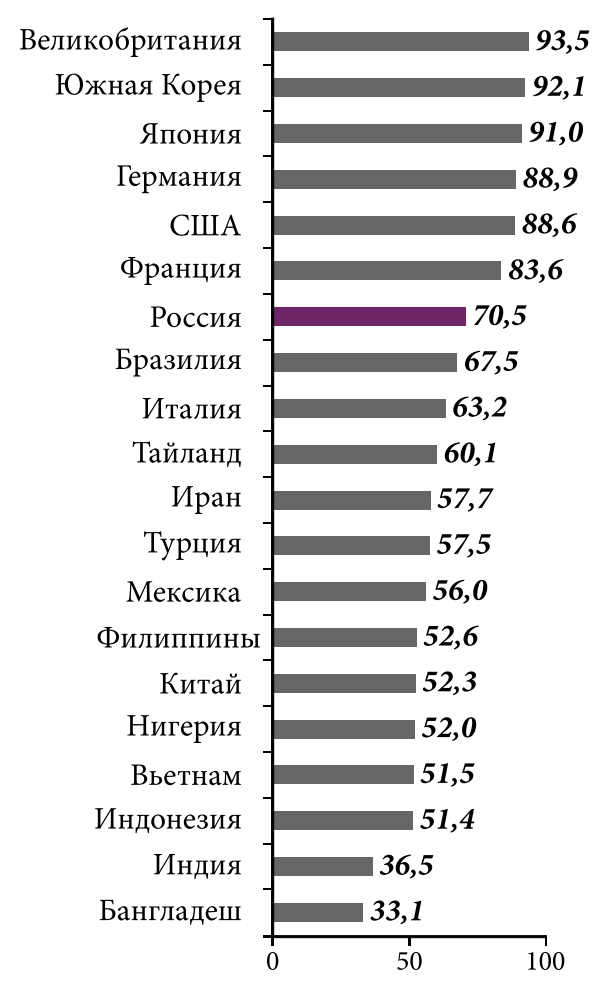

Рейтинг стран по уровню проникновения Интернета, \%

Рис. 3. Распространение Интернета в разных странах [16]

Правительство РФ приняло постановление ${ }^{1}$, в котором утверждена функциональная структура системы управления реализацией программы «Цифровая экономика». Сформированы рабочие группы по направлениям, куда вошли правительственная комиссия по использованию информационных технологий, некоммерческие организации, федеральные органы исполнительной власти, центры компетенций.

Исходя из июльского отчета «Цифровая Россия: новая реальность» [14], есть предпосылки для того, чтобы объем цифровой экономики России к 2025 г. вырос до 9,6 трлн р. (в ценах 2015 г.), по сравнению с 3,2 трлн р. в 2015 г., в результате цифровых преобразований традиционных отраслей и развития самостоятельной высокотехнологичной индустрии.

Основным резервом роста ВВП является цифровая трансформация экономики, и произойдет это в результате повышения человеческих инновационных ресурсов. В 2017 г. цифровая трансформация перешла в решающую фазу, и цифровые преобразования стали одним из главных факторов мирового экономического роста. В Китае к 2025 г. интернет-технологии могут дать до 22\% увеличения ВВП. В США ожидаемый

${ }^{1}$ Постановление Правительства РФ от 28 августа 2017 г. № 1030 «О системе управления реализацией программы „Цифровая экономика Российской Федерации“». 
прирост стоимости, создаваемый цифровыми технологиями, к 2025 г. может составить 1,6-2,2 трлн дол. Прогнозы базируются не только на автоматизации существующих процессов, но и на внедрении принципиально новых бизнес-моделей и технологий: цифровых платформ - экосистем, углубленной аналитики больших данных, 3D-печати, роботизации, Интернета вещей. По оценке McKinsey Global Institute, только Интернет вещей до 2025 г. будет ежегодно приносить мировой экономике от 4 до 11 трлн дол. [17].

Следует отметить, что цифровые трансформации в экономике будут внедряться с применением робоэдвайзеров, киборгов, роботов (в дальнейшем VS). В США при управлении активами используется искусственный интеллект робоэдвайзеров (рис. 4).

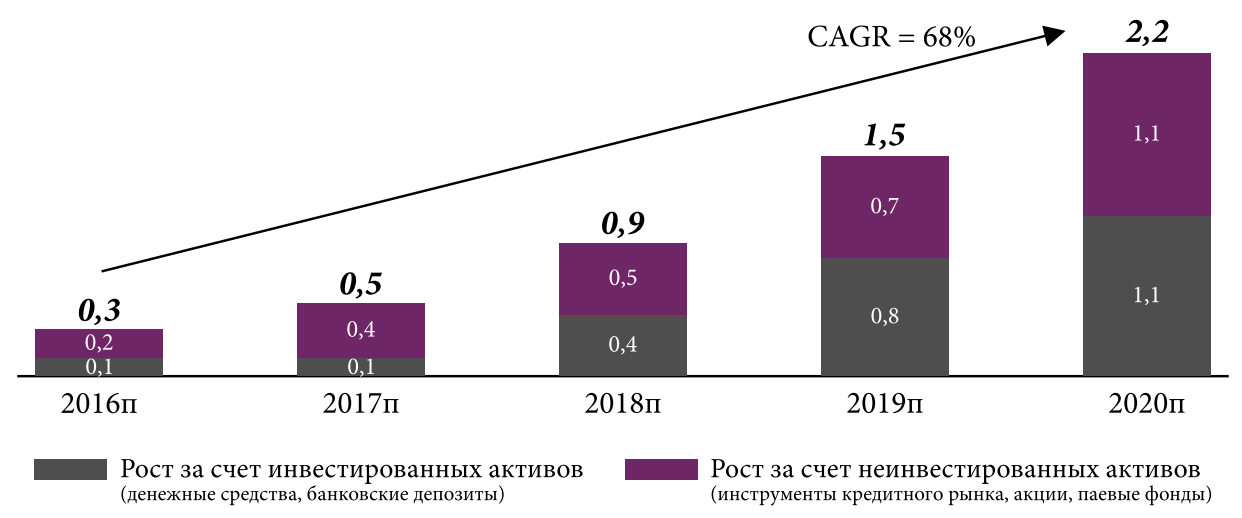

Рис. 4. Прогноз активов под управлением робоэдвайзеров в США, трлн дол. ${ }^{1}$

Применение роботов в промышленном производстве началось по историческим меркам не так давно - немного больше полувека назад. В этих условиях мало какое производство можно представить себе без автоматических линий, стальных манипуляторов и зорких стеклянных зрачков роботов. Эти железные «VS-ребята» прочно вошли в большинство производственных процессов.

Архитектура микросервисов может сыграть важнейшую роль в цифровой трансформации, особенно в организациях, модернизирующих унаследованные приложения и базы кода. Микросервисы делают как унаследованные, так и новые приложения более легкими, масштабируемыми и простыми в управлении. Цифровая трансформация означает полную перестройку организации с целью использования новой технологии. Микросервисы помогают в этом, расширяя их возможности.

При определении вектора технологических процессов и кореляции макроэкономической теории в эволюционном смысле экономическое развитие выходит за пределы известных принципов, поэтому требуется фундаментальное изучение данного феномена. Для разработки практических решений необходимо сформировать общее взаимопонимание между институциональными, законодательными и производственными отношениями, применяя теоретико-методологические основы формирования эффективной хозяйственной системы.

\section{Заключение}

Анализ технического прогресса указывает на то, что внедрение новых технологий сместит парадигму сегодняшнего восприятия мира во всех слоях организации общества от философского до производственного. Накопленный объем знаний уже сейчас отражает следующие феномены.

${ }^{1}$ Источник: Искусственный интеллект в банках // Интернет-сайт «Tadviser. Государства. Бизнес. ИT». URL: http://www.tadviser.ru. 
Техническая автоматизация понятия «доверие» - это прежде всего автоматизация исполнительной власти государства. Более глубокая автоматизация этого понятия позволяет разъединить функцию контроля и функцию управления. При этом функция контроля полностью автоматизируется, а функция управления (включая законодательную часть) поддается техническому моделированию.

Контракт и деньги - это единое целое. Система и общество, построенные по данному принципу, позволяют использовать контрактные отношения в качестве программируемых денег. Концепция программируемых денег открывает потенциал самой великой социальной сети всех времен. Ключевой фразой становится «социальная сеть», основой которой является социально-экономическое общение.

Человечество стоит на пороге еще одной восходящей «технической сети» - Интернет вещей, в основе которой также находится социально-экономическое общение, выражающееся в общении по схемам.

Платформенная экономика-экосистема представляет собой следующий техноэкономический виток. На этом этапе происходит колоссальная экономия через снижение транзакционных издержек на всех уровнях. В корне меняются механизмы производственных отношений, переходя на механизмы и законы экономики платформ, имеющие все уровни производств и все формы предприятий, объединенных одной главной целью и задачами.

Экосистема - это новая форма организации экономики и общества. B-to-Bи B-to-C-модели обобщаются в E-to-Е-модель (everyone to everyone). Экосистема отходит от экономической модели прибавочной стоимости и переходит к новой модели затрат на управление робоэдвайзерами с производственным соучастием. На этом уровне автоматизация понятия «доверие» проявляется в феномене инверсии управления.

\section{Источники}

1. Абрамов А. Российский финансовый рынок: факторы развития и барьеры роста / науч. ред. А. Д. Радыгин. М.: Изд-во Ин-та Гайдара, 2017.

2. Базилевич В.Д., Ильин В. В. Философия экономики. История. К.: Знання; М.: Рыбари, 2011.

3. Бондаренко Ю.Г. Учение ПИ, или «Золотое отношение» природного интеллекта: Куда=Как²/Откуда. Вологда; с. Молочное: Вологодская ГМХА, 2017.

4. Борщ Л. М. Эволюционные процессы социально-экономического развития в цифровых технологиях // Научный вестник: финансы, банки, инвестиции. 2017. № 4 (41). C. $98-107$.

5. Буркальцева Д.Д. Концептуальная модель рационального взаимодействия субъектов хозяйствования с учетом влияния институциональных факторов в современных условиях // Гуманитарные, социально-экономические и общественные науки. 2017. № 3. C. $179-187$.

6. Костень Д. Биткоин как новая форма товарно-денежных отношений. Блокчейн как новая форма инфраструктуры. Платформа как первая форма управления // Проблемы формирования правового социального государства в современной России: материалы XII Всерос. науч.-практ. конф. (Новосибирск, 27 октября 2016 г.). Новосибирск: Новосибирский государственный аграрный университет, 2016. С. 46-52.

7. Костин К.Б. Роль цифровых технологий в продвижении товаров и услуг на глобальных рынках // Российское предпринимательство. 2017. Т. 18, № 17. С. 2451-2460.

8. Силин Я.П., Анимица Е. Г. Российская модель новой индустриализации: к постановке проблемы // Известия Уральского государственного экономического университета. 2017. № 5 (73). С. 44-53.

9. Сухарев О.С. Технологическое развитие экономики: «созидательное разрушение» и комбинаторный эффект // Экономические стратегии. 2018. Т. 20, № 1 (151). С. 68-81. 
10. Сухарев О.С., Попов Е. В. Движение к цифровой экономике: влияние технологических факторов // Экономика. Налоги. Право. 2018. Т. 11, № 1. С. 26-35.

11. Татаркин А.И. Политическая экономия как научная основа экономической политики: экскурс по работам академика Л.И. Абалкина // Журнал экономической теории. 2015. № 3. С. 7-27.

12. Управление организационными нововведениями: учебник и практикум для бакалавриата и магистратуры / А. Н. Асаул, М. А. Асаул, И. Г. Мещеряков, И. Р. Шегельман; под ред. А.Н. Асаула. М.: Юрайт, 2017.

13. Хейфец Б. А. Новые экономические мегапартнерства и глобальная экономика // Международная жизнь. 2016. № 3. С. 127-146.

14. Цифровая Россия: новая реальность / А. Аптекман, В. Калабин, В. Клинцов и др. McKinsey \& Company, 2017.

15. Шумпетер Й. Теория экономического развития. Капитализм, социализм и демократия. М.: ЭКСМО, 2007.

16. Piketty T. Capital in the Twenty-First Century / translated by A. Goldhammer. Cambridge, MA; L.: The Belknap Press of Harvard University Press, 2014.

17. The Internet of Things: Mapping the Value Beyond the Hype / J. Manyika, M. Chui, P. Bisson and others; McKinsey Global Institute. McKinsey \& Company, 2015.

\title{
Modernisation of the Economy: Technologies vs Humans
}

\author{
by Lyudmila M. Borshch
}

The paper studies a relevant scientific and practical problem of economic theory and puts forward a hypothesis based on the origin of theory of the rationality and irrationality without violating the golden ratio theory. The author provides an analytical review of theoretical approaches of Russian and foreign economists on the problem brought into focus, which allowed identifying theoretical, methodological and applied aspects to determine the directions for the government strategy of planning socioeconomic development. The article offers an assessment of an academic discussion about the conditions for changing the model economic development, modernisation of the economy with the transition to the platforms of the first and second generation, further referred to as ecosystems. The paper reveals principal distinctions of the theoretical arguments of the proponents of digital technologies and their opponents. The author analyses the arguments about the impact on the change of the driving forces with the aim to correct the methods of the government policy and choice of the vector of technological processes. Finally, the paper considers the issue of macroeconomic theory correlation in an evolutionary sense, which goes beyond the known principles of the economic thought of digital transformation. A review of the theoretical approaches to the problem under study will allow a more accurate determination of their control functions while effecting digital transformation.

Keywords: technological process; rationality; irrationality; the golden ratio; digital economy; correlation coefficient.

References:

1. Abramov A., Radygin A.D. (ed.) Rossiyskiy finansovyy rynok: faktory razvitiya i baryery rosta [Russian financial market: Development factors and growth barriers]. Moscow: Gaydar Institute, 2017.

2. Bazilevich V.D., Ilyin V. V. Filosofiya ekonomiki. Istoriya [Philosophy of economics]. Kiev: Znannya Publ.; Moscow: Rybari Publ., 2011.

3. Bondarenko Yu. G. Uchenie PI, ili "Zolotoe otnoshenie" prirodnogo intellekta: Kuda=Kak²/Otkuda [The teaching of PI, or the "Golden ratio" of natural intelligence: Where=How $2 /$ Where from]. Vologda; Molochnoe village: Vologda State Dairy Farming Academy named after N.V. Vereshchagin, 2017.

4. Borshch L. M. Evolyutsionnye protsessy sotsial'no-ekonomicheskogo razvitiya $\mathrm{v}$ tsifrovykh tekhnologiyakh [Evolutionary processes of social and economic development in digital technologies]. Nauch- 
nyy vestnik: finansy, banki, investitsii - Scientific Bulletin: Finance, Banks, Investments, 2017, no. 4(41), pp. 98-107.

5. Burkaltseva D.D. Kontseptual'naya model' ratsional'nogo vzaimodeystviya subyektov khozyaystvovaniya s uchetom vliyaniya institutsional'nykh faktorov v sovremennykh usloviyakh [Conceptual model of rational interaction of economic entities taking into account the influence of institutional factors in modern conditions]. Gumanitarnye, sotsialno-ekonomicheskie i obshchestvennye nauki - Human, Socioeconomic and Social Sciences, 2017, no. 3, pp. 179-187.

6. Kosten' D. Bitkoin kak novaya forma tovarno-denezhnykh otnosheniy. Blokcheyn kak novaya forma infrastruktury. Platforma kak pervaya forma upravleniya [Bitcoin as a new form of monetary relations. Blockchain as a new form of infrastructure. Platform as the first form of management]. Materialy XII Vserossiyskoy nauchno-prakticheskoy konferentsii "Problemy formirovaniya pravovogo sotsial'nogo gosudarstva $v$ sovremennoy Rossii" [Proc. 12 ${ }^{\text {th }}$ All-Russian Sci.-Prac. Conf. "Problems of Formation of Social State of Law in Modern Russia]. Novosibirsk: Novosibirsk State Agrarian University 2016, pp. 46-52.

7. Kostin K. B. Rol' tsifrovykh tekhnologiy v prodvizhenii tovarov i uslug na global'nykh rynkakh [The role of digital technologies in the promotion of goods and services in global markets]. Rossiyskoe predprinimatelstvo - Russian Entrepreneurship, 2017, vol. 18, no.17, pp. 2451-2460.

8. Silin Ya. P., Animitsa Ye. G. Rossiyskaya model' novoy industrializatsii: k postanovke problemy [Russian model of the new industrialisation: Formulating the problem]. Izvestiya Uralskogo gosudarstvennogo ekonomicheskogo universiteta - Journal of the Ural State University of Economics, 2017, no. 5 (73), pp. 44-53.

9. Sukharev O.S. Tekhnologicheskoe razvitie ekonomiki: "sozidatel'noe razrushenie" i kombinatornyy effect [Technological development of ethe economy: "Creative destruction" and combination effect]. Ekonomicheskie strategii - Economic Strategies, 2018, vol. 20, no. 1 (151), pp. 68-81.

10. Sukharev O.S., Popov E. V. Dvizhenie k tsifrovoy ekonomike: vliyanie tekhnologicheskikh faktorov [The move towards digital economy: The impact of technological factors]. Ekonomika. Nalogi. Pravo - Economy. Taxes. Law, 2018, vol. 11, no. 1, pp. 26-35.

11. Tatarkin A. I. Politicheskaya ekonomiya kak nauchnaya osnova ekonomicheskoy politiki: ekskurs po rabotam akademika L. I. Abalkina [Political economy as a scientific basis of economic policy: An excursion into the works of academician L.I. Abalkin]. Zhurnal ekonomicheskoy teorii - Russian Journal of Economic Theory, 2015, no. 3, pp. 7-27.

12. Asaul A.N. (ed.), Asaul M.A., Meshcheryakov I. G., Shegelman I. R. Upravlenie organizatsionnymi novovvedeniyami [Management of organisational innovations]. Moscow: Yurayt Publ., 2017.

13. Kheyfets B. A. Novye ekonomicheskie megapartnerstva i global'naya ekonomika [New economic mega-partnerships and the global economy]. Mezhdunarodnaya zhizn - International Life, 2016, no. 3, pp. 127-146.

14. Aptekman A., Kalabin V., Klintsov V. et al. Tsifrovaya Rossiya: novaya real'nost' [The digital Russia: New reality]. McKinsey \& Company, 2017.

15. Schumpeter J. Teoriya ekonomicheskogo razvitiya. Kapitalizm, sotsializm i demokratiya [The theory of economic development. Capitalism, socialism and democracy]. Moscow: EKSMO Publ., 2007.

16. Piketty T. Capital in the Twenty-First Century: translated by A. Goldhammer. Cambridge, MA; L.: The Belknap Press of Harvard University Press, 2014.

17. Manyika J., Chui M., Bisson P. et al. The Internet of Things: Mapping the Value Beyond the Hype. McKinsey \& Company, 2015.

Contact Info:

Lyudmila M. Borshch, Dr. Sc. (Econ.), Prof. of Company Finance and Insurance Dept.

Phone: (3652) 27-05-65

e-mail: 1-borsh49@mail.ru

\author{
Crimean Federal University \\ named after V.I. Vernadsky \\ 21/4 Sevastopolskaya St., Simferopol, Russia, \\ 295015
}

\footnotetext{
Ссылка для цитирования: Борщ Л.М. Модернизация экономики: технологии vs человек // Известия Уральского государственного экономического университета. 2018. Т. 19, № 3. C. 42-54. DOI: 10.29141/20731019-2018-19-3-5

For citation: Borshch L. M. Modernizatsiya ekonomiki: tekhnologii vs chelovek [Modernisation of the economy: Technologies vs humans]. Izvestiya Uralskogo gosudarstvennogo ekonomicheskogo universiteta - Journal of the Ural State University of Economics, 2018, vol. 19, no. 3, pp. 42-54. DOI: 10.29141/2073-1019-2018-19-3-5
} 


\title{
РОМАНОВА Ольга Александровна
}

Доктор экономических наук, профессор, главный научный сотрудник

Институт экономики Уральского отделения РАН

620014, РФ, г. Екатеринбург, ул. Московская, 29

Контактный телефон: (343) 371-45-36

e-mail: econ@uran.ru

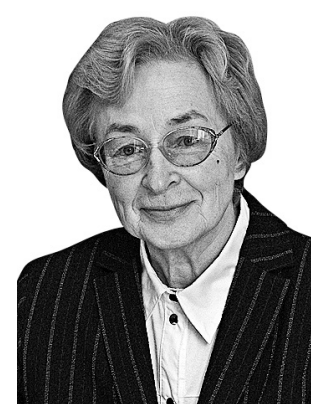

\section{Стратегии социально-экономического развития регионов РФ в контексте вызовов цифровой экономики'}

\begin{abstract}
Исследование направлено на обоснование того, что развитие в России цифровой экономики предъявляет новые требования к формированию региональных документов стратегического развития. Проанализированы некоторые базовые понятия, характеризующие феномен цифровой экономики, основные тренды ее развития, характер воздействия на экономическую среду, что позволило предложить авторское понятие цифровой экономики. Систематизированы новые технологические тренды, определяющие будущий образ промышленности мировой экономики. Показана целесообразность формирования в стратегических документах социально-экономического развития субъектов РФ «образ будущего» регионов. Выявлены тренды развития информационно-коммуникационных технологий в промышленном комплексе Свердловской области, проанализирована его информационная обеспеченность в сравнении с данными по России в целом. Сформулированы основные черты «образа будущего» промышленного комплекса Среднего Урала. Отмечено, что сложность процесса его перепозиционирования требует для управления им создания специализированных инвестиционных технологических партнерств в форме консорциумов.
\end{abstract}

JEL classification: O14, О33

Ключевые слова: цифровая экономика; стратегия социально-экономического развития; регион; информационно-коммуникационные технологии.

\section{Введение}

$B^{n}$ ысокие темпы появления принципиально новых, ранее трудно прогнозируемых глобальных трендов технологического развития, усиление в связи с этим многообразных рисков и неустойчивости социально-экономических систем разного уровня предопределяют появление новых требований к исследованиям в области стратегического развития России и ее регионов, в том числе с позиции формирования их «образа будущего». Наступление четвертой промышленной революции, которая определяет трансформирующие преобразования не только систем производства, потребления, транспортировки, финансов, но и систем образования, здравоохранения, разнообразных видов социальной деятельности, стало современной реальностью. Особенностью и уникальной характеристикой четвертой промышленной революции все в большей степени становятся интеграция и гармонизация научных дисциплин, на базе которых формируются новые технологические решения. Их общей особенностью является использование цифровых и информационных технологий, которые глубоко

${ }^{1}$ Статья подготовлена при поддержке РФФИ (проект № 18-010-01156 «Моделирование технологической трансформации промышленного комплекса России в условиях цифровизации экономики»). 
интегрируются во все области экономики и общественной жизни, предопределяя появление цифровой экономики. Все чаще не только в популярной, но и в научной литературе используется термин «цифровой мир». Бурное развитие Интернета, онлайнсервисов, мобильных коммуникаций, т. е. базовых инструментов формирования цифровой экономики, приводит к развитию этого мира со все ускоряющимися темпами. Цифровой мир, складывающаяся здесь система ценностей, а значит, и поведение человека, принципиально отличаются от того природного мира, в котором человечество находилось основное время своего существования [9. С. 122].

\section{Цифровая экономика}

Для более ясного понимания новых требований, предъявляемых к документам стратегического характера в области регионального развития, целесообразно уточнить некоторые базовые определения, характеризующие феномен цифровой экономики, основные тренды ее развития и характер воздействия на экономическую среду.

Анализ доступных публикаций позволяет сделать вывод, что в настоящее время отсутствует надежная теоретическая база для формируемой цифровой экономики. Нет устоявшегося понятия «цифровая экономика», открытым остается вопрос о ее предмете. Дискутируется в этой области понимание цифровой экономики как экономики исключительно цифровых объектов при альтернативном ее понимании как экономики последующей фазы развития традиционных и формирования новых отраслей на основе активизации использования Интернета и цифровых технологий прежде всего в реальном секторе экономики. В настоящее время в России понятие «цифровая экономика» закреплено в отечественных законодательных документах. Так, в «Стратегии развития информационного общества в Российской Федерации на 2017-2030 годы» цифровая экономика определена как «...деятельность, в которой ключевыми факторами производства являются данные, представленные в цифровом виде, а их обработка и использование в больших объемах позволяют существенно повысить эффективность, качество и производительность в различных видах производства при хранении, продаже, доставке и потреблении товаров и услуг»'. Утвержденная двумя месяцами позднее программа «Цифровая экономика Российской Федерации» содержит несколько иное понятие цифровой экономики: «...хозяйственная деятельность, ключевым фактором производства в которой являются данные в цифровой форме, способствующая формированию информационного пространства с учетом потребностей граждан и общества в получении качественных и достоверных сведений, развитию информационной инфраструктуры РФ, созданию и применению российских информационно-телекоммуникационных технологий, а также формированию новой технологической основы для социальной и экономической среды» ${ }^{2}$.

Понятие цифровой экономики в исследованиях некоторых авторов связывается с образованием нового, так называемого гибридного мира, т. е. мира, формирующегося в результате слияния реального и виртуального миров. С этой позиции цифровая экономика определяется как «...экономика, существующая в условиях гибридного мира» [3. С. 6]. Гибридный мир, в свою очередь, отличается возможностью совершения всех «жизненно необходимых действий» в реальном мире через виртуальный, но обязательными условиями этого процесса являются высокая эффективность и низкая стоимость информационно-коммуникационных технологий (ИКТ) и доступность цифровой инфраструктуры [3. С. 6].

${ }^{1}$ Указ Президента РФ от 9 мая 2017 г. № 203 «О Стратегии развития информационного общества в Российской Федерации на 2017-2030 годы».

${ }^{2}$ Распоряжение Правительства РФ от 28 июля 2017 г. № 1632-р «Об утверждении программы „Цифровая экономика Российской Федерации“». 
С целью уточнения понятия «цифровая экономика», которое учитывало бы ее функциональное предназначение, авторским коллективом Сретенского клуба имени С.П. Курдюмова предложено следующее ее определение: «...цифровая» (электронная) экономика - это экономика, характерной особенностью которой является максимальное удовлетворение потребностей всех ее участников за счет использования информации, в том числе персональной. Это становится возможным благодаря развитию информационно-коммуникационных и финансовых технологий, а также доступности инфраструктуры, вместе обеспечивающих возможность полноценного взаимодействия в гибридном мире всех участников экономической деятельности: субъектов и объектов процесса создания, распределения, обмена и потребления товаров и услуг» [3. С. 12].

Систематизация исследований в этой области позволяет нам предложить свое понимание цифровой экономики. Цифровая экономика, по нашему мнению, - это своеобразный экономический уклад и новый тип хозяйственных отношений, это экономика данных, в рамках которой они создаются, передаются, хранятся, формируя в совокупности цифровые активы, отражающие динамичное развитие технологических и экономических процессов, меняющуюся социальную парадигму жизни людей. Цифровые активы в такой экономике являются базой принятия обоснованных управленческих решений, повышающих эффективность государственного управления, экономические выгоды бизнеса и благосостояние граждан.

Предложенная трактовка понятия цифровой экономики опирается на тот факт, что в ее рамках основным инструментом создания добавленной стоимости являются данные и программные продукты. Подчеркнуто, что они же являются главным механизмом управления всеми технологическими процессами и основой принятия управленческих решений на разных уровнях иерархии. Появление все новых цифровых технологий приводит к быстрому снижению стоимости хранения, совместного использования, обработки, анализа и передачи данных. Переход промышленности на цифровые технологии позволяет создавать сверхбыстрые и высокопроизводительные системы, которые не только управляются автоматически, но и способны производить кастомизированный продукт, соответствующий индивидуальным требованиям потребителей. Поскольку миссией цифровой экономики является повышение качества жизни, обеспечение конкурентоспособности страны и ее национальной безопасности, то в предлагаемом определении делается акцент на скоординированные преобразования в экономической и социальной сферах жизнедеятельности.

Основные направления развития цифровой экономики, прежде всего ее промышленного сектора, учет которых важен при формировании стратегий развития, как России, так и ее индустриальных регионов, могут быть систематизированы по трем блокам (рис. 1): технологический, информационный и социально-этический [19; 20]. Технологический блок цифровых технологий целесообразно сформировать на базе инстурментов, объединяемых под названием «Индустрия 4.0». Это анализ больших массивов данных, сетевые решения в производстве и исследованиях, 3D-печать, робототехника, беспилотные транспортные средства и новые материалы. Информационный блок формируют информационно-коммуникационные технологии (ИКТ), бизнес, основанный на платформах, новые сервисы, Интернет вещей и промышленный Интернет, обработка больших данных. Социально-этический блок во многом определяется кардинальными изменениями профиля компетенций, востребованных на рынке труда, что формирует новую структуру занятости; развитием биологической инженерии, трудно прогнозируемые последствия которой могут породить серьезные этические и психологические проблемы.

Для оценки цифровизации экономики наиболее интересен индекс цифровизации экономики и общества (Digital Economy and Society Index - DESI), рассчитываемый 
с 2014 г. для всех стран ЕС. С 2015 г. появился международный вариант индекса по ряду государств, не входящих в Европейский союз. В 2016 г. DESI для России составил 0,47, что ниже среднего показателя по ЕС за тот же год $(0,54)$. Лидерами по уровню цифровизации среди стран ЕС в 2016 г. стали Дания $(0,67)$, Финляндия $(0,66)$, Швеция $(0,65)$ и Нидерланды $(0,64)[11]$. По уровню развития информационно-коммуникационных технологий и созданию бизнес-моделей, определяемому в качестве подиндекса глобального инновационного индекса (Global Innovation Index), Россия занимает 91-е место среди 127 стран, которые принимали участие в рейтинге [18. С. 10-12].

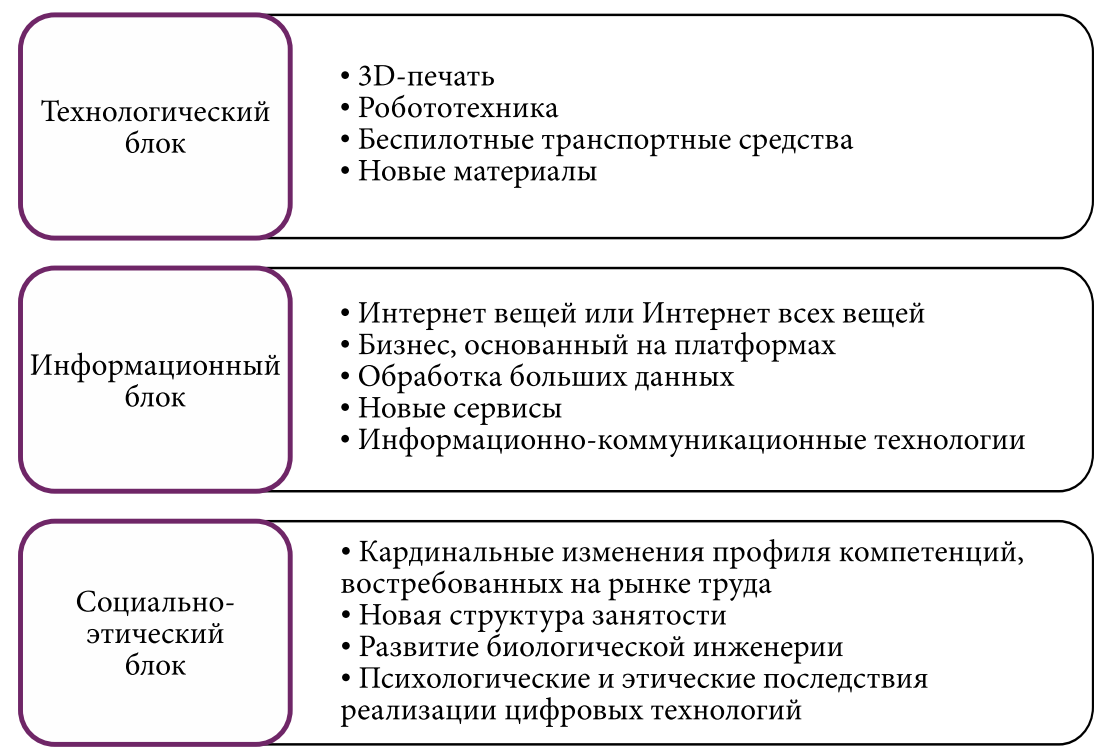

Рис. 1. Основные направления развития цифровой экономики России

По оценке аналитиков Digital McKinsey - глобальной экспертной группы, объединяющей специалистов McKinsey по цифровым технологиям, доля цифровой экономики в ВВП России составляет 3,9\% при аналогичном показателе в США, равном 10,9\% [17. С. 4]. Исследования данной группы показали, что в России к 2025 г. возможно утроение цифровой экономики. Потенциальный эффект для ВВП России от цифровизации экономики оценивается в 4,1-8,9 трлн р., что составит 19-34\% общего увеличения ВВП. [17. С. 62]. Основными источниками получения такого эффекта являются оптимизация производственных и логистических операций, рост эффективности рынка труда, повышение производительности оборудования, эффективности научно-исследовательских и опытно-конструкторских работ (НИОКР) и разработки продуктов.

Такие оптимистичные цифры подвергаются сомнению в связи с серьезным отставанием России в области цифровизации экономики [8] и неготовностью большинства российских компаний работать в новых условиях. Это было выявлено в 2017 г. экспертами Фонда «Сколково» и Аналитического центра Национального агентства финансовых исследований (НАФИ) ${ }^{1}$. Одной из проблем, снижающих готовность отечественных предприятий работать в условиях цифровой экономики, является, как установлено экспертами, психология предпринимателей, просто не готовых работать в условиях формирующихся новых бизнес-моделей. Это делает необходимым усиление акцента

\footnotetext{
${ }^{1}$ Большинство российских компаний не готовы к цифровой экономике: эксперты // Информационное агентство Eurasia Daily (EADaily). URL: https://eadaily.com/ru/news/2017/10/16/bolshinstvo-rossiyskih-kompaniy-ne-gotovy-k-cifrovoy-ekonomike-eksperty.
} 
в федеральных и региональных стратегиях социально-экономического развития на формирование и поддержку культуры предпринимательства, учитывающей развитие цифровой экономики.

\section{Региональные стратегии социально-экономического развития: образ будущего}

Формирование культуры предпринимательства является важным, но далеко не единственным направлением в стратегических документах регионального развития. В условиях цифровой экономики, определяющей принципиально новые тренды технологического и социально экономического развития и повышающей перспективность стратегий, направленных на инновационные способы предложения продуктов и услуг, необходимым становится поиск новых подходов к формированию стратегических документов социально-экономического развития отечественной экономики и ее регионов.

Актуализация проблем разработки стратегических документов регионального развития возрастает в условиях отсутствия четко сформулированной цели и приоритетов региональной политики, т. е. при неопределенности самой модели регионального развития и должного законодательного обеспечения региональной политики. Региональная политика должна строиться на основе не только реальных ситуаций и проблем, характерных для каждого периода функционирования государства и регионов. Она должна учитывать меняющиеся представления о приоритетности регулирования регионального развития, о значимости ресурсных возможностей регионов. На Гайдаровском форуме (январь 2018 г.) активно анализировалась проблема формирования новой региональной политики России. Особое значение придавалось нахождению баланса между ставкой на сильные регионы и поддержкой отстающих. Обсуждалось также, насколько существующая система распределения полномочий обеспечивает необходимые стимулы и ресурсы для экономики регионов. Естественно, что развитие каждого из российских регионов будет существенно различаться. В некоторых из них возможно осуществление технологических прорывов, в некоторых основное внимание будет уделено развитию местных сообществ. По мнению А. Кудрина, важнейшей задачей для развития регионов является улучшение системы регионального управления. Оно должно совершенствоваться таким образом, чтобы политика выравнивания помогала поднять уровень жизни в дотационных регионах, но никак не сдерживала развитие тех территорий-лидеров, власти которых добиваются больших успехов. Обсуждение новой региональной политики необходимо сделать обязательным на всех основных форумах, таких как Сочинский, Красноярский и Санкт-Петербургский, результатом должна быть выработка новой стратегии регионального развития, которая будет составной частью Стратегии развития России на период 2018-2024 гг. ${ }^{1}$ Во всех стратегических разработках должна быть учтена такая современная реальность, как не только обязательность учета социальных и экономических последствий принимаемых управленческих решений в области регионального развития, но и ответственность регионов за принимаемые решения с позиции учета меняющегося контекста политической жизни [16].

Важнейшей задачей в период развития цифровой экономики становится формирование в регионах благоприятного инвестиционного климата. С этой целью Правительством России разработан целый ряд новых инструментов, прежде всего это гранты, которые направляются субъектам Федерации и могут быть выданы тем из них, в которых достигнуты показатели роста инвестиций, создания новых рабочих мест, роста ВРП. Регионам, которые обеспечили прирост инвестиций, может быть обеспечен возврат

${ }^{1}$ Новая региональная политика России - обсуждение на Гайдаровском форуме // Официальный сайт Алексея Кудрина. URL: https://akudrin.ru/news/novaya-regionalnaya-politika-rossiiobsuzhdenie-na-gaydarovskom-forume. 
налога на прибыль, зачисляемой в Федеральный бюджет. С 2018 г. предусмотрен новый формат специального инвестиционного контракта, в рамках которого для крупных инвесторов, вложивших в проекты более миллиарда рублей, создаются особые условия неизменения налогового законодательства, стабильных инфраструктурных решений, а также льготного порядка налогообложения [2]. Субъектам РФ будут предоставляться дотации в целях стимулирования роста налогового потенциала по налогу на прибыль организаций.

В документах социально-экономического развития регионов особую значимость приобретает не просто разработка стратегий развития, в том числе стратегий развития цифровой экономики, а формирование того образа будущего, для достижения которого и разрабатываются соответствующие стратегии. Важность проблемы формирования образа будущего акцентируется в Национальной технологической инициативе, подчеркивающей необходимость планирования работы от будущего, так называемой «предпочтительной реальности», к настоящему. О формировании образа будущего отечественной экономики все чаще говорится и в публикациях современных авторов [6; 7; 15]. Известны работы профессора С.Д. Бодрунова, связанные с его видением будущего экономики России как «ноономики», формирующей не только качественно новую индустрию, но и вызывающей изменения во всех сферах общественной жизни, что приведет к рождению качественно новой системы хозяйственных отношений [1].

Долгосрочный проект «Образ будущего России» разрабатывается группой исследователей, которая самоорганизовалась в виде Сретенского клуба имени С. П. Курдюмова. Разрабатывается не только образ будущего России, но и целевой образ государственных корпораций, ориентиры которого на 2024 и 2035 гг. основаны на достижении показателей глобальной конкурентоспособности компаний и максимизации добавленной стоимости на единицу произведенной ими продукции или услуги.

Координация исследований в области формирования образа будущего на региональном уровне проводится экспертным институтом социальных исследований (ЭИСИ). Хотя разрабатываемый здесь доклад имеет основной целью формирование образа будущего России в целом, основой его являются результаты, полученные в ходе проведения региональных сессий «Стратегия - 2030» [10]. Фонд «Петербургская политика» в процессе подготовки этого доклада оценил работу губернаторов с позиции видения ими образа будущего своих регионов. Лидерами оказались губернаторы трех областей (Белгородской, Самарской и Ульяновской), которые набрали максимальное количество баллов - $10^{1}$.Образ будущего отмеченных регионов в стратегиях их развития в полном смысле этого слова не разрабатывался, но отдельные направления развития региона, соответствующие вышеотмеченным технологическим трендам развития цифровой экономики, рассмотрены достаточно подробно. Активное развитие рынка промышленного Интернета, изготовление и широкое применение роботов не только в промышленности, энергетике, транспорте, но и в государственном управлении декларируются в стратегии развития Белгородской области. Особое внимание здесь уделяется активному применению 3D-технологий.

Стратегически важным направлением деятельности в Ульяновской области является поддержка IT-сектора как самостоятельного направления работы. Значительное внимание уделяется его интеграции с региональными отраслями экономики. Для расширения международного сотрудничества в Ульяновской области введена должность IT-посла. Приоритетно стимулирование структурных перемен на действующих заводах Ульяновской области с целью их постепенного включения в процессы локализации передовых технологий, связанных, в том числе с формированием цифровой экономики.

${ }^{1}$ Рейтинг Фонда «Петербургская политика» за июль 2017 г. URL: https://fpp.spb.ru/fpp-rating-2017-07. 
В Самарской области особое внимание уделяется сотрудничеству Центра для одаренных детей с ведущими вузами региона и Самарским научным центром РАН. Coздается система отбора и комплексного сопровождения талантливой молодежи, работающей в области технологических решений, соответствующих трендам развития цифровой экономики. Такой подход представляется вполне оправданным, ибо «цифровые» кадры - это стратегический актив цифровой экономики.

В других регионах Российской Федерации, которые не попали в число лидеров по оценке Фонда «Петербургская политика» и в которых прямо не заявлено о видении региональными властями образа будущего своих регионов, процессы, связанные с отдельными направлениями формирования цифровой экономики, тем не менее развиваются достаточно активно.

\section{«0браз будущего» промышленного комплекса Свердловской области}

Свердловская область, также не оказавшаяся в числе лидеров по формированию образа будущего региона, тем не менее в полной мере учитывает технологические вызовы, которые могут принципиально изменить будущее экономики Среднего Урала. В научноисследовательских и образовательных институтах, на промышленных предприятиях региона проводятся серьезные исследования и выполняются работы в сфере НИОКР по отдельным важнейшим направлениям, соответствующим технологическим трендам развития цифровой экономики.

При губернаторе Свердловской области создана рабочая группа по развитию цифровой экономики, основной задачей которой является внедрение современных технологий в соответствии с федеральной программой «Цифровая экономика Российской Федерации». Кроме того, в проекте «Концепция промышленного и инновационного развития Свердловской области на период до 2035 года», разработанном Министерством промышленности и науки Свердловской области совместно с Институтом экономики Уральского отделения РАН, заявлена цель - формирование нового образа промышленности Свердловской области за счет структурных и технологических трансформаций, продуктовых изменений, непрерывных инноваций, направленных на повышение конкурентоспособности промышленных предприятий и укрепление их рыночных позиций на мировом и внутреннем рынке.

Выявление возможностей формирования нового образа промышленности Свердловской области связано, в первую очередь, с оценкой имеющегося потенциала развития цифровой экономики. С этой целью выделены сложившиеся тренды развития ИКТ в промышленном комплексе Среднего Урала. Анализ статистических показателей области в сравнении с показателями других регионов России на базе данных статистического сборника «Информационное общество: тенденции развития в субъектах Российской Федерации» выявил высокий уровень дифференциации региональных показателей, характеризующих развитие ИКТ ${ }^{1}$. Разница этих показателей колеблется от 1,5 до более чем 300 раз. Информационное неравенство регионов России создает серьезные преграды развитию цифровой экономики [14]. Такое неравенство наблюдается не только между субъектами РФ, но и между муниципальными образованиями в рамках практически каждого субъекта [5]. В то же время показательным является тот факт, что использование ИКТ органами власти в субъектах РФ превышает аналогичные показатели по ряду направлений, как федеральных органов власти, так и органов местного самоуправления (рис. 2).

Проведенные нами более детальные исследования, с точки зрения информационной обеспеченности субъектов РФ, прежде всего Свердловской области, показали, что

${ }^{1}$ Информационное общество: тенденции развития в субъектах Российской Федерации. Вып. 2: стат. сб. М.: НИУ ВШЭ, 2015. 
показатели Среднего Урала превышают средние показатели развития ИКТ по России в целом (рис. 3).

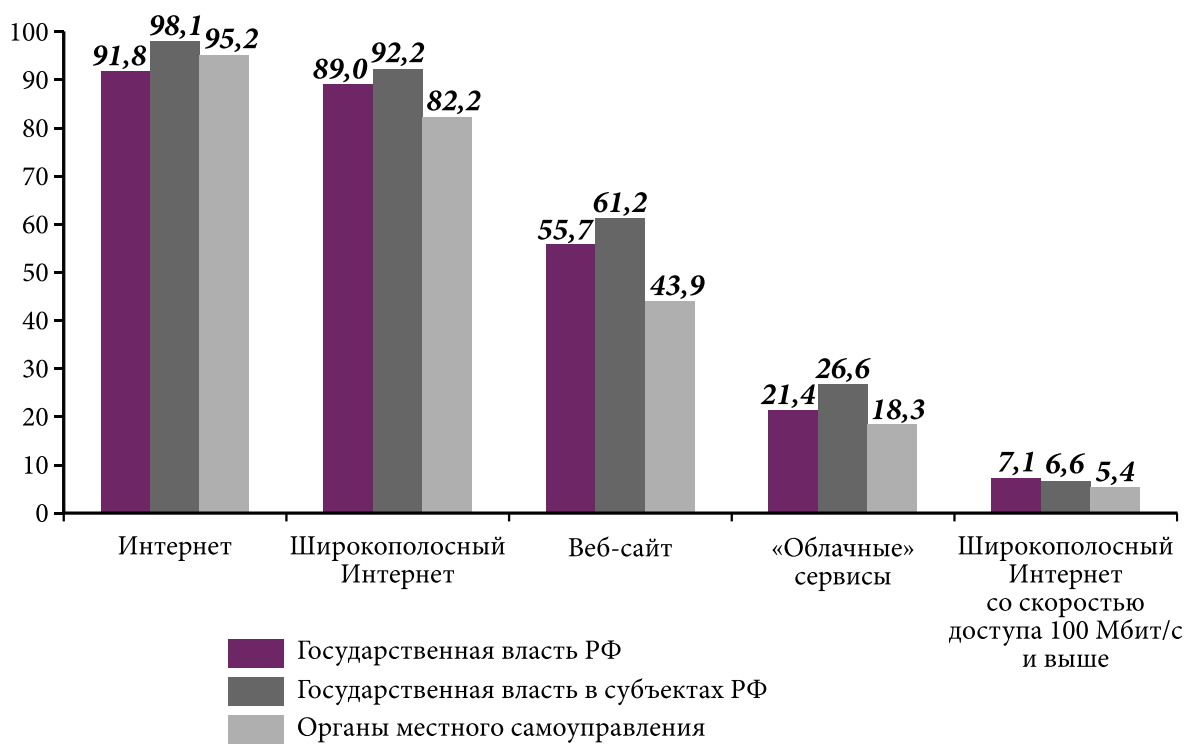

Рис. 2. Использование информационно-коммуникационных технологий органами власти в 2016 г., \% от общего числа органов государственной власти и местного самоуправления

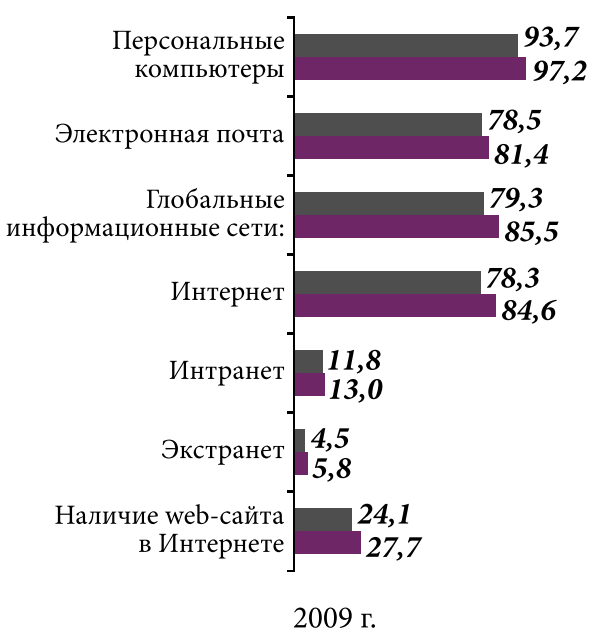

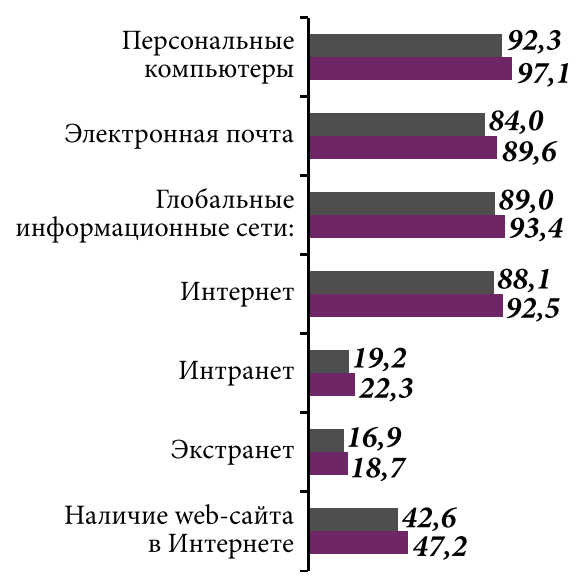

2015 г.

Россия

Свердловская область

Рис. 3. Удельный вес организаций, использующих информационно-коммуникационные технологии, \% от общего числа обследованных организаций

Информационно-коммуникационная деятельность в Свердловской области в 2009-2015 гг. развивалась достаточно активно. За этот период произошел рост оснащенности организаций по всем видам программных средств (см. таблицу).

О росте инновационного потенциала региона говорит тот факт, что за анализируемый период в 1,4 раза увеличилось число организаций, использующих специальные 
программные средства для научных исследований. Наиболее значительный рост (в 2,4 раза) отмечается в применении сложных комплексных систем, управляющих различными процессами экономической деятельности (CRM-, ERP-, SCM-системы). Если в 2009 г. такие технологии применяли только 8,5\% предприятий от числа имевших специальные программные средства, то в 2015 г. их доля выросла до 20,2\%.

\section{Программные средства, использованные на предприятиях России \\ и Свердловской области, \% от числа предприятий, имеющих специальные программные средства}

\begin{tabular}{|l|c|c|c|c|}
\hline \multicolumn{1}{|c|}{ Программные средства } & \multicolumn{2}{|c|}{2009} & \multicolumn{2}{|c|}{2015} \\
\cline { 2 - 5 } & Россия & $\begin{array}{c}\text { Свердловская } \\
\text { область }\end{array}$ & Россия & $\begin{array}{c}\text { Свердловская } \\
\text { область }\end{array}$ \\
\hline $\begin{array}{l}\text { Для управления автоматизированным } \\
\text { производством и/или отдельными тех- } \\
\text { ническими средствами и технологиче- } \\
\text { скими процессами }\end{array}$ & 15,2 & 20,5 & 15,1 & 20,7 \\
\hline $\begin{array}{l}\text { Для решения организационных, управ- } \\
\text { пенческих и экономических задач }\end{array}$ & 60,6 & 66,5 & 52,3 & 65,6 \\
\hline $\begin{array}{l}\text { Для управления закупками товаров } \\
\text { (работ, услуг) }\end{array}$ & - & - & 38,4 & 47,0 \\
\hline $\begin{array}{l}\text { Для управления продажами товаров } \\
\text { (работ, услуг) }\end{array}$ & - & - & 21,9 & 29,2 \\
\hline $\begin{array}{l}\text { Для осуществления финансовых рас- } \\
\text { четов в электронном виде }\end{array}$ & 60,3 & 68,1 & 55,1 & 66,8 \\
\hline $\begin{array}{l}\text { Для предоставления доступа к базам } \\
\text { данных через глобальные информаци- } \\
\text { онные сети, включая Интернет }\end{array}$ & 23,7 & 27,8 & 31,5 & 38,2 \\
\hline $\begin{array}{l}\text { Электронные справочно-правовые } \\
\text { системы }\end{array}$ & 56,2 & 68,8 & 52,3 & 65,1 \\
\hline СRМ-, ЕRР-, ЛСМ-системы & 6,4 & 8,5 & 15,4 & 20,2 \\
\hline Для научных исследований & 3,0 & 4,0 & 3,9 & 5,7 \\
\hline Для проектирования & 11,0 & 14,9 & 11,0 & 14,1 \\
\hline Редакционно-издательские системы & 5,4 & 6,2 & 5,3 & 6,0 \\
\hline Обучающие программы & 17,3 & 19,4 & 14,3 & 18,0 \\
\hline
\end{tabular}

За 2009-2015 гг. существенный рост наблюдался на Среднем Урале по всем видам использования Интернета в коммерческих целях. Число организаций, использующих Интернет для связи с поставщиками, в 2015 г. достигло 95,1\% от общего числа организаций, использовавших Интернет для этих целей. Это более чем на $20 \%$ превышает число организаций, использующих его для связи с потребителями. Необходимо отметить, что такой важный показатель использования Интернета в коммерческой деятельности, как послепродажное обслуживание (сервис), составляет всего 7,7\% от числа организаций, использующих Интернет в коммерческих целях. В то же время его рост с 2009 по 2015 г. в 1,5 раза позволяет говорить о развитии благоприятной тенденции увеличения этого значимого показателя, который в экономике развитых стран играет важную роль.

Как видно из рис. 3, Свердловская область в 2009 г. и в 2015 г. имела более высокие показатели, в сравнении с РФ, по использованию ИКТ в организациях. Однако темпы роста отдельных направлений использования ИКТ в Свердловской области не всегда превышали аналогичные показатели по России. Так, темпы роста Интернета по России за 2009-2015 гг. составили 112,5\%, по Свердловской области - лишь 109,3\%. Аналогичная ситуация наблюдалась в таком сегменте информационных сетей, как экстранет 
(инструмент, позволяющий компании осуществлять связь с внешними пользователями без допуска их к внутрикорпоративной информации). Его рост по России в целом за вышеуказанный период составил 375,5\%, по Свердловской области - 322,4\%. При этом темпы роста интранета (использование Интернета в корпоративных целях) в Свердловской области превышали аналогичный показатель по России - соответственно 171,5 и $162,7 \%$.

О степени готовности экономики Среднего Урала к цифровой экономике отчасти свидетельствуют вышеприведенные данные о развитии ИКТ. Косвенные подтверждения этому приведены в работе [12]. Исследования авторов данной работы показали, что отрасли, являющиеся отраслями специализации региона (металлургия, электрооборудование, химическое производство, машины и оборудование), имеют рейтинг готовности к цифровой экономике выше среднего. Такой взгляд авторов представляется излишне оптимистичным. Прямо противоположная оценка готовности к цифровизации отраслей экономики России дана в работе [4], в которой приведены итоги по выявлению разницы цифровизации отраслей экономики РФ в сравнении с цифровизацией ведущих стран ЕС. Показано, что наименьшее отставание в этой области характерно для отечественных секторов информационно-коммуникационных технологий и образований (отставание менее 30\%). Однако в таких профильных для Урала видах экономической деятельности, как добыча полезных ископаемых, нефтегазовая отрасль и обрабатывающая промышленность, отмечается наибольшее отставание - более $50 \%$.

«Стратегия промышленного и инновационного развития Свердловской области на период до 2035 года», проект Концепции которой разработан Министерством промышленности и науки Свердловской области совместно с Институтом экономики УрО РАН, может стать действенным документом стратегического характера только при условии, если она будет сформирована с учетом новых технологических трендов, определяющих будущий образ промышленности мировой экономики. Важнейшим из новых трендов является рост рынков, основанных на сетевых решениях, что кардинально меняет цепочки создания добавленной стоимости. Не менее актуален тренд, связанный с формированием сетевого подхода в организации научных исследований. Это позволяет более успешно развиваться кооперационным взаимодействиям научных и научно-технологических организаций, а также бизнес-структур в рамках крупных мультидисциплинарных центров. Возрастает роль компаний, успешно комбинирующих наилучшие доступные технологии и разнообразные форматы спроса. Все более актуальным становится учет трендов, которые определяют кардинальные изменения профиля компетенций, востребованных на рынке труда, формирование новых портфелей и компетенций, которые определяются ожидаемым спросом компаний. Особое значение выявленных трендов связано с усложнением мотивационных, этических и психологических проблем. Эти проблемы обусловлены отчасти отсутствием должных исследований по оценке последствий реализации принципиально новых технологических решений в области цифровизации экономики, отчасти неготовностью общества воспринимать кардинальные нововведения.

В программе «Цифровая экономика Российской Федерации» указано, что основные принципы цифровой экономики реализуются в сферах «здравоохранение», «государственное управление» и «Умный город». Но при таких приоритетах данная программа, как на федеральном уровне, так и на уровне индустриально развитых регионов, где около $30 \%$ и более составляет промышленность в структуре экономики, не сможет оказать решающего влияния на модернизацию реального сектора экономики. Для Свердловской области принципиально важным можно считать развитие цифровой экономики именно в ее промышленном секторе - концентрование на таких направлениях, как улучшение позиционирования промышленных компаний на рынке, а также повышение эффективности функционирования традиционных производств. 
Однако для этого необходим переход традиционных секторов уральской промышленности на платформенную организацию, а также развитие в традиционных секторах новых бизнес-моделей. На базе данных моделей возможно создание ценностей не только посредством продажи самого изделия, но и продажи обработанных данных, производимых изделием. Принципиальной особенностью новых бизнес-моделей уральской промышленности должна стать их преимущественная сервис-ориентация.

Создание новых секторов в уральской промышленности связывается с экспериментальными проектами Национальной технологической инициативы. В проекте вышеотмеченной Стратегии установлены точки технологического роста металлургического, машиностроительного, химического, лесопромышленного комплекса, которые рассмотрены в соответствии с прогнозируемыми Национальной технологической инициативой рынками высокотехнологичной продукции. Так, точки технологического роста машиностроительного комплекса Свердловской области предусматривают развитие аддитивных технологий, фотоники, сенсорных систем и интеллектуальных систем управления, участие в формировании космических систем и технологий, в развитии ядерной медицины и т. д. В металлургическом комплексе региона такими точками роста являются производство порошков для аддитивных технологий, выплавка специальных сталей и сплавов, развитие технологии глубокой переработки титана и изготовление изделий на основе титановых сплавов.

В проведенных нами ранее исследованиях показано, что Средний Урал обладает высоким научно-технологическим, интеллектуальным, институциональным и ресурсным потенциалами; здесь есть реальная возможность учета мировых трендов технологического развития и адаптации промышленности региона к возникающим рискам. Это позволяет сформировать возможный образ будущего промышленного комплекса Свердловской области. Такой комплекс может быть представлен как сетевое сообщество структурно сбалансированных, конкурентоспособных производств, соответствующих критериям технологической перспективности, в том числе на новых рынках, предусмотренных Национальной технологической инициативой и Программой развития цифровой экономики РФ; социально-экономической эффективности и экологической привлекательности. Продукция таких производств, реализующих принципы цифровой экономики, будет обладать высокой добавленной стоимостью и удовлетворять индивидуализированные потребности высокотехнологичного сектора экономики в наукоемких товарах и услугах, а также возрастающие качественные потребности традиционных отраслей экономики, что позволит увеличить вклад промышленности в формирование валового регионального продукта [13].

Процесс перепозиционирования промышленного комплекса региона является достаточно сложным, имеет кросс-отраслевой характер. Для управления этим процессом необходимо сформировать специальное научно-технологическое агентство, которое отвечало бы за процесс создания новых и модернизацию традиционных секторов уральской промышленности, за реализацию на Среднем Урале экспериментальных проектов, связанных с развитием цифровой экономики. Кроме того, основным организационным механизмом, содействующим перепозиционированию промышленного комплекса региона в направлении развития цифровой экономики, могут стать широко распространенные в мировой практике инвестиционные технологические партнерства в форме консорциумов.

\section{Заключение}

Формирование цифровой экономики неизбежно приведет к созданию нового мира с другой системой ценностей, с новыми управленческими парадигмами и новыми социальными нормами. Развитие цифровой экономики может сопровождаться существенным возрастанием рисков увеличения социального неравенства, нарушения 
неприкосновенности частной жизни, непредсказуемыми последствиями применения биологической инженерии и т. д. С другой стороны, отдельные технологии цифровой экономики, такие как, например, блокчейн, не только позволяют получить значительный экономический выигрыш, но и могут с новых позиций в результате распределения ответственности между отдельными членами общества сформировать основу для взаимного доверия.

Многочисленные вызовы и проблемы развития цифровой экономики, как и четвертой промышленной революции в целом, предопределяют необходимость формирования новой цивилизационной парадигмы, которая обрисовала бы притягательный образ будущего и основные этапы его построения, а также была бы способна объединить человечество. Среди направлений ее формирования можно отметить два наиболее значимых, получающих все более широкое общественное признание: идеология импакт-инвестирования (Impact Investing), так называемое преобразующее инвестирование, а также инклюзивное развитие, позволяющее вовлекать менее развитые страны, различные социальные слои отдельных стран в формирование общего будущего. Совмещение бесспорных экономических выгод цифровой экономики с приоритетной значимостью факторов, влияющих непосредственно на человека, позволит снизить возможные риски новой технологической революции.

\section{Источники}

1. Бодрунов С. Д. Ноономика. М.: Культурная революция, 2018.

2. Важнейшая задача - создание условий для развития экономик российских регионов (интервью министра финансов Российской Федерации А. Г. Силуанова) // Финансы. 2018. № 2. С. 3-6.

3. Введение в «Цифровую» экономику / А. В. Кешелава, В. Г. Буданов, В. Ю. Румянцев и др.; под общ. ред. А. В. Кешелава. М.: ВНИИГеосистем, 2017.

4. Грамматчиков А. Цифровая реальность // Эксперт. 2017. № 29 (1038).

5. Дронов В., Махрова О. Цифровое неравенство районных образований Рязанской области // Экономика и управление. 2017. № 8 (142). С. 9-14.

6. Ермак С. Понять грядущее // Эксперт Урал. 2017. № 36. С. 9-12.

7. Иванов В.В. Проблемы научно-технологического развития России в контексте промышленной революции // Инновации. 2016. № 6 (212). С. 3-8.

8. Коровин Г.Б. Цифровизация промышленности в контексте новой индустриализации РФ // Общество и экономика. 2018. № 1. С. 47-66.

9. Макаров В.Л. Глобальное цифровое общество и трансформация ценностей // Глобальный мир: системные сдвиги, вызовы и контуры будущего: XVII Международные Лихачевские научные чтения (18-20 мая 2017 г.). СПб.: Изд-во СПбГУП, 2017. C. $121-123$.

10. Нагорных И. Борис Грызлов поработает над образом будущего // Коммерсантъ. 2017. № 145. С. 3.

11. Новая технологическая революция: вызовы и возможности для России. Экспертно-аналитический доклад / Г. И. Идрисов, А. С. Кузьмина, Е. С. Рожкова, Д. К. Султанов; под науч. рук. В.Н. Княгинина. М.: Центр стратегических разработок, 2017.

12. Попов Е.В., Семячков К.А. Оценка готовности отраслей РФ к формированию цифровой экономики // Инновации. 2017. № 4(222). С. 37-41.

13. Романова О.А., Сиротин Д.В. Образ желаемого будущего экономики индустриального региона: тенденции развития и методология оценки // Экономика региона. 2017. Т. 13, вып. 3. С. 746-763.

14. Соловьева Ю.Н., Фейгин Г.Ф. Тенденции развития ИКТ в России: феномен развития информационного неравенства в регионах // Вестник Института экономики PAH. 2017. № 5. C. 79-94. 
15. Структурно-инвестиционная политика в целях устойчивого роста и модернизации экономики // Экономист. 2017. № 3. С. 3-23.

16. Харитонов Н.В. О состоянии и основных направлениях совершенствования законодательства в сфере государственной региональной политики // Промышленная политика в Российской Федерации. 2017. № 7-9. С. 3-9.

17. Цифровая Россия: новая реальность / А. Аптекман, В. Калабин, В. Клинцов и др. McKinsey \& Company, 2017.

18. Цифровая экономика: кр. стат. сб. / Г.И. Абдрахманова, Л. М. Гохберг, А. В. Демьяненко и др. М.: НИУ ВШЭ, 2018.

19. Lee J., Kao H.-A., Yang S. Service Innovation and Smart Analytics for Industry 4.0 and Big Data Environment // Procedia CIRP. 2014. Vol. 16. Pp. 3-8.

20. Man and Machine in Industry 4.0. How Will Technology Transform the Industrial Workforce Through 2025? / M. Lorenz, M. Ruessmann, R. Strack, K. Lueth, M. Bolle. Boston Consulting Group, 2015.

\title{
Russian Regions' Socioeconomic Development Strategies in the Context of Challenges Posed by the Digital Economy
}

\author{
by Olga A. Romanova
}

The research aims to prove that the development of the digital economy in Russia sets out new requirements to drawing up regional documents of strategic development. The paper examines basic concepts characterising the phenomenon of the digital economy, its main development trends, the nature of its impact on economic environment, what allows proposing author's own treatment of the digital economy. The paper systematises new technological trends shaping the future image of the industry in the global economy. The author justifies the necessity to build "the image of the future" of regions in the strategic documents of socioeconomic development prepared by the subjects of the Russian Federation. The researcher detects trends in the development of information and communication technologies in the industry of Sverdlovsk oblast and assesses its information sufficiency in contrast to the data on Russia generally. The paper formulates main features of "the image of the future" of industrial complex in the Middle Urals. The author points to that the complexity of its repositioning requires creating specialised investment and technological partnerships in the form of consortia to manage the process.

Keywords: digital economy; socioeconomic development strategy; region; information and communication technology.

References:

1. Bodrunov S. D. Noonomika [Noomics]. Moscow: Kul'turnaya revolyutsiya Publ., 2018.

2. Vazhneyshaya zadacha - sozdanie usloviy dlya razvitiya ekonomik rossiyskikh regionov (interv'yu ministra finansov Rossiyskoy Federatsii A.G. Siluanova) [The most important task is the creation of conditions for the development of the Russian regions' economies (interview with A.G. Siluanov, the Minister of Finance of the Russian Federation,)]. Finansy - Finance, 2018, no. 2, pp. 3-6.

3. Keshelava A.V. (ed.), Budanov V.G., Rumyantsev V.Yu. et al. Vvedenie v "Tsifrovuyu" ekonomiku [Introduction to the "Digital" Economy]. Moscow: VNIIGeosistem Publ., 2017.

4. Grammatchikov A. Tsifrovaya real'nost' [The digital reality]. Ekspert - Expert, 2017, no. 29(1038).

5. Dronov V., Makhrova O. Tsifrovoe neravenstvo rayonnykh obrazovaniy Ryazanskoy oblasti [Digital inequality of districts in Ryazan oblast]. Ekonomika i upravlenie - Economics and Management, 2017, no. 8(142), pp. 9-14.

6. Yermak S. Ponyat' gryadushchee [To understand the future]. Ekspert Ural - Expert the Urals, 2017, no. 36, pp. 9-12.

7. Ivanov V. V. Problemy nauchno-tekhnologicheskogo razvitiya Rossii v kontekste promyshlennoy revolyutsii [Problems of scientific and technological development of Russia in the context of the industrial revolution]. Innovatsii - Innovations, 2016, no. 6(212), pp. 3-8. 
8. Korovin G. B. Tsifrovizatsiya promyshlennosti v kontekste novoy industrializatsii RF [Digitalisation of industry in the context of the new industrialisation of the Russian Federation]. Obshchestvo i ekonomika - Society and Economics, 2018, no. 1, pp. 47-66.

9. Makarov V.L. Global'noe tsifrovoe obshchestvo i transformatsiya tsennostey [Global digital society and the transformation of values]. Materialy XVII Mezhdunarodnykh Likhachevskikh nauchnykh chteniy "Global'nyy mir: sistemnye sdvigi, vyzovy i kontury budushchego" [Proc. 17 $7^{\text {th }}$ Int. Likhachev Scientific Readings "The Global World: System Shifts, Challenges and Contours of the Future"]. Saint Petersburg: Saint Petersburg University of the Humanities and Social Sciences, 2017, pp. 121-123.

10. Nagornykh I. Boris Gryzlov porabotaet nad obrazom budushchego [Boris Gryzlov will work on the image of the future]. Kommersant - Entrepreneur, 2017, no. 145, pp. 3.

11. Knyaginin V.N. (ed.), Idrisov G. I., Kuzmina A.S., Rozhkova Ye.S., Sultanov D. K. Novaya tekhnologicheskaya revolyutsiya: vyzovy $i$ vozmozhnosti dlya Rossii. Ekspertno-analiticheskiy doklad [The new technological revolution: challenges and opportunities for Russia. Expert-analytical report]. Moscow: Center for Strategic Developments, 2017.

12. Popov E. V., Semyachkov K. A. Otsenka gotovnosti otrasley RF k formirovaniyu tsifrovoy ekonomiki [Assessment of the readiness of Russian industries to form a digital economy]. Innovatsii - Innovations, 2017, no. 4(222), pp. 37-41.

13. Romanova O. A., Sirotin D. V. Obraz zhelaemogo budushchego ekonomiki industrial'nogo regiona: tendentsii razvitiya i metodologiya otsenki [The image of the desired future of an industrial region's economy: Development trends and evaluation methodology]. Ekonomika regiona - Economy of Region, 2017, vol. 13, issue 3, pp. 746-763.

14. Solovyeva Yu. N., Feygin G. F. Tendentsii razvitiya IKT v Rossii: fenomen razvitiya informatsionnogo neravenstva $\mathrm{v}$ regionakh [Trends in the development of ICT in Russia: The phenomenon of the information inequality in the regions]. Vestnik IE RAN - Bulleting of the Institute of Economics of RAS, 2017, no. 5, pp. 79-94.

15. Strukturno-investitsionnaya politika $\mathrm{v}$ tselyakh ustoychivogo rosta i modernizatsii ekonomiki [Structural and investment policy to ensure sustainable growth and modernisation of the economy]. Ekonomist - Economist, 2017, no. 3, pp. 3-23.

16. Kharitonov N. V. O sostoyanii i osnovnykh napravleniyakh sovershenstvovaniya zakonodatel'stva $\mathrm{v}$ sfere gosudarstvennoy regional'noy politiki [On a condition and the basic directions of the legislation perfection in sphere of the state regional policy]. Promyshlennaya politika $v$ Rossiyskoy Federatsii - Industrial Policy in the Russian Federation, 2017, no. 7-9, pp. 3-9.

17. Aptekman A., Kalabin V., Klintsov V. et al. Tsifrovaya Rossiya: novaya real'nost' [The digital Russia: New reality]. McKinsey \& Company, 2017.

18. Abdrakhmanova G.I., Gokhberg L.M., Demyanenko A.V. Tsifrovaya ekonomika [The digital economy. A brief statistical collection]. Moscow: SU HSE, 2018.

19. Lee J., Kao H.-A., Yang S. Service Innovation and Smart Analytics for Industry 4.0 and Big Data Environment. Procedia CIRP, 2014, vol. 16, pp. 3-8.

20. Lorenz M., Ruessmann M., Strack R., Lueth K., Bolle M. Man and Machine in Industry 4.0. How Will Technology Transform the Industrial Workforce Through 2025? Boston Consulting Group, 2015.

Contact Info:

Olga A. Romanova, Dr. Sc. (Econ.), Prof.,

Chief Researcher

Phone: (343) 371-45-36

Institute of Economics (Ural branch of RAS)

29 Moskovskaya St., Yekaterinburg, Russia, 620014

e-mail: econ@uran.ru

Ссылка для иитирования: Романова О.А. Стратегии социально-экономического развития регионов РФ в контексте вызовов цифровой экономики // Известия Уральского государственного экономического университета. 2018. Т. 19, № 3. С. 55-68. DOI: 10.29141/2073-1019-2018-19-3-6

For citation: Romanova O. A. Strategii sotstialno-ekonomicheskogo razvitiya regionov RF v kontekste vyzovov tsifrovoy ekonomiki [Russian regions' socioeconomic development strategies in the context of challenges posed by the digital economy]. Izvestiya Uralskogo gosudarstvennogo ekonomicheskogo universiteta - Journal of the Ural State University of Economics, 2018, vol. 19, no. 3, pp. 55-68. DOI: 10.29141/2073-1019-2018-19-3-6 


\section{ВЛАСОВА Наталья Юрьевна}

Доктор экономических наук, профессор кафедры государственного

и муниципального управления

Уральский государственный экономический университет 620144, РФ, г. Екатеринбург, ул. 8 Марта/Народной Воли, 62/45 Контактный телефон: (343) 221-27-36 e-mail: nat-vlasova@yandex.ru

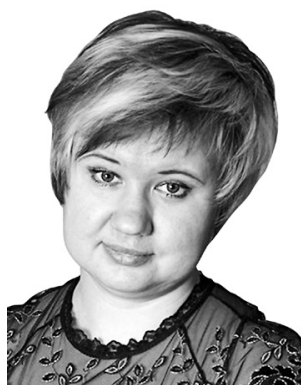

\section{кУЛИКОВА Елена Сергеевна}

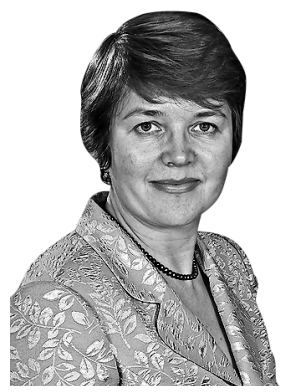

Кандидат экономических наук, доцент кафедры государственного и муниципального управления

Уральский государственный экономический университет 620144, РФ, г. Екатеринбург, ул. 8 Марта/Народной Воли, 62/45 Контактный телефон: (343) 221-27-36

e-mail: e.s.kulikova@mail.ru

\section{Маркетинг территории в условиях становления цифровой экономики}

Исследование направлено на систематизацию понятийного аппарата в сфере цифрового маркетинга и виртуального потенциала территории. Предлагается авторская трактовка понятия «цифровой маркетинг территории». На основе теорий цифровой экономики выявляются особенности и принципиальные изменения, которые происходят в сфере маркетинга и брендинга территории в эпоху цифровизации. Рассмотрена возможность использования цифровых каналов взаимодействия в маркетинге территорий, выявлены их достоинства. Вводится понятие и предлагается структура виртуального потенциала территории, формулируется методический подход к его анализу. Проводится сравнительный анализ официальных порталов крупнейших городов РФ с использованием ряда е-метрик, исследуется представленность крупнейших городов РФ в социальных сетях. Делается вывод о необходимости формирования целостной концепции цифровой идентичности крупнейших городов РФ.

JEL classification: M31, R10

Ключевые слова: цифровая экономика; цифровой маркетинг территории; Web 2.0; виртуальный потенциал территории; портал города; крупнейший город.

\section{Введение}

$B$ Европейском союзе в 2010 г. была провозглашена Цифровая повестка Европы (Digital Agenda for Europe) и ежегодно рассчитывается индекс цифровизации экономики и общества; Министерство экономики и энергетики Германии в 2017 г. подготовило доклад «Цифровая платформа. Цифровая регуляторная политика для роста, инноваций, конкурентоспособности и участия»; Правительство РФ в 2017 г. утвердило программу «Цифровая экономика Российскй Федерации». Очевидно, что цифровизация экономики и развитие виртуального пространства стали неотъемлемыми чертами экономики ведущих стран, затрагивающими все сферы жизнедеятельности. Темпы роста в цифровом секторе экономики в разы превышают динамику в традиционных секторах. Эти стремительные изменения и новые вызовы необходимо учитывать в концепциях и методах регулирования и управления, в том числе в сфере территориального управления и планирования. 
Цифровые технологии все шире используются для продвижения и продажи товаров и услуг и постепенно начинают внедряться с сферу маркетинга территории. Однако отсутствуют какие-либо целостные концепции цифрового маркетинга территории, возможные каналы коммуникации используются недостаточно эффективно, само понятие цифрового маркетинга пока что достаточно расплывчато.

\section{Понятие цифрового маркетинга территории}

Маркетинг территории в самом широком смысле трактуется как технология управления, направленная на повышение конкурентоспособности и обеспечение экономического роста. При реализации маркетинговой концепции территории речь идет не только о рекламе территории, ее брендов и формировании благоприятного имиджа, но и четком понимании локальных проблем, последовательном их решении, чтобы территория стала более привлекательной для жителей, туристов и инвесторов [8].

Под цифровым маркетингом, или е-маркетингом, понимают маркетинг с использованием цифровых технологий. Цифровой маркетинг иногда трактуется как онлайнмаркетинг, виртуальный маркетинг или веб-маркетинг [17]. При цифровом маркетинге используются все цифровые каналы взаимодействия с аудиторией, включая Интернет и устройства, предоставляющие к нему доступ (компьютеры, планшеты, смартфоны и т. д.); мобильные устройства; цифровое телевидение; интерактивные экраны; различные устройства, которые могут собирать информацию и передавать ее на другие носители («умные часы», фитнес-браслеты и др.).

В настоящее время возможно использование всех обозначенных цифровых каналов. Например, широко распространен анализ абонентов сотовой связи для получения различных данных. А. А. Пономарев проводит анализ наиболее популярных маршрутов абонентов сотовой связи в г. Санкт-Петербург, что, по его мнению, можно использовать для планирования размещения рекламных носителей, торговых точек и т. п. [11].

Преимущества и недостатки интернет-маркетинга и его возможности с позиций комплекса маркетинга «4Р» рассмотрели Л. М. Капустина и И.Д. Мосунов [5].

И.В. Гужова, говоря о виртуальной конкуренции городов как мест проживания, туризма или ведения бизнеса, подчеркивает: «...новые медиа как совокупность возможности Сети (Web 2.0), мультимедийных и цифровых форматов коммуникации нивелируют географические, государственные и социальные границы, активизируя межкультурные связи» [4. С. 46].

В исследованиях подчеркивается, что Интернет существенно меняет выбор инструментов продвижения бренда и все большее распространение получает понятие цифрового брендинга как метода управления брендом с использованием цифровых технологий [6]. Отмечается, что поскольку в брэндинге территории личный опыт и «сарафанное радио» имеют большое значение, информационные технологии и социальные медиа в скором времени могут заменить традиционную рекламу территории в качестве основного инструмента [18].

Цифровой маркетинг и брендинг территории можно рассматривать как один из компонентов проекта «Умный город», в том числе для решения вопросов городского планирования и управления. Особенности стратегии цифрового брендинга мест, ориентированного на создание технологичной инновационной экосистемы бизнеса для высококвалифицированных жителей, изучались также на примере международного делового района Сонгдо в Южной Корее, г. Масдар в Абу-Даби и в Сколково в России [17].

С нашей точки зрения цифровой маркетинг территории - это деятельность, направленная на создание, продвижение локальных продуктов и услуг, а также территории в целом с использованием цифровых технологий; это формирование и продвижение виртуального потенциала территории с целью повышения конкурентоспособности ее реального потенциала. 
При реализации подобных проектов жизненно важным аспектом являются сотрудничество и координация действий многочисленных акторов, включая правительственные структуры, неправительственные организации, общественные объединения, коммерческие структуры, например специалистов по культурному наследию, исторические общества, корпорации развития территории, туристические агентства.

Выделим основные тенденции, которые трансформируют сущность маркетинга и брендинга территории в цифровой экономике.

1. Цифровой маркетинг использует большие базы данных, в силу чего способен охватить огромное количество потеницальных потребителей одновременно, но при этом продвижение становится все более адресным и нацеленным. Большие данные рассматриваются как ключевой вектор развития современного маркетинга, так как позволяют проводить гибкую сегментацию клиентов, быстрее реагировать на изменение потребностей покупателей и, исходя из этого, персонализировать потребителя [7].

Массивами данных о потребителях располагают интернет-провайдеры, сотовые операторы. Социальные сети, блоги, форумы, мобильные приложения, многочисленные ресурсы для обмена видео- и фотоматериалов, с одной стороны, генерируют информацию о потребителях территории, их возрасте, поле, уровне доходов, потребительских предпочтениях, а с другой - аккумулируют сведения о территории на основе отзывов туристов и горожан об определенных сервисах и местах. Цифровой маркетинг открывает возможности для гибкой сегментации и микросегментации, для персонализации и многофакторной кластеризации целевой аудитории. Это также дает возможность более быстрого реагирования на изменения потребностей целевой аудитории. Основываясь на недавней истории поиска возможного потребителя в Интернете, можно привязывать к нему соответствующую рекламу продуктов и услуг, делая ее более нацеленной. Реклама все больше строится на принципах высокоточного таргетинга, что позволяет повысить ее эффективность.

2. Меняются каналь коммуникации и инструменты продвижения, используемые территориями. Если раньше территории для продвижения в основном использовали буклеты, брошюры, постеры, печатную информацию, то сейчас большинство территорий активно использует Интернет. В первую очередь, это официальные порталы и сайты территорий. Официальный портал города, области или страны содержит важную информацию для различных категорий потребителей, предоставляет различные сервисы, способствует формированию единого информационного пространства, открывает новые возможности для создания, построения и управления взаимоотношениями с различными потребителями территории. Поэтому все больше территорий уделяют внимание эффективности официальных порталов: используя программы вебаналитики анализируют посещаемость, количество просмотров, число уникальных пользователей, число зарегистрированных пользователей, юзабилити. Применяются специальные показатели, например конверсия в интернет-маркетинге, рассчитываемая как процентное отношение числа посетителей сайта, выполнивших какие-либо действия на данном сайте, к общему числу посетителей.

3. Взаимодействие становится сетевым и подразумевает обратную связь и вовлеченность аудитории. Меняются традиционные роли потребителей. Наблюдается переход от линейного маркетингового подхода с односторонней коммуникацией к модели взаимного диалога - обмена мнениями, ценностями, причем такие взаимодействия все больше становятся нелинейными [9; 19]. С развитием Web 2.0 пользователи стали активно создавать собственный контент, который непосредственно влияет на формирование имиджа территории.

Информация может распространяться через многочисленные каналы, такие как Twitter, YouTube, Facebook, Instagram, Snapchat, Pinterest и множество других платформ. Интернет-сообщества и социальные сети позволяют людям легко создавать контент 
и публиковать свои мнения, ускоряя распространение информации. Пользователи превращаются в активных производителей информации, создавая огромные массивы пользовательского контента. Важным аспектом таких коммуникаций является то, что социальная сегрегация не играет никакой роли в социальной среде из-за отсутствия непосредственного взаимодействия интернет-пользователей «лицом к лицу».

Контент, создаваемый туристами, путешественниками, профессиональными блогерами и журналистами, которые публикуют, комментируют и делятся информацией в социальных сетях, является, возможно, самой большой цифровой проблемой брендинга туристской дестинации. Контент, создаваемый туристами и путешественниками, может генерировать ценность бренда, если он будет интегрирован в стратегию брендинга туристской дестинации. Тем не менее отсутствуют теоретическая осведомленность и эмпирические исследования о роли контента социальных сетей в формировании брендов дестинации.

Социальные сети широко используются для продвижения продуктов компании, и исследования подтверждают эффективность таких маркетинговых инструментов. Многие предприятия используют Twitter в качестве маркетингового инструмента. В результате одного из исследований на примере Китая было выявлено, что ретвиты в большинстве случаев увеличивают количество просмотров телевизионных шоу. Кроме того, ретвиты влиятельных пользователей более эффективны, чем твиты компании в привлечении новых потребителей, что также косвенно увеличивает количество просмотров [21].

Социальные сети можно рассматривать как один из инструментов продвижения товаров, услуг и территорий, которые классически относятся к неформальным каналам коммуникации (по типу «сарафанного радио»), однако ряд исследований доказывают, что коммуникации в социальных сетях имеют существенные отличия от традиционных коммуникаций «лицом к лицу». Отличительными характеристиками электронного общения является то, что в коммуникацию могут вступать люди, не знающие друг друга, принадлежащие к разным социальным группам, не локализованные на одной территории. Таким образом, доверие к коммуникатору в «электронном сарафанном радио» строится по несколько иным принципам [20]. К подобному же выводу приходят авторы исследования процессов формирования «культов личности» в YouTube. Сравнивая их с концепцией харизматической власти М. Вебера, они подчеркивают, что новые «культы личности» формируются посредством совместной взаимозависимости между культовой фигурой и блогерами. М. Вебер видел истоки харизматического авторитета во врожденных и исключительных качествах личности человека, тогда как в современной цифровой экономике популярность различных известных личностей становится своего рода совместным предприятием [12]. Подобный вывод можно применить и к цифровому маркетингу территории.

Современные маркетологи формируют онлайн-сообщества, чтобы выстраивать обратную связь с потребителями, в силу чего бренд организации все в большей степени является «коллективным» брендом: он видоизменяется и модифицируется под влиянием мнений и действий потребителей. Индивидуальные представления, суждения о текстах и действиях по ним в онлайн-сообществе переплетаются с организационным и общественным контекстом, формирующим легитимность бренда в обществе и за его пределами, в том числе с использованием технологий краудсорсинга. Эта практика может как поддержать представленный бренд, так и нанести ему ущерб [12].

Многие территории достаточно активно используют цифровые технологии. В ЛосАнжелесе, например, агентством по туризму был представлен рекламный фильм-слоган: «Мы пришли отовсюду. Мы приветствуем всех. Помогите Лос-Анджелесу поделиться этим посланием со всем миром», а также хэштэг \#EveryoneIsWelcome, которым призывают делиться во всех социальных сетях. Понимание важности социальных 
сетей в продвижении территории привело Совет по туризму региона Эмилия-Романья (Италия) к идее разработать специальный проект для привлечения блогеров, которым предоставляется жилье сроком на неделю в обмен на посты о территории в социальных сетях. В результате за пять лет было отмечено более 1200 сообщений в блогах и 18 миллионов пользователей ${ }^{1}$.

\section{Методические подходы к анализу виртуального потенциала территории}

Виртуальный потенциал территории - это информация о реальном потенциале, размещенная на различных ресурсах виртуального пространства. Имидж в эпоху цифровизации все в большей степени формируется на основе виртуального потенциала. В определенном смысле виртуальный потенциал - это цифровой след и цифровая тень территории. В научной литературе обсуждается понятие «цифровой след личности»совокупность информации, которую пользователь сознательно размещает о себе в Интернете. Цифровая тень - это информация, которая неявно собирается о личности в Интернет на основании всех действий, так или иначе связанных с виртуальным пространством - запросов, перемещений, покупок, видеозаписей с камер наблюдения и т. п. [2].

По аналогии с цифровым следом и цифровой тенью личности, можно говорить о цифровом следе и цифровой тени места - это совокупность, как официальной информации о территории, так и всех неявных действий множества субъектов, поисковых запросов о территории в виртуальном пространстве - на веб-сайтах, в социальных сетях, мобильных приложениях и т. п.

Исследования доказывают наличие взаимосвязи между экономической ситуацией и экономическим потенциалом и виртуальным поведением потребителей. Анализ с использованием онлайн-сервиса Wordstat Yandex для исследования динамики применения ключевых слов в Приволжском федеральном округе продемонстрировал зависимость между этапами кризиса и содержанием поисковых запросов населения [1].

Виртуальный потенциал территории складывается из туристического, инвестиционного, социально-экономического и иных потенциалов. В наибольшей степени в виртуальном пространстве представлен туристический потенциал, поскольку цифровой маркетинг активно используется в продвижении туристских дестинаций. Цифровые технологии все шире применяются для продвижения крупных туристических объектов путем создания специальных порталов, виртуальных туров и мобильных приложений, которые базируются на принципах краудсорсинга и открытых данных. Это позволяет существенно увеличить масштаб привлекаемой аудитории и вовлечь туристов в создание контента в процессе путешествия. В качестве примера можно привести итальянский проект «Пешеходный маршрут Via Regina» [3].

Перспективным является использование таких цифровых технологий, как создание виртуальных 3D-туров, QR-кодификация архитектурных памятников и других объектов и технология дополненной реальности.

Появляются исследования эффективности цифровых технологий для продвижения туристических объектов. В частности, были изучены характеристики образа Тайваня, который сформировался у туристов на основе анализа онлайн-фотографий, размещенных в социальных сетях. Сравнение образа Тайваня в социальных сетях и образа, созданного маркетологами, показывает существенные различия. Выявлено, что целостный образ, сформировавшийся у туристов, включает уникальные черты Тайваня, исторические объекты, природные ландшафты, традиционную местную культуру, обычаи и национальную кухню. Это дает возможность корректировать стратегию эффективного позиционирования и продвижения туристических дестинаций онлайн,

${ }^{1}$ Blog Ville: Eat, feel and live like a local in Europe. URL: https://www.blog-ville.com. 
поскольку продвигаемый образ должен максимально отвечать ожиданиям и запросам потребителей [13].

Виртуальный инвестиционный потенциал городов может быть представлен на официальных сайтах соответствующего субъекта РФ, официальных сайтов городов, в том числе сконцентрированный на специализированных ресурсах; на сайтах специальных организаций, ориентированных на продвижение инвестиционного потенциала (торгово-промышленных палат, корпораций развития, инвестиционных фондов и т. п.). В ряде случаев продвижение инвестиционного потенциала города может происходить и на сайте страны, если данный город входит в перечень приоритетных проектов (программ развития). Виртуальный инвестиционный потенциал в гораздо меньшей степени, чем, например, туристический потенциал, представлен в социальных сетях. Однако имеются примеры использования социальных сетей (например, YouTube) для размещения роликов, рекламирующих инвестиционный потенциал той или иной территории.

При отборе компонентов виртуального потенциала территории была принята во внимание методика ранжирования брендов стран, предложенная компанией Consulting Bloom (см. рисунок). Из четырех параметров, влияющих на силу бренда, два напрямую касаются цифровых технологий: цифровой спрос, выражаемый через количество поисковых запросов в Интернете, и представленность территории в социальных сетях ${ }^{1}$.

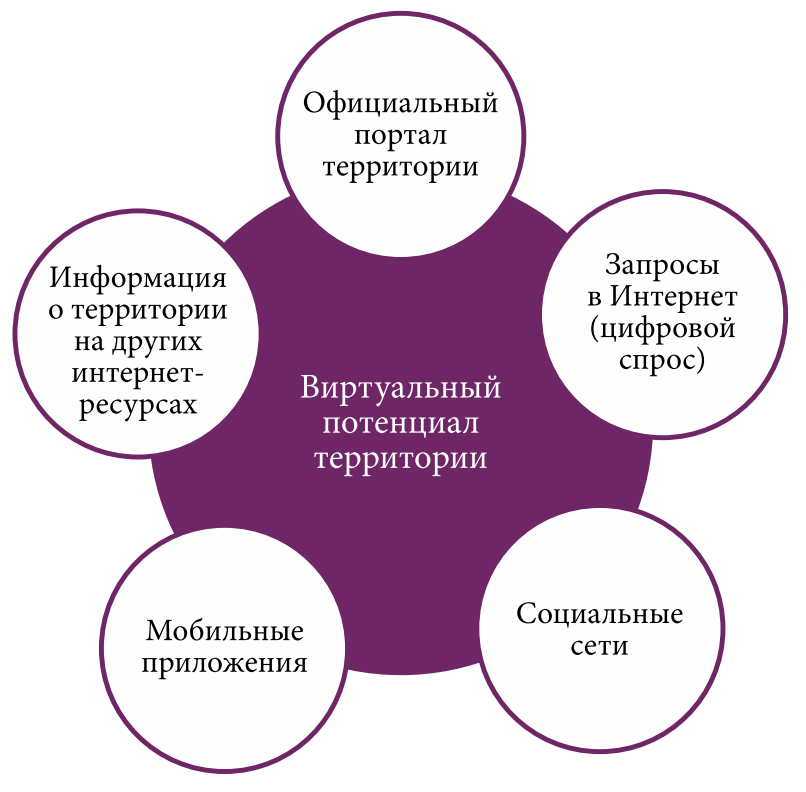

Структура виртуального потенциала территории

Количество обращений к официальным порталам территории во многом зависит от их качества и возможности получения информации и дополнительных онлайн-услуг, в том числе цифровых государственных услуг.

Цифровой спрос будет зависеть от наличия и доступности широкополосной связи и ее качества, от удельного веса населения, подключенного к Интернету, и цифровых навыков населения. Подобные показатели учитываются в уже упомянутом индексе цифровизации экономики и общества стран Европейского союза.

${ }^{1}$ Bloom Consulting Country Brand Ranking. URL: https:/www.bloom-consulting.com/en/pdf/ rankings/Bloom_Consulting_Country_Brand_Ranking_Tourism.pdf. 
Виртуальное население России, его вовлеченность в интернет-пространство представлено на интерактивных картах в проекте «Интерактивный атлас» населения России, который формируется на основании информации, собранной из анкет пользователей социальной сети «ВКонтакте», находящихся в открытом доступе ${ }^{1}$.

\section{Сравнительный анализ официальных порталов крупнейших городов РФ}

Проблема формирования виртуального имиджа актуальна для всех российских городов. Качество официального городского портала оказывает безусловное влияние на формирование виртуального имиджа города, особенно если первое впечатление от города строится на основе посещения портала. Официальный портал может быть востребован разными целевыми аудиториями. Анализ географии посещаемости порталов крупнейших российских городов свидетельствует о том, что они наиболее востребованы местным населением, поскольку современный портал обеспечивает горожан целым рядом сервисов и необходимой информацией, является виртуальной площадкой для взаимодействия с бизнесом и населением.

Сравнительная оценка посещаемости официальных порталов крупнейших городов проводилась с помощью Alexa Rank, который дает возможность увидеть мировой и российский рейтинги портала по посещаемости (табл. 1). Чем показатель ниже, тем лучше. Екатеринбург занимает первое место в глобальном и в российском рейтинге, что можно частично связать с участием города в заявочных кампаниях ЭКСПО-2020 и ЭКСПО-2025.

Таблица 1

Оценка посещаемости официальных порталов крупнейших городов РФ

\begin{tabular}{|l|c|c|c|c|}
\hline \multicolumn{1}{|c|}{ Город } & $\begin{array}{c}\text { Alexa Global } \\
\text { Rank }\end{array}$ & $\begin{array}{c}\text { Alexa Rank } \\
\text { in Russia }\end{array}$ & $\begin{array}{c}\text { Место города } \\
\text { в глобальном рейтинге }\end{array}$ & $\begin{array}{c}\text { Место города } \\
\text { в рейтинге по России }\end{array}$ \\
\hline Волгоград & 311486 & 16115 & 11 & 9 \\
\hline Екатеринбург & 51870 & 2148 & 1 & 1 \\
\hline Воронеж & 304096 & 16792 & 10 & 5 \\
\hline Казань & 189916 & 11544 & 3 & 3 \\
\hline Красноярск & 204971 & 10424 & 5 & 12 \\
\hline Нижний Новгород & 420297 & 24135 & 12 & 2 \\
\hline Новосибирск & 193881 & 11055 & 4 & 8 \\
\hline Омск & 157252 & 9318 & 2 & 7 \\
\hline Пермь & 281949 & 15865 & 9 & 10 \\
\hline Ростов-на -Дону & 278412 & 15164 & 8 & 6 \\
\hline Самара & 274827 & 16160 & 7 & 13 \\
\hline Уфа & 213984 & 12645 & 6 & 13 \\
\hline Челябинск & 438396 & 27338 & & 2 \\
\hline
\end{tabular}

Помимо Alexa Rank ряд городов размещают на порталах иные счетчики веб-аналитики, что также позволяет проанализировать различные параметры посещаемости сайтов (табл. 2).

Портал города - это важнейший ресурс и инструмент продвижения: «Портал должен стать инструментом социологических опросов, сбора идей, проведения интернетконференций, дискуссий, - всего, что содействует развитию территориального краудсорсинга» [10. С. 11].

Помимо официальных порталов администрации крупнейших городов достаточно активно создают страницы в различных социальных сетях, причем все больше

\footnotetext{
${ }^{1}$ Виртуальное население России. URL: http://webcensus.ru.
} 
понимается важность подобной деятельности. Ряд чиновников используют административные ресурсы, чтобы повысить виртуальную представленность региона в Интернете или представленность власти в социальных сетях. Так, и. о. министра культуры Красноярского края Е. Мироненко, продвигая культуру, ввела в оборот хэштэг \#культураКрасноярья и призывает к его максимальному использованию룰.

Таблица 2

Сравнительный анализ виртуальной популярности порталов крупнейших российских городов в Яндекс и Google ${ }^{2}$

\begin{tabular}{|c|c|c|c|c|c|c|c|}
\hline Город & 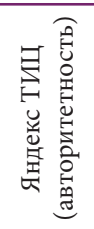 & 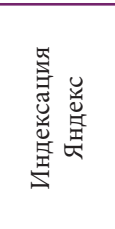 & 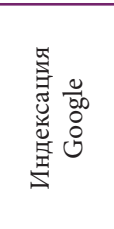 & 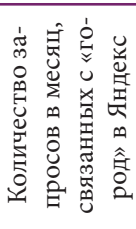 & 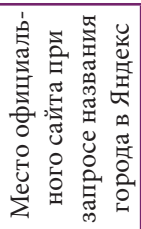 & 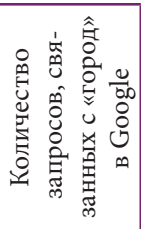 & 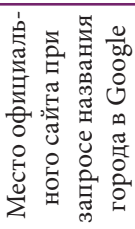 \\
\hline Волгоград & 2000 & 63282 & 20700 & 58767 & 7 & 12100 & 4 \\
\hline Екатеринбург & 850 & 136648 & 550000 & 103071 & 9 & 40500 & 2 \\
\hline Воронеж & 850 & 35977 & 20100 & 59869 & 11 & 34225 & 2 \\
\hline Казань & 2400 & 34772 & 162000 & 58296 & 10 & 22000 & 6 \\
\hline Красноярск & 1700 & 78417 & 28300 & 46020 & 8 & 22200 & 4 \\
\hline Нижний Новгород & 1100 & 105645 & 40900 & 66081 & 10 & 27100 & 2 \\
\hline Новосибирск & 1700 & 69902 & 165000 & 77708 & 6 & 21995 & 2 \\
\hline Омск & 550 & 218994 & 40000 & 46792 & 8 & 4880 & 6 \\
\hline Пермь & 1500 & 148163 & 124000 & 38316 & 7 & 12100 & 4 \\
\hline Ростов-на-Дону & 1200 & 471055 & 94000 & 64623 & 4 & 15000 & 2 \\
\hline Самара & 1300 & 256189 & 116000 & 51696 & 4 & 14488 & 3 \\
\hline Уфа & 1200 & 259879 & 258000 & 50143 & 13 & 17004 & 4 \\
\hline Челябинск & 1200 & 48653 & 28300 & 8503 & 20 & 18100 & 9 \\
\hline
\end{tabular}

Социальные сети могут стать источником данных о потребностях и мнении потенциальных потребителей. Эксперты считают, что в ближайшее время социальные сети могут частично заменить традиционные опросы покупателей.

В данном исследовании представленность крупнейших городов РФ в социальных сетях анализировалось только по тем сетям, ссылки на которые были даны на официальном портале города (табл. 3).

Таблица 3

\section{Представленность крупнейших городов РФ в социальных сетях в} (по ссылке с официального портала города)

\begin{tabular}{|l|c|c|c|c|c|c|}
\hline \multicolumn{1}{|c|}{ Город } & Facebook & YouTube & Instagram & Twitter & $\begin{array}{c}\text { Однокласс- } \\
\text { ники }\end{array}$ & Вконтакте \\
\hline Екатеринбург & 7248 & - & 308 & 5756 & 12469 & 92096 \\
\hline Казань & 2140 & - & 29,4 тыс. & 1124 & - & 75798 \\
\hline Красноярск & - & - & - & - & - & 13191 \\
\hline $\begin{array}{l}\text { Красноярск (Зимняя } \\
\text { универсиада 2019 г.) }\end{array}$ & 7518 & 410 & 15,3 тыс. & 1481 & 19179 & 122303 \\
\hline
\end{tabular}

${ }^{1}$ Новый министр намерена «раскручивать» культуру Красноярья при помощи хэштегов и «себяшечек» // Информационное агентство «FlashSiberia». URL: http:/flashsiberia.com/news/ novyy-ministr-namerena-raskruchivat-kulturu-krasnoyarya-pri-pomoshchi-heshtegov-i-sebyashechek.

${ }^{2}$ Авторы выражают благодарность А. Д. Назарову за помощь в составлении данной таблицы. 
Окончание табл. 3

\begin{tabular}{|l|c|c|c|c|c|c|}
\hline \multicolumn{1}{|c|}{ Город } & Facebook & YouTube & Instagram & Twitter & $\begin{array}{c}\text { Однокласс- } \\
\text { ники }\end{array}$ & Вконтакте \\
\hline Новосибирск (мэр) & 1529 & & 6313 & 5756 & 13303 & 58137 \\
\hline Омск & - & - & - & - & - & \\
\hline Пермь & - & - & - & - & - & 2246 \\
\hline $\begin{array}{l}\text { Ростов-на-Дону } \\
\text { (туристический портал) }\end{array}$ & 1409 & - & 4506 & 35 & - & - \\
\hline Самара & 117 & 94 & - & 12,3 тыс. & 36 & 1179 \\
\hline Уфа & 1816 & 410 & 8736 & 2589 & 10180 & - \\
\hline Челябинск & 198 & - & 899 & - & 37 & 552 \\
\hline
\end{tabular}

Составлено по данным официальных сайтов администраций городов на 15 февраля 2018 г.

Наиболее популярными социальными сетями являются «ВКонтакте» и Facebook. Подавляющее большинство крупнейших городов имеет там свои странички и количество подписчиков, как правило, превышает несколько тысяч человек.

На официальных порталах городов Волгоград, Воронеж, Нижний Новгород, Ростов-на-Дону отсутствуют какие-либо ссылки на представленность города в социальных сетях. Однако во многих случаях такие странички существуют. Они могут создаваться как органами местного самоуправления, так и общественными организациями, туристическими фирмами и отдельными людьми. Так, страница г. Нижний Новгород в «ВКонтакте» имеет 231729 подписчиков, г. Воронеж - 2243.

Важным параметром портала с точки зрения доступности для зарубежной аудитории является его представленность на иностранном языке (табл. 4). Практически все официальные порталы крупнейших городов представлены на английском языке. Порталы городов Уфа и Казань представлены также на национальных языках республик башкирском и татарском соответственно.

Таблица 4

Иностранные языки, на которых представлены официальные порталы крупнейших городов РФ

\begin{tabular}{|c|c|c|c|c|c|}
\hline \multirow{2}{*}{ Город } & \multicolumn{5}{|c|}{ Язык } \\
\hline & английский & немецкий & французский & испанский & китайский \\
\hline Волгоград & - & - & - & - & - \\
\hline Екатеринбург & + & - & - & - & - \\
\hline Воронеж & & - & - & - & - \\
\hline Казань & + & - & - & - & - \\
\hline Красноярск & + & - & - & - & - \\
\hline Нижний Новгород & + & + & + & + & \\
\hline Новосибирск & + & + & - & - & + \\
\hline \multicolumn{6}{|l|}{ Омск } \\
\hline Пермь & + & - & - & - & - \\
\hline Ростов-на-Дону & $\begin{array}{c}+ \\
\text { (Туристический } \\
\text { портал) } \\
\end{array}$ & - & - & - & - \\
\hline Самара & + & - & - & - & - \\
\hline Уфа & & - & - & - & - \\
\hline Челябинск & + & + & - & - & - \\
\hline
\end{tabular}

В ряде случаев возможен перевод на другие иностранные языки только на определенной части портала или на отдельных сайтах, что не видно на основной странице. Так, в г. Казань страницы Чемпионата мира по футболу - 2018 доступны на английском, 
немецком, французском и испанском языках), а в г. Волгоград эта страница переведена на 21 иностранный язык.

Анализ показывает, что во всех крупнейших городах разрабатываются мобильные приложения (Мой Екатеринбург, Мой Челябинск, Мой Волгоград и т. п.), которые ориентированы в основном на жителей города и предоставляют информацию о событиях, дают возможность посмотреть цены на товары и услуги, заказать такси. Для всех крупнейших российских городов созданы аудиогиды, размещенные, например, на базе сервиса izi.TRAVEL ${ }^{1}$, а также разрабатываемые при поддержке региональных центров развития туризма. Все крупнейшие города представлены на национальном туристическом портале Россииㄹ․ Следующим шагом может стать анализ качества контента на данных ресурсах, в том числе для анализа официального портала города может использоваться модель «7 С» $[14 ; 16]$.

\section{Заключение}

Использование цифровых технологий, с одной стороны, делает продвижение территорий более диверсифицированным, нацеленным и вовлекает потребителей по всему миру. С другой стороны, это усложняет восприятие территорий и может способствовать формированию противоречивого имиджа, поскольку в процесс включаются множественные стейкхолдеры и сами потребители. Цифровой маркетинг - это не просто процесс представления территории в Интернете, не только цифровизация культурного и исторического наследия, а в большей степени процесс организации взаимодействия различных стейкхолдеров для максимального представления реального потенциала территории в виртуальном пространстве и его совместного согласованного продвижения.

Важным фактором является электронная интеграция всех слоев населения, включение граждан в информационное общество, которое зависит от технологических решений и уровня цифровой грамотности.

Виртуальный потенциал не менее важен, чем реальный потенциал территории, для формирования ее благоприятного имиджа и решения многочисленных маркетинговых задач. Однако в настоящее время отсутствует понимание совокупного виртуального маркетингового потенциала территории и действия по его созданию и регулированию не так масштабны, как требует современная цифровая экономика.

\section{Источники}

1. Андреев А.Л., Садчикова А.С. Поисковые запросы в Интернете как средство анализа социального поведения россиян в условиях социально-экономического кризиса (на примере Приволжского федерального округа) // Социологическая наука и социальная практика. 2016. Т. 4, № 4 (16). С. 7-18.

2. Бояркина Л.А., Бояркин В.В. Цифровой след и цифровая тень как производные персональных данных // Сборники конференций НИЦ Социосфера. 2016. № 62. C. $78-81$.

3. Бровелли М. А. Открытые данные, бесплатное программное обеспечение с открытым исходным кодом и открытый доступ к геоданным для валоризации культурного туризма на примере проекта «Пешеходные маршруты Via Regina») // Интерэкспо Гео-Сибирь: сб. материалов ХI Междунар. конгресса (Новосибирск, 13-25 апреля 2015 г.). Новосибирск: СГУГиТ, 2015. С. 30-31.

4. Гужова И.В. Визуализация культурного кода города в имиджевой коммуникации с помощью ново-медийных технологий (семиотический подход) // Исторические,

\footnotetext{
${ }^{1}$ The storytelling platform «izi.TRAVEL». URL: https://izi.travel.

${ }^{2}$ Национальный туристический портал «Russia Travel». URL: https://russia.travel.
} 
философские, политические и юридические науки, культурология и искусствоведение. Вопросы теории и практики. 2014. № 2-2 (40). С. 45-49.

5. Капустина Л.М., Мосунов И.Д. Комплекс «4Р» и модель «6I» интернет-маркетинга // Известия Уральского государственного экономического университета. 2014. № 6 (56). С. 101-107.

6. Капустина Л. М., Мосунов И. Д., Сысоева Т. Л. Инструменты продвижения бренда в интернете: алгоритм выбора // Маркетинг и маркетинговые исследования. 2015. № 2. C. $104-112$.

7. Коростелёв Д. А., Химич Е.В. Маркетинг, основанный на данных // Научно-техническое и экономическое сотрудничество стран АТР в XXI веке. 2017. Т. 1. С. 312-316.

8. Маркетинг мест. Привлечение инвестиций, предприятий, жителей и туристов в города, коммуны, регионы и страны Европы / Ф. Котлер, К. Асплунд, И. Рейн, Д. Хайдер. СПб.: Стокгольмская школа экономики, 2005.

9. Нижегородцев Р.М., Петренко Е.С. Использование института потребительских сетей в системе современного маркетинга // Вестник экономической интеграции. 2011. № 1. С. $106-115$.

10. Панкрухин А.П. Маркетинговые резервы российских туристских дестинаций // Практический маркетинг. 2012. № 8. С. 4-16.

11. Пономарев А.А. Использование больших данных сотовыми операторами на примере построения маршрутов абонентов // Вестник Новосибирского государственного университета. Сер.: Информационные технологии. 2017. Т. 15, № 1. С. 70-78.

12. Cocker H. L., Cronin J. M. Charismatic Authority and the YouTuber. Unpacking the New Cults of Personality // Marketing Theory. 2017. Vol. 17, no. 4. Pp. 455-472.

13. Do Marketers Use Visual Representations of Destinations That Tourists Value? Comparing Visitors' Image of a Destination with Marketer-Controlled Images Online / N. Michaelidou, N.-T. Siamagka, C. Moraes, M. Micevski // Journal of Travel Research. 2013. Vol. 52, issue 6. Pp. 789-804.

14. Govers R. Rethinking Virtual and Online Place Branding // Kavaratzis M. et al. (eds.) Rethinking Place Branding. Springer International Switzerland, 2015. Pp. 73-83.

15. Hakala H., Niemi L., Kohtamäki M. Online Brand Community Practices and The Construction of Brand Legitimacy // Marketing Theory. 2017. Vol. 17, no. 4. Pp. 537-558.

16. Hanna S.A., Rowley J. Rethinking Strategic Place Branding in the Digital Age // Kavaratzis M. et al. (eds.) Rethinking Place Branding. Springer International Switzerland, 2015. Pp. 85-100.

17. Kolotouchkina, O., Seisdedos, G. Place Branding Strategies in the Context of New Smart Cities: Songdo IBD, Masdar and Skolkovo // Place Brand Public Diplomacy. 2018. Vol. 14, issue 2. Pp. 115-124.

18. Oliveira E., Panyik E. Content, Context and Co-Creation: Digital Challenges in Destination Branding with References to Portugal as a Tourist Destination // Journal of Vacation Marketing 2015. Vol. 21, issue 1. Pp. 53-74.

19. Sevin H. E. Understanding Cities Through City Brands: City Branding as a Social and Semantic Network // Cities. 2014. Vol. 38. Pp. 47-56.

20. Tham A., Croy G., Mair J. Social Media in Destination Choice: Distinctive Electronic Word-of-Mouth Dimensions // Journal of Travel \& Tourism Marketing 2013. Vol. 30, no. 1-2. Pp. 144-155.

21. Tweeting as a Marketing Tool: A Field Experiment in the TV Industry / S. Gong, J. Zhang, P. Zhao, X. Jiang // Journal of Marketing Research. 2017. Vol. 54, no. 6. Pp. 833-850. 


\title{
Place Marketing in Conditions of the Forming Digital Economy
}

\author{
by Natalya Yu. Vlasova and Yelena S. Kulikova
}

The paper aims to systematise principal concepts in the field of digital marketing and virtual potential of a territory. The authors suggest their own interpretation of the concept "digital place marketing". On the basis of the theories of digital economy the authors identify peculiarities and fundamental changes occurring in the sphere of place marketing and branding in the era of digitalisation. The research considers the possibility of using digital channels of interaction in marketing of territories and reveals their advantages. The paper discusses the concept and structure of virtual potential of a territory and formulates a methodological approach to its analysis. Having performed a comparative analysis of official portals of the largest cities of the Russian Federation with the use of a set of e-metrics, and analysis of the representation of the largest cities of the Russian Federation in various social networks the authors conclude that it is necessary to form an integral concept of digital identity of the Russian largest cities.

Keywords: digital economy; digital place marketing; Web 2.0; virtual potential of a territory; city website; the largest city.

References:

1. Andreev A.L., Sadchikova A.S. Poiskovye zaprosy v internete kak sredstvo analiza sotsial'nogo povedeniya rossiyan $\mathrm{v}$ usloviyakh sotsial'no-ekonomicheskogo krizisa (na primere Privolzhskogo federal'nogo okruga) [Search requests on the Internet as a means of analysing the social behaviour of Russians in the conditions of the social and economic crisis (case of the Volga Federal District)]. Sotsiologicheskaya nauka i sotsialnaya praktika - Sociological Science and Social Practice, 2016, vol. 4, no. 4(16). pp. $7-18$.

2. Boyarkina L. A., Boyarkin V. V. Tsifrovoy sled i tsifrovaya ten' kak proizvodnye personal'nykh dannykh [Digital trace and digital shadow as derivatives of personal data]. Sborniki konferentsiy NITs Sotsiosfera - Proceedings of the SIC Sotsiosphera, 2016, no. 62, pp. 78-81.

3. Brovelli M. A. Otkrytye dannye, besplatnoe programmnoe obespechenie s otkrytym iskhodnym kodom i otkrytyy dostup k geodannym dlya valorizatsii kul'turnogo turizma na primere proekta "Peshekhodnye marshruty Via Regina") [Open data, free open source software and open access to geodata for valorization of cultural tourism at the example of the project "Pedestrian routes Via Regina")]. Materialy Mezhdunarodnogo kongressa "Interekspo Geo-Sibir" [Proc. Int. Congress "Interexpo Geo-Siberia"]. Novosibirsk: Siberian State University of Geosystems and Technologies, 2015, pp. 30-31.

4. Guzhova I. V. Vizualizatsiya kul'turnogo koda goroda v imidzhevoy kommunikatsii s pomoshch'yu novo-mediynykh tekhnologiy (semioticheskiy podkhod) [Visualization of the cultural code of the city in image communication with the help of new media technologies (semiotic approach)]. Istoricheskie, filosofskie, politicheskie i yuridicheskie nauki, kulturologiya i iskusstvovedenie. Voprosy teorii i praktiki Historical, Philosophical, Political and Juridical Sciences, Culturology and Art History. Issues of Theory and Practice, 2014, no. 2-2(40), pp. 45-49.

5. Kapustina L. M., Mosunov I.D. Kompleks “4P” i model' “6I” internet-marketinga [The Four Ps and " 6 " Model in Internet Marketing]. Izvestiya Uralskogo gosudarstvennogo ekonomicheskogo universiteta - Journal of the Ural State University of Economics, 2014, no. 6 (56), pp. 101-107.

6. Kapustina L. M., Mosunov I. D., Sysoeva T.L. Instrumenty prodvizheniya brenda v internete: algoritm vybora [Brand promotion tools on the Internet: Selection algorithm]. Marketing i marketingovye issledovaniya - Marketing and Marketing Research, 2015, no. 2, pp. 104-112.

7. Korostelev D.A., Khimich Ye. V. Marketing, osnovannyy na dannykh [Data-driven marketing]. Nauchno-tekhnicheskoe i ekonomicheskoe sotrudnichestvo stran ATR vXXI veke - Scientific, Technical and Economic Cooperation of the APR Countries in the $21^{\text {st }}$ Century, 2017, vol. 1, pp. 312-316.

8. Kotler Ph., Asplundh K., Rein I., Haider D. Marketing mest. Privlechenie investitsiy, predpriyatiy, zhiteley i turistov $v$ goroda, kommuny, regiony $i$ strany Evropy [Marketing places. Attracting investments, industry, and tourism to cities, states and nations]. Saint Petersburg: Stockholm School of Economics, 2005.

9. Nizhegorodtsev R. M., Petrenko Ye.S. Ispol'zovanie instituta potrebitel'skikh setey v sisteme sovremennogo marketinga [Use of the institute of consumer networks in the modern marketing system]. Vestnik ekonomicheskoy integratsi - Bulletin of Economic Integration, 2011, no. 1, pp. 106-115.

10. Pankrukhin A. P. Marketingovye rezervy rossiyskikh turistskikh destinatsiy [Marketing reserves of Russian tourist destinations]. Prakticheskiy marketing - Practical Marketing, 2012, no. 8, pp. 4-16. 
11. Ponomarev A. A. Ispol'zovanie bol'shikh dannykh sotovymi operatorami na primere postroeniya marshrutov abonentov [Use of big data by mobile network operators at the example of constructing subscriber routes]. Vestnik Novosibirskogo gosudarstvennogo universiteta. Seriya: Informatsionnye tekhnologii - Bulletin of Novosibirsk State University. Series: Information Technologies, 2017, vol. 15, no. 1, pp. 70-78.

12. Cocker H. L., Cronin J. M. Charismatic Authority and the YouTuber. Unpacking the New Cults of Personality. Marketing Theory, 2017, vol. 17, no. 4, pp. 455-472.

13. Michaelidou N., Siamagka N.-T., Moraes C., Micevski M. Do Marketers Use Visual Representations of Destinations That Tourists Value? Comparing Visitors' Image of a Destination with MarketerControlled Images Online. Journal of Travel Research, 2013, vol. 52, issue 6, pp. 789-804.

14. Govers R. Rethinking Virtual and Online Place Branding. In: Kavaratzis M. et al. (eds.) Rethinking Place Branding. Springer International Switzerland, 2015, pp. 73-83.

15. Hakala H., Niemi L., Kohtamäki M. Online Brand Community Practices and the Construction of Brand Legitimacy. Marketing Theory, 2017, vol. 17, no. 4, pp. 537-558.

16. Hanna S.A., Rowley J. Rethinking Strategic Place Branding in the Digital Age. In: Kavaratzis M. et al. (eds.) Rethinking Place Branding. Springer International Switzerland, 2015, pp. 85-100.

17. Kolotouchkina O., Seisdedos G. Place Branding Strategies in the Context of New Smart Cities: Songdo IBD, Masdar and Skolkovo. Place Brand Public Diplomacy, 2018, vol. 14, issue 2, pp. 115-124.

18. Oliveira E., Panyik E. Content, Context and Co-Creation: Digital Challenges in Destination Branding with References to Portugal as a Tourist Destination. Journal of Vacation Marketing, 2015, vol. 21, issue 1, pp. 53-74.

19. Sevin H. E. Understanding Cities Through City Brands: City Branding as a Social and Semantic Network. Cities, 2014, vol. 38, pp. 47-56.

20. Tham A., Croy G., Mair J. Social Media in Destination Choice: Distinctive Electronic Word-ofMouth Dimensions. Journal of Travel \& Tourism Marketing, 2013, vol. 30, no. 1-2, pp. 144-155.

21. Gong S., Zhang J., Zhao P., Jiang X. Tweeting as a Marketing Tool: A Field Experiment in the TV Industry. Journal of Marketing Research, 2017, vol. 54, no. 6, pp. 833-850.

Contact Info:

Natalya Yu. Vlasova, Dr. Sc. (Econ.), Prof. of State and Municipal Governance Dept.

Phone: (343) 221-27-36

e-mail: nat-vlasova@yandex.ru

Yelena S. Kulikova, Cand. Sc. (Econ.),

Associate Prof. of State and Municipal

Governance Dept.

Phone: (343) 221-27-36

e-mail: e.s.kulikova@mail.ru
Ural State University of Economics

62/45 8 Marta/Narodnoy Voli St., Yekaterinburg, Russia, 620144

Ural State University of Economics

62/45 8 Marta/Narodnoy Voli St., Yekaterinburg, Russia, 620144

Ссылка для циттрования: Власова Н. Ю., Куликова Е. С. Маркетинг территории в условиях становления цифровой экономики // Известия Уральского государственного экономического университета. 2018. Т. 19, № 3. C. 69-81. DOI: 10.29141/2073-1019-2018-19-3-7

For citation: Vlasova N. Yu., Kulikova Ye. S. Marketing territorii v usloviyakh stanovleniya tsifrovoy ekonomiki [Place marketing in conditions of the forming digital economy]. Izvestiya Uralskogo gosudarstvennogo ekonomicheskogo universiteta - Journal of the Ural State University of Economics, 2018, vol. 19, no. 3, pp. 69-81. DOI: 10.29141/2073-10192018-19-3-7 


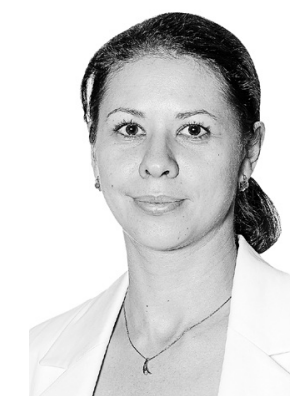

\title{
АКБЕРДИНА ВикТория Викторовна
}

Доктор экономических наук, профессор РАН, заведующая отделом региональной промышленной политики и экономической безопасности Институт экономики Уральского отделения РАН 620014, РФ, г. Екатеринбург, ул. Московская, 29

Профессор кафедры региональной экономики, инновационного предпринимательства и безопасности Уральский федеральный университет имени первого Президента России Б.Н. Ельцина 620002, РФ, г. Екатеринбург, ул. Мира, 19

Контактный телефон: (343) 371-45-36 e-mail:akb_vic@mail.ru

\section{Трансформация промышленного комплекса России в условиях цифровизации экономики'}

\begin{abstract}
Статья посвящена обоснованию методического подхода к оценке процесса трансформации промышленного комплекса в условиях глубокого проникновения цифровых технологий в материальный сектор экономики. Сформулирована теоретическая платформа исследования, базирующаяся на теории нового индустриального общества, обоснована методология, включающая воспроизводственный, институциональный и синергетический подходы. Показано, что трансформация промышленного комплекса - это всегда дискретный процесс структурных изменений и институциональных преобразований. Предложена методика выделения стадий трансформации промышленного комплекса в виде пирамиды. Авторская пирамида процесса цифровизации включает первичную информационно-коммуникационную цифровизацию; электронный обмен данными с внешними партнерами; использование специального программного обеспечения; собственное производство информационно-коммуникационных технологий и оборудования; производство и применение промышленных роботов и датчиков. Анализ цифровизации промышленного комплекса по авторской методике показал достаточно высокую степень первичной компьютеризации, включенность промышленных предприятий в «цифровой» обмен с поставщиками и потребителями, динамичное развитие отечественного программного обеспечения и выявил, что процесс цифровой трансформации российской промышленности находится на начальных стадиях, а достижение поставленных амбициозных задач возможно лишь при реализации грамотной промышленной политики.
\end{abstract}

JEL classification: $014, \mathrm{O} 25, \mathrm{O} 33$

Ключевые слова: цифровизация; новая индустриализация; трансформация промышленности; «ген цифровизации».

\section{Введение}

$\Phi$ ормирование цифровой экономики - это не только вопрос национальной безопасности, но и задел для повышения конкурентоспособности российской продукции на мировых рынках в будущем. И хотя доля цифровой экономики в валовом внутреннем продукте (ВВП) страны в настоящее время не столь значима, как для традиционных отраслей материального производства (по разным оценкам не выше 5\%), темпы роста ее объема уже выше темпов роста ВВП в 8,0-8,5 раза. К приоритетным направлениям цифровой экономики в промышленном комплексе отнесены разработка и промышленное производство роботов, датчиков и сенсоров, внедрение аддитивных технологий и новых материалов для обеспечения цифровизации, формирование российских цифровых платформ для интеллектуальных систем управления.

${ }^{1}$ Статья подготовлена при финансовой поддержке РФФИ (проект № 18-010-01156 «Моделирование технологической трансформации промышленного комплекса России в условиях цифровизации экономики»). 
Тема построения цифровой экономики в России в последнее время стала не только предметом изучения на государственном и экспертном уровне, не только самым модным трендом общественных обсуждений и самой молодой федеральной программой, но и самой большой проблемой, связанной с ее реализацией. Технологический уровень развития промышленного производства и структурные перекосы в сторону низкотехнологичных и экологически неблагополучных секторов позволяют с осторожностью воспринимать прогнозы о всеобъемлющей цифровизации промышленности в ближайшем будущем.

Под реальной, или «аналоговой», экономикой понимается хозяйственная деятельность общества, а также совокупность отношений, складывающихся в системе производства, распределения, обмена и потребления. И поэтому иифровой экономики как самостоятельной сферы экономики не существует, есть иифровой сегмент материальной экономики - виртуальная среда, дополняющая реальность. Цифровая экономика представляет собой инфраструктурную надстройку над материальным сектором экономики, призванную повысить эффективность взаимодействия участников процессов производства и реализации промышленной продукции, а также взаимоотношения индивидов в процессе экономической деятельности. Следовательно, если внедрение цифровых технологий будет проводиться без соразмерного развития материального производства, общий экономический эффект от цифровизации не будет иметь решающего значения: мы будем и дальше «оцифровывать» технологическую отсталость.

Уровень развития цифровой экономики напрямую коррелирует с уровнем развития материальной сферы: только там, где формируется высокотехнологичный сегмент в промышленном комплексе, развитие иифрового сегмента наиболее целесообразно. Но можно с уверенностью говорить, что верно и обратное: чем больше оцифровываются и виртуализируются процессы на производстве, тем более активный толчок к развитию получают аналоговые виды сервисов и производство.

Цель исследования, представленного в статье, связана с обоснованием методологического подхода к оценке процесса трансформации промышленного комплекса в условиях глубокого проникновения цифровых технологий в реальный сектор. Цифровое преобразование такой полиструктурной системы со значительным количеством вертикальных и горизонтальных связей, как российский промышленный комплекс, является достаточно продолжительным процессом, включающим в себя несколько последовательных стадий. Крайне важно систематизировать стадии, обосновать их качественные и количественные характеристики, выявить закономерности и условия перехода между ними. Определение стадий процесса цифровой трансформации реального сектора позволит не только оценить современный этап, но и спрогнозировать перспективы цифровизации промышленности.

\section{Теоретическая платформа цифровой трансформации промышленности}

Более полувека назад сначала в зарубежной экономической литературе $[3 ; 15 ; 20 ; 21]$, а потом и в публикациях российских ученых-экономистов $[9 ; 10 ; 11 ; 12]$ достаточно прочно укрепилась мысль о необходимости формирования постиндустриального общества, практическим результатом которого являются уменьшение роли промышленного производства в ВВП страны и многократный рост третичного сектора экономики. Данный процесс, конечно, мог бы рассматриваться в контексте улучшения качества жизни населения и развития индустрии знаний, если бы не очевидное замедление темпов роста производительности труда, снижение технологической оснащенности предприятий, утрата производственным персоналом опыта, навыков и умений, понижение общего квалификационного уровня в промышленности и т. д.

Оценивая масштабы потерь объемов индустриального производства, сокращения доли промышленности в валовой добавленной стоимости, а также даже сжатие 
национального экспортного сегмента промышленной продукции, еще в конце XX века экономисты ввели понятие деиндустриализации [6; 8]. По мнению С. Д. Бодрунова, деиндустриализация снижает «индустриальную насыщенность» экономики через деградацию всех компонент материального производства. Исследователи Института нового индустриального развития им. С. Ю. Витте выделяют катастрофические последствия деиндустриализации, которые сводятся к «эффекту 4Д»: дезорганизация, деградация, деквалификация, декомплицирование [5].

Поэтому в течение последнего десятилетия экономисты, социологи, политологи пишут и говорят о том, что идея постиндустриального общества была если не утопичной [16; 22; 23; 24], то во всяком случае преждевременной [4; 7]. Никакая экономика не сможет прирастать без материального сегмента, в связи с чем реиндустриализация экономики становится главным курсом экономического развития во многих странах. Но восстановление доли промышленности в структуре валового внутреннего продукта не может означать механическое возвращение прежней промышленности. Промышленность качественно меняется, и речь уже идет о новой индустриализации - о формировании высокотехнологичного сектора экономики и технологической инклюзии (вовлечении) традиционных отраслей в этот вектор развития [14].

Новая индустриализация сопряжена с зарождением четвертой глобальной промышленной революции, создающей новаторские промышленные и экономические модели с использованием гибридных NBIC-технологий, среди которых информационные технологии являются технологиями-интеграторами.

Переход от третьей к четвертой промышленной революции имеет достаточно много аналогий с переходом от первой ко второй промышленной революции. Первоначально инновации генерируются на вертикальном (отраслевом) уровне, изменяя производственные и институциональные отношения внутри отрасли. В последующем горизонтальные связи между сложившимися вертикальными инновациями формируют новые производственные бизнес-модели. В ходе третьей промышленной революции появляется отрасль электроники и информационно-коммуникационные технологии (ИКТ), создав платформу для развития глобальных промышленных сетей, сетевого производства и распределенной энергетики. Поэтому переход от третьей к четвертой промышленной революции - это скорее эволюция, нежели революция, поскольку это неизбежный переход от простой иифровизации (третья промышленная революиия) $\kappa$ инновациям на основе гибридных, конвергентных технологий (четвертая промыиленная револющия), результатом которого станет полностью автоматизированное цифровое производство, управляемое интеллектуальными системами в режиме реального времени в постоянном взаимодействии с внешней средой, выходящее за границы одного предприятия, с перспективой объединения в глобальную промышленную сеть вещей и услуг.

Внедрение сетевого взаимодействия между машинами, оборудованием, зданиями и информационными системами, возможность осуществлять мониторинг и анализ окружающей среды, процесса производства и собственного состояния в режиме реального времени, передача функции управления и принятия решений интеллектуальным системам приводят к смене «парадигмы» технологического развития [13].

Ключевыми признаками и отличиями нового индустриального производства станут, в первую очередь, его модульность в отличие «монолитности» производственных мощностей в рамках одного предприятия; во-вторых, распределенность производства в противовес существующему сейчас иерархическому подходу; в-третьих, беспроводные коммуникаиии между сенсорами, исполнительными механизмами и сборочными единицами.

Переход к парадигме четвертой промышленной революции будет связан с формированием кросс-индустриальных открытых (по горизонтали и вертикали) производ- 
ственно-сервисных экосистем, объединяющих множество различных информационных систем управления разных предприятий и задействующих множество различных устройств. Такой подход позволит реализовать в виртуальном пространстве сколь угодно сложные сквозные бизнес-процессы, которые способны в автоматическом режиме осуществлять оптимизационное управление (сквозной инжиниринг) различного рода ресурсами через всю цепочку поставок и создания стоимости продукции - от разработки идеи, дизайна, проектирования до производства, эксплуатации и утилизации.

Не только цифровая парадигма является основой четвертой промышленной революции. Основой «Индустрии 4.0» является конвергенция технологий - процесс сближения и взаимного проникновения промышленных технологий, при котором границы между отдельными промышленными технологиями стираются, а многие интересные результаты возникают в рамках междисциплинарной работы на стыке областей. Это приводит к структурно-пространственным трансформациям промышленных систем. Технологии начинают использовать один и тот же обобщенный ресурс, и отбор приводит к количественному улучшению эффективности уже утвердившихся типов технологий или форм хозяйствования в рамках новой технико-экономической парадигмы.

\section{Методологические подходы к трансформации промышленного комплекса в условиях цифровизации}

Цифровизация индустриального развития предполагает создание и распространение в промышленности целого ряда технологий, среди которых обработка больших объемов данных, промышленный Интернет, аддитивные технологии, роботизация, автоматизация сбора и обработки данных, специальные датчики и средства управления и др. Подобные технологии в промышленности требуют использования инструментов предварительного прогнозирования, объяснения неопределенностей, принятия наиболее обоснованных решений.

В этой связи фундаментальная научная задача данных направлений исследования должна быть нацелена на решение формулируемых в статье следующих методологических проблем как гипотезы:

1) экономико-математического моделирования кросс-индустриальных сетевых производственно-сервисных экосистем;

2) формирования промышленной политики, основанной на принципах саморазвития, саморегулирования, распределенности и сетецентричности (сетевая промышленная политика);

3) оценки и прогнозирования эффектов технологической трансформации с использованием количественных показателей.

Проблема экономико-математического моделирования кросс-индустриальных сетевых производственно-сервисных экосистем. Решение данной проблемы возможно лишь на комбинированной методологической платформе, включающей три подхода: воспроизводственный, институциональный и синергетический. С одной стороны, многообразие типов технологий и видов инноваций позволяет говорить о необходимости использования в процессе промышленного развития всего спектра технологий, формирующих «сеть технологий», основой которой должен стать не только высокотехнологичный сектор, но и среднетехнологичные секторы (так называемая структурная технологическая инклюзия). Кроме того, в будущем все рынки будут устроены как сетевые сообщества - это новый, принципиально важный принцип инновационнотехнологического развития, который начинает доминировать практически везде. В высокотехнологичном секторе нужен переход от промышленных гигантов, работающих с поставщиками, на сетевые модели координации, когда люди создают продукты небольшими сериями, координируясь через Сеть. Многие компании, особенно в новых 
отраслях, переходят на принципы сетевой организации без прежней роли вертикального менеджмента. С другой стороны, сам научный сектор - генератор технологий должен претерпеть организационные изменения и выйти на сетевую модель организации, построенную на принципах S2B (science-to-business).

Основными методами исследования в данном направлении должны стать:

1) дискретно-событийное моделирование, предполагающее описание процесса функционирования исследуемого сетевого промышленного комплекса в виде последовательности событий, знаменующих изменение определенных параметров объекта и происходящих в определенные моменты виртуального времени. Метод наилучшим образом подходит для описания технологических процессов по критерию соотношения достигаемой степени детализации моделируемого объекта и трудоемкости разработки имитационной модели;

2) агентное моделирование, предполагающее описание моделируемого сетевого промышленного комплекса в виде совокупности активных объектов - агентов, обладающих уникальными правилами поведения и находящихся в постоянном взаимодействии в некоторой среде.

Проблема формирования сетевой промышленной политики. Переход к новой модели развития экономики предполагает трансформацию институтов промышленного развития и совершенствование самой промышленной политики. В условиях цифровизации особую роль приобретает консенсус регуляторного и саморегулирующего принципов промышленной политики [2]. Регулирующее воздействие института промышленной политики достаточно эффективно проявило себя в условиях традиционной формы организации промышленности, основанной на принципах технологической сопряженности от первичного до третичного сектора. Однако при движении формы организации промышленного комплекса в сторону преобладания сетевой формы отношений появляется блок самоорганизационных мер, относимых к компетенции самих сетевых предприятий. В этом случае создается возможность гармонизации интересов участников данных процессов, повышения эффективности их сетевого сотрудничества.

Проблема оценки и прогнозирования эббектов технологической трансформации с использованием количественных показателей. Одним из глобальных вызовов является конвергенция промышленных технологий на основе цифровизации, представляющая собой радикально новый этап научно-технического прогресса, не имеющий исторических аналогов по степени влияния на человеческую цивилизацию. Новые промышленные технологии, обладая колоссальным потенциалом изменения направления технологического развития, в то же время имеют неоднозначные социальные и экологические последствия. И это становится еще одним вызовом, требующим разработки механизмов управления рисками технологической трансформации промышленного комплекса.

Ключевым методом оценки технологических, экономических, социогуманитарных и экологических эффектов цифровизации в промышленности должен стать метод экономического резонанса на национальном и региональном уровнях, под которым понимается явление ускорения экономического развития подверженной волновой динамике экономической системы, вызванное периодическим изменением инновационно-технологических параметров за счет каталитического механизма, встроенного в триадную синергетическую систему отношений «наука - государство - бизнес» [1]. Результатом оценки резонансных эффектов цифровизации промышленности должна стать модель экономической безопасности сетевого промышленного комплекса в условиях цифровизации и ее институциональное закрепление. 


\section{Методика определения стадий трансформации промышленного комплекса в условиях цифровой экономики}

Трансформация промышленного комплекса, вызванная любыми факторами и реализуемая в любых условиях, - это всегда дискретный процесс качественных изменений, приводящий к существенным структурным изменениям и институцииональным преобразованиям. Выделение стадий трансформации промышленного комплекса возникло в связи с необходимостью этапной оценки качественных изменений, носящих необратимый характер и формирующих переход в принципиально новое состояние с более высокими социально-экономическими показателями эффективности на пути к формированию будущей модели промышленности. Любое качественное изменение системы всегда сопровождается преобразованием ее структуры, что приводит к изменению форм экономической деятельности и социально-экономических институтов. В такой трактовке термин «трансформация» не включает весь процесс подготовки этого перехода, который делится, как известно, на разные периоды количественных и качественных преобразований. В этом случае трансформация есть только результат предшествующих преобразований, момент преображения, а не сам процесс преобразования системы.

Автор предлагает выделить стадии трансформации промышленного комплекса, представляя их в виде пирамиды, каждая из которых имеет определенный «ген цифровизации» (рис. 1).

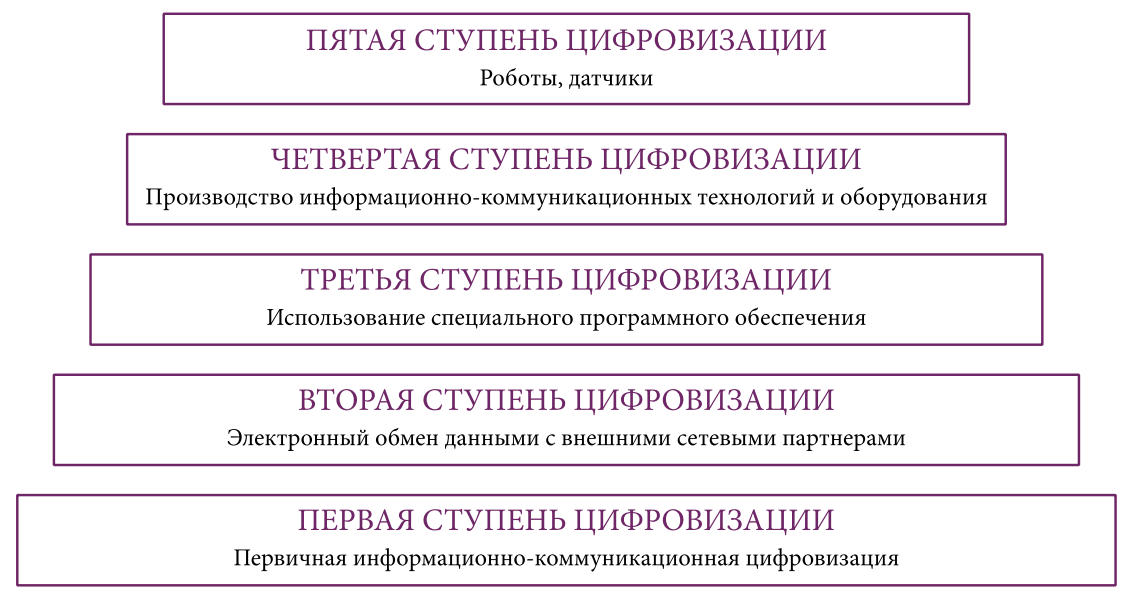

Рис. 1. Пирамида процесса цифровизации промышленного комплекса

Первая стадия ицифровой трансформации промышленности - первичная информационно-коммуникационная ицифровизация. Данная стадия предполагает компьютеризацию в широком смысле этого слова, масштабное внедрение электронно-вычислительных машин в сферу производства в различных отраслях промышленности. Компьютеризация является центральным и обязательным условием развития информационных взаимодействий, определяющих промышленное развитие. Компьютеризацию в промышленности принято рассматривать как процесс внедрения и технической модернизации компьютеров, обеспечивающих автоматизацию информационных процессов промышленных предприятий, например, для управления технологическими процессами, производством и передачей энергии и другими производственными процессами; проектирования сложных объектов; планирования, учета и обработки статистических данных, организационно-административного управления; научно-исследовательских и опытно-конструкторских работ, обучения, диагностирования и т. д. 
Использование компьютеров в различных сферах управления и промышленного производства, совершенствование их технической базы и оснащение современными коммуникационными средствами увеличивает оперативность накопления и переработки информации, становится фактором повышения эффективности управленческих взаимодействий и надежности технико-экономических обоснований проектов промышленного развития.

К числу показателей, характеризующих данную стадию, относятся доли предприятий, использующих персональные компьютеры, серверы, локальные вычислительные сети, электронную почту, глобальные информационные сети, веб-сайты в Интернете, «облачные» сервисы, выделенные технические средства для мобильного доступа к Интернету (смартфоны, планшетные компьютеры, GSM/GPRS/UMTS/CDMA/3G/LTE-модемы), как в целом по промышленности, так и по отдельным отраслям.

Вторая стадия иифровой трансформации промышленности - электронный обмен данными с внешними сетевыми партнерами (EDI). EDI в соединении с Интернетом позволяет осуществлять электронные транзакции в реальном времени и тем самым существенно ускорять процессы взаимодействия между поставщиками, подрядчиками, кооператорами и потребителями. Обмен коммерческой информацией (производственные заказы, доставки, счета, денежные переводы и т. д.) на бумажных носителях предусматривает в основном ручной ввод информации в компьютерную систему компаний-партнеров. Использование стандартов электронного документооборота позволяет избежать этого, применение автоматических процедур повышает скорость и точность сбора данных.

К числу показателей, характеризующих данную стадию, можно отнести:

- долю предприятий, использующих EDI по форматам обмена (EDIFACT, EANCOM, ANSI X12; основанным на XML-стандартах, например ebXML, RosettaNet, UBL, papiNET; проприетарных стандартах), как в целом по промышленному комплексу, так и по видам экономической деятельности, относимых к промышленности;

- удельный вес стоимости закупок (продаж) товаров/работ/услуг по заказам, переданным (полученным) предприятием по Интернету, другим глобальным информационным сетям (с использованием веб-сайтов, системы автоматизированного обмена сообщениями между организациями (EDI-систем));

- долю предприятий, использовавших Интернет для связи с поставщиками (получение сведений о товарах/работах/услугах и их поставщиках; предоставление сведений о потребностях предприятий в товарах/работах/услугах; размещение заказов на товары/работы/услуги; оплата поставляемых товаров/работ/услуг; получение электронной продукции и др.);

- долю предприятий, использовавших Интернет для связи с потребителями (предоставление сведений об организации, ее товарах/работах/услугах; получение заказов на товары/работы/услуги; осуществление электронных расчетов с потребителями; распространение электронной продукции; послепродажное обслуживание и др.).

Третья стадия иифровой трансформации промышленности - использование специального программного обеспечения. Специальное программное обеспечение представляет собой совокупность программ, применяемых для решения определенного класса задач. Предназначено для построения программно-аппаратных комплексов на базе имеющихся у пользователя аппаратных средств (компьютеры, оборудование с ЧПУ и др.). Данная стадия тесно связана с широко внедренным процессом автоматизации, использующим саморегулирующие технические средства и математические методы с целью освобождения человека от участия в процессах получения, преобразования, передачи и использования энергии, материалов, изделий или информации, либо значительного уменьшения степени этого участия или трудоемкости выполняемых операций. Цифровая трансформация данной стадии достигает уровней, разница между 
которыми аналогична разнице между двумя терминами: «оцифровка» (перевод информации с физических носителей на цифровые) и «цифровизация» (создание нового продукта на основе цифровых технологий).

Как правило, специальное программное обеспечение предназначено для поддержки принятия решения должностным лицом, а именно выбора из устоявшейся базы данных оптимального (способа) метода решения, на основе разработанного и опробованного алгоритма. Являясь генератором и потребителем технологических новшеств, промышленность, как никакая другая отрасль экономики, остро восприимчива к применению специального программного обеспечения, использование которого обеспечивает продукции дополнительные конкурентные преимущества. Но не только наличие специального программного обеспечения идентифицирует третью стадию цифровизации. Важной составляющей данной стадии является структура станочного парка и доля оборудования с числовым программным управление в нем.

К показателям, характеризующим третью стадию цифровой трансформации промышленности, отнесем:

- доли промышленных предприятий, использующих специальное программное обеспечение для: 1) научных исследований; 2) проектирования; 3) управления автоматизированным производством и/или отдельными процессами; 4) CRM-, ERP-, SCM-системы; 5) решения организационных, управленческих и экономических задач; 6) управления закупками и продажами товаров (работ, услуг); 7) осуществления финансовых расчетов в электронном виде;

- долю оборудования с ЧПУ и обрабатывающих центров в станочном парке.

Четвертая стадия изифровой трансформации промышленности - производство информационно-коммуникационных технологий и оборудования. Данная стадия все больше приближает промышленность к статусу «цифровая» и характеризует переход от простого потребления результатов сферы информационно-коммуникационных технологий к их производству, масштабному развитию внутреннего рынка электронных компонентов и оборудования, формированию импортозамещающих программ.

Отраслью промышленности, ответственной за четвертый этап цифровизации промышленности, является производство электроборудования, электронного и оптического оборудования. В связи с этим основными показателями, характеризующими данную стадию, является доли товаров (работ, услуг) собственного производства, связанных с ИКТ, в общем объеме отгрузки, как в целом, так и по видам: ИКТ-оборудование (в том числе компьютеры и периферийное оборудование), программное обеспечение, базы данных, компьютерные, информационные ресурсы, услуги, связанные с ИКТ.

Пятая стадия иифровой трансформации промылиленности - производство и использование роботов и датчиков (промышленный Интернет). Данная стадия подразумевает цифровизацию в самом широком смысле - как процесс внедрения цифровых систем передачи на уровне первичных сетей, средств коммутации и управления, обеспечивающих передачу и распределение потоков информации в цифровом виде на уровне вторичных сетей. Промышленный Интернет вещей представляет собой многоуровневую систему, в которой посредством использования Интернета объединены в сеть различные промышленные объекты со встроенными датчиками, контроллерами и программным обеспечением для сбора и обмена данными с возможностью удаленного контроля и управления в автоматизированном режиме.

Основные компоненты промышленного Интернета вещей - это умные сенсоры, которые способны собирать данные прямо во время процесса производства, контроллеры, установленные на конкретных узлах промышленного объекта, средства передачи собираемых данных, облачные сервисы, мощные аналитические инструменты интерпретации получаемой информации. Ключевая идея предполагает, что производственные мощности предприятий будут взаимодействовать с производимыми товарами 
и по ходу производственного процесса адаптироваться к новым запросам потребителей. Роль умных машин, приборов в таком мире настолько возрастет, что они реально будут участвовать в производстве и управлении. Они также будут объединяться в сети, самостоятельно анализировать данные и принимать решения. В одну сеть будут объединены станки на производстве, сборочные линии (конвейеры) и даже целые заводы и фабрики. При этом взаимодействовать они будут без участия человека. Ключевыми трендами концепции «Индустрии 4.0» были обозначены роботы и автоматизация, аддитивные технологии и цифровые технологии - Интернет вещей (IoT) и искусственный интеллект [18; 19].

\section{Эмпирическое исследование стадий трансформации промышленного комплекса России}

Промышленный комплекс был и остается системообразующей отраслью российской экономики. В настоящее время четвертая часть валового внутреннего продукта (ВВП) Российской Федерации создается в промышленности. Тем не менее за последние 15 лет обозначился очевидный тренд деиндустриализации. Если в 2002 г. промышленный комплекс создавал 34,4\% ВВП, то в 2017 г. эта величина составила 26\% (рис. 2).

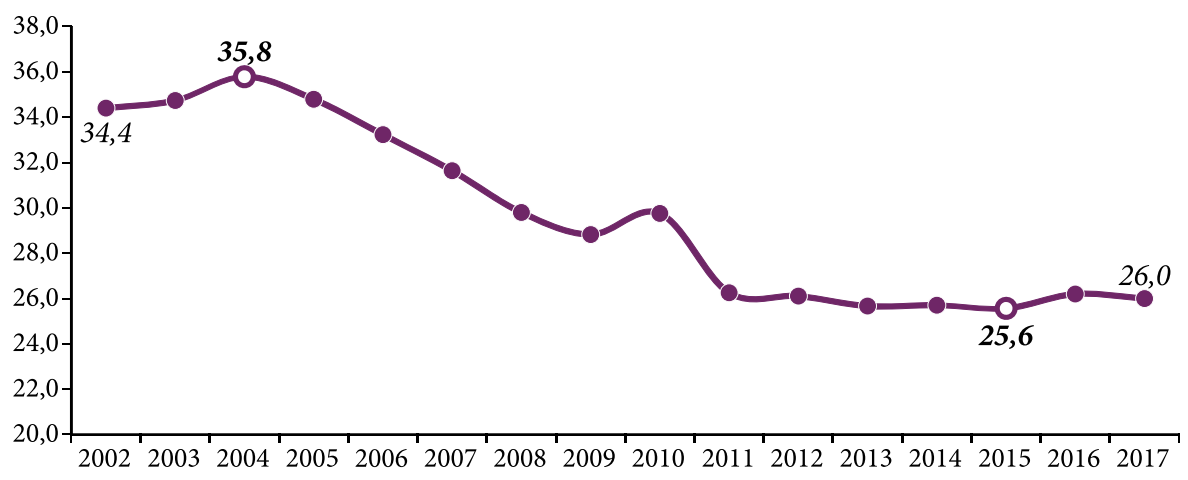

Рис. 2. Доля промышленности в ВВП РФ, \%

Не вдаваясь в детали эффектов деиндустриализации, по С. Д. Бодрунову, («эффект $4 Д »)$, отметим лишь катастрофический на этом фоне тренд замедления темпов роста производительности труда (рис. 3).

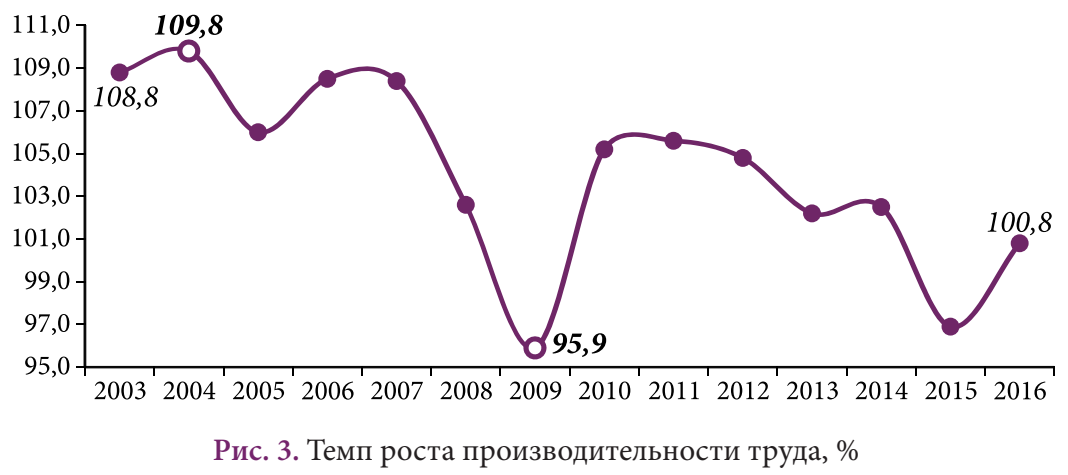

Рост эффективности в пределах 1\% и стагнация на рынке труда означают крайне вялый рост ВВП. Аналогичные тренды отмечаются и в развитых странах. Однако если в этих странах замедление темпов роста производительности, объясняемое «эффектом Солоу», сопровождается значительной цифровизацией в промышленности, то в России 
указанный тренд наблюдается на фоне недостаточной готовности предприятий к цифровизации в терминах промышленного Интернета (IoT).

Рассмотрим стадии трансформации промышленного комплекса России в условиях цифровизации по предложенной выше пирамиде.

Первичная информационно-коммуникационная иифровизация (первая ступень «пирамиды иифровизации»). Экономика России в целом и промышленность в частности имеют достаточно высокий уровень первичной компьютеризации (табл. 1). Привычные персональные компьютеры, электронную почту, глобальные информационные сети используют более 90\% промышленных предприятий. Значения, приближенные к 100\%, имеют предприятия обрабатывающих производств, среди которых лидерами являются предприятия высокотехнологичного сегмента - химическое производство и производство электро- и электронного оборудования. Вместе с тем нельзя сказать, что высокая первичная компьютеризация обеспечивает высокие показатели первичной информатизации. Зачастую персональные компьютеры выполняют лишь функцию печатной машинки с простым набором офисных программ. При этом серверы эксплуатируют лишь 66,4\% промышленных предприятий, веб-сайты в Интернете имеют только 54,5\% предприятий, а «облачные» технологии использует всего каждое пятое предприятие.

Электронный обмен данными с внешними сетевыми партнерами (вторая ступень «пирамиды иифровизаиии»). Промышленные предприятия достаточно интегрированы в информационные потоки с контрагентами, однако можно наблюдать интересный парадокс. Промышленные предприятия интенсивнее включены в «цифровой» обмен с поставщиками, нежели с потребителями, что лишний раз подтверждает факт оторванности промышленных предприятий от рынков сбыта. Чуть более 80\% промышленных предприятий применяют глобальные сети для связи с поставщиками, но при этом только 68,7\% предприятий используют Интернет для коммуникаций с потребителями (табл. 2).

Большую часть в «цифровом» обмене составляет информационный обмен сведениями о продукции и потребностях. Так, с использованием глобальных сетей $75,2 \%$ предприятий получают сведения от поставщиков, 63,4\% предприятий предоставляют сведения о продукции своим потребителям и 55,5\% предприятий предоставляют информацию о своих потребностях. При этом доля предприятий, размещающих электронные заказы на поставку сырья, материалов и комплектующих с использованием Интернет, составляет только $42,1 \%$, а доля предприятий, получающих заказы через Интернет, еще меньше - 32,2\%.

В отраслевом разрезе наименее интегрированы в электронный обмен данными с внешними поставщиками предприятия легкой промышленности, деревообработки, а также машиностроительные предприятия, производящие транспортные средства и оборудование. Невысока доля предприятий, включенных в «цифровой» обмен с потребителями, в машиностроительном (кроме сегмента электроники) и лесопромышленном комплексах.

Использование специального программного обеспечения (третья ступень "пирамиды иифровизации»). Если на первых двух ступенях можно было говорить о достаточно высоком уровне готовности предприятий к сетевым цифровым взаимоотношения, то на третьей ступени, где происходит переход от «оцифровки» к «цифровизации», показатели значительно хуже (табл. 3). Несмотря на то, что доля промышленных предприятий, использовавших специальное программное обеспечение, высока (90,3\%), состав программных средств демонстрирует явный перекос в сторону специальных программ для решения управленческих и экономических задач (бухгалтерский учет, правовые базы и др.). При этом катастрофически низкой остается доля промышленных предприятий, применяющих программное обеспечение для научных исследований $(4,5 \%)$ и проектирования $(29,1 \%)$. 
善
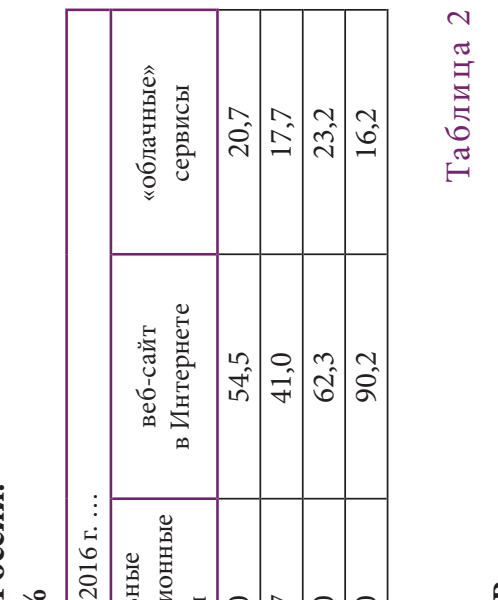

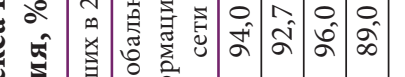



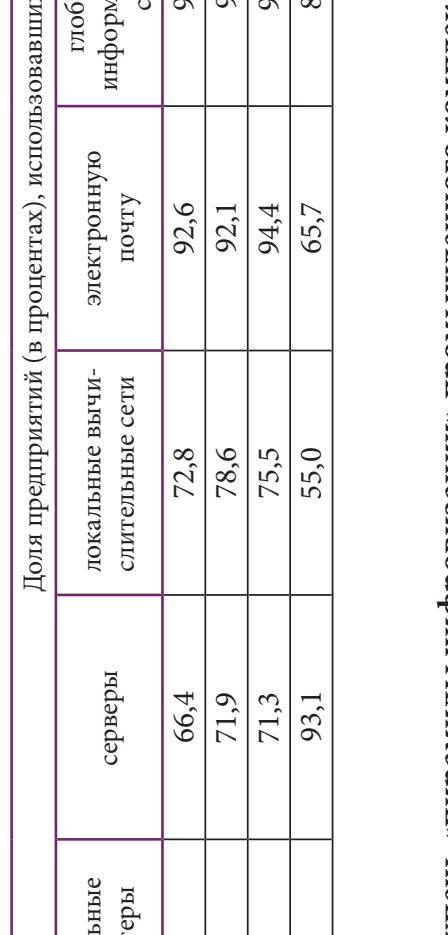

章

\begin{tabular}{|c|c|c|c|c|}
\hline $\begin{array}{c}\text { (әияdəว) } \\
\text { әинеяижКцюуо } \\
\text { әонженоошюгош }\end{array}$ & $\frac{2}{n}$ & Oे & $\mid \begin{array}{l}m \\
\hat{0} \\
=\end{array}$ & $\stackrel{\vec{s}}{s}$ \\
\hline
\end{tabular}

иипуКНош

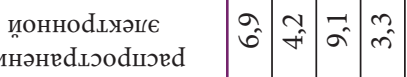

әинәнедцодшое

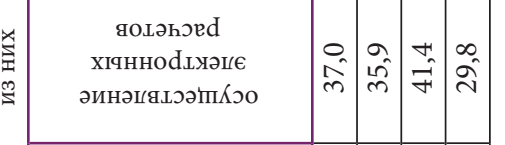

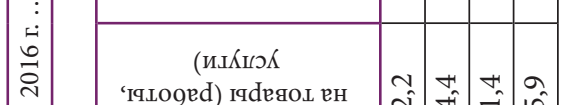

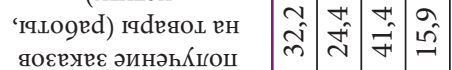

वortrec an

\begin{tabular}{|c|c|c|c|}
\hline $\begin{array}{l}\text { иипеєине.dо 9о } \\
\text { ииннәнәяว } \\
\text { әинәшяецәоНәdш }\end{array}$ & & \begin{tabular}{c|c}
0 & 2 \\
$\hat{\sigma}$ & $?$
\end{tabular} & $\overrightarrow{R^{\prime}}$ \\
\hline
\end{tabular}

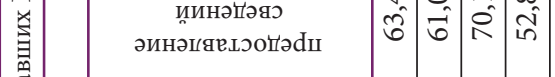

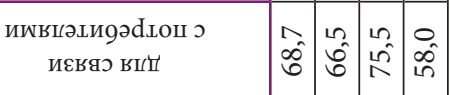

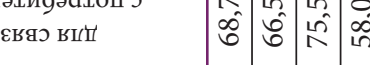

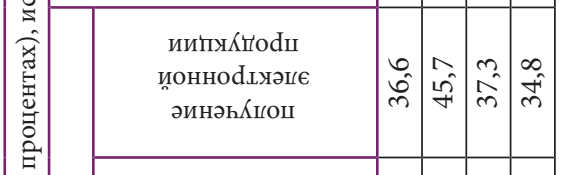

(IКLоК 'Lоgеd) gоdegol

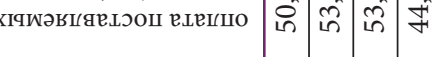

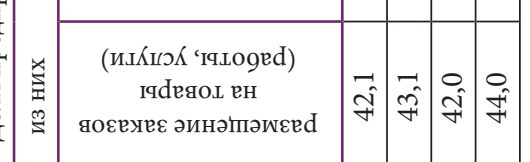

\begin{tabular}{|c|c|c|c|c|}
\hline 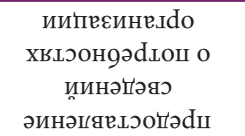 & $\begin{array}{l}10 \\
10 \\
10\end{array}$ & $\begin{array}{l}\text { nn } \\
\text { fi }\end{array}$ & - & $\hat{\hat{o}}$ \\
\hline 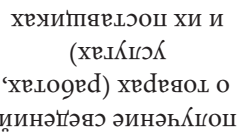 & $\begin{array}{l}2 \\
n \\
n\end{array}$ & $\begin{array}{l}\infty \\
\hat{\Omega}\end{array}$ & & $\begin{array}{l}0 \\
\hat{\theta} \\
0\end{array}$ \\
\hline
\end{tabular}

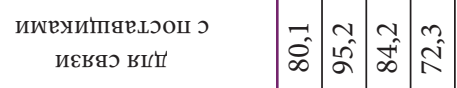

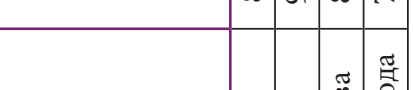

\begin{tabular}{|c|c|}
\hline 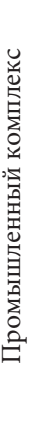 & 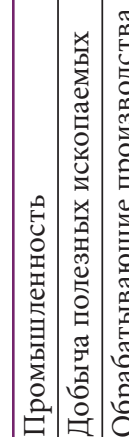 \\
\hline
\end{tabular}



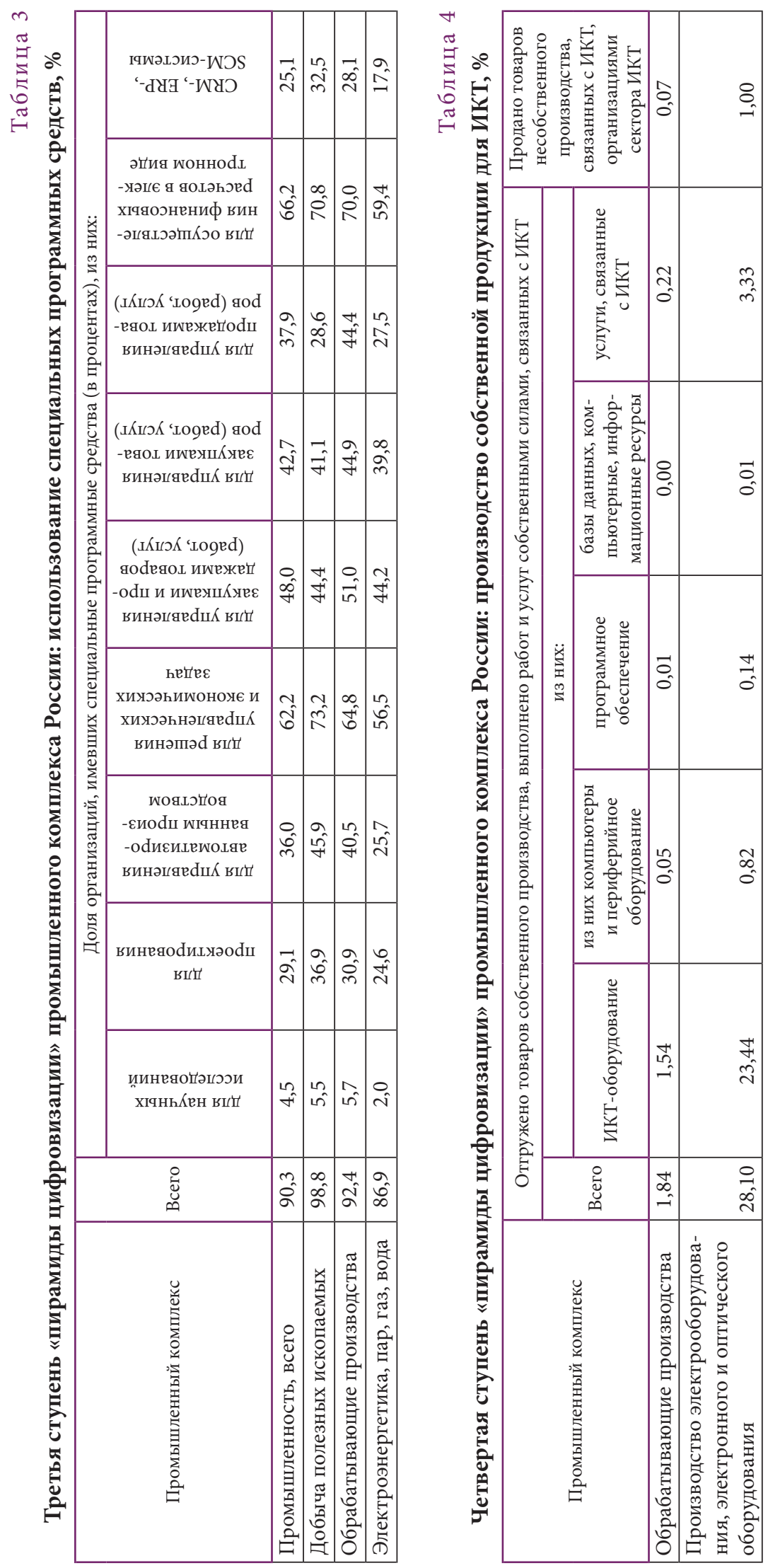
Как уже отмечалось, третья стадия напрямую связана с применением программных систем интеграции производства и управления трудовыми и финансовыми ресурсами, обеспечивающих общую модель данных и процессов для всех сфер деятельности (ERPсистемы), а также систем управления взаимоотношениями с клиентами (CRM-системы). В этом отношении промышленный комплекс России только в середине пути: ERP-, SCM- и CRM-системы имеет одно предприятие из четырех $(25,1 \%)$, специальные программные средства для управления автоматизированным производством - одно предприятие из трех (36\%), программное обеспечение для управления закупками и продажами товаров (работ, услуг) - каждое второе (48\%).

В отраслевом разрезе лидерами эксплуатации специальных программных средств (помимо бухгалтерских программ и правовых баз) ожидаемо являются высокотехнологичные предприятия электротехнической и химической промышленности. Здесь доля предприятий, внедривших ERP- и CRM-системы, 35-40\%, а предприятий, использующих программные средства для научных исследований, 12-18\%. Число предприятий, использующих программное обеспечение для проектирования достаточно высоко в производстве электро- и электронного оборудования (57\%) и в металлургическом производстве (53,7\%). В машиностроительном комплексе применение специального программного обеспечения значительно меньше в сегменте транспортного машиностроения, а в целом низкие значения демонстрирует легкая, пищевая и деревообрабатывающая промышленность.

Один из важный трендов российского рынка специальных программных средств это разворот спроса в сторону услуг по внедрению или разработке решений, замещающих зарубежные. И дело тут не только в прямых запретах на закупку зарубежного программного обеспечения для государственных нужд, но и в высокой стоимости ежегодного сопровождения западных решений. Поэтому все чаще ставятся задачи по замене программного обеспечения на базе западного проприетарного софта на решения на СПО-платформах или на продукцию российских разработчиков. В новых стартующих проектах промышленные предприятия, которые не хотят рисковать при замене уже работающих систем, в большинстве случаев готовы рассматривать российское решение как приоритетное.

В настоящее время по объему потребляемой станкостроительной продукции Россия занимает 8-е место в мире, при том, что по объему производства станков лишь 21-е место. Можно предположить, что сегодняшнее потребление станков определяет возможности производства завтрашнего дня, так как, покупая определенное количество оборудования, производители обновляют текущие мощности и увеличивают возможности для наращивания производства в будущем. И если, к примеру, Китай в разы опережает ближайшего конкурента (США) по потреблению станков, то надо полагать, что в недалеком будущем он будет опережать США в промышленном производстве примерно в том размере, в каком он сейчас опережает американцев в обновлении и установке нового оборудования.

Не обнадеживает и то, что Россия в списке потребителей оборудования за постсоветский период не поднималась выше 7-го места. Усугубляет ситуацию то, что доля нового оборудования невелика, а станки с ЧПУ, по разным оценкам, составляют около 5\% парка, тогда как в странах ЕС - 21\%. Стоит также отметить почти полную зависимость нашего станкостроения от импорта систем ЧПУ даже для собственного производства станков.

Собственное производство информационно-коммуникационного оборудования (четвертая ступень «пирамиды иифровизации»). Уровень развития и объемы собственного производства предприятий электротехнической промышленности выступают индикатором общего технологического уровня развития любой страны (табл. 4). В России отрасль по производству электрооборудования, электронного и оптического 
оборудования занимает менее 5\% в объеме промышленного производства при незначительной динамике доли - с 3,3\% в 2005 г. до 4,4\% в настоящее время. При этом российский рынок электроники и компонентов консолидирован с доминирующим положением зарубежных производителей, импорт составляет $73 \%$.

В электротехнической отрасли объем отгрузки товаров собственного производства, связанных с ИКТ, составляет 28,1\%, что в пересчете на весь объем промышленного производства дает пугающую величину - 1,8\%. Основные причины низких темпов роста производства микроэлектронных компонентов в России кроются в технологическом отставании. Кроме того, производители микроэлектронных компонентов очень зависимы от государственных заказов на внутреннем рынке сбыта (более чем 40\% объема занимает продукция военного и специального назначения). При этом в большинстве развитых государств главный спрос формируется в частном секторе, а государственные заказы составляют примерно 14\% в структуре потребления микроэлектроники в мире. Развитие электронной промышленности на основе использования отечественных электронных компонентов может и должно обеспечить независимость в важнейших областях информатизации, телекоммуникации и связи.

Производство и использование роботов и датчиков - промышленный Интернет (пятая ступень «пирамиды иифровизации»).

Робототехника в России является одной из важнейших отраслей для будущего технологического и экономического развития страны. Роботы уже давно активно используются российской промышленностью, армией, силовыми ведомствами, в научных исследованиях и в сфере образования. Однако потенциал применения роботов гораздо выше современных масштабов их использования. В России еще очень мало роботов, рассчитанных на частного и коммерческого массового потребителя. По данным Национальной ассоциации участников рынка робототехники, среднегодовые продажи промышленных роботов в России составляют 500-600 ед., это около 0,25\% мирового рынка.

В целом плотность роботизации (использование промышленных роботов - запрограммированных манипуляторов на 10 тыс. занятых) в России почти в 70 раз ниже. Однако если рассмотреть сегмент промышленных роботов на основе манипулятора, то их в 10 раз больше, чем сервисных роботов. Этот рынок в России достаточно зрелый, ему 20 лет, и он растет в среднем на $11 \%$ в год - лучше, чем металлургия, чем автомобильная промышленность. Но положительной динамики еще недостаточно, чтобы говорить о «пятой ступени» цифровизации.

Аналогична ситуация с датчиками. Важной материальной составляющей технологического уровня являются контрольно-измерительные приборы и средства автоматизации. Данный рынок в России давно сформирован, на нем присутствуют и отечественные производители. Рост потребности в датчиках и аналитическом оборудовании идет опережающими темпами по сравнению с общим ростом отраслей промышленности. Это связано с тем, что, помимо создания новых производственных мощностей, происходит активная модернизация оборудования, установленного 20 или 30 лет назад и давно не отвечающего современным требованиям. Значительную долю занимает также плановая замена и ремонт датчиков на уже работающих производствах. Однако динамичный рост спроса на датчики и сенсоры еще не залог успешного развития промышленного Интернета. Ведь промышленный «Интернет вещей» - это компьютеризация всего на предприятии, когда в единую информационную сеть объединяются не только все производственные объекты, оборудование и рабочие места, но и детали, компоненты, готовая продукция. Таким образом формируется среда, где машины начинают понимать свое окружение и общаться между собой по интернет-протоколу, минуя операторов, самостоятельно решая вопросы повышения эффективности или, например, предотвращая внештатные ситуации. 
Внедрение новейших систем управления и средств автоматизации в России находится на начальном этапе развития. Сейчас основная цель для страны не в том, чтобы научить машины обходиться без людей, а в том, чтобы помочь людям и машинам взаимодействовать. Потенциал повышения эффективности на основе внедрения элементов промышленного Интернета в России значительно выше, чем в развитых странах. На современных западных производствах уже многое автоматизировано, и повышение эффективности на 1-2\% - это уже очень хорошо. В России, где «все только начинается», возможен скачок продуктивности на 10-30\%.

\section{Заключение}

Увлечение концепцией постиндустриального общества, делающей ставку на развитие сферы услуг, необоснованно преуменьшило роль промышленности в обеспечении роста национального благосостояния. Между тем для устойчивого роста экономики необходимо развитие всех составляющих ее элементов (производственной системы и системы дистрибуции/сферы услуг). При этом здоровый производственный сектор является драйвером развития сферы услуг, а также источником долгосрочных успехов и процветания национальной экономики.

Безальтернативно, что именно цифровизация станет «локомотивом» развития отечественной промышленности. По оценкам компании McKinsey, цифровизация экономики России позволит увеличить ВВП страны на 4,1-8,9 трлн р. к 2025 г., что составит от 19 до 34\% общего ожидаемого роста ВВП [17]. По оценкам министерства промышленности и торговли РФ, системный переход на цифровую модель развития позволит обеспечить к 2024 г. рост производительности труда в обрабатывающих отраслях более чем на $30 \%$, а увеличение вклада секторов, базирующихся на передовых производственных технологиях, в ВВП страны - до $15 \%{ }^{1}$. Даже если реальные достижения окажутся скромнее, этот тренд позволит говорить о полноценной последовательной цифровизации промышленности России. Причем интенсивное развитие может и должно идти одновременно по всем стадиям трансформации, представленным в настоящей статье, а особенно на верхних ступенях «пирамиды».

Помимо решения основных задач цифровизации, особое внимание должно быть уделено вопросам оценки и моделирования эффектов цифровизации в промышленности. Угрозы для рынка труда, вероятность усиления монополизации, цифровое неравенство регионов, усиление многоукладности российской промышленности без решения их системным путем могут стать серьезными барьерами процесса цифровизации промышленности России.

\section{Источники}

1. Акбердина В. В., Гребенкин А. В., Бухвалов Н. Ю. Моделирование инновационного резонанса в индустриальных регионах // Экономика региона. 2015. № 4 (44). С. 289-308.

2. Акбердина В.В., Смирнова О.П. Сетевые сопряженные производства в контексте четвертой промышленной революции // Журнал экономической теории. 2017. № 4. С. $116-125$.

3. Белл Д. Грядущее постиндустриальное общество. М.: Академия, 1999.

4. Белл Д., Иноземцев В. Л. Эпоха разобщенности: размышления о мире XXI века. М.: Свободная мысль: Центр исследований постиндустриального общества, 2007.

5. Бодрунов С. Д. Интеграция производства, науки и образования как основа реиндустриализации российской экономики // Экономическое возрождение России. 2015. № 1 (43). С. 7-22.

${ }^{1}$ Пресс-релиз заседания Совета при Президенте РФ по стратегическому развитию и приоритетным проектам, 5 июля 2017 г. URL: http://minpromtorg.gov.ru/press-centre/news. 
6. Бодрунов С.Д. Реиндустриализация российской экономики - возможности и ограничения // Научные труды Вольного экономического общества России. 2014. № 1. C. $15-46$.

7. Бодрунов С. Д. Реиндустриализация. Круглый стол в Вольном экономическом обществе России // Мир новой экономики. 2014. № 1. С. 11-17.

8. Бодрунов С.Д., Гринберг Р.С., Сорокин Д.Е. Реиндустриализация российской экономики: императивы, потенциал, риски // Экономическое возрождение России. 2013. № 1 (35). С. 19-49.

9. Валентей С.Д. Реиндустриализация экономики России в условиях новых угроз. М.: РЭУ им. Г. В. Плеханова, 2015.

10. Иноземцев В.Л. За пределами экономического общества. Постиндустриальные теории и постэкономические тенденции в современном мире. М.: Academia - Наука, 1998.

11. Иноземцев В.Л. Постиндустриально/индустриальная дихотомия // Мир перемен. 2014. № 1. С. 144-147.

12. Иноземцев В.Л. Современное постиндустриальное общество: природа, противоречия, перспективы. Введение. М.: Логос, 2000.

13. Романова О.А., Акбердина В.В., Бухвалов Н. Ю. Общие ценности в формировании современной технико-экономической парадигмы // Экономические и социальные перемены: факты, тенденции, прогноз. 2016. № 3 (45). С. 173-190.

14. Татаркин А.И., Акбердина В.В., Бухвалов Н. Ю. Инклюзивное технологическое развитие как новый элемент технико-экономической парадигмы // Стратегии развития социальных общностей, институтов и территорий: материалы II Междунар. науч.практ. конф. (Екатеринбург, 18-20 апреля 2016 г.): в 2 т. Екатеринбург: Изд-во Урал. ун-та, 2016. С. 41-47.

15. Тоффлер Э. Третья волна. М.: Изд-во АСТ, 2010.

16. Уэбстер Ф. Теории информационного общества: пер. с англ. М.: Аспект Пресс, 2004.

17. Цифровая Россия: новая реальность / А. Аптекман, В. Калабин, В. Клинцов и др. McKinsey \& Company, 2017.

18. Черняк Л. Платформа Интернета вещей // Открытые системы. СУБД. 2012. № 7. C. $98-104$.

19. Ashton K. That «Internet of Things» Thing. In the Real World, Things Matter More Than Ideas // RFID Journal. 2009. Jun 22. URL: http://www.rfidjournal.com/articles/view? 4986.

20. Clark C. The Conditions of Economic Progress. L.: Logan Pub., 1991.

21. Fouratie J. Le Grand Espoir du XXe siècle: Progres Technique, Progress Economique, Progress Social. P.: Presses Universitaires de France, 1949.

22. Heilbroner R. An Inquiry into the Human Prospect. $2^{\text {nd }}$ ed. W. W. Norton, 1980.

23. Kumar K. From Post-Industrial to Post-Modern Society: New Theories of the Contemporary World. Oxford, UK \& Cambridge, USA: Blackwell, 1996.

24. Kumar K. Prophecy and Progress: The Sociology of Industrial and Post-Industrial Society. Alein Lane, 1978. 


\title{
The Transformation of the Russian Industrial Complex Under Digitalisation
}

\author{
by Viktoria V. Akberdina
}

The article presents an approach to assessing the transformation of an industrial complex in the conditions of deep penetration of digital technologies into the material sector of the economy. It formulates a theoretical research platform based on the theory of the new industrial society, and substantiates a methodology encompassing reproductive, institutional and synergetic approaches. The paper shows that the transformation of the industrial complex, caused by any factors and implemented in any conditions, is always a discrete process of qualitative changes, leading to significant structural changes and institutional transformations. The author proposes a method for identifying the stages of the industrial complex transformation in the digital economy, representing them in the form of a pyramid, each of which has a certain "gene of digitalisation". The author's digitalisation pyramid includes five stages: primary ICT digitalisation; electronic data exchange with external partners; application of special software; own production of information and communication technologies and equipment; production and application of industrial robots and sensors. Having applied the described method, the author assesses the level of digitalisation of the Russian industrial complex and makes a conclusion about quite high degree of primary computerisation, inclusion of industrial enterprises into "digital" exchange with suppliers and consumers, and dynamic development of the domestic software. At the same time, the analysis demonstrated that the process of digital transformation of the Russian industry is at its initial stages, and the achievement of the ambitious goals is possible only provided the goverment implements a competent industrial policy.

Keywords: digitalisation; new industrialisation; transformation of industry; digitalisation gene.

References:

1. Akberdina V.V., Grebenkin A. V., Bukhvalov N. Yu. Modelirovanie innovatsionnogo rezonansa $\mathrm{v}$ industrial'nykh regionakh [Modeling of innovative resonance in industrial regions]. Ekonomika regiona - Economy of Region, 2015, no. 4 (44), pp. 289-308.

2. Akberdina V. V., Smirnova O. P. Setevye sopryazhennye proizvodstva v kontekste chetvertoy promyshlennoy revolyutsii [Network productions in the context of the fourth industrial revolution]. Zhurnal ekonomicheskoy teorii - Russian Journal of Economic Theory, 2017, no. 4, pp. 116-125.

3. Bell D. Gryadushchee postindustrial'noe obshchestvo [The coming of post-industrial society]. Moscow: Akademiya Publ., 1999.

4. Bell D., Inozemtsev V.L. Epokha razobshchennosti: razmyshleniya o mire XXI veka [The era of disunity: Thinking about the world of the $21^{\text {st }}$ century]. Moscow: Svobodnaya mysl Publ., Center for Post-Industrial Society Research, 2007.

5. Bodrunov S.D. Integratsiya proizvodstva, nauki i obrazovaniya kak osnova reindustrializatsii rossiyskoy ekonomiki [Integration of production, science and education as the basis for the reindustrialization of the Russian economy]. Ekonomicheskoe vozrozhdenie Rossii - Economic Revival of Russia, 2015, no. 1 (43), pp. 7-22.

6. Bodrunov S.D. Reindustrializatsiya rossiyskoy ekonomiki - vozmozhnosti i ogranicheniya [Reindustrialization of the Russian economy - opportunities and limitations]. Nauchnye trudy Volnogo ekonomicheskogo obshchestva Rossii - Scientific Works of the Free Economic Society of Russia, 2014, no. 1, pp. 15-46.

7. Bodrunov S. D. Reindustrializatsiya. Kruglyy stol v Vol'nom ekonomicheskom obshchestve Rossii [Reindustrialization. Roundtable in the Free Economic Society of Russia]. Mir novoy ekonomiki - World of the New Economy, 2014, no. 1, pp. 11-17.

8. Bodrunov S. D., Grinberg R.S., Sorokin D. Ye. Reindustrializatsiya rossiyskoy ekonomiki: imperativy, potentsial, riski [Reindustrialization of the Russian economy: Imperatives, potential, risks]. Ekonomicheskoe vozrozhdenie Rossii - Economic Revival of Russia, 2013, no. 1 (35), pp. 19-49.

9. Valentey S.D. Reindustrializatsiya ekonomiki Rossii v usloviyakh novykh ugroz [Reindustrialization of the Russian economy in the face of new threats]. Moscow: Plekhanov Russian University of Economics, 2015.

10. Inozemtsev V.L. Za predelami ekonomicheskogo obshchestva. Postindustrial'nye teorii i postekonomicheskie tendentsii v sovremennom mire [Outside the economic society. Post-industrial theories and post-economic trends in the modern world]. Moscow: Academia - Nauka Publ., 1998.

11. Inozemtsev V.L. Postindustrial'no/industrial'naya dikhotomiya [Postindustrial / industrial dichotomy]. Mir peremen - World of Changes, 2014, no. 1, pp. 144-147. 
12. Inozemtsev V. L. Sovremennoe postindustrial'noe obshchestvo: priroda, protivorechiya, perspektivy. Vvedenie [Modern post-industrial society: Nature, contradictions, perspectives. Introduction]. Moscow: Logos, 2000.

13. Romanova O.A., Akberdina V.V., Bukhvalov N. Yu. Obshchie tsennosti v formirovanii sovremennoy tekhniko-ekonomicheskoy paradigmy [Common values in the formation of a modern technical and economic paradigm]. Ekonomicheskie i sotsialnye peremeny: fakty, tendentsii, prognoz - Economic and Social Changes: Facts, Trends, Forecast, 2016, no. 3 (45), pp. 173-190.

14. Tatarkin A.I., Akberdina V.V., Bukhvalov N. Yu. Inklyuzivnoe tekhnologicheskoe razvitie kak novyy element tekhniko-ekonomicheskoy paradigmy [Inclusive technological development as a new element of the technical and economic paradigm]. Materialy II Mezhdunarodnoy nauchno-prakticheskoy konferentsii "Strategii razvitiya sotsial'nykh obshchnostey, institutov i territoriy" [Proc. $2^{\text {nd }}$ Int. Sci.-Prac. Conf. "Development Strategies of Social Communities, Institutions and Territories"]. Yekaterinburg: Ural University Publ., 2016, pp. 41-47.

15. Toffler E. Tretya volna [The third wave]. Moscow: AST Publ., 2010.

16. Webster F. Teorii informatsionnogo obshchestva [Theories of the information society]. Moscow: Aspekt Press Publ., 2004.

17. Aptekman A., Kalabin V., Klintsov V. et al. Tsifrovaya Rossiya: novaya real'nost' [The digital Russia: New reality]. McKinsey \& Company, 2017.

18. Chernyak L. Platforma Interneta veshchey [The platform of the Internet of things]. Otkrytye sistemy. SUBD - Open Systems. DBMS, 2012, no. 7, pp. 98-104.

19. Ashton K. That "Internet of Thing" Thing. In the Real World, Things Matter More Than Ideas. RFID Journal, 2009, June 22. Available at: http://www.rfidjournal.com/articles/view? 4986.

20. Clark C. The Conditions of Economic Progress. L.: Logan Pub., 1991.

21. Fouratie J. Le Grand Espoir du XXe siècle: Progrès Technique, Progrès Economique, Progrès Social. P.: Presses Universitaires de France, 1949.

22. Heilbroner R. An Inquiry into the Human Prospect. $2^{\text {nd }}$ ed. W. W. Norton, 1980.

23. Kumar K. From Post-Industrial to Post-Modern Society: New Theories of the Contemporary World. Oxford, UK \& Cambridge, USA: Blackwell, 1996.

24. Kumar K. Prophecy and Progress: The Sociology of Industrial and Post-Industrial Society. Alein Lane, 1978.

Contact Info:

Viktoria V. Akberdina, Dr. Sc. (Econ.), Prof. of RAS, Head of Regional Industrial Policy and Economic Security Dept.

Prof. of Regional Economics, Innovative

Business and Security Dept.

Phone: (343) 371-45-36

e-mail: akb_vic@mail.ru

Institute of Economics (Ural branch of RAS) 29 Moskovskaya St., Yekaterinburg, Russia, 620014

Ural Federal University named after. B. N. Yeltsin 19 Mira St., Yekaterinburg, Russia, 620002

Ссылка для цитирования: Акбердина В.В. Трансформация промышленного комплекса России в условиях цифровизации экономики // Известия Уральского государственного экономического университета. 2018. T. 19, № 3. С. 82-99. DOI: 10.29141/2073-1019-2018-19-3-8

For citation: Akberdina V.V. Transformatsiya promyshlennogo kompleksa Rossii v usloviyakh tsifrovizatsii ekonomiki [The transformation of the Russian industrial complex under digitalisation]. Izvestiya Uralskogo gosudarstvennogo ekonomicheskogo universiteta - Journal of the Ural State University of Economics, 2018, vol. 19, no. 3, pp. 82-99. DOI: 10.29141/2073-1019-2018-19-3-8 


\section{Grigory B. KOROVIN}

Cand. Sc. (Econ.), Head of Industrial Markets' Economic Problems Sector

Institute of Economics (Ural branch of RAS)

29 Moskovskaya St., Yekaterinburg, Russia, 620016

Phone: (343) 371-45-36

e-mail: grig_korovin@mail.ru

\section{Problems of Industrial Digitalisation in Russia'}

The paper examines Industry 4.0, which is a world-leading concept of industrial development, involving the use of a wide range of advanced digital technologies and total automation of production. From a methodological perspective, the author considers digitalisation of production in three aspects: application of digital technologies in traditional industry; rapid development of the digital sector of the economy; emergence of new opportunities for human development. Adopting such an approach the research systematises technological changes and economic models critical to the industrial development. By performing a bibliographical search the author outlines the modern concepts of digital production development. The paper carries out an assessment of economy digitalisation in Russia and its regions on the basis of statistical and information materials published domestically and internationally. The author identifies the risks for the domestic industry, associated with its probable lag in technological development, and proposes potential ways to neutralise them.

JEL classification: $\mathrm{O} 33, \mathrm{O} 38$

Keywords: Industry 4.0; digitalisation; industry; digital economy; technological development.

\section{Introduction}

$\mathrm{T}$ he main global industrial development concept is a phenomenon called Industry 4.0 to which the terms "industrial Internet of things" and "digital production" are directly related. Industry 4.0 involves end-to-end digitalisation of technological and business processes and their comprehensive integration into digital ecosystem. There are a number of interrelated, not yet well-established concepts: "digitalisation", "digital economy", and "digital production". Despite the fact that in the initial understanding, digitalisation means replacement of analog data collection and processing systems with digital ones, in the modern sense, it refers to application of a wide range of advanced digital technologies (computers, networks, and software) and total automation of production and business processes in the economy, as well as mass application of digital technologies in the social sphere. Integrity of the phenomena known as the digital economy and importance of global trends for domestic industry necessitate a search for new scientific approaches to assess and systematize digitalisation, to manage risks and threats, and to develop measures for their mitigation. The abovementioned ideas predetermined the objectives and tasks of this study.

\section{Research methodology}

From our perspective, digitalisation of productions manifests itself in three important trends: application of digital technologies in legacy industries; rapid growth of industries and companies associated with the production of software, electronic components, data storage, processing, and transmission, e-commerce, creation of web services; the emergence of new opportunities for human development, including knowledge sharing, occupational skills training, etc.

${ }^{1}$ The reported study was funded by RFBR according to the research project no. 18-010-01156. 
In this context, we will discuss the manifestations of digital economy in three main aspects (Fig. 1):

- Creation and development of new industries, primarily in the information and communication technologies sector of the economy.

- Modernisation of the existing production facilities by adopting digital technologies.

- Development of digital services for personal and social advancement.

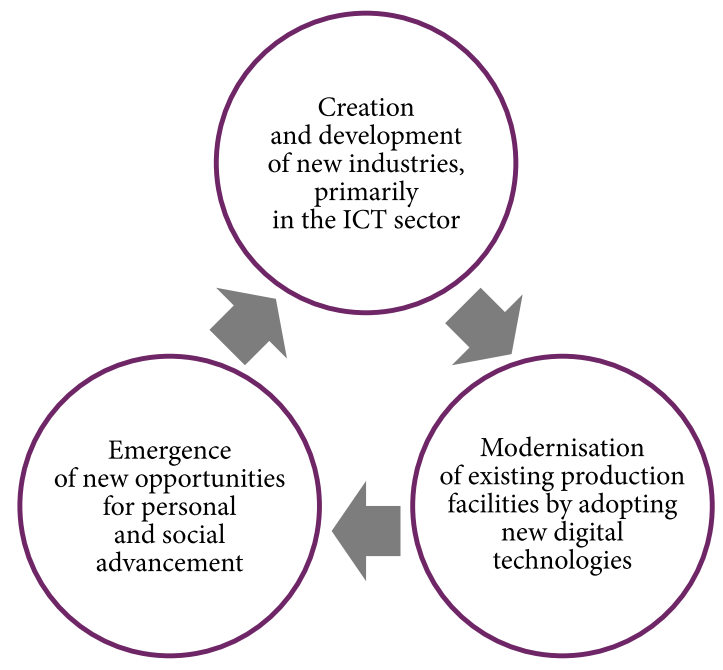

Fig. 1. Systematisation of digital economy manifestations

Some researchers believe digitalisation is a stage in the IT development as part of the sixth wave of innovation $[1 ; 3 ; 4]$. In this case, development of information services is part of an infrastructure specific for the emerging wave, and the leading companies in the digital economy can form a core of it. Rating of the world's largest companies in their industries can serve as one of confirmations of this approach. The largest companies today are involved in ICT, while 50 years ago they were mainly machine-building and energy firms. When studying the digital economy development, we tried to apply the above approach of assessing its manifestations in the three spheres.

\section{Digital economy concepts}

Digital technology development processes and prospects of their industrial application were first presented in 2011 in Germany as part of the government concept "Industry 4.0.... This event is regarded as a starting point for the development and application of such concepts by the leading nations of the globe including the Internet of Things, Industrial Internet (USA), Industry Value Chain Initiative (Japan), Industrial Innovation 3.0 (South Korea), Productivity 4.0 (Taiwan), Smart Factory (Netherlands), Usine du Futur (France), High Value Manufacturing Catapult (Great Britain), and Fabbrica del Futuro (Italy).

In Russia, both the government and the business community monitored these processes and formally responded in 2017 by developing the State Program named "Digital Economy of the Russian Federation". Regional programs are also being prepared locally (for example, the Planning Office of the Government of the Sverdlovsk Region is setting up a regional program on digital economy).

Such concepts usually contain goals and schedule for modernisation of the existing production facilities by employing new digital technologies, establishment and development of ICT enterprises, and creation of an appropriate infrastructure and legal framework in the country. Apart from the Program "Digital Economy of the Russian Federation", a number 
of strategic documents that have been adopted in Russia have a significant effect on application of digital technologies in the Russian economy:

- Strategy of scientific and technological development of the Russian Federation;

- Strategy of IT industry development in the Russian Federation for 2014-2020 and projected up to 2025;

- The State Program of the Russian Federation "Information Society (2011-2020)";

- National security strategy of the Russian Federation.

- Open Government projects (portals: electronic budget, public e-services, open data, etc.) are being implemented, electronic registration and trade platforms (third-party only insurance, medicines, prescriptions, register of apartment rental patents, etc.) have been created, road maps have been formed for the National technological initiative - Healthnet, Neuronet, Aeronet, and Marinet, which determine the lines of technological development.

\section{Lines of development and key technologies of digital economy}

Prerequisites to digital revolution, as already noted, include rapid development of existing and emergence of a number of new technologies with the key ones being: growth of information networks - population and enterprise coverage reaches $90 \%$ or higher; production equipment and personal devices connected to global networks; remote computing power and storage facilities options; emergence of programs, computing resources and sensors capable of collecting and analyzing huge amounts of data. Products become more sophisticated and include not only mechanical, but also essential electrical and electronic components, and more recently software, the "weight" of the latter keeps growing. Apart from these technologies, it is worthwhile to mention robotisation, artificial intelligence, virtual reality, geolocation, etc., which are also associated with digitalisation.

For the industry, the most important technologies in this sphere are 3D-printing, robotisation, artificial intelligence, Internet of things and connectivity of facilities, automated engineering, new sensors and transmitters, and application of intelligent networks in power industry. In general, these technologies allow the cyber-physical systems - i.e. facilities where devices operate without human intervention and are controlled by software through advanced sensors - to be set up and employed in the industry. The evidence of this is total automation of production and business processes, and maximum horizontal and vertical integration of information. Moreover, such facilities can be distributed among countries and managed as a single package via the Internet.

Technological development within the concept of digital economy implies a reorientation of various engineering and technological systems, which would affect both the high-tech sector of the economy and conventional industries. Transition to a new model of economic development involves both the transformation of industrial development institutions and business models, and improvement of industrial policy. Technologies, organisational features, and economic effects associated with digital economy are summarized in Table 1.

The Industry 4.0 technologies and their possible impact on the industry, as well as their applications in production, have been described in a variety of publications, for instance in $[13 ; 15]$.

\section{Digital production}

Technological changes have made it possible to create and apply a number of scientific and practical concepts that allow modern digital technologies to be comprehensively implemented in industrial production. Bibliographic search helped identify a number of approaches including Intelligent Manufacturing [17], Cybermanufacturing [9], Distributed Manufacturing Systems [12; 14], Cloud manufacturing [10], Cloud-based design and manufacturing for serviceoriented products [16], IoT-enabled manufacturing [7], Hybrid Manufacturing Cloud [11], 
Table 1

Technologies, organizational features, and economic effects of economy digitalization

\begin{tabular}{|c|c|c|c|}
\hline & $\begin{array}{l}\text { Information and } \\
\text { communication technologies } \\
\text { sector }\end{array}$ & Conventional industries & Society \\
\hline Technologies & $\begin{array}{l}\text { Big data. } \\
\text { Internet of things. } \\
\text { Cloud computing. } \\
\text { Artificial Intelligence. } \\
\text { Virtual reality applications. } \\
\text { Connectivity of facilities } \\
\text { and people via the Internet. } \\
\text { Geolocation }\end{array}$ & $\begin{array}{l}\text { Big data. } \\
\text { Additive technologies } \\
\text { and atomic precision } \\
\text { manufacturing. } \\
\text { Automation and } \\
\text { robotization. } \\
\text { Internet of things. } \\
\text { Computer-aided } \\
\text { engineering. } \\
\text { Cloud computing. } \\
\text { New sensors and } \\
\text { transmitters. } \\
\text { Low- and post-carbon } \\
\text { energy. } \\
\text { Utilization of intelligent } \\
\text { networks and distributed } \\
\text { generation. } \\
\text { Connectivity of facilities }\end{array}$ & $\begin{array}{l}\text { Smart mobile devices. } \\
\text { Broadband Internet } \\
\text { connection. } \\
\text { Augmented reality. } \\
\text { E-commerce. } \\
\text { Personalized advertising. } \\
\text { Different types of 3D } \\
\text { simulations. } \\
\text { Geolocation technologies, } \\
\text { geolocation marketing. } \\
\text { Blockchain. } \\
\text { Digital services to monitor } \\
\text { home, movement, health } \\
\text { condition, etc. }\end{array}$ \\
\hline Organization & $\begin{array}{l}\text { End-to-end automation } \\
\text { of business processes, } \\
\text { application of ERP, CRM, } \\
\text { PLM. } \\
\text { Digital platforms. } \\
\text { Knowledge sharing. } \\
\text { Lean production }\end{array}$ & $\begin{array}{l}\text { Distributed cyber-physical } \\
\text { systems. } \\
\text { Industrial networks. } \\
\text { Distributed generation. } \\
\text { End-to-end automation, } \\
\text { application of ERP, CRM, } \\
\text { PLM. } \\
\text { Digital platforms. } \\
\text { Establishment of service- } \\
\text { oriented business } \\
\text { architecture }\end{array}$ & $\begin{array}{l}\text { Disappearance of jobs, } \\
\text { the emergence of new } \\
\text { occupations. } \\
\text { Distance learning, } \\
\text { knowledge sharing. } \\
\text { Public e-services. } \\
\text { Growth in non-cash } \\
\text { financial payments. } \\
\text { Development } \\
\text { of telemedicine }\end{array}$ \\
\hline Economy & $\begin{array}{l}\text { Achievement of high } \\
\text { levels of complexity in } \\
\text { information products and } \\
\text { services. } \\
\text { Reduction of the time } \\
\text { required to manufacture } \\
\text { and market goods. } \\
\text { Growth in productivity. } \\
\text { Increase in the number } \\
\text { of new products }\end{array}$ & $\begin{array}{l}\text { Increase of manageability } \\
\text { of production and } \\
\text { technological processes. } \\
\text { Reduction of costs and } \\
\text { time consumption }\end{array}$ & $\begin{array}{l}\text { Automated pricing. } \\
\text { Product sharing. } \\
\text { Personalized production } \\
\text { and consumption }\end{array}$ \\
\hline
\end{tabular}

etc. Moreover, the number of academic papers on the subject in the global research databases has been steadily growing for more than 25 years.

Formation of a digital ecosystem for the industry, namely new digital platforms, is an important feature of digitalisation. Typically, these include:

- technological design - networks, data centers, cloud technologies, data processing and data submission applications;

- new business models, ecosystems of developers and suppliers of individual modules and applications formed around a platform company; 
- new principles of interaction between producers and consumers, an open, publicly accessible infrastructure for interaction.

According to the Center for Strategic Research Foundation [5], in 2015 there were 64 platform companies in China, 63 in the US, and 9 in the UK, while Russia accounted for only three companies classed as platform.

In the sphere of social development, we are primarily speaking about the emergence of network technologies and various types of networked devices that allow a remote, real-time acquisition, processing, and transmission of significant amounts of data. These technologies made it possible to implement a number of services that have significantly changed the life of society. In regard to the problem of increase of human capital for the purposes of industrial development, the following new technological capabilities can be identified:

- customisation of products and services produced by the industry at client's request;

- digital services for real-time monitoring of home, movement, health, etc.

- a new quality of education, remote services (for example, about 18 million students are signed up for the Coursera online educational platform), switching from project-oriented to experiment-oriented education;

- feasibility of conducting research based on "big data", artificial intelligence, and digitalisation;

- development of “4P" medicine (preventive, prognostic, patient-oriented, personified);

- growth in non-cash financial payments;

- public e-services and computer-aided control of legally binding actions.

It should also be noted that the change in the labour market structure towards robotisation (according to some sources, up to $25-30 \%$ of jobs will be displaced in the near future), disappearance of a number of "obsolete" occupations and demand for the new ones associated with the use of advanced production technologies, intellectualisation, robotisation of production, stronger creative component of labour, etc.

The integrated approach allowed the author to summarize the features of industrial digitalisation with regard to the drivers and structural principles of production systems (Fig. 2).

\begin{tabular}{|c|c|c|}
\hline $\begin{array}{l}\text { Drivers: } \\
\text { - technological; } \\
\text { - organisational; } \\
\text { - innovative; } \\
\text { - operational }\end{array}$ & $\begin{array}{l}\text { Outcomes: } \\
\text { - smart products and services; } \\
\text { - mass customisation; } \\
\text { - decentralisation of production } \\
\text { management; } \\
\text { - flexible production networks; } \\
\text { - flexible logistic chains; } \\
\text { - data-based improvement } \\
\text { of production; } \\
\text { - flexible innovations } \\
\text { in the product life cycle }\end{array}$ & $\begin{array}{l}\text { Structural principles } \\
\text { of production systems: } \\
\text { - compatible functionality; } \\
\text { - virtuality; } \\
\text { - real time accessibility; } \\
\text { - decentralisation; } \\
\text { - service orientation; } \\
\text { - modularity }\end{array}$ \\
\hline
\end{tabular}

Fig. 2. Drivers, principles, and outcomes of industrial digitalisation

A thorough literature review suggests how the adoption of digital technologies would occur in the main sectors of domestic industry. For the extractive industries, the most promising directions are automation, robotisation and personnel cuts, digitalisation of extraction, with growth in business models based on supply of digital services and assets (e.g. cloud technologies), 3D modeling of deposits, radar monitoring systems, Mine of the Future [6] and Digital Mine [8] concepts. Processing industries, as part of transition to product platforms and the need to manage the entire life cycle of a product, will use big data analysis, artificial intelligence, and new digital modeling methods. At the production stage, "smart" factories, additive production, atomically precise manufacturing, and advanced materials will be created. 
Production of metallic materials for additive manufacturing, materials with targeted properties will be highly relevant in metallurgy. In the energy sector there is a tendency towards system disintegration, transition to so-called smart networks, scaling up the renewable energy sources, distributed generation, control automation, application of energy storage technologies, security protection, and expansion of energy applications. As a consequence of technological development there will be a change in business models and formation of flexible markets with a demand management capability. Industrial infrastructure will also undergo significant changes including, in particular, the emergence of intelligent transport and autonomous vehicles, high-speed communications, data storage facilities and much more. Similar changes should also occur in financial activities, security, education, and healthcare.

It is important to create new industries oriented to cultivating industrial consumption markets, including those for fundamentally new branches of economy. Critical technological directions for these industries will involve the use of equipment and materials for the post-carbon energy; new materials; microelectronics and new generation element base; biotechnology and production of medical equipment; new sensors, transmitters, and measuring instruments, etc.

\section{Assessment of the actual state of Russia's economy digitalisation}

A number of indicators are used to assess the digital economy state in the Russian Federation and its regions. Traditionally, Rosstat, the Russian Federal State Statistics Service, determines the share of organisations that use computers, information networks, conventional and specific software. Indicators used to assess the regions characterize the population's involvement into using networks, high bandwidth networks coverage, online services for purchases, etc.

These statistics were generally studied in the author's previous research and indicated that Russia's industry does not yet demonstrate the ability to follow the global trends in this area. The quality of renewal of production indicates that existing technological structure and organisational solutions in the industry are reproduced with a low level of innovation and corresponding labour productivity. Application of modern information technologies demonstrates moderately positive dynamics, especially in the sphere of human services. In the industry, there has been an increase in the use of software products to computerize a wide range of economic tasks and, in particular, specialist software. The specialist software range employed by the industry predetermines the use of global databases, computerized interaction with partners, but does not provide for extensive use of design and process control tools (Fig. 3).

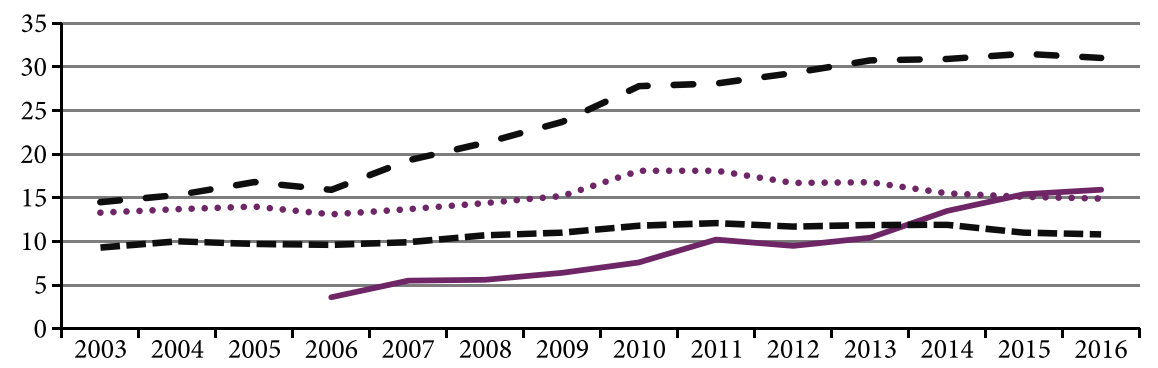

\footnotetext{
....... Organisations using tools to control engineering processes and computer-aided manufacturing

- Organisations using CRM, ERP, SCM systems

- Organisations using means of access to global databases

-r- Organisations using design tools
}

Fig. 3. Shares of organisations using different types of specialist software, $\%$ 
In the sphere of human resourcing, Russia's industry does not demonstrate an increased need for specialists in automation, IT, and communications. At the same time, judging by the estimated number of university graduates in these spheres up to 2020, an increase in demand for them in the economy is expected (Fig. 4).

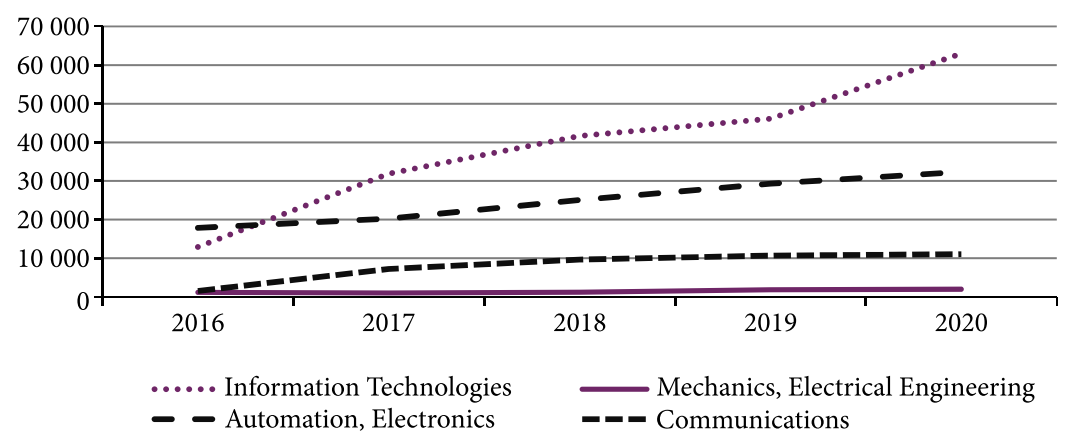

Fig. 4. Estimated number of specialists graduated from Russia's higher educational institutions by job clusters, people

By most of the indices that assess countries' information society advancement, development of information services and digitalisation, Russia usually occupies $30^{\text {th }}$ or $40^{\text {th }}$ places. For example, according to the ICT development index for 2017 (https://www.itu.int), Russia ranked $45^{\text {th }}$. This is also confirmed by research published domestically. For instance, according to the compilation by the Institute for Statistical Studies and the Economics of Knowledge (ISSEK), a branch of the National Research University "Higher School of Economics" (NRU HSE), Russia generally holds $30-40^{\text {th }}$ places in the world [2].

As for the degrees of digital economy development in the regions of the Russian Federation, among the leaders should be named Moscow and St. Petersburg, the republic of Tatarstan, Moscow oblast. Regions of the Urals and Siberia (Chelyabinsk, Sverdlovsk, Novosibirsk, Tyumen oblasts, and Khanty-Mansi autonomous okrug) have good positions but play in the second league (Table 2).

Table 2

\section{Leading regions by the development of digital economy} (rank in the Russian Federation) [2]

\begin{tabular}{|c|c|c|c|c|c|c|c|c|c|}
\hline Region & 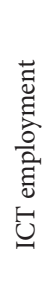 & 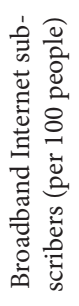 & 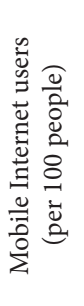 & 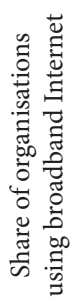 & 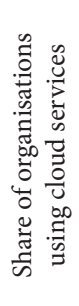 & 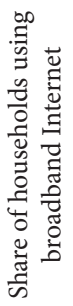 & 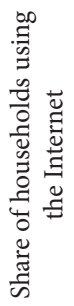 & 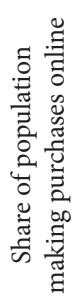 & 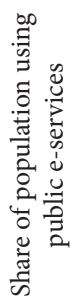 \\
\hline Moscow & 1 & 2 & 1 & 2 & 1 & 7 & 5 & 4 & 6 \\
\hline Saint Petersburg & 2 & 3 & 12 & 3 & 10 & 2 & 2 & 13 & 33 \\
\hline Tatarstan & 3 & 6 & 25 & 28 & 13 & 7 & 9 & 17 & 1 \\
\hline Sverdlovsk oblast & 6 & 8 & 65 & 8 & 13 & 20 & 19 & 28 & 50 \\
\hline Tyumen oblast & 9 & 72 & 82 & 19 & 28 & 9 & 7 & 7 & 5 \\
\hline Chelyabinsk oblast & 12 & 8 & 80 & 19 & 20 & 26 & 19 & 32 & 20 \\
\hline Novosibirsk oblast & 4 & 1 & 50 & 65 & 35 & 32 & 40 & 55 & 29 \\
\hline
\end{tabular}


Table 2 (concluded)

\begin{tabular}{|c|c|c|c|c|c|c|c|c|c|}
\hline Region & 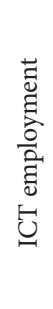 & 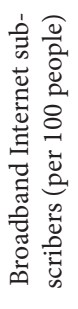 & 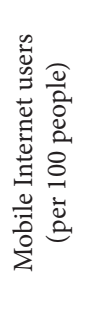 & 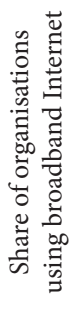 & 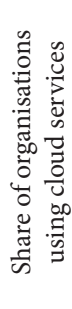 & 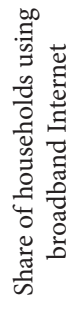 & 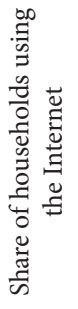 & 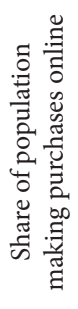 & 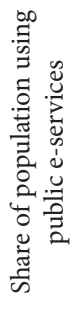 \\
\hline $\begin{array}{l}\text { Khanty-Mansi autono- } \\
\text { mous okrug }\end{array}$ & 17 & 17 & 35 & 14 & 13 & 3 & 2 & 4 & 2 \\
\hline Nizhny Novgorod oblast & 4 & 6 & 45 & 14 & 28 & 53 & 72 & 59 & 33 \\
\hline Moscow oblast & 7 & 65 & 1 & 14 & 13 & 20 & 11 & 28 & 42 \\
\hline Kaluga oblast & 47 & 13 & 25 & 28 & 20 & 74 & 72 & 76 & 3 \\
\hline
\end{tabular}

\section{Risks of industrial digitalisation in Russia}

The trends presented in the paper pose a number of risks for the Russian economy.

First, it is its critical dependence on technologies, equipment, and software products of foreign origin. According to the Russia's Ministry of Industry and Trade, dependence on imports in the automotive, shipbuilding sector, in agricultural, oil and gas, and heavy engineering industries exceeds 50\%. And as for the pharmaceutical, medical, radio electronic, and machine-tool industries, it is beyond $70 \%$. This risk should be reduced by stimulating and creating conditions for the emergence of domestic proprietary designs, as well as by diversifying suppliers of technology and equipment.

Second, there is a growing threat that the Russia's industry will drastically lag behind in terms of labour productivity, resource efficiency, and time required to develop a new product, which leads to a risk of weakening the country's positions on the new and even the traditional markets. As a result of intensive technological progression of the leading countries, the Russian Federation may fall out of the global production chains in high-tech industries.

Third, dramatic changes in the employment structure and freed-up labour may occur as a result of computer-aided manufacturing and changes in the structure of economy (structural shift from energy and metal industries to those of information and communication technologies, engineering). In this regard, the risks associated with the Russia's low ability to convert a high level of human capital development and research insights into technological innovations should be taken into account.

\section{Conclusion}

In order to neutralize the risks and ensure that the Russian industry evolves in accordance with the current trends, an effective system should be built for managing the modernisation of the national economy in the context of a clear orientation toward catching a new wave of innovation.

Important directions include timely regulatory changes to secure the processes of technological and industrial modernisation. It is necessary to modernize the system for managing scientific and technological development to ensure an increase in the share of R\&D expenditures in GDP, and to improve scientific and technological performance. To increase the innovative potential of the industry, it is critical to develop an industrial and information infrastructure capable of providing secure access to global networks, knowledge sharing, development of IT companies at the international level and their participation in leading digital platforms and ecosystems. 


\section{References}

1. Glazyev S. Velikaya tsifrovaya revolyutsiya: vyzovy i perspektivy dlya ekonomiki XXI veka [The great digital revolution: Challenges and prospects for the economy of the $21^{\text {st }}$ Century]. Available at: http://www.glazev.ru/articles/6-jekonomika/54923-velikaja-tsifrovaja-revoljutsija-vyzovy-i-perspektivy-dlja-jekonomiki-i-veka.

2. Abdrakhmanova G.I., Gokhberg L.M., Kevesh M.A. (eds.) Indikatory tsifrovoy ekonomiki: 2017 [Indicators of the digital economy: 2017: Statistical yearbook]. Moscow: HSE VShE Publ., 2017.

3. Kovalchuk Yu. A., Stepnov I.M. Tsifrovaya ekonomika: transformatsiya promyshlennykh predpriyatiy [The Digital Economy: Transformation of Industrial Enterprises]. Innovatsii $v$ menedzhmente - Innovations in Management, 2017, no. 11, pp 33-43.

4. Konina N. Yu. Shestoy tekhnologicheskiy uklad i menedzhment sovre-mennykh kompaniy [The sixth technological structure and management of modern companies]. Voprosy ekonomiki i prava - Economic and Law Issues, 2014, no. 3, pp. 43-46.

5. Knyaginin V.N. (ed.). Novaya tekhnologicheskaya revolyutsiya: vyzovy i vozmozhnosti dlya Rossii. Ekspertno-analiticheskiy doklad [The new technological revolution: Challenges and opportunities for Russia. Expert-analytical report]. Moscow, 2017.

6. Batterham R. J. The Mine of the Future - Even More Sustainable. Minerals Engineering, 2017, vol. 107, pp. $2-7$.

7. Brown E. Who Needs the Internet of Things? Available at: http://www.linux.com.

8. Chaulya S. K., Prasad G. M. (eds.) Sensing and Monitoring Technologies for Mines and Hazardous Areas. Elsevier, 2016.

9. Lee J., Bagheri B., Kao H. A. A Cyber-Physical Systems Architecture for Industry 4.0-based Manufacturing Systems. Manufacturing Letters, 2015, no. 3, pp. 18-23.

10. Li B. H., Zhang L., Wang S. L; Tao F., Cao J. W., Jiang X. D., Song X., Chai X. D. Cloud Manufacturing: A New Service-Oriented Networked Manufacturing Model. Computer Integrated Manufacturing Systems, 2010, vol. 16, no. 1, pp. 1-7.

11. Lu Y., Xu X., Xu J. Development of a Hybrid Manufacturing Cloud. Journal of Manufacturing Systems, 2014, vol. 33, no. 4, pp. 551-566.

12. Matt D. T., Rauch E., Dallasega P. Trends Towards Distributed Manufacturing Systems and Modern Forms for Their Design. Proc. CIRP, 2015, no. 33, pp. 185-190.

13. Santosa C., Mehrsaia A., Barrosa A. C., Araújob M., Aresc E. Towards Industry 4.0: An Overview of European Strategic Roadmaps. Procedia Manufacturing, 2017, no. 13, pp. 972-979.

14. Shen W., Wang L., Hao Q. Agent-based Distributed Manufacturing Process Planning and Scheduling: A State-Of-The-Art Survey. Systems, Man, and Cybernetics, Part C: Applications and Reviews, 2006, vol. 36, no. 4, pp. 563-577.

15. Vaidyaa S., Ambadb P., Bhoslec S. Industry 4.0 - A Glimpse. Procedia Manufacturing, 2018, no. 20, pp. 233-238.

16. Wu D., Thames J. L., Rosen D. W., Schaefer D. Enhancing the Product Realisation Process with Cloud-Based Design and Manufacturing Systems. Journal of Computing and Information Science in Engineering, 2013, vol. 13, no. 4, pp. 1-14.

17. Zhong R. Y., Xu X., Klotz E., Newman S. T. Intelligent Manufacturing in the Context of Industry 4.0: A Review. Engineering, 2017, vol. 3, no. 5, pp. 616-630. 


\title{
Проблемы цифровизации промышленности в Российской Федерации ${ }^{1}$
}

\author{
Г.Б. Коровин
}

Статья посвящена исследованию наиболее актуальной в мире концепции развития промышленности, называемой «Индустрия 4.0», с которой связаны применение широкого спектра новейших цифровых технологий и тотальная автоматизация производства. Методологически цифровизация промышленного производства рассматривается в трех сферах: применение цифровых технологий в традиционной промышленности; стремительное развитие «цифрового» сектора экономики; появление новых возможностей развития человеческого потенциала. В рамках этого подхода нами систематизированы технологические изменения и экономические модели, важные для развития промышленности. Библиографический поиск позволил выделить современные концепции развития цифрового производства. Проведена оценка цифровизации экономики в Российской Федерации и регионах на основе отечественных и иностранных статистических и информационных материалов. Определены риски для отечественной промышленности, связанные с ее отставанием от технологического уровня развитых стран, а также возможные подходы к их нейтрализации.

Ключевые слова: Индустрия 4.0; цифровизация; промышленность; цифровая экономика; технологическое развитие.

Источники

1. Глазьев С. Великая цифровая революция: вызовы и перспективы для экономики XXI века. URL: http://www.glazev.ru/articles/6-jekonomika/54923-velikaja-tsifrovaja-revoljutsija-vyzovy-iperspektivy-dlja-jekonomiki-i-veka.

2. Индикаторы цифровой экономики: 2017: стат. сб. / Г.И. Абдрахманов, Л.М. Гохберг, М. А. Кевеш и др. М.: НИУ ВШЭ, 2017.

3. Ковальчук Ю.А., Степнов И.М. Цифровая экономика: трансформация промышленных предприятий // Инновации в менеджменте. 2017. № 11. С. 33-43.

4. Конина Н.Ю. Шестой технологический уклад и менеджмент современных компаний // Вопросы экономики и права. 2014. № 3. С. 43-46.

5. Новая технологическая революция: вызовы и возможности для России. Экспертно-аналитический доклад / Г.И. Идрисов, А. С. Кузьмина, Е. С. Рожкова, Д. К. Султанов; под науч. рук. В.Н. Княгинина. М.: Центр стратегических разработок, 2017.

6. Batterham R. J. The Mine of the Future - Even More Sustainable // Minerals Engineering. 2017. Vol. 107. Pp. 2-7.

7. Brown E. Who Needs the Internet of Things? URL: http://www.linux.com.

8. Chaulya S. K., Prasad G. M. (eds.) Sensing and Monitoring Technologies for Mines and Hazardous Areas. Elsevier. 2016.

9. Lee J., Bagheri B., Kao H. A. A Cyber-Physical Systems Architecture for Industry 4.0-based Manufacturing Systems // Manufacturing Letters. 2015. No. 3. Pp. 18-23.

10. Li B. H., Zhang L., Wang S. L., Tao F., Cao J. W., Jiang X. D., Song X., Chai X. D. Cloud Manufacturing: A New Service-oriented Networked Manufacturing Model // Computer Integrated Manufacturing Systems. 2010. Vol. 16, no. 1. Pp. 1-7.

11. Lu Y., Xu X., Xu J. Development of a Hybrid Manufacturing Cloud // Journal of Manufacturing Systems. 2014. Vol. 33, no. 4. Pp. 551-566.

12. Matt D. T., Rauch E., Dallasega P. Trends Towards Distributed Manufacturing Systems and Modern Forms for Their Design // Proc. CIRP. 2015. No. 33. Pp. 185-190.

13. Santosa C., Mehrsaia A., Barrosa A. C., Araújob M., Aresc E. Towards Industry 4.0: An Overview of European Strategic Roadmaps // Procedia Manufacturing. 2017. No. 13. Pp. 972-979.

14. Shen W., Wang L., Hao Q. Agent-based Distributed Manufacturing Process Planning and Scheduling: A State-Of-The-Art Survey // Systems, Man, and Cybernetics, Part C: Applications and Reviews. 2006. Vol. 36, no. 4. Pp. 563-577.

15. Vaidyaa S., Ambadb P., Bhoslec S. Industry 4.0 - A Glimpse // Procedia Manufacturing. 2018. No. 20. Pp 233-238.

${ }^{1}$ Исследование выполнено при финансовой поддержке РФФИ (проект № 18-010-01156). 
16. Wu D., Thames J. L., Rosen D. W., Schaefer D. Enhancing the Product Realisation Process with Cloud-Based Design and Manufacturing Systems // Journal of Computing and Information Science in Engineering. 2013. Vol. 13, no. 4. Pp. 1-14.

17. Zhong R. Y., Xu X., Klotz E., Newman S. T. Intelligent Manufacturing in the Context of Industry 4.0: A Review // Engineering. 2017. Vol. 3, no. 5, Pp. 616-630.

Сведения об авторе:

Г. Б. Коровин, канд. экон. наук,

Институт экономики УрО РАН

зав. сектором экономических проблем

620014, РФ, Екатеринбург, ул. Московская, 29

отраслевых рынков

Контактный телефон: (343) 371-45-36

e-mail: grig_korovin@mail.ru

Ссылка для изитирования: Korovin G. B. Problems of Industrial Digitalisation in Russia // Известия Уральского государственного экономического университета. 2018. Т. 19, №3. C. 100-110. DOI: 10.29141/2073-1019-201819-3-9

For citation: Korovin G. B. Problems of Industrial Digitalisation in Russia. Izvestiya Uralskogo gosudarstvennogo ekonomicheskogo universiteta - Journal of the Ural State University of Economics, 2018, vol. 19, no. 3, pp. 100-110. DOI: 10.29141/2073-1019-2018-19-3-9 


\section{БАЕВ Игорь Александрович}

Доктор экономических наук, профессор, заведующий кафедрой

финансов, денежного обращения и кредита

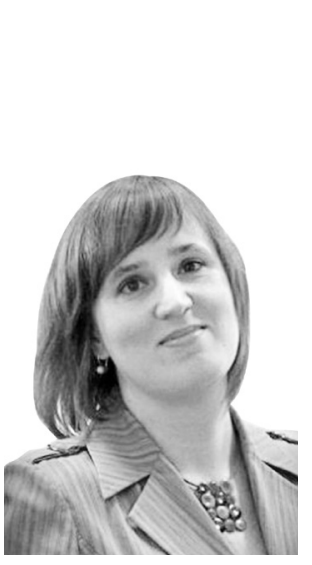

Южно-Уральский государственный университет (национальный исследовательский университет) 454080, РФ, г. Челябинск, пр. Ленина, 76 Контактный телефон: (351) 267-98-17 e-mail: baevia@susu.ru

\section{СОЛОВЬЕВА Ирина Александровна}

Кандидат экономических наук, доцент кафедры финансов, денежного обращения и кредита

Южно-Уральский государственный университет (национальный исследовательский университет) 454080, РФ, г. Челябинск, пр. Ленина, 76 Контактный телефон: (351) 267-92-81 e-mail: solovevaia@susu.ru

\section{ДЗЮБА Анатолий Петрович}

Кандидат экономических наук, заместитель генерального директора

000 «МСК Энерго»

454021, РФ, г. Челябинск, ул. С. Юлаева, 15, офис 53

Контактный телефон: (351) 267-92-81

e-mail: dzyuba-a@yandex.ru
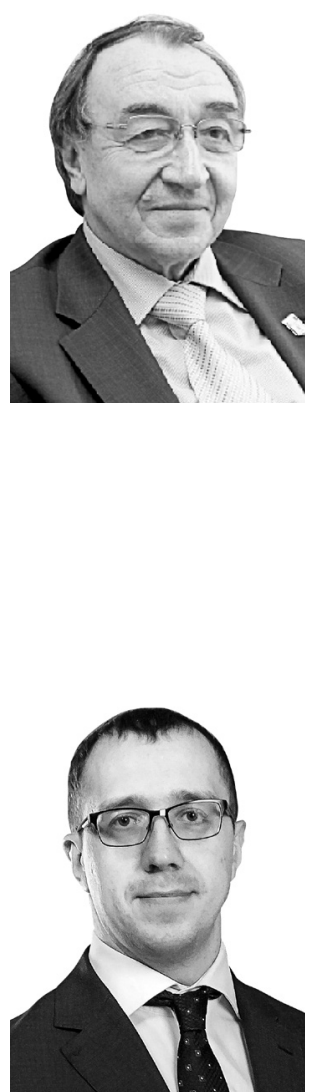

\section{Управление спросом на поставку энергоресурсов в условиях развития информационно-коммуникационных технологий ${ }^{1}$}

Исследование направлено на разработку комплексной модели управления спросом на потребление электрической энергии и природного газа в условиях развития цифровой экономики. Проведена классификация направлений цифровизации в управлении энергопотреблением с выделением результатов, определяющих новые функциональные свойства энергетических систем и формирование в отрасли новых экономических и управленческих полей. Построена схема интеллектуального управления ценозависимым потреблением электроэнергии, основой которой является информационно-коммуникационная платформа. Доказана необходимость внедрения совмещенной многоуровневой модели управления спросом на потребление электроэнергии и природного газа в пределах страны. Авторами разработана комплексная модель управления спросом, преимущества которой состоят в совместном управлении спросом на электроэнергию и газ, в интеграции всех уровней управления - от уровня отдельного предприятия до уровня энергосистемы страны в целом, в ориентации на передовые достижения цифровых технологий и инновационное развитие экономики.

JEL classification: L11, L94, L95, 014

Ключевые слова: управление спросом; умные сети электроснабжения; потребление электроэнергии; потребление газа; энергоэффективность; цифровая экономика; информационно-коммуникационные технологии; учет энергопотребления.

${ }^{1}$ Статья выполнена при поддержке Правительства Российской Федерации (постановление № 211 от 16 марта 2013 г., соглашение № 02.А03.21.0011). 


\section{Введение}

$\mathrm{O}$ дним из базовых направлений долгосрочной социально-экономической стратегии развитых и развивающихся стран мира является реализация политики энергосбережения и повышения энергетической эффективности во всех сферах экономической деятельности. Реализация программ энергосбережения на уровне отдельных субъектов экономической деятельности позволяет без существенных вложений снизить себестоимость производимой продукции и оказываемых услуг. Повышение энергетической эффективности на уровне национальной экономики обеспечивает рост валового внутреннего продукта (ВВП), конкурентоспособность продукции на мировых рынках, укрепляет энергетическую безопасность и снижает уровень экологической нагрузки в масштабах всей страны. В последние годы рост цен на первичные энергоресурсы на мировых энергетических рынках и постоянный рост общемирового энергопотребления привели к притоку инвестиций в исследовательские и производственные направления энергосбережения.

Развитие новых технологических трендов в энергетическом комплексе вызвало институциональные и структурные изменения процессов обращения энергоресурсов, формирование новых функциональных свойств энергосистемы [4], новых экономических и управленческих полей, способствующих постепенному снижению общесистемных затрат на всех уровнях создания конечного продукта в отрасли [10].

Формирование новых экономических полей проявляется в образовании соответствующих типов взаимоотношений между производителями и потребителями электроэнергии на оптовом и розничном рынках электрической энергии. На энергорынках закупка электрической энергии производится в режиме реального времени. При этом операторы рынка способны контролировать объемы производства и потребления электроэнергии одновременно у всех участников с выполнением точных расчетов обязательств и требований участников на основе параметров потребления.

Формирование управленческих полей проявляется в новых технологиях планирования и организации процессов обращения электрической энергии, начиная от общегосударственного уровня и заканчивая уровнем конечных промышленных и бытовых потребителей [16]. Сущность изменений в управлении энергетическим комплексом заключается в расширении объемов информации о параметрах энергопотребления на всех уровнях и повышении оперативности ее обработки и передачи. В связи с этим меняется структура субъектов энергетики, появляются операторы коммерческого учета энергоресурсов, усиливается степень влияния некоторых участников энергорыночных отношений в процессах обращения энергоресурсов.

Целью настоящего исследования является разработка комплексной модели управления спросом на потребление электрической энергии и природного газа в условиях развития цифровой экономики.

Для достижения поставленной цели в рамках исследования были решены следующие задачи:

- проанализированы факторы, влияющие на модели управления спросом на энергоресурсы;

- выявлены специфические для России характеристики управления спросом на потребление электрической энергии и природного газа;

- сформирована система принципов управления спросом на потребление электроэнергии и природного газа в России;

- разработана комплексная модель управления спросом на потребление электроэнергии и природного газа с учетом российской специфики в условиях развития информационно-коммуникационных технологий (ИКТ). 


\section{Методика исследования}

Развитие цифровых технологий в энергетике привело к существенным инновационным преобразованиям в отрасли, как в технологической, так и в организационно-экономической сфере. Платформой для инновационных преобразований в энергетике стала цифровая модернизация учета энергетических ресурсов, что влечет за собой изменения в технологических трендах управления энергопотреблением и на уровне отдельных объектов, и на уровне всей энергосистемы. Современные направления цифровизации технологий в области учета энергоресурсов и управления энергопотреблением систематизированы и представлены в табл. 1 .

Таблица 1

\section{Направления цифровых технологий в области управления энергопотреблением}

\begin{tabular}{|c|c|c|}
\hline Направление цифровизации & Полученное новшество & Результаты внедрения \\
\hline $\begin{array}{l}\text { Цифровизация первич- } \\
\text { ных методов измерения } \\
\text { параметров потребления } \\
\text { энергоресурсов }\end{array}$ & $\begin{array}{l}\text { Повышение качества ре- } \\
\text { зультатов измерений }\end{array}$ & $\begin{array}{l}\text { Снижение потерь, вызванных низким } \\
\text { классом точности измерительных } \\
\text { приборов }\end{array}$ \\
\hline $\begin{array}{l}\text { Цифровизация измери- } \\
\text { тельных приборов }\end{array}$ & $\begin{array}{l}\text { Увеличение числа из- } \\
\text { меряемых параметров, } \\
\text { возможность хранения } \\
\text { результатов внутри изме- } \\
\text { рительного прибора }\end{array}$ & $\begin{array}{l}\text { Расширение функциональных воз- } \\
\text { можностей использования изме- } \\
\text { рительных приборов, повышение } \\
\text { надежности учета на уровне первич- } \\
\text { ного измерения }\end{array}$ \\
\hline $\begin{array}{l}\text { Цифровизация процессов } \\
\text { консолидации измеряе- } \\
\text { мых параметров в пре- } \\
\text { делах электроустановки } \\
\text { либо единого объекта } \\
\text { потребления }\end{array}$ & $\begin{array}{l}\text { Возможность объедине- } \\
\text { ния отдельных измери- } \\
\text { тельных приборов в еди- } \\
\text { ную систему }\end{array}$ & $\begin{array}{l}\text { Удаленное, единовременное измере- } \\
\text { ние параметров энергопотребления } \\
\text { для отдельного объекта энергопотре- } \\
\text { бления, имеющего несколько точек } \\
\text { учета [11] }\end{array}$ \\
\hline $\begin{array}{l}\text { Цифровизация процессов } \\
\text { верификации результатов } \\
\text { измерений }\end{array}$ & $\begin{array}{l}\text { Определение полноты } \\
\text { и качества результатов из- } \\
\text { мерений на программном } \\
\text { уровне }\end{array}$ & $\begin{array}{l}\text { Повышение качества результатов } \\
\text { измерений, повышение произво- } \\
\text { дительности труда при обработке } \\
\text { результатов измерений, возможность } \\
\text { обработки большего количества из- } \\
\text { мерений }\end{array}$ \\
\hline $\begin{array}{l}\text { Цифровизация процес- } \\
\text { сов передачи результатов } \\
\text { измерения на большие } \\
\text { расстояния }\end{array}$ & $\begin{array}{l}\text { Возможность автомати- } \\
\text { зированной удаленной } \\
\text { передачи результатов } \\
\text { измерений на любые рас- } \\
\text { стояния по запросу с при- } \\
\text { нимающей стороны } \\
\end{array}$ & $\begin{array}{l}\text { Единовременное удаленное измере- } \\
\text { ние параметров энергопотребления } \\
\text { для множества объектов управления, } \\
\text { расположенных в значительной уда- } \\
\text { ленности друг от друга и от центра } \\
\text { сбора данных }\end{array}$ \\
\hline $\begin{array}{l}\text { Цифровизация процессов } \\
\text { обработки результатов } \\
\text { измерения }\end{array}$ & $\begin{array}{l}\text { Возможность обработки } \\
\text { результатов замеров пара- } \\
\text { метров энергопотребле- } \\
\text { ния в автоматизирован- } \\
\text { ном режиме по заранее } \\
\text { заданному алгоритму } \\
\end{array}$ & $\begin{array}{l}\text { Увеличение производительности тру- } \\
\text { да в процессе обработки результатов } \\
\text { измерений, повышение точности об- } \\
\text { работки данных, возможность агре- } \\
\text { гирования результатов измерений [1] }\end{array}$ \\
\hline $\begin{array}{l}\text { Цифровизация процессов } \\
\text { хранения измеряемых } \\
\text { параметров и результатов } \\
\text { измерений }\end{array}$ & $\begin{array}{l}\text { Появление баз данных } \\
\text { для хранения больших } \\
\text { массивов }\end{array}$ & $\begin{array}{l}\text { Возможность долговременного хра- } \\
\text { нения результатов измерений пара- } \\
\text { метров энергопотребления в рамках } \\
\text { больших массивов данных с возмож- } \\
\text { ностью их быстрого извлечения для } \\
\text { последующей обработки }\end{array}$ \\
\hline
\end{tabular}


Окончание табл. 1

\begin{tabular}{|c|c|c|}
\hline Направление цифровизации & Полученное новшество & Результаты внедрения \\
\hline $\begin{array}{l}\text { Цифровизация процессов } \\
\text { визуализации агрегиро- } \\
\text { ванных результатов изме- } \\
\text { рений }\end{array}$ & $\begin{array}{l}\text { Возможность вывода } \\
\text { результатов измерений } \\
\text { параметров энергопотре- } \\
\text { бления на монитор }\end{array}$ & $\begin{array}{l}\text { Оперативность процессов выполне- } \\
\text { ния анализа и принятия управленче- } \\
\text { ских решений [14] }\end{array}$ \\
\hline $\begin{array}{l}\text { Цифровизация процессов } \\
\text { принятия решений }\end{array}$ & $\begin{array}{l}\text { Появление алгоритмов } \\
\text { и математических моделей } \\
\text { анализа и управления }\end{array}$ & $\begin{array}{l}\text { Повышение скорости и эффективно- } \\
\text { сти процессов управления }\end{array}$ \\
\hline $\begin{array}{l}\text { Цифровизация процессов } \\
\text { управления параметрами } \\
\text { потребления энергоре- } \\
\text { сурсов }\end{array}$ & $\begin{array}{l}\text { Появление технических } \\
\text { средств, способных уда- } \\
\text { ленно выполнять физи- } \\
\text { ческое регулирование } \\
\text { параметров энергопо- } \\
\text { требления отдельных } \\
\text { промышленных элементов } \\
\text { либо выполнять процессы } \\
\text { коммутации энергетиче- } \\
\text { ского оборудования }\end{array}$ & $\begin{array}{l}\text { Расширение возможностей управле- } \\
\text { ния процессами энергопотребления, } \\
\text { повышение эффективности управ- } \\
\text { ления }\end{array}$ \\
\hline
\end{tabular}

Развитие цифровых технологий в области учета энергетических ресурсов обусловило ужесточение требований к структурным механизмам, действующим в энергетике:

- качеству энергоресурсов;

- надежности энергоснабжения;

- качеству учета энергоресурсов и глубине выполнения измерений;

- учету потерь энергоресурсов [8];

- прозрачности расчета затрат на производство и передачу энергоресурсов;

- снижению затрат на всех уровнях цепочки создания ценности в отрасли;

- субъектам энергетики;

- степени государственного участия в процессах обращения энергоресурсов.

Одним из ярких проявлений влияния инновационных технологий на развитие энергетических комплексов стран мира стало создание и распространение технологий интеллектуальных энергосистем (Smart Grid) [6; 15]. Технология таких энергосистем базируется на концепции полностью интегрированной, саморегулирующейся и самовосстанавливающейся электроэнергетической системы, имеющей сетевую топологию и включающей в себя все генерирующие источники, магистральные сети, в том числе межгосударственные системообразующие линии электропередачи (ЛЭП), местные распределительные сети и все виды потребителей электрической энергии, управляемые единой сетью информационно-управляющих устройств и систем в режиме реального времени [19]. В настоящее время концепция Smart Grid выступает в качестве основы национальной политики энергетического и инновационного развития многих стран мира [3]. В странах ЕС политика развития умных сетей реализуется на единой платформе Smart Grid European Technology Platform ${ }^{1}$, в США - на основе Закона об энергетической независимости и безопасности ${ }^{2}$ В России процесс реализации политики Smart Grid находится на этапе разработки концепции.

Наиболее распространенным элементом системы Smart Grid является технология управления спросом на электропотребление, которая представляет собой инициативную форму экономического взаимодействия субъектов электроэнергетики с конечны-

\footnotetext{
${ }^{1}$ Smart Grids European Technology Platform. URL: http://www.smartgrids.eu.

${ }^{2}$ Energy Independence and Security Act of 2007. Act of Congress concerning the energy policy of the United States. URL: https://www.gpo.gov.
} 
ми потребителями электрической энергии, обеспечивающую взаимовыгодное экономически эффективное регулирование объемов и режимов электропотребления [13]. В общемировой практике механизм управления спросом на электропотребление носит название Demand Side Management [18] и позволяет выравнивать графики электрических нагрузок конечных потребителей, тем самым сокращая затраты электроэнергетической системы на поддержание суточной и сезонной неравномерности спроса [17]. Несмотря на то, что компоненты механизмов Demand Side Management реализуются более чем в 30 странах мира, в России технология управления спросом практически не используются [12]. При этом интенсивное внедрение цифровых технологий в экономику России, глобальные технологические тренды в области энергосбережения и коммерческого учета энергопотребления, а также высокая энергоемкость экономики России «требуют» внедрения модели управления спросом на электропотребление в ближайшей перспективе.

Базовой платформой Demand Side Management выступает технология интеллектуального (ценозависимого) потребления электрической энергии, основанная на управлении собственными объемами электропотребления потребителями посредством учета ценовых сигналов энергорынка.

В рамках современных концепций Demand Side Management интеллектуальное (ценозависимое) потребление электрической энергии опирается на цифровые технологии управления и может быть как полностью, так и частично автоматизированным (с элементами использования человеческого труда), реализуясь через интеграцию информационного и коммуникационного уровней управления энергопотреблением (рис. 1).

\begin{tabular}{|c|c|c|}
\hline & Информационный уровень & \\
\hline $\begin{array}{c}\text { Информация о параметрах } \\
\text { электропотребления }\end{array}$ & $\begin{array}{c}\text { Информация об объемах } \\
\text { и диапазонах возможного } \\
\text { регулирования нагрузки }\end{array}$ & $\begin{array}{c}\text { Информация о ценовых } \\
\text { индикаторах } \\
\text { рыночной среды }\end{array}$ \\
\hline \multirow[t]{5}{*}{$\begin{array}{l}\text { • Фактические параметры } \\
\text { электропотребления. } \\
\text { • Плановые параметры } \\
\text { электропотребления }\end{array}$} & $\begin{array}{l}\text { - Возможные объемы снижения } \\
\text { нагрузки электропотребления. } \\
\text { • Возможные диапазоны снижения } \\
\text { нагрузки электропотребления }\end{array}$ & $\begin{array}{l}\text { - Цены на электрическую энергию, } \\
\text { электрическую мощность, } \\
\text { услуги по передаче. } \\
\text { - Временные диапазоны ценовых } \\
\text { параметров. } \\
\text { - Прогнозная величина затрат } \\
\text { на электропотребление }\end{array}$ \\
\hline & $\square$ & \\
\hline & 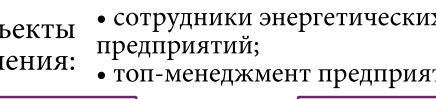 & х служб \\
\hline & 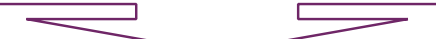 & \\
\hline & Коммуникационный уровень & \\
\hline $\begin{array}{c}\text { Системы автоматизиро- } \\
\text { ванного учета параметров } \\
\text { электроэнергии }\end{array}$ & $\begin{array}{l}\text { Системы управления } \\
\text { нагрузкой } \\
\text { электропотребления }\end{array}$ & $\begin{array}{c}\text { Производственные } \\
\text { объекты }\end{array}$ \\
\hline $\begin{array}{l}\text { • Учет параметров электро- } \\
\text { энергии на уровне объектов } \\
\text { управления }\end{array}$ & $\begin{array}{l}\text { - Технические средства управ- } \\
\text { ления нагрузкой электро- } \\
\text { потребления по заданию } \\
\text { сигнала системы управления }\end{array}$ & $\begin{array}{l}\text { - Технические средства управ- } \\
\text { ления производственными } \\
\text { процессами с целью управления } \\
\text { электропотреблением }\end{array}$ \\
\hline
\end{tabular}

Рис. 1. Схема интеллектуального управления ценозависимым потреблением электрической энергии 
На информационном уровне происходит обобщение информационных потоков параметров электропотребления, технологических и экономических возможностей изменения нагрузки, ценовых сигналов энергорынка. На коммуникационном уровне интегрируются системы автоматизированного учета параметров электропотребления, информация систем управления нагрузкой, информация о параметрах работы производственных объектов. Результирующие управляющие воздействия на объекты электропотребления основываются на анализе баланса параметров экономической эффективности затрат на электропотребление и технологической возможности изменения нагрузки электропотребляющего оборудования.

Технологии управления спросом существенно варьируются по странам мира, что обусловлено рядом индивидуальных характеристик функционирования энергетических комплексов (табл. 2).

Таблица 2

\section{Индивидуальные характеристики энергетических комплексов стран мира в аспекте управления спросом на электропотребление}

\begin{tabular}{|c|c|c|}
\hline $\begin{array}{c}\text { Характеристика энерге- } \\
\text { тического комплекса }\end{array}$ & Описание & $\begin{array}{c}\text { Влияние на модель управления спросом } \\
\text { на уровне национальной экономики }\end{array}$ \\
\hline $\begin{array}{l}\text { Величина } \\
\text { общего спроса на } \\
\text { электропотребление }\end{array}$ & $\begin{array}{l}\text { Общий объем электропотре- } \\
\text { бления в рамках национальной } \\
\text { экономики }\end{array}$ & $\begin{array}{l}\text { Определяет масштабы модели } \\
\text { управления спросом и степень охва- } \\
\text { та объектов управления }\end{array}$ \\
\hline $\begin{array}{l}\text { Структура спроса на } \\
\text { электропотребление }\end{array}$ & \begin{tabular}{|l|} 
Распределение общего спроса на \\
электропотребление по катего- \\
риям потребителей
\end{tabular} & $\begin{array}{l}\text { Определяет целевую направлен- } \\
\text { ность модели управления спросом }\end{array}$ \\
\hline $\begin{array}{l}\text { Характеристика } \\
\text { параметров спроса по } \\
\text { временным периодам }\end{array}$ & $\begin{array}{l}\text { Изменение спроса в рамках се- } \\
\text { зонных, недельных и суточных } \\
\text { периодов }\end{array}$ & $\begin{array}{l}\text { Определяет компоненты периодов } \\
\text { управления модели управления } \\
\text { спросом }\end{array}$ \\
\hline $\begin{array}{l}\text { Состав факторов, } \\
\text { влияющих на } \\
\text { параметры спроса }\end{array}$ & \begin{tabular}{|l|} 
Превалирование влияния се- \\
зонных, технологических либо \\
организационно-экономических \\
факторов на особенности спроса
\end{tabular} & $\begin{array}{l}\text { Определяет структурные элементы } \\
\text { модели управления спросом }\end{array}$ \\
\hline $\begin{array}{l}\text { Связь энергосистем } \\
\text { сопредельных } \\
\text { государств }\end{array}$ & $\begin{array}{l}\text { Влияние спроса в рамках страны } \\
\text { на параметры работы энергоси- } \\
\text { стем, с которыми производится } \\
\text { работа в параллельных техноло- } \\
\text { гических режимах }\end{array}$ & $\begin{array}{l}\text { Определяет порядок учета влияния } \\
\text { изменения спроса на работу } \\
\text { смежных энергосистем }\end{array}$ \\
\hline $\begin{array}{l}\text { Структура } \\
\text { генерирующих } \\
\text { мощностей, } \\
\text { покрывающих спрос }\end{array}$ & $\begin{array}{l}\text { Угольные, газовые, гидро-, } \\
\text { атомные электростанции, } \\
\text { возобновляемые источники } \\
\text { энергии объединенной } \\
\text { энергосистемы, работающие } \\
\text { в разных режимах }\end{array}$ & \multirow[t]{2}{*}{$\begin{array}{l}\text { Определяет учет экономического } \\
\text { эффекта от выравнивания спроса } \\
\text { при различной структуре покрытия } \\
\text { нагрузок }\end{array}$} \\
\hline $\begin{array}{l}\text { Режимы генерирую- } \\
\text { щих мощностей, по- } \\
\text { крывающих спрос } \\
\end{array}$ & $\begin{array}{l}\text { Работа электростанций } \\
\text { в конденсационных } \\
\text { и теплофикационных режимах } \\
\end{array}$ & \\
\hline $\begin{array}{l}\text { Уровни управления } \\
\text { спросом на электро- } \\
\text { потребление }\end{array}$ & $\begin{array}{l}\text { Общестрановой, уровень ОЭС, } \\
\text { уровень регионов, уровень от- } \\
\text { дельных предприятий }\end{array}$ & \multirow[t]{2}{*}{$\begin{array}{l}\text { Определяет масштабы модели } \\
\text { управления спросом и степень охва- } \\
\text { та объектов управления }\end{array}$} \\
\hline $\begin{array}{l}\text { Связь энергосистемы } \\
\text { со смежными отра- } \\
\text { слями экономики }\end{array}$ & $\begin{array}{l}\text { Влияние изменения параметров } \\
\text { работы потребителей, управ- } \\
\text { ляющих спросом, на смежные } \\
\text { отрасли }\end{array}$ & \\
\hline
\end{tabular}


Энергетический комплекс России имеет ряд индивидуальных особенностей спроса на электропотребление:

- значительный объем общего спроса на электропотребление (пятое место в рейтинге стран мира (рис. 2);

- большое количество потребителей электроэнергии, действующих в рамках ЕЭС;

- большое количество субъектов электроэнергетики, действующих на разных уровнях управления [7];

- существенная доля электропотребления промышленным сектором [5];

- глубокая регионализация спроса на электропотребление (85 регионов с индивидуальными географическими, климатическими и прочими условиями, влияющими на спрос на электропотребление);

- климатогеографические параметры (покрытие зимнего спроса на электропотребление генерирующими мощностями, работающими в теплофикационном цикле);

- работа большей части энергосистемы в едином технологическом режиме [2];

- наличие большого числа электростанций, работающих на разном типе топлива;

- существенная связь энергетического комплекса с Единой системой газоснабжения (ЕСГ).

Выявленные особенности энергетического комплекса России обусловливают необходимость внедрения многоуровневой платформы управления спросом на электропотребление в рамках Единой энергетической системы (ЕЭС) страны с сопоставлением каждого уровня управления спросом с особенностями вышестоящего уровня.

Связь и единство ЕЭС России и ЕСГ определяется рядом параметров:

- высокая доля электрификации и газификации регионов России;

- работа отраслей энергетики и газоснабжения в рамках единых систем, объединяющих единым технологическим режимом всех производителей и потребителей энергии через магистральные и распределительные сети;

- обеспечение электроэнергетической и газоснабжающей системами одновременно большого количества потребителей энергоресурсов, действующих в рамках единой системы;

- необходимость адаптации режимов производства электрической энергии и природного газа под мгновенные параметры спроса на энергоресурсы со стороны потребителей;

- отсутствие возможности мгновенного ограничения спроса на потребление электрической энергии и природного газа отдельных потребителей ЕЭС и ЕСГ;

- необходимость согласования единства режимов производства и потребления электрической энергии и природного газа между производителями и всеми потребителями системы;

- одновременное потребление электрической энергии и природного газа на общие нужды потребителей, такие как промышленное производство либо отопление;

- схожесть параметров волатильности спроса на потребление электрической энергии и природного газа в рамках ЕЭС и ЕСГ России (рис. 3,4 ) в сезонных и посуточных периодах;

- общность факторов, влияющих на параметры спроса на потребление электрической энергии и природного газа в рамках ЕЭС и ЕСГ России;

- значительная доля потребления газа на выработку электроэнергии и соответственно существенная доля газовой генерации в структуре топливного баланса ЕЭС России;

- взаимное влияние параметров спроса на потребление электроэнергии и природного газа.

Систематизация возможных эффектов, получаемых потребителями энергосистемы от управления спросом на электрическую энергию и природный газ, представлена в табл. 3. 


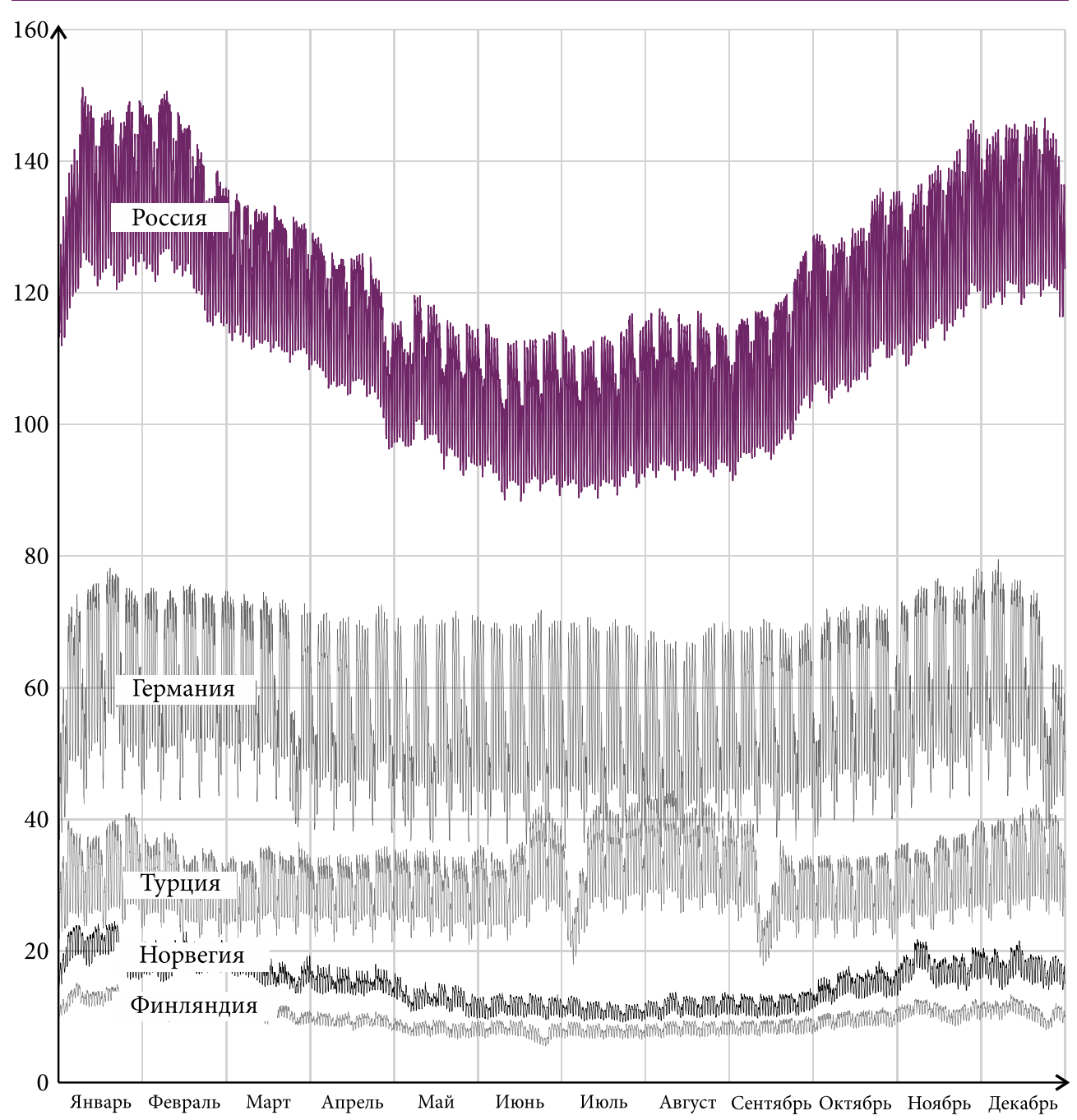

Рис. 2. Почасовые графики нагрузки электропотребления различными странами в 2016 г. (масштабы сохранены), ГВт ${ }^{1}$

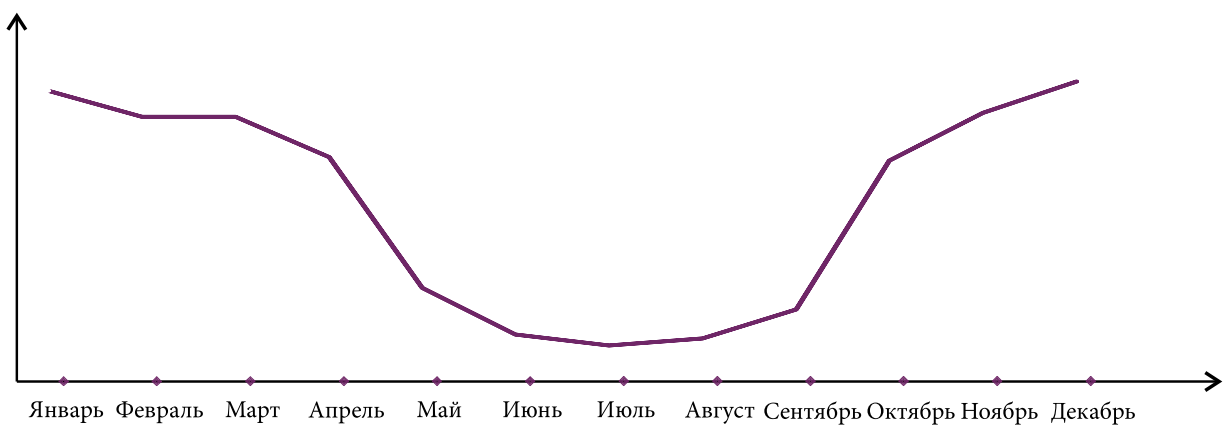

Рис. 3. Диаграмма месячного спроса на потребление природного газа Свердловской областью в 2016 г., тыс. м $^{3}$

${ }^{1}$ Официальный интернет-сайт Системного оператора оптового рынка электроэнергии ЕЭС России. URL: https://so-ups.ru. 


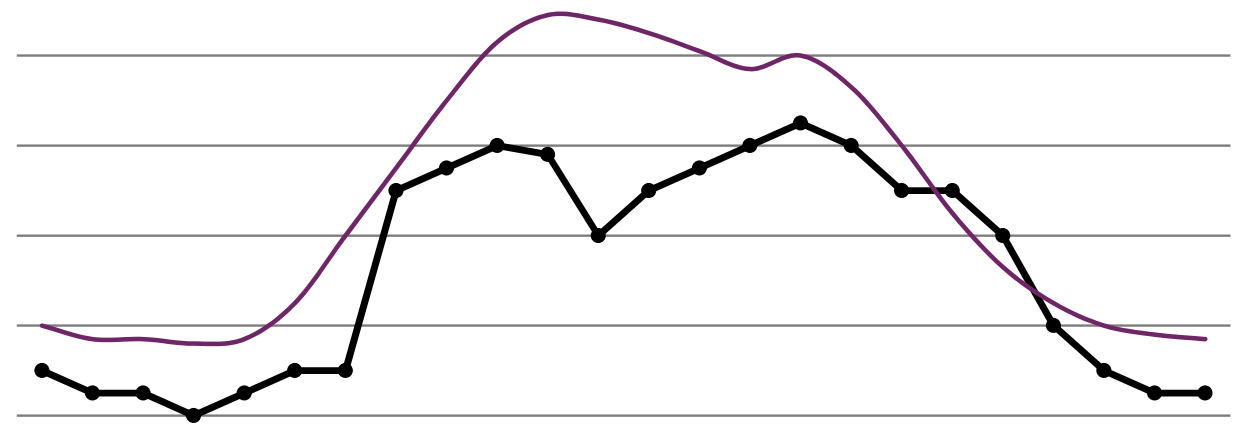

$\begin{array}{llllllllllllllllllllllll}1 & 2 & 3 & 4 & 5 & 6 & 7 & 8 & 9 & 10 & 11 & 12 & 13 & 14 & 15 & 16 & 17 & 18 & 19 & 20 & 21 & 22 & 23 & 24\end{array}$

— Почасовое потребление электроэнергии —— Почасовое потребление газа

Рис. 4. Диаграмма почасового спроса на потребление электроэнергии и природного газа машиностроительным предприятием, расположенным в Свердловской области

(за типовые сутки 2016 г.)

Таблица 3

Эффекты от управления спросом на потребление электрической энергии и природного газа на различных уровнях

\begin{tabular}{|c|c|c|}
\hline \multirow{2}{*}{$\begin{array}{c}\text { Уровень } \\
\text { управления }\end{array}$} & \multicolumn{2}{|c|}{ Получаемый эффект } \\
\hline & Электроэнергия & Природный газ \\
\hline $\begin{array}{l}\text { Уровень } \\
\text { производства }\end{array}$ & $\begin{array}{l}\text { Повышение устойчивости режимов } \\
\text { производства. } \\
\text { Снижение удельных расходов топли- } \\
\text { ва на выработку электроэнергии [9]. } \\
\text { Снижение требуемых запасов топлива. } \\
\text { Снижение «горячего» резерва генери- } \\
\text { рующих мощностей. } \\
\text { Снижение инвестиционных затрат на } \\
\text { обновление основных фондов }\end{array}$ & $\begin{array}{l}\text { Повышение устойчивости режимов } \\
\text { производства. } \\
\text { Снижение удельных затрат на произ- } \\
\text { водство газа. } \\
\text { Снижение необходимых запасов } \\
\text { в ПХГ }\end{array}$ \\
\hline $\begin{array}{l}\text { Уровень } \\
\text { передачи }\end{array}$ & $\begin{array}{l}\text { Снижение резерва электросетевых } \\
\text { мощностей. } \\
\text { Снижение аварийности. } \\
\text { Снижение технологических потерь } \\
\text { электроэнергии }\end{array}$ & $\begin{array}{l}\text { Снижение резерва распределитель- } \\
\text { ных мощностей. } \\
\text { Повышение точности управления ре- } \\
\text { жимами распределения газа. } \\
\text { Повышение качества обеспечения } \\
\text { обязательств по поставке газа по ме- } \\
\text { ждународным контрактам }\end{array}$ \\
\hline $\begin{array}{l}\text { Уровень } \\
\text { распределения }\end{array}$ & $\begin{array}{l}\text { Высвобождение мощностей для под- } \\
\text { ключения новых потребителей. } \\
\text { Повышение качества электроэнергии. } \\
\text { Снижение коммерческих потерь элек- } \\
\text { троэнергии }\end{array}$ & $\begin{array}{l}\text { Снижение потерь в процессе распре- } \\
\text { деления. } \\
\text { Высвобождение мощностей для под- } \\
\text { ключения новых потребителей. } \\
\text { Сокращение ограничений в постав- } \\
\text { ках газа }\end{array}$ \\
\hline
\end{tabular}

Таким образом, совместное управление спросом на потребление электрической энергии и природного газа в России дает мультипликативный эффект снижения затрат на производство электрической энергии и природного газа. 


\section{Модель комплексного ценозависимого управления}

Учитывая уникальные особенности спроса на потребление электрической энергии и природного газа в России, совмещенная модель управления спросом на потребление электрической энергии и природного газа, с нашей точки зрения, должна основываться на следующих принципах:

1) интеграции - учет экономического эффекта от управления спросом на уровне всей ЕЭС и ЕСГ;

2) дифференциации - учет различия параметров спроса на электроэнергию и природный газ различными категориями потребителей энергоресурсов;

3) иерархии - учет уровней управления процессами обращения электроэнергии и природного газа;

4) региональной категоризации - учет различий параметров спроса на потребление электроэнергии и природного газа в региональном разрезе;

5) структурной категоризации - учет различий в структуре потребителей энергоресурсов для различных периодов и территорий управления;

6) сезонности - учет изменений волатильности спроса для различных сезонов и суточных периодов;

7) минимизации предельных затрат на производство электроэнергии и природного газа - управление спросом должно соответствовать условию минимизации конечных тарифов на электроэнергию, как в долгосрочной, так и в краткосрочной перспективе;

8) гармонизации интересов - управление спросом должно обеспечивать учет экономических интересов всех субъектов энергетики и всех категорий потребителей;

9) надежности и устойчивости- управление спросом должно обеспечивать условие системной надежности и устойчивости функционирования ЕЭС и ЕСГ и устойчивости технологических процессов производства электроэнергии;

10) синергии - управление спросом должно обеспечивать минимизацию предельных затрат на поставку электроэнергии и природного газа одновременно;

11) улучшений - управление спросом должно обеспечивать постоянное совершенствование механизмов управления спросом с учетом современных трендов развития экономики в направлении минимизации затрат на электро- и газоснабжение и дальнейшего расширения и развития ЕЭС и ЕСГ.

Учитывая индивидуальные особенности спроса на электропотребление в России, связь и единство ЕЭС с ЕСГ России, авторы на базе предложенной системы принципов управления разработали комплексную модель управления спросом на потребление электрической энергии и природного газа (рис. 5).

Модель состоит из последовательно реализуемых блоков, которые делятся на информационный и коммуникационный уровни. В рамках коммуникационного уровня производится сбор параметров потребления электроэнергии и природного газа со всех уровней управления - от уровня потребителей электроэнергии до уровня ЕЭС и ЕСГ России, а также транслирование управляющих воздействий на потребителей электроэнергии и природного газа для целей управления спросом.

В рамках информационного уровня производится агрегирование и анализ параметров спроса на потребление энергоресурсов и экономических и технологических возможностей ЕЭС и ЕСГ. Важной особенностью является то, что на информационном уровне ведется оценка взаимного влияния изменения спроса на потребление электроэнергии и природного газа, а также оценка экономического эффекта, получаемого в результате реализации управленческих воздействий для различных уровней и периодов управления в рамках ЕЭС и ЕСГ России.

Основой модели является цифровая платформа, которая обеспечивает функционирование каждого элемента модели, начиная от сбора первичных данных об 


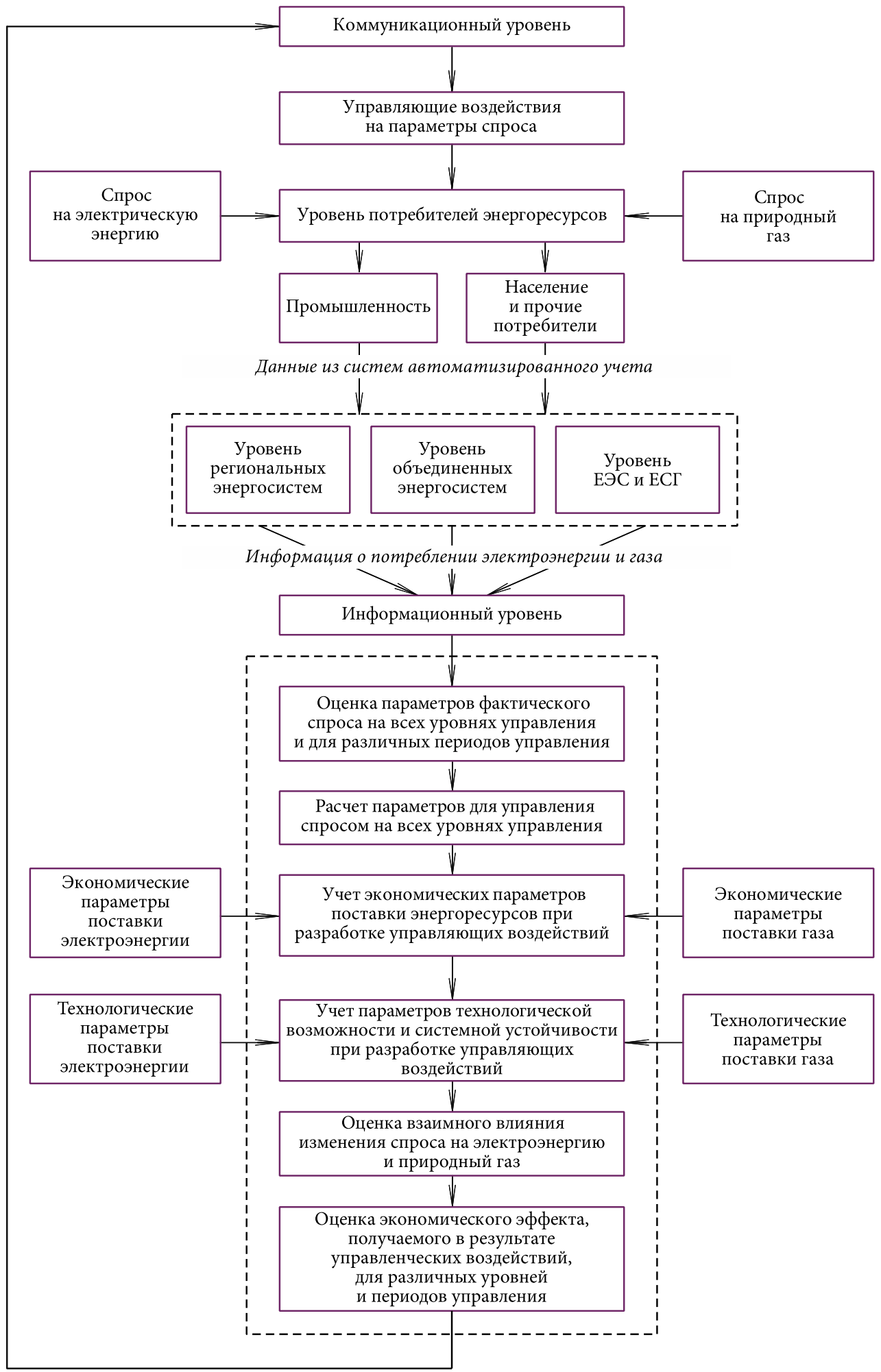

Рис. 5. Структура совмещенной модели управления спросом на потребление электрической энергии и природного газа в России 
энергопотреблении на электроустановках и пунктах учета газа, заканчивая расчетом моделей формирования экономического эффекта и выдачи управленческих воздействий всем потребителям ЕЭС и ЕСГ.

\section{Заключение}

Таким образом, преимуществами предложенной комплексной модели управления спросом на потребление электрической энергии и природного газа являются:

- совместное управление спросом на электроэнергию и газ;

- интеграция в единой модели всех уровней управления - от уровня отдельного предприятия до уровня энергосистемы страны в целом;

- ориентация на передовые достижения цифровых технологий и условия инновационного развития экономики.

Реализация концепции управления спросом на энергоресурсы в России будет способствовать повышению эффективности функционирования энергетического комплекса страны и росту энергетической эффективности национальной экономики.

\section{Источники}

1. Андреева Л.В., Осика Л.К., Тубинис В.В. Коммерческий учет электроэнергии на оптовом и розничном рынках. М.: АВОК-ПРЕСС, 2010.

2. Ветров В.И., Быкова Л.Б., Ключенович В.И. Режимы электрооборудования электрических станций. Новосибирск: Изд-во НГТУ, 2010.

3. Волкова И.О., Сальникова Е.А. Переход к интеллектуальной энергетике в России: научные и институциональные аспекты // Экономика и управление. 2010. № 5(55). C. $77-82$.

4. Волкова И.О., Шувалова Д.Г., Сальникова Е.А. Активный потребитель в интеллектуальной энергетической системе: возможности и перспективы // Сайт НИУ ВШЭ. URL: https://www.hse.ru/pubs/share/direct/document/71899800.

5. Гальперова Е.В., Мазурова О.В. Долгосрочные тенденции электропотребления в экономике и ее основных секторах в России и мире // Энергетическая политика. 2014. № 1. С. 39-50.

6. Кобец Б. Б., Волкова И.О. Инновационное развитие электроэнергетики на базе концепции SMART GRID. М.: ИАЦ Энергия, 2010.

7. Кокшаров В.А. Управление энергопотреблением при формировании топливноэнергетического баланса промышленности региона: теория и методология. Екатеринбург: УрФУ, 2013.

8. Копылов С. И., Липа О. А., Липа Д. А. Потери в электроэнергетике - предпосылки для внедрения АИИС КУЭ // Техника и оборудование для села. 2016. № 4. С. 29-33.

9. Кукель-Краевский С.А., Гуревич Б.А. Перспективы развития энегросистем в СССР // ОНТИ ГРЭЛ Серия лекций на энегретическом факультете. 1936. Вып. III.

10. Логинов Е.Л., Логинов А.Е. Переход к интеллектуальной электроэнергетической системе с активно-адаптивной сетью: глобализационное конструирование новых управленческих полей в ЕЭС России // Национальные интересы: приоритеты и безопасность. 2018. № 33. С. 14-18.

11. Осика Л. К. Коммерческий и технический учет электрической энергии на оптовом и розничных рынках. Теория и практические рекомендации. СПб.: Политехника, 2005.

12. Соловьева И.А., Дзюба А.П. Управление спросом на электропотребление на мезоуровне по показателям волатильности // Вестник Ивановского государственного энергетического университета. 2017. № 1. С. 76-86.

13. Управление спросом на энергию. Уникальная инновация для российской электроэнергетики / Л.Д. Гительман, Б.Е. Ратников, М. В. Кожевников, Ю. П. Шевелев. Екатеринбург, 2013. 
14. Яхина Р. М. Внедрение современных автоматизированных систем коммерческого учета электроэнергии // Современные проблемы и тенденции развития экономики и управления: сб. науч. ст. Междунар. науч.-практ. конф. (Казань, 15 января 2018 г.): в 3 ч. Казань: НИЦ Аэтерна, 2018. Ч. 3. С. 252-254.

15. Carmoab C., Detlefsenb N., Nielsena M. Smart Grid Enabled Heat Pumps: An Empirical Platform for Investigating How Residential Heat Pumps Can Support Large-Scale Integration of Intermittent Renewables // Energy Procedia. 2014. Vol. 61. Pp. 1695-1698.

16. Chiu W.-Y., Sun H., Poor H. V. Energy Imbalance Management Using a Robust Pricing Scheme // IEEE Transactions on Smart Grid. 2013. Vol. 4, no. 2. Pp. 896-904.

17. Loughran D., Kulick J. Demand-Side Management and Energy Efficiency in the United States // The Energy Journal. 2004. Vol. 25, no. 1. Pp. 19-43.

18. Saffre F., Gedge R. Demand-Side Management for the Smart Grid // 2010 IEEE/IFIP Network Operations and Management Symposium Workshops. Institute of Electrical \& Electronics Engineers (IEEE), 2010. Pp. 300-303.

19. Smart Power Grids - Talking about a Revolution. IEEE Emerging Technology Portal, 2009. Pp. 38-42.

\title{
Managing the Demand for Energy Resources in Conditions of Development of Information and Communication Technologies
}

\author{
by Igor A. Baev, Irina A. Solovyeva and Anatoly P. Dzyuba
}

The research aims to design a comprehensive model for managing demand for electricity and natural gas in conditions of the digital economy development. The classification of the digitalisation directions in energy consumption management allowed identifying new functional qualities of energy systems and new economic and management fields emerging in the sector. The authors develop a scheme of intellectual management of the price-dependent consumption of electricity, based on the information and communication platform. The researchers prove the necessity of introducing a combined multi-level platform for managing electricity and natural gas demand in Russia. The clear advantages of the comprehensive model for managing the demand developed by the authors are that it manages the demand for electricity and gas simultaneously, integrates all levels of control: from the level of a particular enterprise to the level of the national energy system, uses the recent advances in digital technologies and allows for conditions of innovative development of the economy.

Keywords: demand management; smart electricity supply networks; electricity consumption; gas consumption; energy efficiency; digital economy; information and communication technologies; energy consumption metering.

References:

1. Andreeva L. V., Osika L. K., Tubinis V.V. Kommercheskiy uchet elektroenergii na optovom i roznichnom rynkakh [Commercial metering of electricity in the wholesale and retail markets]. Moscow: AVOKPRESS Publ., 2010.

2. Vetrov V. I., Bykova L. B., Klyuchenovich V. I. Rezhimy elektrooborudovaniya elektricheskikh stantsiy [Modes of electrical equipment of power plants]. Novosibirsk: Novosibirsk State Technical University, 2010.

3. Volkova I.O., Salnikova Ye.A. Perekhod k intellektual'noy energetike v Rossii: nauchnye i institutsional'nye aspekty [Transition to intellectual energy in Russia: scientific and institutional aspects]. Ekonomika i upravlenie - Economics and Management, 2010, no. 5(55), pp. 77-82.

4. Volkova I. O., Shuvalova D. G., Salnikova Ye. A. Aktivnyy potrebitel' $v$ intellektual'noy energeticheskoy sisteme: vozmozhnosti i perspektivy [Active consumers in the intellectual energy system: Opportunities and prospects]. Available at: https:// www.hse.ru/pubs/share/direct/document/71899800. 
5. Galperova Ye. V., Mazurova O. V. Dolgosrochnye tendentsii elektropotrebleniya v ekonomike i ee osnovnykh sektorakh $\mathrm{v}$ Rossii i mire [Long-term trends in electricity consumption in the economy and its major sectors in Russia and the world]. Energeticheskaya politika - Energy Policy, 2014, no. 1, pp. 39-50.

6. Kobets B.B., Volkova I. O. Innovatsionnoe razvitie elektroenergetiki na baze kontseptsii SMART GRID [Innovative development of electric power industry based on the SMART GRID concept]. Moscow: IATs Energiya Publ., 2010.

7. Koksharov V.A. Upravlenie energopotrebleniem pri formirovanii toplivno-energeticheskogo balansa promyshlennosti regiona: teoriya i metodologiya [Management of energy consumption in the formation of the fuel and energy balance of a region's industry: Theory and methodology.]. Yekaterinburg: Ural Federal University, 2013.

8. Kopylov S. I., Lipa O. A., Lipa D. A. Poteri v elektroenergetike - predposylki dlya vnedreniya AIIS KUE [Losses in the electric power industry are prerequisites for the introduction of AIIS KUE]. Tekhnika i oborudovanie dlya sela - Equipment for Rural Areas, 2016, no. 4, pp. 29-33.

9. Kukel-Kraevskiy S.A., Gurevich B.A. Perspektivy razvitiya enegrosistem v SSSR [Prospects for the development of energy systems in the USSR]. In: ONTI GREL Seriya lektsiy na enegreticheskom fakul'tete [ONTI GREL A series of lectures at the Department of Energy], 1936, issue III.

10. Loginov Ye.L., Loginov A. Ye. Perekhod k intellektual'noy elektroenergeticheskoy sisteme s aktivno-adaptivnoy set'yu: globalizatsionnoe konstruirovanie novykh upravlencheskikh poley v EES Rossii [Transition to an intelligent electric power system with an actively-adaptive network: Globalised design of new management fields in the UES of Russia]. Natsionalnye interesy: prioritety i bezopasnost - National Interests: Priorities and Security, 2018, no. 33, pp. 14-18.

11. Osika L. K. Kommercheskiy i tekhnicheskiy uchet elektricheskoy energii na optovom i roznichnykh rynkakh. Teoriya i prakticheskie rekomendatsii [Commercial and technical accounting of electricity in the wholesale and retail markets. The theory and practical recommendations]. Saint Petersburg: Politekhnika Publ., 2005.

12. Solovyeva I.A., Dzyuba A.P. Upravlenie sprosom na elektropeotreblenie na mezourovne po pokazatelyam volatil'nosti [Managing the demand for electricity consumption at the meso level by volatility indicators]. Vestnik Ivanovskogo gosudarstvennogo energeticheskogo universiteta - Bulletin of the Ivanovsk State University of Energy, 2017, no. 1, pp. 76-86.

13. Gitelman L. D., Ratnikov B. Ye., Kozhevnikov M. V., Shevelev Yu. P. Upravlenie sprosom na energiyu. Unikal'naya innovatsiya dlya rossiyskoy elektroenergetiki [Management of the demand for energy. A unique innovation for the Russian power industry]. Yekaterinburg, 2013.

14. Yakhina R.M. Vnedrenie sovremennykh avtomatizirovannykh sistem kommercheskogo ucheta elektroenergii [Introduction of modern automated systems for commercial metering of electricity]. Sbornik nauchnykh statey Mezhdunarodnoy nauchno-prakticheskoy konferentsii "Sovremennye problemy i tendentsii razvitiya ekonomiki i upravleniya" [Proc. Int. Sci.-Prac. Conf. "Modern Problems and Trends in Development of Economics and Management"]. Kazan: NITs Aeterna Publ., 2018, part 3, pp. $252-254$.

15. Carmoab C., Detlefsenb N., Nielsena M. Smart Grid Enabled Heat Pumps: An Empirical Platform for Investigating how Residential Heat Pumps can Support Large-scale Integration of Intermittent Renewables. Energy Procedia, 2014, vol. 61, pp. 1695-1698.

16. Chiu W.-Y., Sun H., Poor H. V. Energy Imbalance Management Using a Robust Pricing Scheme. IEEE Transactions on Smart Grid, 2013, vol. 4, no. 2, pp. 896-904.

17. Loughran D., Kulick J. Demand-Side Management and Energy Efficiency in the United States. The Energy Journal, 2004, vol. 25, no. 1, pp. 19-43.

18. Saffre F., Gedge R. Demand-Side Management for the Smart Grid. 2010 IEEE/IFIP Network Operations and Management Symposium Workshops. Institute of Electrical \& Electronics Engineers (IEEE), 2010, pp. 300-303.

19. Smart Power Grids - Talking about a Revolution. IEEE Emerging Technology Portal, 2009. P. $38-42$.

Contact Info:

Igor A. Baev, Dr. Sc. (Econ.), Prof., Head of Finance, Money Circulation and Credit Dept.

Phone: (351) 267-98-17

e-mail: baevia@susu.ru
South Ural State University

(national research university)

76 Lenina Ave., Chelyabinsk, Russia, 454080 
Irina A. Solovyeva, Cand. Sc. (Econ.), Associate Prof. of Finance, Money Circulation and Credit Dept.

Phone: (351) 267-92-81

e-mail: solovevaia@susu.ru

Anatoly P. Dzyuba, Cand. Sc. (Econ.), Deputy

General Director

Phone: (351) 267-92-81

e-mail: dzyuba-a@yandex.ru
South Ural State University

(national research university)

76 Lenina Ave., Chelyabinsk, Russia, 454080

OOO MSK Energo

office 53, 15 S. Yulaeva St., Chelyabinsk, Russia, 454021

Ссылка для изитирования: Баев И.А., Соловьева И.А., Дзюба А.П. Управление спросом на поставку энергоресурсов в условиях развития информационно-коммуникационных технологий // Известия Уральского государственного экономического университета. 2018. T. 19, №3. C. 111-125. DOI: 10.29141/2073-1019-201819-3-10

For citation: Baev I. A., Solovyeva I. A., Dzyuba A.P. Upravlenie sprosom na postavku energoresursov v usloviyakh razvitiya informatsionno-kommunikatsionnykh tekhnologiy [Managing the demand for energy resources in conditions of development of information and communication technologies]. Izvestiya Uralskogo gosudarstvennogo ekonomicheskogo universiteta - Journal of the Ural State University of Economics, 2018, vol. 19, no. 3, pp. 111-125. DOI: 10.29141/2073-1019-2018-19-3-10 


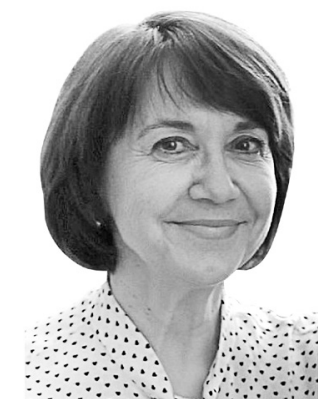

\title{
ВАЙСМАН Елена Давидовна
}

Доктор экономических наук, профессор кафедры финансов, денежного обращения и кредита

Южно-Уральский государственный университет (национальный исследовательский университет) 454080, РФ, г. Челябинск, пр. Ленина, 76 Контактный телефон: (351) 267-92-81 e-mail: vaismaned@susu.ru

\section{НИКИФОРОВА Наталья Сергеевна}

Аспирант кафедры финансов, денежного обращения и кредита

Южно-Уральский государственный университет (национальный исследовательский университет) 454080, РФ, г. Челябинск, пр. Ленина, 76 Контактный телефон: (351)267-92-81 e-mail: nikiforovans@susu.ru

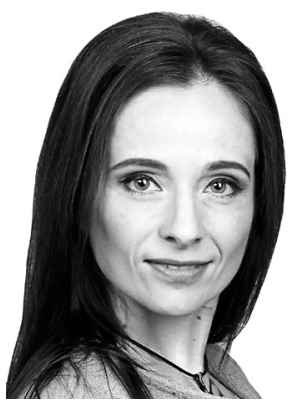

\section{Развитие динамических способностей промышленных предприятий в условиях цифровой экономики}

\begin{abstract}
Статья посвящена актуальной проблеме повышения степени готовности российских промышленных предприятий к цифровой экономике и угрозам гиперконкуренции. Сформулирована гипотеза относительно возможности формирования устойчивых конкурентных преимуществ в условиях цифровой экономики на основе формирования и развития динамических способностей промышленных предприятий. Разработан метод оценки динамических способностей, адаптированный к оценке российских промышленных отраслей. Рассчитан уровень развития цифровой экономики каждой отрасли. Путем сопоставления полученных результатов построена карта позиционирования обрабатывающей промышленности в координатах «Уровень динамических способностей отрасли - Степень развития цифровой экономики в отрасли». Выделены четыре группы отраслей, отличающиеся по степени готовности к развитию цифровой экономики и по потенциалу такого развития. Полученные результаты могут быть использованы предприятиями данных отраслей при принятии решений о целесообразности инвестирования в развитие динамических способностей для формирования устойчивых конкурентных преимуществ в условиях цифровой экономики.
\end{abstract}

JEL classification: D20, D29, 014

Ключевые слова: промышленное предприятие; стратегическое управление; динамические способности; цифровая экономика; гиперконкуренция.

\section{Введение}

Перспективы экономического роста национальных экономик все в большей степени связывают с развитием цифровой экономики. По оценкам, к 2020 г. десять ведущих мировых экономик в результате цифровизации увеличат общий объем валового внутреннего продукта (ВВП) на 2,3\%, что составит 1,36 трлн дол. При этом прогноз для развивающихся стран, с учетом относительно низкой базы, более оптимистичен - рост их ВВП должен увеличиться на $34 \%{ }^{1}$. Соответственно, прогнозируется рост затрат,

${ }^{1}$ Accenture Technology Vision 2018. Tech Trends Report. URL: https://www.accenture.com/us-en/ insight-technology-trends-2018. 
связанных с трансформацией традиционной экономики в цифровую. Аналитики International Data Corporation оценивают этот рост на уровне 16,8\% в год.

Цифровая экономика уже оказала влияние практически на все секторы народного хозяйства и общественной жизни (производство, торговлю, транспортные и финансовые услуги, образование, здравоохранение, СМИ), выйдя за пределы информационных технологий. Соответственно растет интерес зарубежных и российских исследователей к ее перспективам, возможностям и угрозам.

В промышленности практически все страны, независимо от уровня технологического развития и масштаба экономики, ориентируются в своих стратегических программах на немецкую программу «Индустрия 4.0». Программа основана на цифровой трансформации традиционных отраслей и направлена на повышение эффективности использования ресурсов, поиск и разработку инновационных решений, новых производственных и управленческих технологий и, в конечном счете, на экономический рост и повышение благосостояния граждан.

Отставание нашей страны от стран лидеров цифровой экономики, по оценке консалтинговой компании The Boston Consulting Group (BCG), составляет от 5 до 8 лет. Аналитики BCG рассматривают три сценария развития цифровизации в России, наихудший из которых «стагнация цифровизации», характеризующаяся долей цифровой экономики в ВВП к 2021 г. в 2,2\% и отставанием от лидеров на 20 лет. Во втором сценарии «цифровизация госсектора» к 2021 г. прямой вклад цифровой экономики РФ превысит 3,2 трлн р., что составит 3\% ВВП. В третьем сценарии «интенсивная цифровизация государства и бизнеса» доля цифровой экономики оценивается в 5,6\% ВВП РФ, что сопоставимо с ожидаемым уровнем цифровизации Европы к 2020 г. - 7,5\% [7]. Консалтинговая компания McKinsey оценивает потенциальный эффект для ВВП РФ от цифровизации экономики к 2025 г. в 4,1-8,9 трлн р., что составит 19-34\% общего увеличения ВВП РФ [8].

Сокращение отставания России от стран лидеров цифровой экономики намечено в программе «Цифровая экономика Российской Федерации», доработанной по итогам Петербургского международного экономического форума (ПМЭФ), прошедшего 1-3 июня 2017 г. Признавая в целом обоснованность намеченных мер, нельзя не отметить тот факт, что в основном эти меры направлены на государственное управление, здравоохранение, образование, формирование информационной инфраструктуры, «умных городов», информационную безопасность, а мероприятия по развитию технологий в основном сводятся к цифровым. Между тем в последние годы исследователи экономически развитых стран пришли к выводу, что успех цифровой экономики и богатство страны в целом, прежде всего, определяется степенью технологических и технических возможностей. Мало того, развитие цифровой экономики усложняет функционирование промышленных отраслей и отдельных предприятий, в том числе вследствие существенного ускорения изменений внешней среды, сокращения продолжительности жизни конкурентных преимуществ, товаров и предприятий, снижения входных барьеров и других признаков гиперконкуренции. В октябре 2017 г. эксперты Национального агентства финансовых исследований (НАФИ) и Фонда «Сколково» в результате совместно проведенного исследования оценили индекс готовности российских компаний к переходу на цифровые технологии на уровне 36 п.п. из 100 возможных. Все это свидетельствует об актуальности проблемы поиска путей повышения степени готовности российских промышленных предприятий к цифровой экономике и угрозам гиперконкуренции [10; 11].

В последние десятилетия темпы технологических и бизнес-инноваций в связи с развитием цифровой экономики ускорились, в результате чего удержание и развитие

${ }^{1}$ Распоряжение Правительства РФ от 28 июля 2017 г. № 1632-р «Об утверждении программы „Цифровая экономика Российской Федерации“». 
устойчивого конкурентного преимущества предприятия становится все более сложной задачей. Интернет, в частности, позволяет в короткие сроки создавать новые типы предприятий дает им возможность преодолевать транснациональные границы и достигать глобального охвата рынка. Устаревает понятие «отрасль» в общеизвестном смысле этого слова, происходит сближение и взаимное проникновение самых разных сфер и видов деятельности. Стремительно нарастающие изменения в окружающей среде требуют от предприятий поиска новых стратегий и методов завоевания конкурентных преимуществ.

В традиционном понимании, основанном на теории М. Портера [5], конкуренция определяется структурой рынка, продуктом и конечным пользователем. В модели М. Портера инновации отсутствуют, а структурные изменения встречаются редко (1980-е годы). Ключевая идея 1990-х годов в литературе по менеджменту состояла в том, что конкурентное преимущество предприятия заключается в его «основных компетенциях», технологиях и ноу-хау, которые являются фундаментом его бизнес-модели [6].

Современное понимание конкурентоспособности предприятия все чаще и все в большей степени базируется на трудно имитируемых ресурсах (VRIN-ресурсы), а не на свойствах и качествах продукта. Развитие ресурсной концепции (Resource Based View), с одной стороны, и теории организационного обучения - c другой, привело к появлению в конце XX века концепции динамических способностей предприятия $[13 ; 16]$. Д. Тис сформулировал гипотезу, согласно которой динамические способности и хорошая стратегия на основе трудно имитируемых ресурсов и опыта предприятия являются основой для получения устойчивого конкурентного преимущества $[15 ; 16]$. В связи с этим понятен рост интереса к концепции динамических способностей как зарубежных (Д. Тис, Г. Пизано, А. Шуен, М. Золло, С. Уинтер, Д. Коллиз, С. Монтгомери, Р. Хендерсон, И. Кокбурн, Б. Когут, У. Зандер,), так и отечественных авторов (Г.Б. Клейнер, В. С. Катькало, Т. Е. Андреева, В. А. Чайка, С. В. Орехова, Е. Е. Чупандина).

Опираясь на результаты проведенного обзора подходов к определению сущности понятия «динамические способности предприятия» [9. Р. 272; 12. Р. 5; 13. Р. 1117; 15. Р. 21; 16. Р. 512; 17. Р. 993] и учитывая такие важные, на наш взгляд, свойства последних, как скорость предвидения рыночных изменений и умение принимать упреждающие решения, мы сформулировали собственное уточненное определение данной категории.

Динамические способности - это высший уровень организационных способностей предприятия, проявляющийся в умении распознавать и прогнозировать слабые рыночные сигналы, фокусироваться на наиболее значимых из них с точки зрения функционирования предприятия, своевременно принимать и реализовывать упреждающие решения по трансформации своих VRIN-ресурсов в соответствии с этими сигналами и с целью получения конкурентных преимуществ.

Все это дает нам основание в качестве цели настоящего исследования поставить разработку метода оценки динамических способностей промышленного предприятия как источника формирования его конкурентных преимуществ в условиях цифровой экономики и определение уровня динамических способностей отраслей промышленности в сравнении со степенью развития цифровой экономики в них.

Достижение поставленной цели предполагает решение следующих задач:

- разработка метода оценки динамических способностей промышленного предприятия с учетом их свойств, определяющих требования к методу оценки и принципов такого метода;

- адаптация разработанного метода к отраслевым особенностям и расчет динамических способностей российских отраслей обрабатывающей промышленности;

- анализ степени готовности российских промышленных отраслей к развитию цифровой экономики с помощью сопоставления уровня их динамических способностей 
со степенью цифровизации и построения карты позиционирования отраслей обрабатывающей промышленности в координатах «Уровень динамических способностей отрасли - Степень развития цифровой экономики в отрасли».

\section{Методология исследования}

Мы выделили ряд наиболее характерных свойств, присущих динамическим способностям хозяйствующего субъекта, на основе чего удалось сформулировать требования к методу их оценки и принципы формирования такого метода. Результаты представлены на рис. 1.

В соответствии со сформулированными принципами, оценку динамических способностей будем производить, во-первых, в разрезе каждого из значимых рыночных сигналов, а во-вторых, учитывая требуемое направление трансформации ресурсов. Полагаем, что метод оценки динамических способностей должен отражать и элементы последних. В концепции динамических способностей [17] выделяются три таких элемента:

- способность распознавать возможности (sense) - это способность предприятия непрерывно проводить мониторинг, анализ, оценку своих внутренних ресурсов (материальных, человеческих, интеллектуальных и др.), внешних возможностей и угроз и реагировать на технологические, маркетинговые, организационные инновации с целью удовлетворения и формирования потребностей рынка;

- возможность фокусироваться (seize) - возможность предприятия использовать время, которое «дает» быстроменяющаяся внешняя бизнес-среда для трансформации ресурсов;

- способность трансформироваться (transformation) - способность фирмы быстро, координированно проводить изменения и обновление ресурсов и активов, реконфигурировать их.

\begin{tabular}{|c|c|c|c|}
\hline \multicolumn{4}{|c|}{ Характерные свойства динамических способностей } \\
\hline $\begin{array}{l}\text { Нематериальный } \\
\text { характер }\end{array}$ & $\begin{array}{l}\text { Способность форми- } \\
\text { ровать конкурентные } \\
\text { преимущества за счет } \\
\text { использования VRIN- } \\
\text { ресурсов }\end{array}$ & $\begin{array}{l}\text { Способность улавли- } \\
\text { вать слабые сигналы }\end{array}$ & $\begin{array}{l}\text { Способность прини- } \\
\text { мать управленческие } \\
\text { решения с опереже- } \\
\text { нием }\end{array}$ \\
\hline \multicolumn{4}{|c|}{ Принципы оценки динамических способностей } \\
\hline $\begin{array}{l}\text { Опосредованность } \\
\text { оценки }\end{array}$ & Ресурсный подход & Обратная связь & Опережение \\
\hline \multicolumn{4}{|c|}{ Требования к методу оценки динамических способностей } \\
\hline $\begin{array}{l}\text { Отслеживание про- } \\
\text { явления воздействия } \\
\text { ДС на конкретные } \\
\text { объекты }\end{array}$ & $\begin{array}{l}\text { Учет объема и струк- } \\
\text { туры имеющихся на } \\
\text { предприятии VRIN- } \\
\text { ресурсов }\end{array}$ & $\begin{array}{l}\text { Улавливание менедж- } \\
\text { ментом предприятия } \\
\text { значения рыночных } \\
\text { сигналов }\end{array}$ & $\begin{array}{l}\text { Учет скорости, с ко- } \\
\text { торой предприятие } \\
\text { способно трансфор- } \\
\text { мировать свои VRIN- } \\
\text { ресурсы }\end{array}$ \\
\hline
\end{tabular}

Рис. 1. Свойства динамических способностей, требования и принципы метода их оценки

Заметим, что элементы динамических способностей достаточно тесно взаимосвязаны с цифровой экономикой: чем они выше, тем скорее предприятие будет внедрять цифровые технологии, а чем развитее у него цифровизация, тем выше должен быть уровень динамических способностей, чтобы реализовать ее возможности.

Опираясь на сформулированные принципы и учитывая отмеченные элементы динамических способностей хозяйствующего субъекта, мы предлагаем следующую формулу их оценки: 


$$
I_{\text {ДС }}=\int_{i}^{0} q k_{i} v_{\text {ск. }} \alpha d W S_{i},
$$

где $I_{\text {дс }}$ - сила динамических способностей; $q$ - величина VRIN-ресурсов; $k_{i}$ - доля VRIN-pесурсов, соответствующих каждому из значимых слабых сигналов внешней среды; $v_{\text {ск.р }}$ - скорость трансформации VRIN-ресурсов; $W S_{i}-$ значимый слабый сигнал внешней среды; $\alpha$ - коэффициент сонаправленности трансформации VRIN-ресурсов и вектора значимых слабых сигналов среды [2; 14].

Введенное понятие «сила динамических способностей предприятия» показывает, с одной стороны, с какой скоростью VRIN-ресурсы могут быть преобразованы для реализации упреждающих управленческих решений, требуемых внешней средой, а с другой - меру сонаправленности динамических способностей и значимых для предприятия слабых сигналов внешней среды.

В целом основное отличие предложенного метода состоит, на наш взгляд, в его комплексности, поскольку в нем удалось связать уровень динамических способностей и их направление. Представляется, что его можно использовать как для отдельных предприятий, так и для промышленных отраслей с некоторой адаптацией метода к особенностям таких расчетов. Для решения этой задачи введем следующий ряд допущений:

1. Динамические способности отраслей промышленности будем оценивать на основе показателей, отслеживаемых Госкомстатом РФ.

2. Трудно имитируемые, или VRIN-ресурсы, отрасли косвенно могут характеризоваться показателями, связанными с затратами на организационные и технологические инновации и на приобретение последних. Это допущение, с одной стороны, основано на теории ресурсного подхода к управлению, в соответствии с которым все ресурсы принято классифицировать на три типа: нематериальные, материальные и человеческие $[1 ; 3]$, а организационные и технологические инновации в зависимости от их специфики могут быть отнесены к каждой из этих групп. С другой стороны, редкость ресурсов или их трудная имитация связана прежде всего со степенью их инновационности.

3. Скорость трансформации VRIN-ресурсов отрасли в ответ на слабые рыночные сигналы может быть охарактеризована показателями динамики. В частности, скорость трансформации материальных ресурсов может быть оценена через динамику обновления основных средств предприятия, а скорость трансформации нематериальных - через динамику затрат на инновации. Что касается человеческих ресурсов, то с некоторой долей условности можно принять, что их трансформация связана с реконфигурацией ресурсов, как материальных, так и нематериальных.

4. Сонаправленность слабых рыночных сигналов и трансформации VRIN-ресурсов означает, что принятые решения должны привести к положительным результатам в деятельности хозяйствующего субъекта. С этой точки зрения примем, что о степени сонаправленности можно судить по результатам этой деятельности. Нам представляется целесообразным в качестве таких результатов принять индекс добавленной стоимости и индекс производительности труда в отрасли.

В соответствии с принятыми допущениями и поставленными задачами, расчет силы динамических способностей российских отраслей обрабатывающей промышленности проведен с помощью многомерной средней по показателям, представленным в табл. 1 (значения показателей взяты по данным Госкомстата за 2015-2016 гг.); результаты расчетов приведены в табл. 2.

В целом удалось выявить в достаточной степени четкую корреляцию силы динамических способностей с удельным весом инновационных товаров, работ, услуг в общем объеме отгруженных товаров, выполненных работ, услуг: с увеличением уровня динамических способностей возрастает доля инновационных товаров в структуре выручки предприятий (табл. 3). Учитывая, что, согласно ресурсной концепции, от силы 
динамических способностей зависит инновационная активность хозяйствующего субъекта, можно считать выбор статистических показателей адекватным.

Таблица 1

Статистические показатели, использованные для оценки динамической способности в разрезе отраслей обрабатывающей промышленности

\begin{tabular}{|c|c|c|}
\hline \multicolumn{3}{|c|}{ Характеристика } \\
\hline VRIN-ресурсов отрасли & $\begin{array}{c}\text { скорости трансформации } \\
\text { VRIN-ресурсов }\end{array}$ & $\begin{array}{c}\text { сонаправленности трансформа- } \\
\text { ции VRIN-ресурсов и значимых } \\
\text { слабых сигналов среды }\end{array}$ \\
\hline $\begin{array}{l}\text { 1. Доля затрат на организа- } \\
\text { ционные инновации в общем } \\
\text { объеме отгруженных товаров, } \\
\text { выполненных работ, услуг }\end{array}$ & $\begin{array}{l}\text { 1. Динамика обновления ос- } \\
\text { новных фондов }\end{array}$ & $\begin{array}{l}\text { 1. Динамика индекса физиче- } \\
\text { ского объема валовой добав- } \\
\text { ленной стоимости }\end{array}$ \\
\hline $\begin{array}{l}\text { 2. Количество приобретенных } \\
\text { организациями новых техно- } \\
\text { логий (технических достиже- } \\
\text { ний) }\end{array}$ & $\begin{array}{l}\text { 2. Динамика доли затрат на } \\
\text { инновации в общем объеме } \\
\text { отгруженных товаров, выпол- } \\
\text { ненных работ, услуг }\end{array}$ & $\begin{array}{l}\text { 2. Индекс производительно- } \\
\text { сти труда }\end{array}$ \\
\hline $\begin{array}{l}\text { 3. Доля затрат на технологи- } \\
\text { ческие инновации в общем } \\
\text { объеме отгруженных товаров, } \\
\text { выполненных работ, услуг }\end{array}$ & $\begin{array}{l}\text { 3. Динамика количества при- } \\
\text { обретенных организациями } \\
\text { новых технологий (техниче- } \\
\text { ских достижений) }\end{array}$ & \\
\hline
\end{tabular}

Таблица 2

Значения силы динамических способностей отрасли и статистического показателя «удельный вес инновационных товаров, работ, услуг в общем объеме выручки отрасли» для соответствующей отрасли обрабатывающей промышленности

\begin{tabular}{|l|c|c|c|c|}
\hline \multicolumn{1}{|c|}{ Отрасль обрабатывающего производства } & $\begin{array}{c}\text { Сила } \\
\text { динамических } \\
\text { способностей } \\
\text { отрасли }\end{array}$ & Ранг & $\begin{array}{c}\text { Удельный вес инно- } \\
\text { вационых товаров, } \\
\text { работ, услуг } \\
\text { в общем объеме } \\
\text { выручки отрасли }\end{array}$ & Ранг \\
\hline $\begin{array}{l}\text { Производство транспортных средств и оборудо- } \\
\text { вания }\end{array}$ & 2,299 & 1 & 23,7 & 1 \\
\hline Производство резиновых и пластмассовых изделий & 2,001 & 2 & 10,2 & 3 \\
\hline $\begin{array}{l}\text { Производство электрооборудования, электрон- } \\
\text { ного и оптического оборудования }\end{array}$ & 1,865 & 3 & 13,8 & 2 \\
\hline Химическое производство & 1,533 & 4 & 9,4 & 4 \\
\hline Производство машин и оборудования & 1,019 & 5 & 5,2 & 7 \\
\hline $\begin{array}{l}\text { Металлургическое производство и производство } \\
\text { готовых металлических изделий }\end{array}$ & 0,858 & 6 & 8,3 & 5 \\
\hline $\begin{array}{l}\text { Производство пищевых продуктов, включая на- } \\
\text { питки, и табака }\end{array}$ & 0,663 & 7 & 4,8 & 8 \\
\hline $\begin{array}{l}\text { Производство прочих неметаллических мине- } \\
\text { ральных продуктов }\end{array}$ & 0,591 & 8 & 4 & 11 \\
\hline Текстильное и швейное производство & 0,498 & 9 & 4,8 & 9 \\
\hline $\begin{array}{l}\text { Целлюлозно-бумажное производство; издатель- } \\
\text { ская и полиграфическая деятельность }\end{array}$ & 0,475 & 10 & 5,8 & 12 \\
\hline $\begin{array}{l}\text { Обработка древесины и производство изделий } \\
\text { из дерева }\end{array}$ & 0,248 & 11 & 2,3 & 6 \\
\hline $\begin{array}{l}\text { Производство кожи, изделий из кожи и произ- } \\
\text { водство обуви }\end{array}$ & 0,169 & 12 & & \\
\hline
\end{tabular}


Таблица 3

Степень развития ИКТ в промышленных отраслях Российской Федерации [4]

\begin{tabular}{|c|c|c|c|c|c|c|c|}
\hline Обрабатывающие производства & 当 & 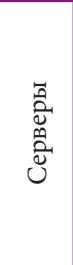 & 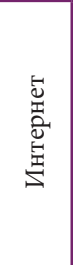 & 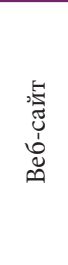 & 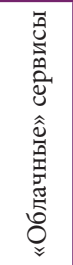 & 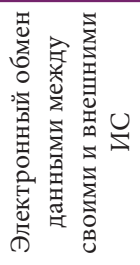 & 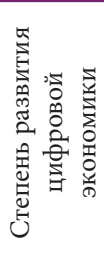 \\
\hline $\begin{array}{l}\text { Производство пищевых продуктов, } \\
\text { ключая напитки и табак }\end{array}$ & 97,7 & 74,8 & 96,7 & 53,4 & 23,7 & 73,6 & 1,049 \\
\hline $\begin{array}{l}\text { Целлюлозно-бумажное производство, изда- } \\
\text { тельская и полиграфическая деятельность }\end{array}$ & 97,9 & 43,6 & 96,5 & 51,0 & 20,9 & 63,9 & 0,920 \\
\hline $\begin{array}{l}\text { Металлургическое производство и произ- } \\
\text { водство готовых металлических изделий }\end{array}$ & 96,8 & 76,7 & 95,9 & 67,5 & 18,9 & 72,9 & 1,050 \\
\hline Производство машин и оборудования & 97,2 & 70,1 & 95,7 & 60,8 & 18,5 & 68,1 & 1,000 \\
\hline Текстильное и швейное производство & 95,5 & 57,4 & 93,6 & 53,4 & 18,9 & 64,4 & 0,935 \\
\hline $\begin{array}{l}\text { Производство кожи, изделий из кожи } \\
\text { и производство обуви }\end{array}$ & 97,0 & 71,0 & 96,0 & 49,0 & 15,0 & 72,0 & 0,947 \\
\hline Химическое производство & 96,8 & 77,2 & 96,6 & 62,9 & 24,1 & 73,4 & 1,084 \\
\hline $\begin{array}{l}\text { Производство резиновых и пластмассовых } \\
\text { изделий }\end{array}$ & 97,9 & 79,9 & 96,9 & 62,4 & 25,1 & 79,9 & 1,115 \\
\hline $\begin{array}{l}\text { Обработка древесины и производство } \\
\text { изделий из дерева }\end{array}$ & 94,2 & 62,7 & 92,4 & 45,1 & 20,4 & 74,1 & 0,955 \\
\hline $\begin{array}{l}\text { Производство транспортных средств } \\
\text { и оборудования }\end{array}$ & 94,2 & 68,0 & 89,3 & 53,8 & 14,5 & 62,1 & 0,910 \\
\hline $\begin{array}{l}\text { Производство электрооборудования, } \\
\text { электронного и оптического оборудования }\end{array}$ & 98,4 & 78,9 & 97,3 & 67,4 & 16,8 & 70,1 & 1,035 \\
\hline
\end{tabular}

Для анализа степени развития цифровой экономики в отраслях обрабатывающей промышленности проведем оценку уровня развития информационно-коммуникационных технологий (ИКТ) этих отраслей. Основанием для такого допущения являются два факта. Во-первых, в основе цифровой экономики лежат ИКТ. Во-вторых, в программе «Цифровая экономика Российской Федерации» определены уровни цифровой экономики, среди которых среда, создающая условия для развития платформ и технологий, для эффективного взаимодействия субъектов рынков и отраслей экономики (сфер деятельности), охватывающая нормативное регулирование, информационную инфраструктуру, кадры и информационную безопасность, что является основными составляющими ИКТ. Оценка проведена с помощью расчета многомерной средней значений приведенных в табл. 3 шести частных показателей, характеризующих степень развития ИКТ в анализируемых отраслях.

Сопоставление результатов расчетов, представленных в табл. 2 и 3, дает возможность позиционировать анализируемые отрасли в координатах «Уровень динамических способностей отрасли - Степень развития цифровой экономики в отрасли» и выделить на карте (рис. 2) четыре квадранта, в каждый из которых попали группы отраслей, отличающихся, по сути, степенью готовности к развитию цифровой экономики и потенциалу к такому развитию.

Первая группа - это отрасли с существенным для РФ уровнем цифровизации и значительной силой динамических способностей, характеризующиеся относительно высокой готовностью к развитию цифровой экономики и способностью использовать ее возможности и инструменты для формирования и сохранения своих конкурентных преимуществ. 


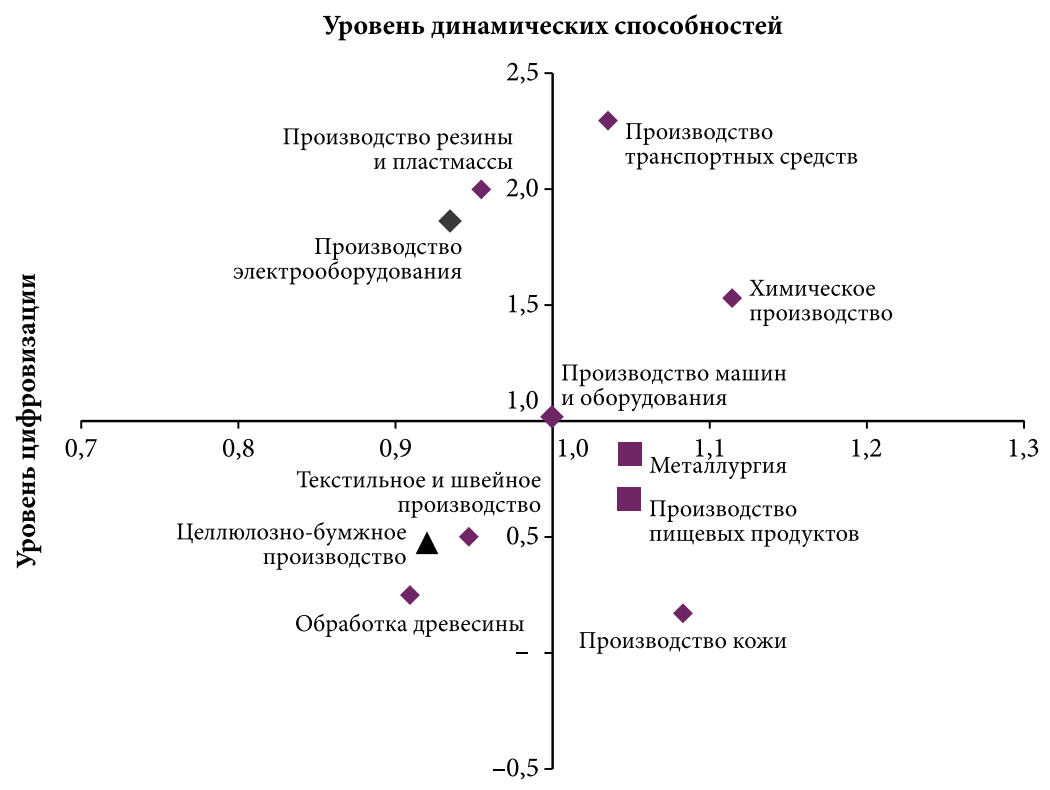

Рис. 2. Карта позиционирования отраслей обрабатывающей промышленности по признаку «уровень динамических способностей» и «уровень цифровизации отрасли»

Во вторую группу попали отрасли, в которых уровень цифровизации ниже среднего по промышленности, но при этом уровень динамических способностей выше среднего. Можно сказать, что и эти отрасли готовы к развитию цифровой экономики, мало того - у них есть потенциал для такого развития. Однако у предприятий этих отраслей невысока целесообразность инвестирования средств в развитие своих динамических способностей.

Отрасли третьей группы характеризуются незначительным уровнем динамических способностей, но развитие цифровой экономики у них выше среднего по промышленности. Это означает, что данные отрасли отличаются низким уровнем готовности к угрозам цифровой экономики и для них велика вероятность потери своих конкурентных преимуществ. Предприятиям таких отраслей целесообразно инвестировать в развитие своих динамических способностей.

Четвертая группа отраслей характеризуется низким уровнем цифровизации и низким значением силы динамических способностей. По сути, это аутсайдеры обрабатывающей промышленности.

\section{Заключение}

На цифровую экономику вполне обоснованно возлагаются надежды как на драйвер экономического роста России. Однако ее развитие сопряжено с усложнением условий функционирования хозяйствующих субъектов, в частности обусловленным ускорением изменений среды, сокращением продолжительности жизненного цикла конкурентных преимуществ и другими проявлениями гиперконкуренции. В этих условиях промышленным предприятиям следует ориентироваться на более сложную инновационную среду, формировать и развивать более сложные цепочки поставок и бизнес-модели, противодействовать более широкому кругу конкурентов, в том числе глобальных. Решение этих задач требует от управленческой команды использования технологий и инструментов стратегического управления, сформированных в рамках цифровой экономики. Одной из таких современных технологий является технология управления на базе формирования и развития динамических способностей предприятий. 
Предложенный в настоящем исследовании метод оценки динамических способностей промышленного предприятия разработан на основе сформулированного определения сущности этого понятия, выявленных свойств и соответствующих требований и принципов. От существующих, в основном экспертных, методов он отличается комплексностью и возможностью получить количественную оценку. Его адаптация дала возможность рассчитать динамические способности отраслей обрабатывающей промышленности.

Анализ полученных оценок, в сравнении с рассчитанным уровнем развития цифровой экономики обрабатывающих отраслей, дал возможность построить карту их позиционирования в координатах «Уровень динамических способностей отрасли - Степень развития цифровой экономики в отрасли» и сформулировать два основных вывода.

1. Уровень развития динамических способностей российских промышленных предприятий относительно невысок, при этом уже в достаточной степени ощутим, несмотря на отставание России от развитых стран по состоянию цифровой экономики. Это может привести к ограничению сфер использования инструментов и технологий цифровой экономики и ее сосредоточению в финансовом секторе, розничной торговле, связи и, по прогнозам, оптовой торговле, но не в промышленности.

2. Предприятиям обрабатывающей промышленности следует повышать степень своей готовности к угрозам гиперконкуренции и вызовам цифровой экономики, определяя целесообразный объем инвестиций в развитие динамических способностей.

\section{Источники}

1. Барни Дж. Б. Может ли ресурсная концепция принести пользу исследователям в области стратегического управления? - Да // Российский журнал менеджмента. 2009. № 7. С. 71-92.

2. Вайсман Е. Д., Никифорова Н. С., Носова С. А. Формирование модели стратегического управления динамическими способностями промышленного предприятия с использованием технологии форсайт // Российское предпринимательство. 2017. Т. 18, № 7. C. 1091-1104.

3. Грант Р. Ресурсная теория конкурентных преимуществ: практические выводы для формирования стратегии // Вестник СПбГУ. Сер.: Менеджмент. 2003. Вып. 3. С. 47-75.

4. Индикаторы информационного общества: 2016: стат. сб. / Г.И. Абдрахманова, Л. М. Гохберг, М. А. Кевеш и др. М.: НИУ ВШЭ, 2016.

5. Портер М. Конкурентная стратегия: методика анализа отраслей и конкурентов. М.: Альпина Паблишер, 2016.

6. Прахалад К. К., Хамел Г. Ключевая компетенция корпорации // Вестник СПбГУ. Сер.: Менеджмент. 2003. Вып. 3. С. 18-41.

7. Россия Онлайн: догнать нельзя отстать / Б. Банке, В. Бутенко, И. Котов и др. Boston Consulting Group, 2016.

8. Цифровая Россия: новая реальность / А. Аптекман, В. Калабин, В. Клинцов и др. McKinsey \& Company, 2017.

9. Barreto I. Dynamic Capabilities: A Review of Past Research and an Agenda for the Future // Journal of Management. 2010. Vol. 36, no. 1. Pp. 256-280.

10. Birkinshaw J., Ansari S. Understanding Management Models: Going Beyond "What" and "Why" to "How" Work Gets Done in Organizations // Foss N. J., Saebi T. (eds.) Business Model Innovation: The Organizational Dimension. Oxford: Oxford University Press, 2015. Pp. 85-103.

11. D’Aveni R., Dagnino B. G., Smith K. G. The Age of Temporary Advantage // Strategic Management Journal. 2010. Vol. 31, issue 13. Pp. 1371-1385.

12. Easterby-Smith M., Lyles M. A., Peteraf M. A. Dynamic Capabilities: Current Debates and Future Directions // British Journal of Management. 2009. Vol. 20, issue s1. Pp. S1-S8. 
13. Eisenhardt K., Martin J. Dynamic Capabilities: What are They? // Strategic Management Journal. 2000. Vol. 21, no. 10/11. Pp. 1105-1121.

14. Strategic Management of Dynamic Capabilities of an Enterprise with Using Foresight Technologies / E. D. Vaisman, S. V. Aliukov, N. S. Nikiforova, S. A. Nosova // Proceedings of the $29^{\text {th }}$ International Business Information Management Association Conference - Innovation Management and Education Excellence Vision 2020: From Regional Development Sustainability to Global Economic Growth (IBIMA) (3-4 May, 2017, Vienna, Austria). Pp. 787-795.

15. Teece D. J. A Dynamic Capabilities-Based Entrepreneurial Theory of the Multinational Enterprise // Journal of International Business Studies. 2014. Vol. 45, issue 1. Pp. 8-37.

16. Teece D. J. Dynamic Capabilities and Strategic Management // Strategic Management Journal. 1997. Vol. 18, no. 7. Pp. 509-533.

17. Winter S. G. Understanding Dynamic Capabilities // Strategic Management Journal. 2003. Vol. 24, no. 10. Pp. 991-995.

\title{
Development of Industrial Enterprises' Dynamic Capabilities in the Digital Economy
}

\author{
by Yelena D. Vaisman and Natalya S. Nikiforova
}

The article considers a relevant problem of the readiness of Russian industrial enterprises to address the threats of hypercompetition under the digital economy. The authors construct a hypothesis on the possibility of overcoming these threats and building sustainable competitive advantages in conditions of the digital economy through forming and developing the industrial enterprises' dynamic capabilities. The researchers develop a method for assessing dynamic capabilities, and adapt it to the Russian manufacturing industries. The paper presents the results of measuring the levels of the digital economy development in every sector and builds a positioning map of manufacturing industries in the coordinates "level of dynamic capabilities of an industry" and "degree of the digital economy development in an industry". The authors specify four groups of industries, which differ in the degree of readiness to the development of the digital economy and in potential for such development. The findings can be useful for enterprises of the industries explored in the research to make decisions about investments into development of dynamic capabilities to form sustainable competitive advantages in the digital economy.

Keywords: industrial enterprise; strategic management; dynamic capabilities; digital economy; hypercompetition.

\section{References:}

1. Barni J. B. Mozhet li resursnaya kontseptsiya prinesti pol'zu issledovatelyam v oblasti strategicheskogo upravleniya? - Da [Is the resource-based view a useful perspective for strategic management research? - Yes]. Rossiyskiy zhurnal menedzhmenta - Russian Journal of Management, 2009, no. 7, pp. 71-92.

2. Vaysman Ye. D., Nikiforova N. S., Nosova S. A. Formirovanie modeli strategicheskogo upravleniya dinamicheskimi sposobnostyami promyshlennogo predpriyatiya s ispol'zovaniem tekhnologii forsayt [Formation of a strategic management model for the dynamic capabilities of an industrial enterprise using a foresight technology]. Rossiyskoe predprinimatelstvo - Russian Entrepreneurship, 2017, vol. 18, no. 7, pp. 1091-1104.

3. Grant R. Resursnaya teoriya konkurentnykh preimushchestv: prakticheskie vyvody dlya formirovaniya strategii [The resource-based theory of competitive advantage: Implications for strategy formulation]. Vestnik SPbGU. Seriya: Menedzhment - Bulletin of Saint Petersburg University of Economics. Series: Management, 2003, issue 3, pp. 47-75.

4. Abdrakhmanova G.I., Gokhberg L.M., Kevesh M.A. et al. Indikatory informatsionnogo obshchestva: 2016 [Indicators of information society: 2016. Statistical yearbook]. Moscow: HSE, 2016.

5. Porter M. Konkurentnaya strategiya: metodika analiza otrasley i konkurentov [Competitive strategy: Techniques for analysing industries and competitors]. Moscow: Alpina Publ., 2016. 
6. Prakhalad K. K., Khamel G. Klyuchevaya kompetentsiya korporatsii [The core competence of corporation]. Vestnik SPbGU. Seriya: Menedzhment - Bulletin of Saint Petersburg University of Economics. Series: Management, 2003, issue 3, pp. 18-41.

7. Banke B., Butenko V., Kotov I. et al. Rossiya Onlayn: dognat' nel'zya otstat' [Russia online: Catch up to not be left behind]. Boston Consulting Group, 2016.

8. Aptekman A., Kalabin V., Klintsov V. et al. Tsifrovaya Rossiya: novaya real'nost' [The digital Russia: New reality]. McKinsey \& Company, 2017.

9. Barreto I. Dynamic Capabilities: A Review of Past Research and an Agenda for the Future. Journal of Management, 2010, vol. 36, no. 1, pp. 256-280.

10. Birkinshaw J., Ansari S. Understanding Management Models: Going Beyond "What" and "Why" to "How" Work Gets Done in Organizations. In: Foss N. J., Saebi T. (eds.) Business Model Innovation: The Organizational Dimension. Oxford: Oxford University Press, 2015, pp. 85-103.

11. D’Aveni R., Dagnino B. G., Smith K. G. The Age of Temporary Advantage. Strategic Management Journal, 2010, vol. 31, issue 13, pp. 1371-1385.

12. Easterby-Smith M., Lyles M. A., Peteraf M. A. Dynamic Capabilities: Current Debates and Future Directions. British Journal of Management, 2009, vol. 20, issue s1, pp. S1-S8.

13. Eisenhardt K., Martin J. Dynamic Capabilities: What are They? Strategic Management Journal, 2000, vol. 21, no. 10/11, pp. 1105-1121.

14. Vaisman E. D., Aliukov S. V., Nikiforova N. S., Nosova S. A. Strategic Management of Dynamic Capabilities of an Enterprise with Using Foresight Technologies. Proceedings of the $29^{\text {th }}$ International Business Information Management Association Conference - Innovation Management and Education Excellence Vision 2020: From Regional Development Sustainability to Global Economic Growth (IBIMA) (3-4 May, 2017, Vienna, Austria), pp. 787-795.

15. Teece D. J. A Dynamic Capabilities-Based Entrepreneurial Theory of the Multinational Enterprise. Journal of International Business Studies, 2014, vol. 45, issue 1, pp. 8-37.

16. Teece D. J. Dynamic Capabilities and Strategic Management. Strategic Management Journal, 1997 , vol. 18 , no. 7 , pp. 509-533.

17. Winter S. G. Understanding Dynamic Capabilities. Strategic Management Journal, 2003, vol. 24, no. 10, pp. 991-995.

Contact Info:

Yelena D. Vaisman, Dr. Sc. (Econ.), Prof. of Finance, Money Circulation and Credit Dept. Phone: (351) 267-92-81

e-mail: vaismaned@susu.ru

Natalya S. Nikiforova, Postgraduate of Finance, Money Circulation and Credit Dept.

Phone: (351) 267-92-81

e-mail: nikiforovans@susu.ru

\author{
South Ural State University \\ (national research university) \\ 76 Lenina Ave., Chelyabinsk, Russia, 454080 \\ South Ural State University \\ (national research university) \\ 76 Lenina Ave., Chelyabinsk, Russia, 454080
}

Ссылка для ицтирования: Вайсман Е.Д., Никифорова Н.С. Развитие динамических способностей промышленных предприятий в условиях цифровой экономики // Известия Уральского государственного экономического университета. 2018. Т. 19, № 3. С. 126-136. DOI: 10.29141/2218-5003-2018-9-3-11

For citation: Vaisman Ye.D., Nikiforova N.S. Razvitie dinamicheskikh sposobnostey promyshlennykh predpriyatiy $\mathrm{v}$ usloviyakh tsifrovoy ekonomiki [Development of industrial enterprises' dynamic capabilities in the digital economy]. Izvestiya Uralskogo gosudarstvennogo ekonomicheskogo universiteta - Journal of the Ural State University of Economics, 2018, vol. 19, no. 3, pp. 126-136. DOI: 10.29141/2218-5003-2018-9-3-11 


\title{
КОНОНОВ Владимир Николаевич
}

Кандидат экономических наук, доцент кафедры бухгалтерского учета

и экономического анализа

Магнитогорский государственный технический университет им. Г. И. Носова 455000, РФ, Челябинская область, г. Магнитогорск, пр. Ленина, 38 Контактный телефон: (3519) 23-03-73 e-mail: jenia-v@yandex.ru

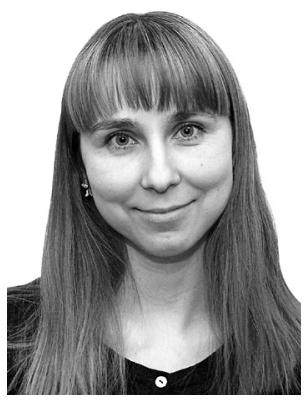

\section{ЗАМБРЖИЦКАЯ Евгения Сергеевна}

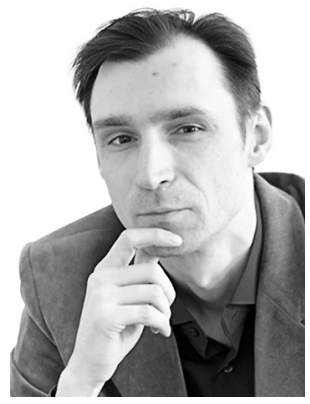

Кандидат экономических наук, доцент кафедры бухгалтерского учета и экономического анализа

Магнитогорский государственный технический университет им. Г. И. Носова 455000, РФ, Челябинская область, г. Магнитогорск, пр. Ленина, 38 Контактный телефон: (3519) 23-03-73 e-mail: jenia-v@yandex.ru

\section{ХАРЧЕНКО Максим Викторович}

Кандидат технических наук, доцент кафедры механики

Магнитогорский государственный технический университет им. Г. И. Носова 455000, РФ, Челябинская область, г. Магнитогорск, пр. Ленина, 38 Контактный телефон: (3519) 29-85-18 e-mail: kharchenko.mv@bk.ru

\section{Жизненный цикл промышленной технологии как объект моделирования и управления ${ }^{1}$}

\begin{abstract}
Исследование направлено на обобщение и систематизацию вопросов моделирования жизненных циклов промышленных технологий для целей прогнозирования и управления ими. Уточнено понятие жизненного цикла промышленной технологии как последовательности стадий развития от момента замысла до отказа от использования, проанализированы подходы к моделированию жизненных циклов промышленных технологий, определены возможности применения результатов моделирования жизненных циклов промышленных технологий на практике. Показано, что для управления жизненными циклами промышленных технологий наиболее полезными являются подходы, основанные на построении s-образных кривых и графиков накопленного эффекта (финансового результата).
\end{abstract}

\section{JEL classification: $\mathrm{C} 02, \mathrm{O} 32$}

Ключевые слова: жизненный цикл технологии; моделирование жизненного цикла; управление жизненным циклом промышленной технологии; промышленные технологии; логистическая функция; стадии цикла.

\section{Введение}

$\mathrm{O}$ беспечение устойчивого, динамичного и сбалансированного научно-технологического развития является для России стратегическим приоритетом, закрепленным

${ }^{1}$ Работа выполнена при финансовой поддержке Министерства образования и науки РФ (проект № 11.2054.2017/4.6 в рамках государственного задания на 2017-2019 гг.). 
на законодательном уровне ${ }^{1}$ и признанным экспертным сообществом². Конкурентоспособность промышленных предприятий, отраслей и экономики страны во многом зависит от применяемых технологий и того, насколько успешно эти технологии развиваются и замещаются более прогрессивными и инновационными. Это сопряжено со значительными расходами и многочисленными рисками, предусмотреть которые можно только при понимании логики и параметров, характеризующих жизненные циклы промышленных технологий.

Обоснование управленческих решений, связанных с разработкой и внедрением новых технологий, развитием существующих и отказом от устаревших, должно опираться на результаты моделирования их жизненных циклов.

В экономической литературе жизненным циклам посвящено множество публикаций, большая часть которых касается жизненных циклов продукции (товаров), проектов, систем или организаций. Гораздо менее исследованными являются вопросы моделирования и управления жизненными циклами промышленных технологий, что актуализирует обобщение и систематизацию научных знаний в данной области, а также разработку инструментария моделирования и управления жизненными циклами промышленных технологий.

\section{Понятие жизненного цикла промышленной технологии и подходы к его описанию}

Рассмотрение жизненного цикла промышленной технологии в качестве объекта моделирования и управления в первую очередь требует определения смысла, вкладываемого в данное понятие.

В научной литературе при относительной изученности родственных понятий содержание непосредственно жизненного цикла промышленной технологии, к сожалению, должным образом не раскрыто и требует уточнения. Для четкого определения понятия «жизненный цикл промышленной технологии» воспользуемся приемами семантического анализа и представим результаты данного анализа в виде семантической сети понятий (рис. 1).

В семантической сети понятий, являющейся ориентированным графом, узлы соответствуют самим понятиям, а ребра определяют отношения между ними (в представленном варианте сети, исходя из специфики решаемой задачи, прежде всего были идентифицированы родовидовые отношения).

Раскрытие смысла самих понятий на основе данных энциклопедических словарей и научных публикаций обобщим в табл. 1.

Базовые понятия «цикл», «технология» и «промышленность» всесторонне раскрываются в многочисленных словарях и научных публикациях [2; 7; 9]. Выбор наиболее подходящих толкований, процитированных в табл. 1, был осуществлен по соображениям либо универсальности, либо близости к объекту исследования.

Дальнейшее раскрытие используемых в исследовании понятий потребовало формулирования авторских определений, поскольку рассмотренные источники были неточны и зачастую касались областей знаний, не имеющих отношения к жизненным

${ }^{1}$ Федеральный закон от 28 июня 2014 г. № 172-Ф3 «О стратегическом планировании в Российской Федерации»; Указ Президента РФ от 1 декабря 2016 г. № 642 «О Стратегии научно-технологического развития Российской Федерации»; Постановление Правительства РФ от 15 апреля 2014 г. № 316 «Об утверждении государственной программы Российской Федерации „Экономическое развитие и инновационная экономика“»; Распоряжение Правительства РФ от 8 декабря 2011 г. № 2227-р «Об утверждении Стратегии инновационного развития Российской Федерации на период до 2020 года».

${ }^{2}$ Интернет-портал «Стратегия научно-технологического развития Российской Федерации», раздел «Мнения экспертов». URL: http://sntr-rf.ru/expert. 
циклам промышленных технологий. Причиной данного обстоятельства является универсальность концепции жизненного цикла, которая находит применение во многих областях знаний: экономике, биологии, социологии, информационных системах и технологиях и т. д. Подробное раскрытие вопросы, связанные с применением концепции жизненного цикла в различных областях деятельности, нашли, например, в работе Г. В. Широковой, Т.Н. Клеминой и Т.Н. Козыревой [11], а более обстоятельный анализ применения данной концепции в экономических исследованиях приведен в работах Д. Б. Берга, С. Л. Гольдштейна, Е. А. Ульяновой и П. В. Добряка [1; 2], М. Портера [12; 13].

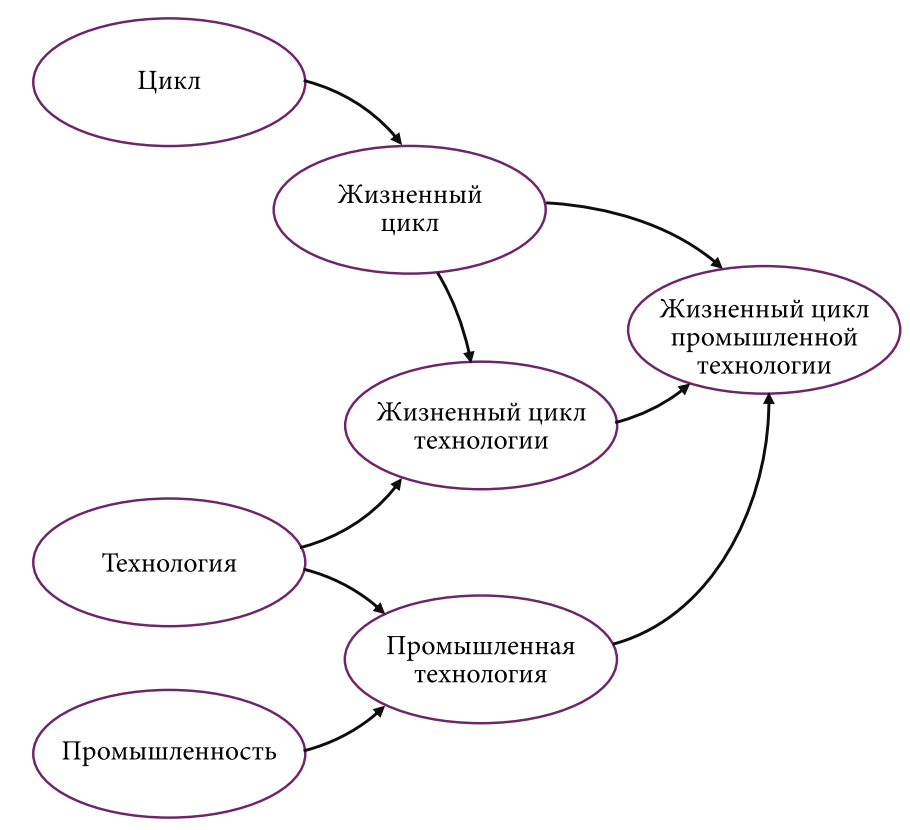

Рис. 1. Семантическая сеть понятий, связанных с жизненным циклом промышленной технологии

В экономике концепция жизненного цикла применима при описании спроса, отраслей, технологий, организаций, продуктов (товаров, изделий), проектов, инноваций, конкуренции, экономических систем в общем и др., поскольку в развитии перечисленных сущностей могут быть выделены схожие по своим характеристикам стадии. В общем случае это стадии возникновения, роста, зрелости, спада и исчезновения. В связи с этим описание жизненного цикла становится характеристикой прохождения объектом перечисленных стадий. Для раскрытия понятия «жизненный цикл промышленной технологии» предлагаем воспользоваться следующим определением: это последовательность стадий развития промышленной технологии от момента ее замысла до отказа от использования. В многообразии подходов к описанию жизненных циклов можно выделить наиболее значимые:

- подход, основанный на построении s-образных кривых, характеризующих достижение предела возможностей (эффективности);

- подход, основанный на построении графиков, характеризующих текущий эффект (финансовый результат);

- подход, основанный на построении кривой, характеризующей накопленный эффект (финансовый результат);

- подход Гартнера, характеризующий изменение ожиданий от использования технологий. 
Толкования (определения) основных понятий, связанных с жизненным циклом промышленной технологии

\begin{tabular}{|c|c|c|}
\hline Понятие & Толкование (определение) & Источник \\
\hline \multirow[t]{2}{*}{ Цикл } & 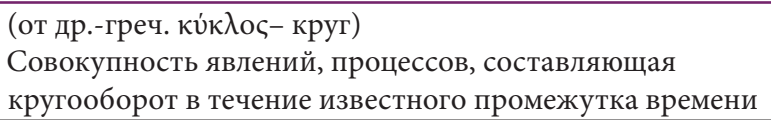 & [9] \\
\hline & $\begin{array}{l}\text { Совокупность взаимосвязанных явлений, процессов, } \\
\text { работ, образующих законченный круг развития в тече- } \\
\text { ние какого-либо промежутка времени }\end{array}$ & [3] \\
\hline \multirow[t]{3}{*}{ Технология } & 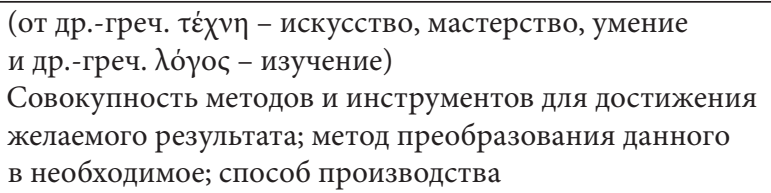 & {$[4]$} \\
\hline & $\begin{array}{l}\text { Совокупность производственных методов и процессов } \\
\text { в определенной отрасли производства, а также научное } \\
\text { описание способов производства }\end{array}$ & [7] \\
\hline & $\begin{array}{l}\text { Применение научных знаний для удовлетворения пра- } \\
\text { ктических жизненных потребностей людей или измене- } \\
\text { ния окружающей среды* }\end{array}$ & $\begin{array}{l}\text { Интернет-сайт } \\
\text { «Encyclopædia } \\
\text { Britannica». URL: } \\
\text { https://www. } \\
\text { britannica.com/ } \\
\text { topic/technology }\end{array}$ \\
\hline \multirow[t]{2}{*}{ Промышленность } & $\begin{array}{l}\text { Сектор народного хозяйства, связанный с производст- } \\
\text { вом промышленных товаров и оказанием производст- } \\
\text { венных услуг }\end{array}$ & [3] \\
\hline & $\begin{array}{l}\text { Отрасль производства, охватывающая переработку } \\
\text { сырья, разработку недр, создание средств производства } \\
\text { и предметов потребления }\end{array}$ & [7] \\
\hline $\begin{array}{l}\text { Промышленная } \\
\text { технология }\end{array}$ & $\begin{array}{l}\text { Совокупность методов и процессов преобразования } \\
\text { имеющихся ресурсов в продукцию и услуги промыш- } \\
\text { ленного производства }\end{array}$ & A \\
\hline Жизненный цикл & $\begin{array}{l}\text { Последовательность стадий в развитии чего-либо от } \\
\text { разработки концепции и (или) возникновения до исчез- } \\
\text { новения }\end{array}$ & $\mathrm{A}$ \\
\hline $\begin{array}{l}\text { Жизненный цикл } \\
\text { технологии }\end{array}$ & $\begin{array}{l}\text { Последовательность стадий развития технологии от } \\
\text { разработки ее концепции и (или) возникновения до от- } \\
\text { каза от использования }\end{array}$ & $\mathrm{A}$ \\
\hline $\begin{array}{l}\text { Жизненный цикл } \\
\text { промышленной } \\
\text { технологии }\end{array}$ & $\begin{array}{l}\text { Последовательность стадий развития промышленной } \\
\text { технологии от момента ее замысла до отказа от исполь- } \\
\text { зования }\end{array}$ & A \\
\hline
\end{tabular}

Примечания. Толкования (определения), источник которых помечен литерой А, являются авторскими.

* В оригинале: technology - the application of scientific knowledge to the practical aims of human life or, as it is sometimes phrased, to the change and manipulation of the human environment [8].

При схожести стадий в описании жизненных циклов отличительной чертой каждого из подходов является то, какие параметры становятся объектами моделирования: предел возможностей (эффективности), текущий или накопленный эффект (финансовый результат), ожидания от использования.

При характеристике прохождения промышленной технологией жизненного цикла значимой является каждая из упомянутых групп параметров. Выбор, сделанный 
в пользу какого-то одного из подходов при игнорировании прочих, заведомо окажется проигрышным, поскольку часть параметров, способных повлиять на принимаемые управленческие решения, окажется недоступной. По этой причине следует сделать вывод о необходимости обеспечения всестороннего описания жизненных циклов промышленных технологий с комплексным применением названных подходов.

\section{Жизненный цикл промышленной технологии как объект моделирования}

Подход к описанию жизненных циклов технологий, основанный на построении $s$-образных кривых, был предложен Р. Фостером [10] в контексте раскрытия динамики конкуренции и выявления зависимости между затратами, связанными с улучшением продукта или технологического процесса, и получаемыми результатами.

Представленный на рис. 2 в виде $s$-образной кривой типовой график жизненного цикла промышленной технологии обращает внимание на следующие важные закономерности:

- достаточно низкая эффективность применения промышленной технологии на начальном этапе, что можно объяснить значительными затратами на разработку и внедрение технологии, недостатком опыта и известности и многими другими факторами;

- скачкообразное увеличение эффективности на этапе совершенствования технологии, обусловленное существенным снижением затрат капитального характера на совершенствование технологии (по сравнению с теми, которые пришлось осуществить на этапе разработки и внедрения), повышением компетентности в использовании технологии, ростом ее известности;

- замедление роста эффективности по мере приближения к пределу эффективности промышленной технологии.

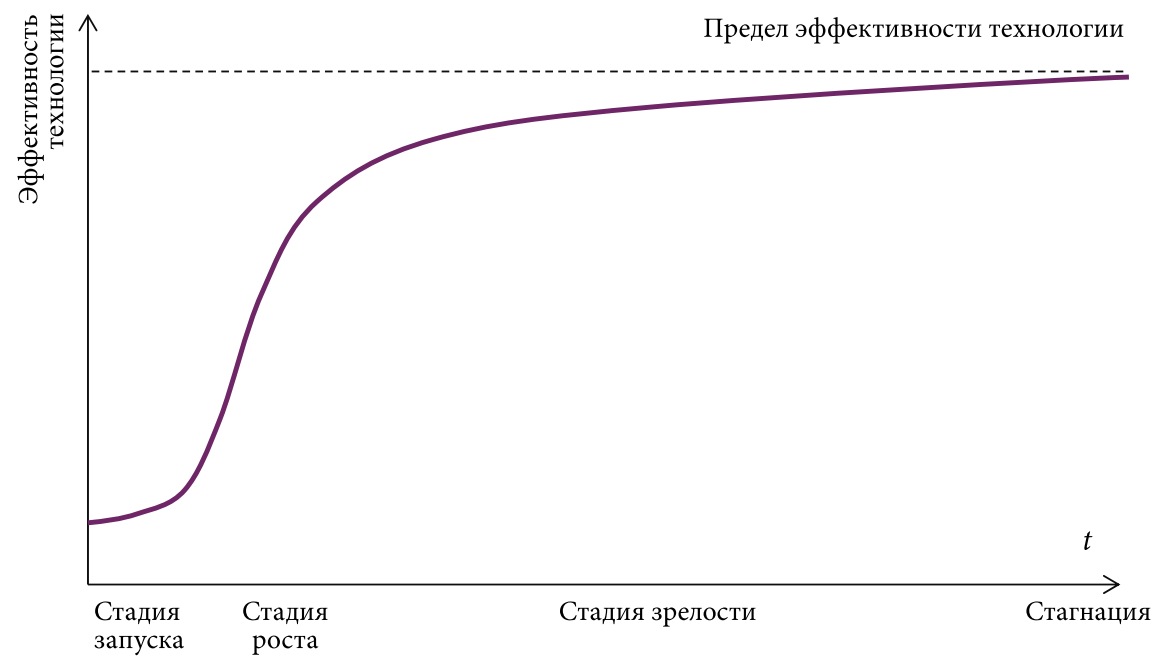

Рис. 2. Описание жизненного цикла промышленной технологии с помощью s-образной кривой (кривой Фостера)

Важнейшим понятием, подвергнутым осмыслению Р. Фостером, стал предел технологии, представляющий собой ее максимально возможную эффективность, которая не может быть превышена в силу объективного влияния физических и экономических законов. Приближение к пределу технологии с практической точки зрения должно означать необходимость поиска, разработки и внедрения новых технологий в качестве замены действующим, способным в любой момент времени перейти в категорию устаревающих. 
Неслучайно своеобразный девиз «атакующие выигрывают» является частью названия научной работы Р. Фостера «Обновление производства...» [10] (в оригинале: R. Foster «Innovation: The Attacker's Advantage»). Автор динамики конкуренции подчеркивает, что перемены, когда они наступают, происходят быстро, подчиняются закономерностям, которые поддаются предсказанию и анализу [10]. В случае с жизненным циклом промышленной технологии таким анализом, результаты которого могут быть использованы в прогнозных целях, является определение переломных точек на графике $s$-образной кривой.

С математической точки зрения $s$-образные кривые жизненных циклов могут быть описаны с помощью так называемой логистической функции или уравнения П. Ф. Ферхюльста $[14 ; 15]$, изначально предложенного его автором для характеристики роста биологических популяций до достижения ими предела, обусловленного возможностями среды обитания. Из современных исследований, посвященных применению логистической функции в экономике, можно отметить работы Р.М. Нижегородцева $[5 ; 6]$.

Интерпретация уравнения П. Ф. Ферхюльста для описания s-образной кривой жизненного цикла промышленной технологии может быть представлена в следующем виде:

$$
\xi(t)=\frac{\xi_{\max } \cdot \xi_{0} \cdot e^{r t}}{\xi_{\max }+\xi_{0} \cdot\left(e^{r t}-1\right)},
$$

где $\xi(t)$ - функция $s$-образной кривой жизненного цикла промышленной технологии, характеризующая ее эффективность; $\xi_{\max }$ - предел эффективности промышленной технологии; $\xi_{0}$ - эффективность промышленной технологии в момент времени, соответствующий началу ее практической эксплуатации; $e$ - экспонента; $r$ - коэффициент повышения эффективности технологии; $t$ - время.

При стремящемся к бесконечности параметре времени значение логистической функции будет приближаться к пределу эффективности промышленной технологии:

$$
\lim _{t \rightarrow \infty} \xi(t)=\xi_{\max } .
$$

Помимо описания поведения самой $s$-образной кривой, математический аппарат удобно может быть применен для определения переломных точек функции кривой жизненного цикла промышленной технологии. Для этого следует определить первую (3) и вторую (4) производные функции кривой жизненного цикла:

$$
\begin{gathered}
\xi(t)^{\prime}=\frac{r \cdot \xi_{\max } \cdot \xi_{0} \cdot e^{r t} \cdot\left(\xi_{\max }-\xi_{0}\right)}{\left(\xi_{\max }+\xi_{0} \cdot\left(e^{r t}-1\right)\right)^{2}} ; \\
\xi(t)^{\prime \prime}=\frac{r^{2} \cdot \xi_{\max } \cdot \xi_{0} \cdot e^{r t} \cdot\left(\xi_{\max }-\xi_{0}\right)}{\left(\xi_{\max }+\xi_{0} \cdot\left(e^{r t}-1\right)\right)^{3}} \cdot\left(\xi_{\max }+\xi_{0} \cdot\left(1+e^{r t}\right)\right) .
\end{gathered}
$$

Пример описания s-образной кривой с помощью логистической функции с нахождением ее первой и второй производных представлен на рис. 3.

Первой производной логистической функции $\xi(t)^{\prime}$ характеризуется скорость роста эффективности использования промышленной технологии. Момент достижения первой производной максимального значения свидетельствует о дальнейшем замедлении роста эффективности. Резерв роста эффективности промышленной технологии в этот момент времени будет оставаться по-прежнему значительным, а вложение средств в совершенствование используемой технологии будет целесообразным и оправданным. 


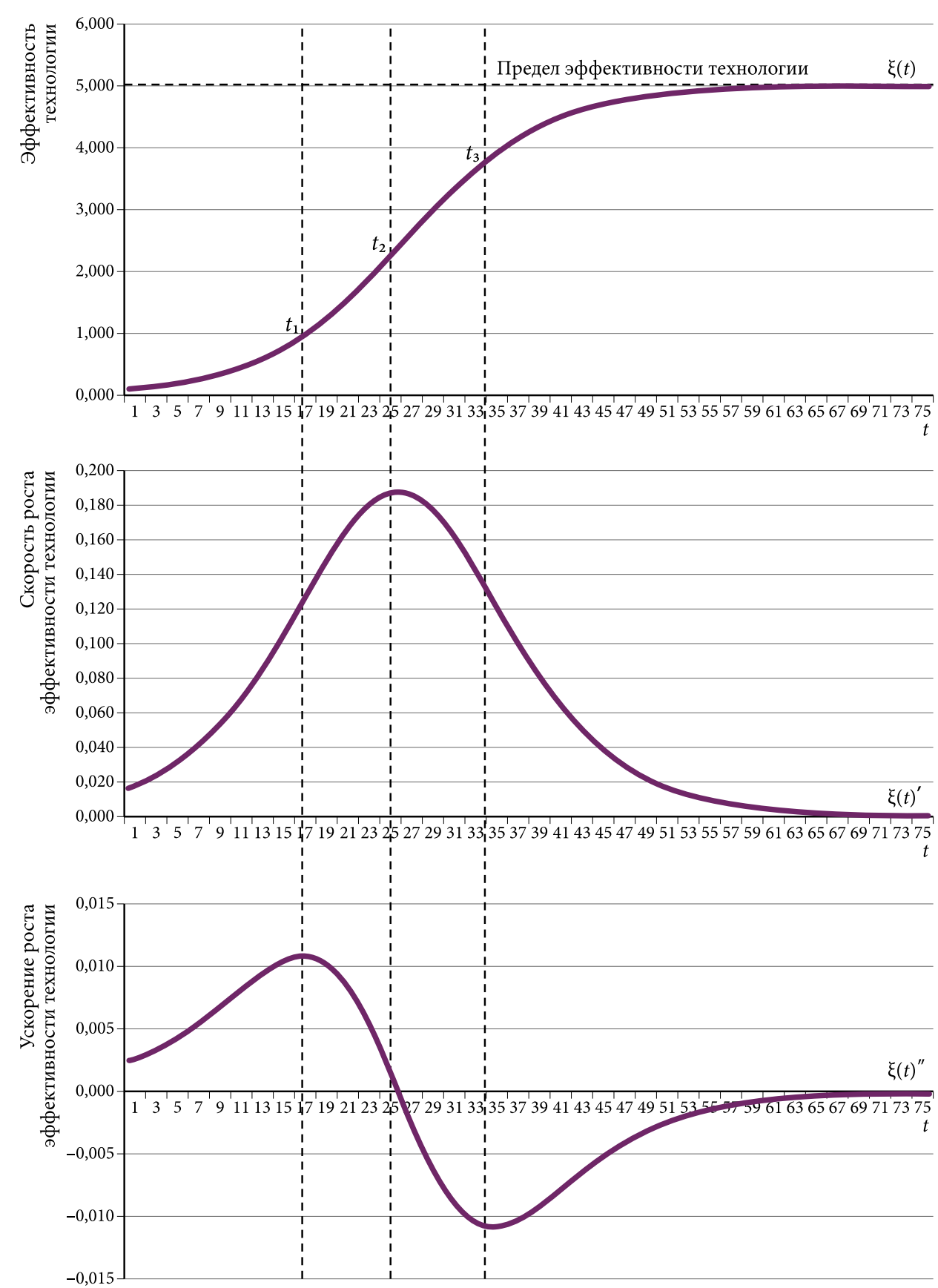

Рис. 3. Определение переломных моментов на графике кривой жизненного цикла промышленной технологии

Минимум второй производной $\xi(t) "$ соответствует моменту времени, когда рост эффективности использования промышленной технологии критически замедляется. Достижение данного момента на практике будет означать нецелесообразность вложений в совершенствование существующей промышленной технологии потому, что, как считает Р. Фостер, не надо вкладывать деньги в то, что уже нельзя усовершенствовать [10]. 
Достижение минимума второй производной логистической функции $\xi(t)^{\prime \prime}$ может рассматриваться в качестве сигнала о необходимости поиска, разработки и внедрения новых промышленных технологий, которые рано или поздно должны прийти на смену используемой. В контексте конкурентной борьбы весомое конкурентное преимущество приобретет тот, у кого получится раньше воспользоваться возможностями новой, более совершенной промышленной технологией. При наличии у новой альтернативной технологии, по сравнению с используемой более высокого предела эффективности, совершенствование именно новой технологии окажется целесообразным.

Помимо использования логистической функции для описания приближения промышленной технологии к пределу своей эффективности, по мнению некоторых специалистов, могут быть применены и другие типы s-образных кривых. В частности, Д. Сахал [8], занимавшийся изучением особенностей диффузии инноваций, обращал внимание на целесообразность применения в ряде случаев асимметричных s-образных кривых, таких как функция Гомпертца или функция логнормального распределения.

Дополнительно при изучении жизненного цикла промышленной технологии необходимо обратить внимание на следующие важные очевидные моменты:

- расходы на разработку и внедрение новой промышленной технологии практически во всех случаях являются значительными (а иногда огромными и просто неподъемными для отдельно взятой компании), что следует рассматривать как ограничивающий фактор при принятии управленческих решений;

- результат от использования промышленной технологии будет достигнут не мгновенно, он распределен во времени и накапливается по мере эксплуатации технологии.

Принятие во внимание указанных особенностей в процессе моделирования является удобным в случае представления жизненного цикла промышленной технологии как результата реализации инвестиционного проекта. Ключевым отслеживаемым параметром в данном случае станет накопленный эффект (финансовый результат) от использования промышленной технологии. Типовой вид графика жизненного цикла промышленной технологии при этом будет выглядеть так, как показано на рис. 4.

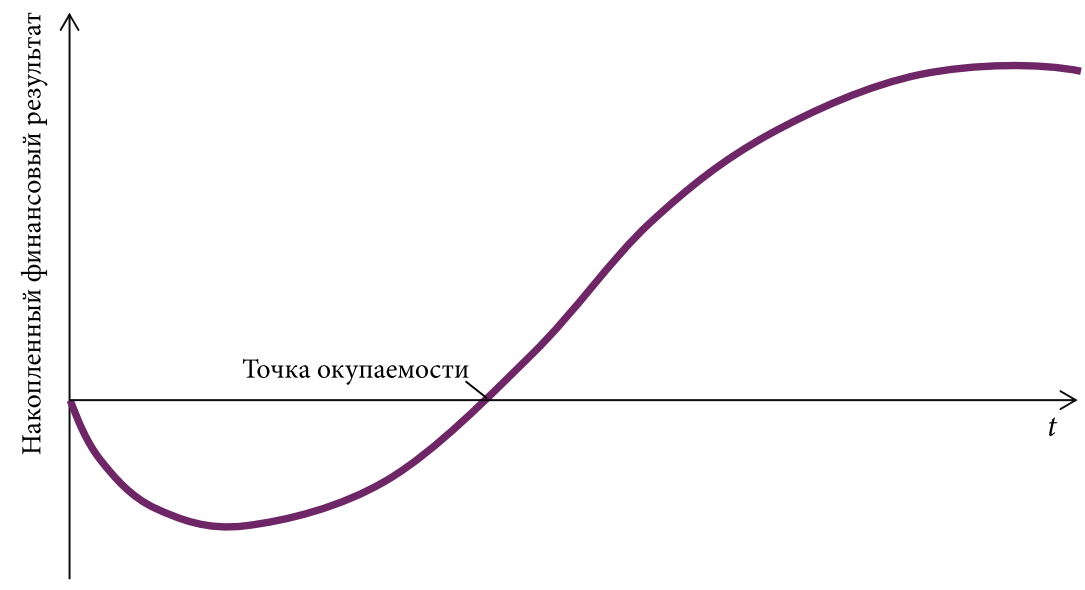

Рис. 4. График жизненного цикла промышленной технологии как инвестиционного проекта

Из оставшихся упомянутых подходов к описанию жизненных циклов технологий построение графиков жизненных циклов, характеризующих текущий эффект (финансовый результат), следует рассматривать в качестве дополнения к тем, на которых иллюстрируется накопленный эффект (финансовый результат).

Подход, основанный на построении кривой Гартнер (по названию консалтинговой компании, его разработавшей), применительно именно к промышленным технологиям, 
хотя и может быть применен, для принятия управленческих решений гораздо менее ценен, в сравнении с остальными рассмотренными подходами ${ }^{1}$. Кривая Гартнер строится для и учитывает специфику информационных, а не промышленных технологий.

\section{Жизненный цикл промышленной технологии как объект управления}

Конкурентные преимущества в бизнесе приобретают те компании, которые при меньших затратах достигают большего эффекта. Однако и осуществляемые затраты, и получаемые результаты далеко не в последнюю очередь обусловливаются применяемыми промышленными технологиями. Таким образом, принципиальным становится понимание того, когда следует инициировать поиск, разработку и внедрение новых технологий, когда требуется вкладывать средства в совершенствование используемой технологии и когда от этого, а в дальнейшем и от самой технологии целесообразно будет отказаться.

Ответы на перечисленные вопросы могут быть получены при восприятии жизненного цикла промышленной технологии в качестве объекта управления, для чего потребуется воспользоваться средствами моделирования, рассмотренными ранее.

В общем виде последовательность взаимных действий, связанных с принятием управленческих решений по поводу жизненного цикла уже эксплуатируемой технологии, может быть упрощенно представлена в виде алгоритма (рис. 5).

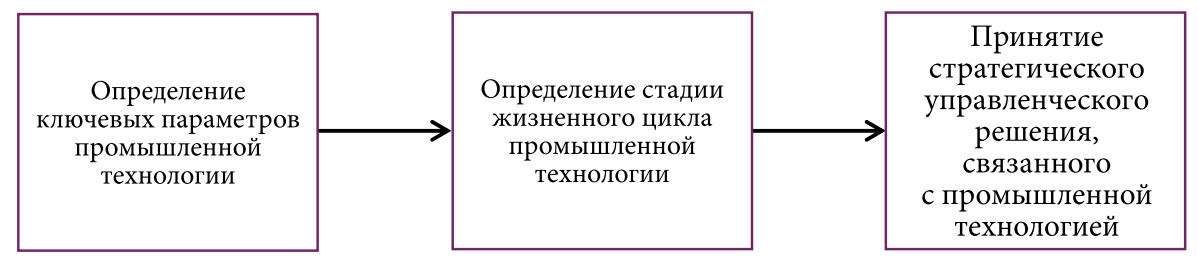

Рис. 5. Упрощенный алгоритм принятия стратегического управленческого решения по эксплуатируемой промышленной технологии

Определение ключевых параметров, характеризующих жизненный цикл промышленной технологии, или (в идеале) его описание в виде функциональной зависимости позволит ответить на принципиальный вопрос: «на какой стадии жизненного цикла находится промышленная технология?». От ответа будет зависеть принимаемое стратегическое решение по поводу эксплуатируемой промышленной технологии.

При нахождении промышленной технологии в начале жизненного цикла, на стадии стремительного роста эффективности, и даже при замедлении роста эффективности, но сохранении его достаточных резервов оправданным является вложение средств в совершенствование существующей технологии. На графиках, представленных на рис. 3, эти этапы соответствуют промежутку времени от старта использования промышленной технологии до достижения второй производной функцией минимума эффективности промышленной технологии, когда падение роста эффективности наиболее ощутимо.

Достижение промышленной технологией стадии жизненного цикла, соответствующей максимальному замедлению роста эффективности, может рассматриваться как сигнал о необходимости поиска, разработки и внедрения новой технологии. При этом решение о немедленной разработке и внедрении одной из таких новых технологий

${ }^{1}$ Gartner's official web-page «Gartner Hype Cycle». URL: http://www.gartner.com/technology/research/methodologies/hype-cycle.jsp; Inside Gartner Research: How the art, science and rigor behind our research process and proprietary methodologies help you make the right decisions, every day, 2016 http://www.gartner.com/imagesrv/research/methodologies/inside_gartner_research.pdf. 
далеко не всегда будет однозначным из-за длительности жизненных циклов промышленных технологий и комбинаций параметров жизненных циклов сравниваемых технологий.

При отборе новых альтернативных технологий первым подлежащим проверке параметром является оценочный уровень их пределов эффективности. Замена эксплуатируемой технологии новой будет оправдана при наличии так называемых технологических разрывов, когда предел эффективности у технологии каждого следующего поколения окажется выше, чем у предыдущего, как это показано на рис. 6.

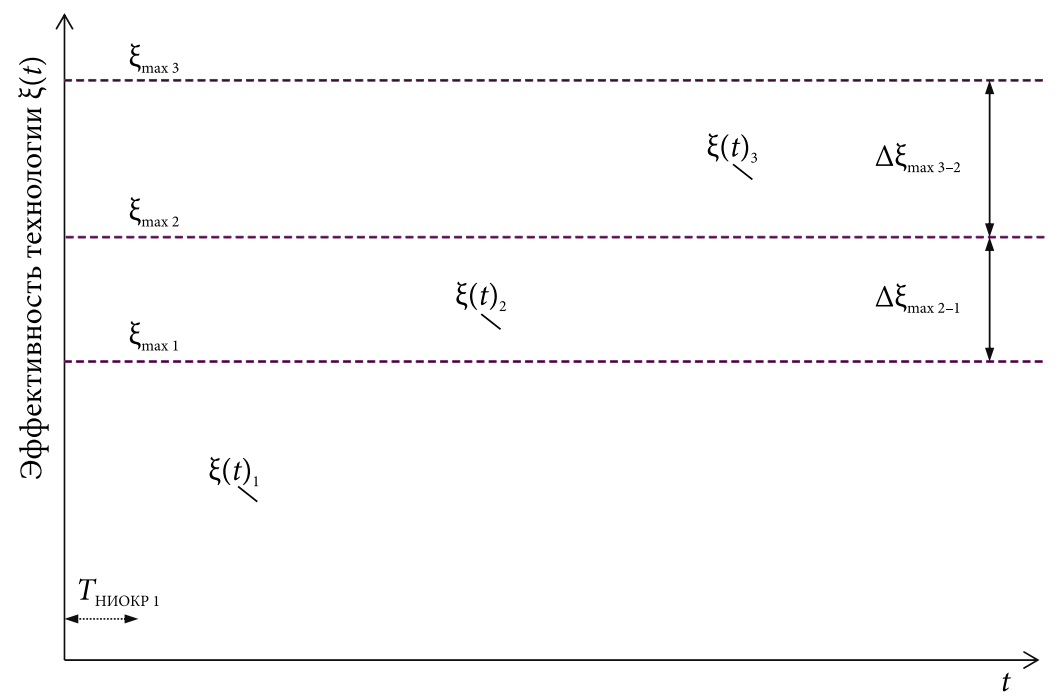

Рис. 6. Технологические разрывы на графиках жизненных циклов промышленных технологий

Вместе с тем более высокий предел промышленной технологии следующего поколения не гарантирует получение компанией экономических выгод в кратко- или даже среднесрочной перспективе. Например, моделирование влияния параметров предела эффективности $\xi_{\max }$ и коэффициента его повышения на текущую эффективность использования двух сравниваемых технологий для комбинаций, когда $\xi_{\max 2}>\xi_{\max 1}$ дало результаты, показанные на рис. 7. Несмотря на то, что вторая из сравниваемых технологий имеет более высокий предел эффективности, его достижение из-за меньшей скорости роста эффективности откладывается на более поздние периоды времени. На практике такая ситуация вероятна в силу большей капиталоемкости второй технологии.

Внешний вид s-образных кривых, представленных на рис. 7, даже для ситуации, когда промышленные технологии будут запущены одновременно, свидетельствует о том, что первая из сравниваемых технологий успеет практически полностью пройти свой жизненный цикл к моменту, когда вторая технология по текущей эффективности превзойдет первую. С учетом этого разработку и эксплуатацию каждой из этих технологий целесообразно рассматривать в качестве самостоятельного инвестиционного проекта. Запуск второй технологии при этом может быть отложен до момента окупаемости первой.

В общем случае на практике каждая комбинация уже эксплуатируемых и альтернативных новых промышленных технологий будет в чем-то уникальной. Для анализа возможностей этих технологий и прохождения ими жизненных циклов следует использовать весь спектр рассмотренных подходов с их корректировкой для каждой конкретной ситуации. 


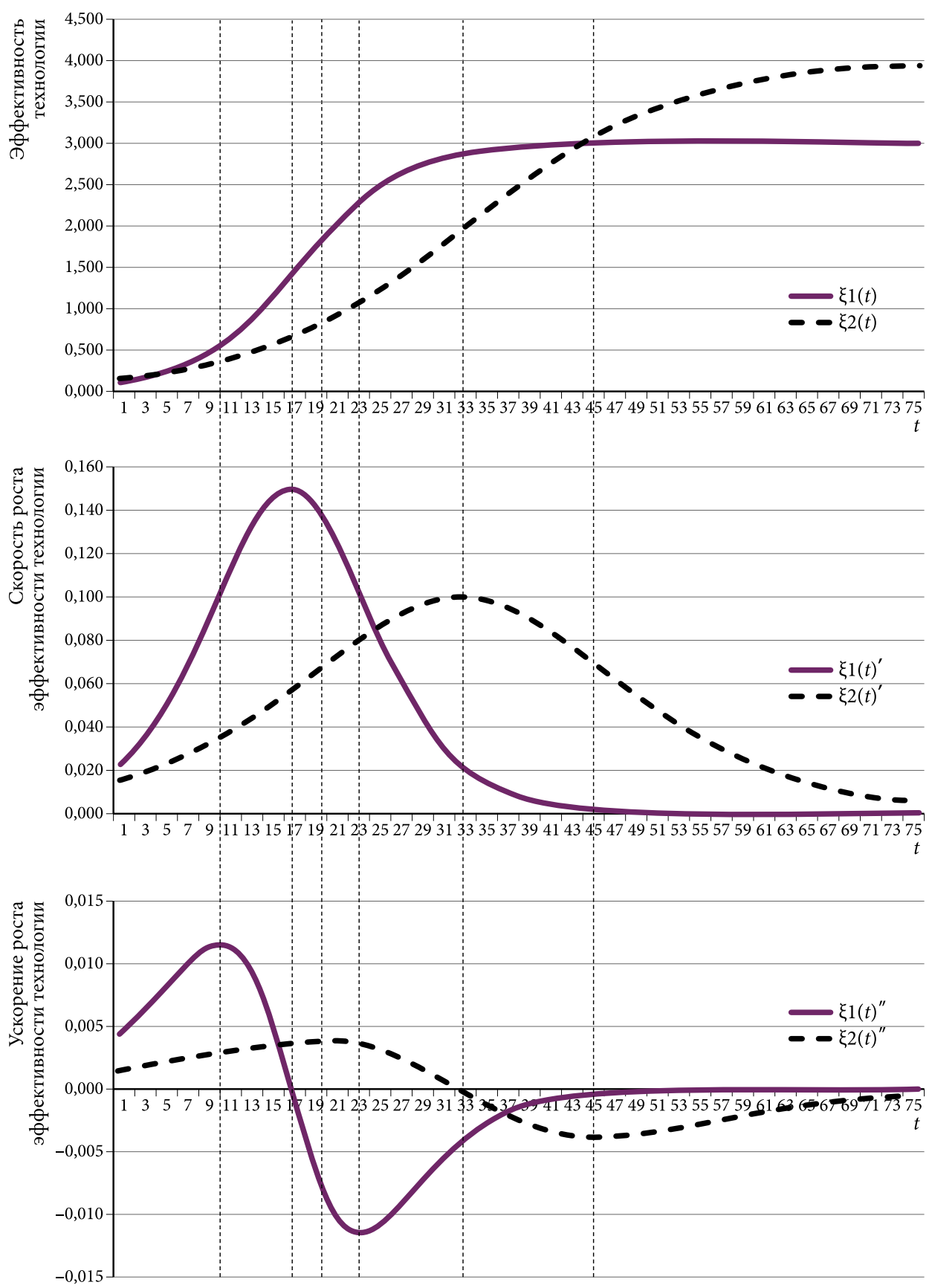

Рис. 7. Влияние предела эффективности и коэффициента его повышения на текущую эффективность промышленной технологии

\section{Заключение}

Совершенствование используемых и внедрение новых промышленных технологий является значимым фактором поддержания конкурентоспособности промышленных предприятий. Принятие обоснованных управленческих решений, связанных с поиском, разработкой, внедрением, совершенствованием и заменой промышленных 
технологий, возможно посредством управления их жизненными циклами, под которыми понимаются последовательности стадий развития от момента замысла до отказа от использования.

Для управления жизненными циклами промышленных технологий наиболее полезными являются подходы к их описанию и моделированию, основанные на построении $s$-образных кривых и графиков накопленного эффекта (финансового результата).

$S$-образные кривые, описываемые при помощи логистической функции, позволяют уточнить ряд ключевых характеристик жизненного цикла промышленной технологии, таких как предел ее эффективности и скорость роста эффективности. Нахождение первой и второй производных логистической функции дополнительно позволяет определить переломные точки жизненного цикла промышленной технологии, которые могут быть использованы в качестве маркеров при принятии управленческих решений.

\section{Источники}

1. Берг Д. Б., Гольдштейн С. Л. Специфика процесса конкуренции и его жизненного цикла // Математические модели в экономике: межвуз. сб. науч. тр. / под ред. А. Ф. Шорикова. Екатеринбург, 2002. С. 64-71.

2. Берг Д. Б., Ульянова Е. А., Добряк П. В. Модели жизненного цикла: учеб. пособие. Екатеринбург: Изд-во Урал. ун-та, 2014.

3. Большой экономический словарь / под ред. А. Н. Азрилияна. 5-е изд. доп. и перераб. М.: Ин-т новой экономики, 2002.

4. Некрасова Н.А., Некрасов С.И. Философия науки и техники: Тематический словарь-справочник. М.: МИИТ, 2009.

5. Нижегородцев Р.М. Логистическое моделирование экономической динамики. Ч. I // Проблемы управления. 2004. № 1. С. 46-53.

6. Нижегородцев Р.М. Логистическое моделирование экономической динамики. Ч. II // Проблемы управления. 2004. № 1. С. 52-58.

7. Ожегов С. И., Шведова Н. Ю. Толковый словарь русского языка. М.: А ТЕМП, 2008.

8. Сахал Д. Технический прогресс: концепции, модели, оценки. М.: Финансы и статистика, 1985.

9. Советский энциклопедический словарь / под ред. А. М. Прохорова. 4-е изд. М.: Сов. энциклопедия, 1988.

10. Фостер Р. Обновление производства: атакующие выигрывают. М.: Прогресс, 1987.

11. Широкова Г.В., Клемина Т.Н., Козырева Т.П. Концепция жизненного цикла в современных организационных и управленческих исследованиях // Вестник СанктПетербургского университета. Сер. 8: Менеджмент. 2007. № 2. С. 3-31.

12. Porter M. Competitive Strategy: Techniques for Analyzing Industries and Competitors. N. Y.: The Free Press, 1980.

13. Porter M. The Competitive Advantage: Creating and Sustaining Superior Performance. N. Y.: The Free Press, 1985.

14. Verhulst P. F. Recherches mathématiques sur la loi d'accroissement de la population. Bruxelles: Hayez, 1845.

15. Verhulst P. F. Notice sur la loi que la population suit dans son accroissement // Correspondance Mathématique et Physique publiée par A. Quetelet. 1838. No. 10. Pp. 113-121. 


\section{The Life Cycle of an Industrial Technology as an Object of Modelling and Control}

\section{by Vladimir N. Kononov, Yevgenia S. Zambrzhitskaya and Maksim V. Kharchenko}

The research aims to generalise about and systematise the issues of modelling of industrial technologies' life cycles for the purposes of forecasting and controlling them. The paper clarifies the concept of industrial technology life cycle and treats it as a sequence of development stages from the moment of conception to the point of disuse. The authors examine approaches to modelling of industrial technologies' life cycles and identify possibilities to apply the results of modelling of industrial technologies' life cycles in practice. The researchers demonstrate that the approaches based on designing s-shaped curves and graphs of accumulated effect (financial result) are the most convenient to control the life cycles of industrial technologies.

Keywords: technology life cycle; life cycle modelling; control of industrial technology life cycle; industrial technologies; logistic function; stages of life cycle.

References:

1. Berg D. B., Goldshtein S. L. Spetsifika protsessa konkurentsii i ego zhiznennogo tsikla [Specificity of the competition process and its life cycle]. In: Shorikov A. F. (ed.) Matematicheskie modeli v ekonomike [Mathematical models in economics]. Yekaterinburg, 2002, pp. 64-71.

2. Berg D. B., Ulyanova Ye. A., Dobryak P.V. Modeli zhiznennogo tsikla [Life cycle models]. Yekaterinburg: Ural University Publ., 2014.

3. Azriliyan A.N. (ed.) Bolshoy ekonomicheskiy slovar [The big explanatory dictionary]. Moscow: Institute of New Economy, 2002.

4. Nekrasova N. A., Nekrasov S. I. Filosofiya nauki i tekhniki: Tematicheskiy slovar'-spravochnik [Philosophy of science and technology: Thematic dictionary and reference book]. Moscow: Russian University of Transport, 2009.

5. Nizhegorodtsev R. M. Logisticheskoe modelirovanie ekonomicheskoy dinamiki Ch. I [Logistic modelling of economic dynamics. Chapter I]. Problemy upravleniya - Problems of Management, 2004, no. 1 , pp. $46-53$.

6. Nizhegorodtsev R. M. Logisticheskoe modelirovanie ekonomicheskoy dinamiki Ch. II [Logistic modelling of economic dynamics. Chapter II]. Problemy upravleniya - Problems of Management, 2004, no. 1 , pp. 52-58.

7. Ozhegov S. I., Shvedova N. Yu. Tolkovyy slovar' russkogo yazyka [The explanatory dictionary of the Russian language]. Moscow: A TEMP Publ., 2008.

8. Sakhal D. Tekhnicheskiy progress: kontseptsii, modeli, otsenki [Technical progress: Concepts, models, estimates]. Moscow: Finansy i statistika Publ., 1985.

9. Prokhorov A.M. (ed.) Sovetskiy entsiklopedicheskiy slovar' [Soviet encyclopaedic dictionary]. Moscow: Sovetskaya entsiklopediya Publ., 1988.

10. Foster R. Obnovlenie proizvodstva: atakuyushchie vyigryvayut [Production modernisation: The attackers win]. Moscow: Progress Publ., 1987.

11. Shirokova G. V., Klemina T.N., Kozyreva T.P. Kontseptsiya zhiznennogo tsikla v sovremennykh organizatsionnykh i upravlencheskikh issledovaniyakh [The concept of the life cycle in modern organisational and management research]. Vestnik Sankt-Peterburgskogo universiteta. Seriya 8: MenedzhmentBulletin of the Saint Petersburg University. Series 8: Management, 2007, no. 2, pp. 3-31.

12. Porter M. Competitive Strategy: Techniques for Analyzing Industries and Competitors. N. Y.: The Free Press, 1980.

13. Porter M. The Competitive Advantage: Creating and Sustaining Superior Performance. N. Y.: The Free Press, 1985.

14. Verhulst P. F. Recherches mathématiques sur la loi d'accroissement de la population. Bruxelles: Hayez, 1845.

15. Verhulst P. F. Notice sur la loi que la population suit dans son accroissement. In: Correspondance Mathématique et Physique publiée par A. Quetelet, no. 10, 1838, pp. 113-121. 


\section{Contact Info:}

Vladimir N. Kononov, Cand Sc. (Econ.), Associate Prof. of Accounting and Economic Analysis Dept.

Phone: (3519) 23-03-73

e-mail: jenia-v@yandex.ru

Yevgenia S. Zambrzhitskaya, Cand Sc. (Econ.), Associate Prof. of Accounting and Economic

Analysis Dept.

Phone: (3519) 23-03-73

e-mail: jenia-v@yandex.ru

Maksim V. Kharchenko, Cand Sc. (Eng.),

Associate Prof. of Mechanics Dept.

Phone: (3519) 29-85-18

e-mail: kharchenko.mv@bk.ru
Nosov Magnitogorsk State Technical University 38 Lenina St., Magnitogorsk, Russia, 455000

Nosov Magnitogorsk State Technical University 38 Lenina St., Magnitogorsk, Russia, 455000

Nosov Magnitogorsk State Technical University 38 Lenina St., Magnitogorsk, Russia, 455000

Ссылка для цитирования: Кононов В.Н., Замбржицкая Е.С., Харченко М.В. Жизненный цикл промышленной технологии как объект моделирования и управления // Известия Уральского государственного экономического университета. 2018. Т. 19, № 3. C. 137-150. DOI: 10.29141/2073-1019-2018-19-3-12

For citation: Kononov V.N., Zambrzhitskaya Ye. S., Kharchenko M. V. Zhiznennyy tsikl promyshlennoy tekhnologii kak obyekt modelirovaniya i upravleniya [The life cycle of an industrial technology as an object of modelling and control]. Izvestiya Uralskogo gosudarstvennogo ekonomicheskogo universiteta - Journal of the Ural State University of Economics, 2018, vol. 19, no. 3, pp. 137-150. DOI: 10.29141/2073-1019-2018-19-3-12 


\section{ТРЕБОВАНИЯ К МАТЕРИАЛАМ, ПРЕДСТАВЛЯЕМЫМ В ЖУРНАЛ «Известия Уральского государственного экономического университета»}

\section{Общие положения}

Для публикации принимаются статьи, соответствующие тематике журнала и настоящим требованиям. Представляемые материалы должны быть актуальными, обладать научно-практической значимостью и новизной.

Статьи, направляемые в редакцию, рецензируются и в случае положительного заключения - редактируются. Редакция не согласовывает с авторами изменения и сокращения рукописи, не затрагивающие принципиальных вопросов.

Статья, отправленная автору на доработку, должна быть возвращена в исправленном виде в максимально короткие сроки с ответами автора на замечания рецензента, а также пояснениями всех изменений, сделанных автором.

Статьи аспирантов и соискателей могут приниматься к публикации без соавторства с доктором или кандидатом наук. Статьи, в число авторов которых входят студенты и магистранты, не принимаются к публикации.

Общее количество авторов статьи - не более трех.

Материалы, представляемые авторами в редакцию:

Материалы пересылаются в редакцию по электронной почте.

Заявка на публикацию включает следующие файлы:

1. Файл, озаглавленный фамилиями авторов на русском языке и содержащий в указанном порядке:

1) 1-3 кода по классификации JEL;

2) сведения об авторах на русском языке*;

3) ключевые слова на русском языке (5-8 слов);

4) аннотацию на русском языке (100-150 слов);

5) название статьи на русском языке;

6) текст статьи;

7) библиографический список на русском языке.

2. Файл, озаглавленный фамилиями авторов на английском языке и содержащий в указанном порядке:

1) перевод сведений об авторах на английский язык;

2) перевод названия статьи на английский язык;

3) перевод ключевых слов на английский язык;

4) перевод аннотации на английский язык;

5) перевод библиографического списка на английский язык.

3. Файлы с фотографиями авторов. Каждый файл должен быть озаглавлен фамилией автора. К публикации принимаются файлы в форматах JPEG или TIFF с разрешением 300 dpi (точек на дюйм), допускается 200 dpi.

* Фамилия, имя, отчество автора; ученая степень; ученое звание; должность; организация, которую представляет автор; адрес организации; контактный телефон (с указанием кода города); e-mail. Адрес организации указывается в последовательности: почтовый индекс, страна, город, улица, дом.

Вся указанная информация подлежит публикации.

Требования к оформлению рукописи

Объем статьи - от 20000 до 40000 знаков с пробелами.

Текст набирается через полтора интервала, кегль - 14 пт, гарнитура - Times New Roman на листе формата А4 с полями по 2 см.

Все страницы рукописи нумеруются.

Каждая таблица должна иметь название, каждый рисунок - подрисуночную подпись. 
Уравнения, рисунки и таблицы нумеруются в порядке их упоминания в тексте.

Графические элементы (рисунки, схемы) должны быть рассчитаны на черно-белое воспроизведение.

\section{Требования к списку источников}

Список источников оформляется в алфавитном порядке: сначала русскоязычные источники, затем источники на иностранном языке в порядке латинского алфавита. Ссылки на использованную литературу оформляются квадратными скобками с указанием страницы (опубликованные источники).

Список должен включать не менее 15 источников, большую часть из них должны составлять «литературные» источники (монографии, научные статьи в рецензируемых научных изданиях). Нормативно-правовые документы, статистические материалы в список источников не включаются, а при необходимости упоминаются в тексте статьи или выносятся в постраничную сноску.

Самоцитирование не должно превышать $10 \%$.

Рукописи, не соответствующие данным требованиям, возвращаются авторам.

Плата за публикацию статей не взимается.

Авторские гонорары редакцией не выплачиваются.

В случае принятия статьи к публикации авторы предоставляют заполненный лицензионный договор и экспертное заключение о возможности открытого опубликования. Бланк договора размещен на сайте журнала http://izvestia.usue.ru.

Прием статей:

Уральский государственный экономический университет 620144, РФ, г. Екатеринбург, ул. 8 Марта/Народной Воли, 62/45, каб. 355

Белоусова Елизавета Александровна

Телефон: (343) 221-26-33

e-mail:journal@usue.ru 


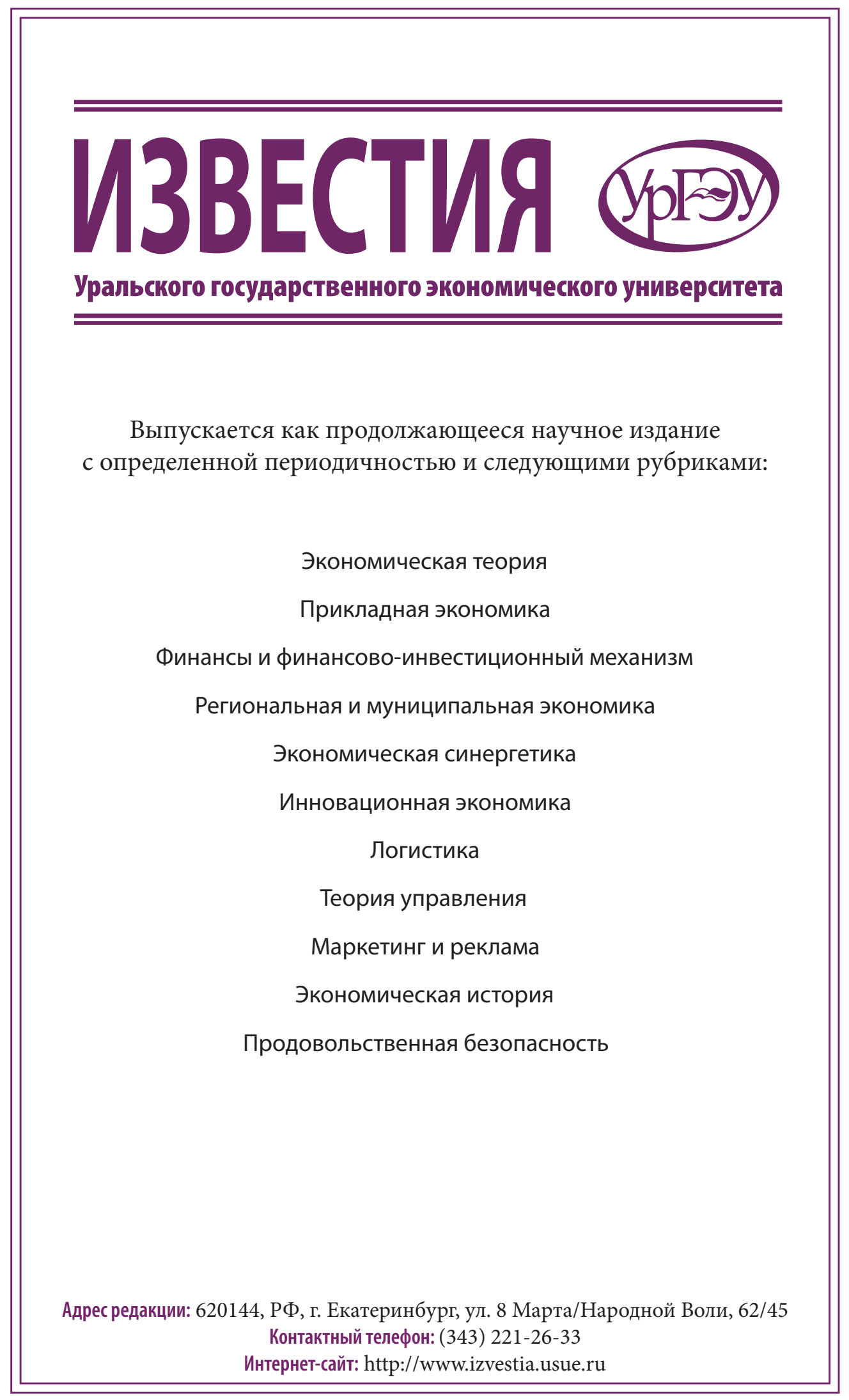




\title{
Известия Уральского государственного экономического университета
}

T. 19 , № 3 2018

\author{
Ответственный редактор \\ С. В. Орехова \\ Редактор и корректор \\ Р. Д. Мочалова \\ Перевод статей \\ Д. А. Азарова, Е. А. Белоусовой \\ Информация на английском языке \\ Е.А. Белоусовой \\ Технический редактор \\ А. А. Гребенщикова \\ Компьютерная верстка \\ А. А. Гребенщиковой
}

Издательство Уральского государственного экономического университета 620144, РФ, г. Екатеринбург, ул. 8 Марта / Народной Воли, 62 / 45

Подписано в печать 26.06.2018. Дата выхода в свет: 02.07.2018. Формат $70 \times 100$ / 16. Уч.-изд. л. 11,5. Усл. печ. л. 12,7. Печ. л. 9,8.

Поз. 44. Тираж 500 экз. Заказ 355.

Отпечатано с готового оригинал-макета

в подразделении оперативной полиграфии УрГЭу 